Effect of (vesicular-) arbuscular mycorrhiza on survival and post vitro development of micropropagated oil palms (Elaeis guineensis Jacq.)

\author{
Dissertation \\ zur Erlangung des Doktorgrades \\ der Fakultät für Agrarwissenschaften \\ der Georg-August-Universität Göttingen
}

vorgelegt von

\title{
Claudia Schultz
}

geboren in Kassel

Göttingen, im Oktober 2001 
D7

1. Referent: Prof. Dr. P. L. G. Vlek

2. Korefferent: Prof. H. Becker

Tag der mündlichen Prüfung: 22.11.2001 


\section{Table of contents}

$\begin{array}{ll}\text { 1. Introduction } & 1\end{array}$

2. Target/objective 3

3. State of the Art 5

3.1 The oil palm 5

3.2 Oil palm in Indonesia 6

$\begin{array}{lll}3.3 & \text { Genetics and breeding of the oil palm } & 6\end{array}$

3.4 Micropropagation of the oil palm $\quad 7$

3.5 The problem of acclimatization 9

$\begin{array}{lll}3.6 & \text { The role of mycorrhizal symbiosis } & 10\end{array}$

$\begin{array}{lll}3.7 & \text { Mycorrhizae and micropropagation } & 13\end{array}$

$\begin{array}{lll}3.8 & \text { Working with mycorrhiza } & 14\end{array}$

4. Material and Methods 16

4.1 Location and climate of the experimental site 16

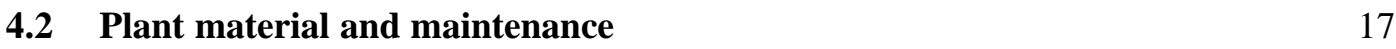

$\begin{array}{ll}\text { 4.2.1 In vitro culture } & 17\end{array}$

4.2.2 Post vitro culture - transfer to greenhouse conditions 18

$\begin{array}{llr}4.3 & \text { Soil preparation } & 19\end{array}$

$\begin{array}{llr}4.4 & \text { Inoculum production } & 20\end{array}$

4.5 Design of the research 21

4.5.1 Experiment $1 \quad 21$

4.5.2 Experiment $2 \quad 22$

4.5.3 Experiment $3 \quad 23$

4.6 Growth parameters 24

4.6.1 Survival and growth measurements $\quad 24$

4.6.2 Plant analysis $\quad 25$

4.6.2.1 Shoot analysis $\quad 25$

4.6.2.2 Root analysis $\quad 25$

$\begin{array}{lll}4.7 & \text { Statistics } & 26\end{array}$

5. Results and Discussion 2

$\begin{array}{ll}5.1 \text { Experiment1 } & \mathbf{2 6}\end{array}$

$\begin{array}{ll}\text { 5.1.1 Survival rate } & 27\end{array}$

5.1.2 Date of mortality 28 
$\begin{array}{lr}\text { 5.1.3 Post vitro plant development } & 29\end{array}$

5.1.3.1 Shoot length $\quad 29$

5.1.3.2 Relative growth rate $\quad 32$

5.1.3.3 Number of leaves $\quad 33$

5.1.4. Plant growth parameter after harvesting $\quad 35$

5.1.4.1. Shoot and root fresh weight, root:shoot fresh weight ratio 35

$\begin{array}{ll}\text { 5.1.4.2 Dry matter } & 37\end{array}$

5.1.4.3 Nutrient concentration and uptake $\quad 39$

5.1.4.3.1 Phosphorus 39

5.1.4.3.2 Potassium 41

5.1.4.3.3 Nitrogen $\quad 42$

5.1.5 (V)AMF infection rate 43

5.1.6 Assessment of plant development 45

5.1.7 Conclusions of Experiment 1 47

5.2 Experiment $2 \quad 48$

5.2.1 Survival rate 49

5.2.2 Date of mortality 51

5.2.3 Post vitro plant development

5.2.3.1 Shoot length 53

5.2.3.2 Number of leaves $\quad 56$

5.2.4. Plant growth parameter after harvesting $\quad 58$

5.2.4.1. Shoot and root fresh weight, root:shoot fresh weight ratio 58

5.2.4.2 Dry matter $\quad 59$

5.2.4.3 Nutrient concentration and uptake $\quad 62$

5.2.4.3.1 Phosphorus 62

5.2.4.3.2 Potassium 66

$\begin{array}{ll}\text { 5.2.4.3.3 Nitrogen } & 68\end{array}$

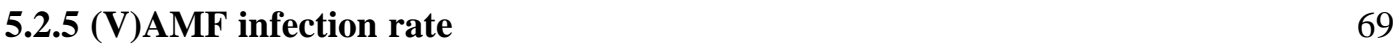

$\begin{array}{ll}\text { 5.2.6 Conclusions of Experiment 2 } & 72\end{array}$

$\begin{array}{lr}\text { 5.3. Experiment } 3 & 73\end{array}$

$\begin{array}{ll}\text { 5.3.1 Survival rate } & 73\end{array}$

$\begin{array}{ll}\text { 5.3.2 Date of mortality } & 75\end{array}$

$\begin{array}{ll}\text { 5.3.3 Post vitro plant development } & 76\end{array}$

$\begin{array}{ll}\text { 5.3.3.1 Shoot length } & 77\end{array}$

$\begin{array}{ll}\text { 5.3.3.2 Number of leaves } & 79\end{array}$ 
$\begin{array}{lr}\text { 5.3.4. Plant growth parameter after harvesting } & 81\end{array}$

5.3.4.1. Shoot and root fresh weight, root:shoot fresh weight ratio 81

$\begin{array}{ll}\text { 5.3.4.2 Dry matter } & 84\end{array}$

$\begin{array}{ll}\text { 5.3.4.3 Nutrient concentration and uptake } & 87\end{array}$

$\begin{array}{ll}\text { 5.3.4.3.1 Phosphorus } & 87\end{array}$

$\begin{array}{ll}\text { 5.3.4.3.2 Potassium } & 89\end{array}$

$\begin{array}{ll}\text { 5.3.4.3.3 Nitrogen } & 91\end{array}$

5.3.5 (V)AMF infection rate 93

$\begin{array}{ll}\text { 5.3.6 Conclusions of Experiment 3 } & 95\end{array}$

6. General discussion 96

6.1 Effect of (V)A mycorrhiza on the post vitro survival

6.2 Effect of (V)A mycorrhiza on post vitro plant development

6.3 Effect of (V)A mycorrhiza on the root development
of micropropagated oil palm clones after 12 weeks of post vitro growth

$\begin{array}{lr}\text { 6.4 Dry matter accumulation } & 102\end{array}$

6.5 Effect of (V)A mycorrhiza on nutrient concentration and uptake $\quad 104$

$\begin{array}{ll}\text { 6.5.1 Phosphorus } & 104\end{array}$

$\begin{array}{ll}\text { 6.5.1 Potassium and Nitrogen } & 106\end{array}$

$\begin{array}{ll}\text { 6.6 (V)AMF infectivity and effectivity } & 107\end{array}$

6.7 Specific effects of experimental factors and measures 109

$\begin{array}{ll}\text { 6.7.1 Efficiency of the selected (V)AMF } & 109\end{array}$

6.7.2 Role of the applied P form 109

6.7.3 Effect of soil sterilization 110

$\begin{array}{ll}\text { 6.7.4 Role of protection measures } & 100\end{array}$

$\begin{array}{lr}\text { 7. Final conclusions and perspectives } & 110\end{array}$

$\begin{array}{lr}\text { 8. Summary } & 113\end{array}$

$\begin{array}{lr}\text { 9. Zusammenfassung } & 119\end{array}$

$\begin{array}{lr}\text { 10. References } & 125\end{array}$

$\begin{array}{lr}\text { 11. Annex } & 143\end{array}$

Acknowledgements

Curriculum vitae 


\section{Abbreviations used}

ANOVA Analysis of Variance

BAY 'BAYFOLAN"

FO no fertilization

g gram

ha hectare

HA hydroxy-apatite (tricalcium phosphate, $\mathrm{Ca}_{5}\left(\mathrm{PO}_{4}\right)_{3} \mathrm{OH}$ ))

IOPRI 'Indonesian Oil Palm Research Institute'

$\mathrm{K}$

Potassium

LSD least significant difference

mg milligram

M mycorrhizal fungi,

mycorrhizal fungus

M1 Glomus manihot

M2 Enthrophospora columbiana

M3 Acaulospora mellea

M4 Acaulospora appendicula

M5 Acaulospora morowiae

M6 Acaulospora rehmii

M7 Gigaspora gigantea

M8 Glomus clarum

M9 Glomus occultum

M10 Glomus mosseae

M11 Scutellispora heterogama

M12 Scutellispora pellucida

$\mathrm{N} \quad$ Nitrogen

NI non-inoculated

ns not significant

ppm part per million

$P \quad$ probatility

P Phosphorus

(V)AM (vesicular-) arbuscular mycorrhiza

(V)AMF (vesicular-) arbuscular mycorrhizal fungus,

(vesicular-) arbuscular mycorrhizal fungi 
$\%$

${ }^{\circ} \mathrm{C}$

$<$ per cent

degree celcius

smaller than 


\section{Introduction}

In the year 2000, about 89.4 million tons of vegetable oil and fats were produced worldwide (FAO, 2000). Oils have an important place in human energy supply, $1 \mathrm{~g}$ of oil gives on average $38 \mathrm{~kJ}$ energy. According to an estimation by the World Health Organisation (WHO,1999) about one third of the world's population consumes less than $8 \mathrm{~kg}$ of oil and fats per capita per year which is well below the $12 \mathrm{~kg}$ considered by the WHO as a minimum requirement to ensure acceptable physical and mental growth in humans. From the present level of 6 billion people the world population is expected to increase to 7.5 billion inhabitants by 2025 (Lupien, 1999). As a consequence, consumption and demand for vegetable oils and fats will increase. More than $90 \%$ of the oil plants are produced in the tropics and subtropics which is the third place in world production in terms of value, after starch plants and fruit (Rehm and Espig, 1993).

The oil palm Elaeis guineensis (Jacq.) is the oilplant species with the highest yield of vegetable oil per hectare, i.e. 5-7 tons, which is over six times more than the oil yields from commercial grown rapeseed (Mielke, 1991). The energy balance expressed in terms of energy output-input ratio is wider for oil palm (1:10) than for other commercial grown oil crops like rapeseed (1:3) (Wood and Corley, 1991). In 2000, the palm oil production amounted to 21.9 million tons and palm oil became the world's second most important vegetable oil after soybean (23.2 million tons, FAO). Oil World (1999) predicts that palm oil will be the leading oil in 2012 and by the year 2020, the world palm oil production is projected to hit 40 million tons.

The Southeast Asian countries dominate the world production of palm oil and account for nearly 79\% of the world's oil palm fresh fruit bunch (FFB) yield. In 2000, Malaysia with 10.8 and Indonesia with 6.9 million tons (FAO, 2000) were the two leading producers covering about $97 \%$ of the total Asian production. Oil palm continues to be Southeast Asia's most rapidly expanding crop (FAO, 1999). There are several reasons for this rapid expansion. Crude palm oil and palm kernel oil are adaptable vegetable oils and have a wide range of markets in food and oleochemical industries. Due to the rapid increase in consumption of dietary oils and fats in the developing economies of China and India, the world market prices are strong, and have increased from 480 US\$ in December 1996 to 680 US\$ in May 1998 (CIFOR, 1998). This has encouraged investors to build up plantations on large areas of suitable land found in the Malaysian peninsular and the Indonesian islands of Sumatra and Kalimantan. Therefore, there is a huge demand for improved planting material for replanting and for the expansion of oil palm plantations. In general, the oil palm in Indonesia is multiplied by seeds of the Tenera-type, a cross-breeding between Dura $x$ Pisifiera. The 
disadvantage of propagation by seed is the heterogeneity of the plant material resulting in a high variability of productivity, quality and disease resistance. On an average, the Teneratypes produce an oil crop of 6 tons/ha/year. A major event in oil palm breeding was the development of tissue culture techniques for vegetative propagation. High-yielding, so-called elite palms of the Tenera varieties, which are able to produce more than 10 tons/ha, were chosen as ortets for micropropagation. The produced clones showed a crop increase of 20$30 \%$ up to 13 tons/ha, and a better uniformity than the seedlings.

The in vitro propagation has several advantages but some hindrances still occur. One of the most critical problems is the transfer of in vitro plantlets to ex vitro conditions. Micropropagated plants have been continuously exposed to a unique microenvironment that has been selected to provide minimal stress and nearly optimal conditions for plant multiplication. These conditions lead to a phenotype which is more fragile than greenhouse grown plants due to different anatomical, morphological and physiological factors. After transfer to ex vitro conditions the plantlets have to correct the above mentioned abnormalities to become adapted to a natural environment. An acclimatization process before transfer to the nursery is required to improve survival and growth of the plantlets. At this transitional stage, plantlets were kept in the greenhouse under a semi-shaded plastic tunnel and misted twice daily during the two first weeks to maintain a saturated air humidity. Despite these measures to prevent plant mortality, 30-40\% of oil palm plantlets died during this phase (Ginting, 1996). The low percentage of surviving plantlet is a problem for expanding the commercial planting of clonal oil palms.

Micropropagation is an excellent tool for rapid production of homogenous, genetically improved plant material but it reduces or even eliminates the population of beneficial microorganisms, such as mycorrhizal fungi, during the early stages of post in vitro acclimatization. This phase is a critical step in the micropropagation cycle and the lack of microorganisms frequently results in poor development of plants, so that their reintroduction during plant production is important. Recent investigations on casava plantlets (AzconAguilar et al., 1997) and micropropagated fruit tree rootstocks (Monticelli et al., 2000) have shown that early mycorrhizal inoculation reduced transplant shock during acclimatization, and thus increases plant survival and establishment rates. Micropropagated Anona cherimola mill. and wild cherry plantlets inoculated with mycorrhizal fungi showed enhanced plant quality, nutrient uptake and plant growth (Azcon-Aguilar et al., 1997; Lovato et al., 1994). The benefits of mycorrhiza for in vitro propagated plantlets have been reported for many value crops such as grapes, apple, plum, pineapple, avocado, strawberry, raspberry, cherry, ash and pear (Varma and Schüepp, 1995; Fortuna et al., 1996; Lovato et al., 1996; Azcon- 
Aguilar and Barea, 1997). In contrast, very little research has been carried out on economically important perennial species such as micropropagated oil palms (Blal et al., 1987; Blal and Gianinazzi-Pearson, 1990). Therefore, there is a high potential for introducing mycorrhizal fungi into the micropropagation system of this high valued plant.

The aim of this thesis was to combine the use of (vesicular-)arbuscular mycorrhizal fungi $((\mathrm{V}) \mathrm{AMF})$ with the production of micropropagated oil palms. Several experiments were carried out to determine whether (V)AMF could enhance transplanting success and plantlet acclimatization as indicated by plant survival, plant growth and nutrient uptake.

\section{Target /objective}

The research project described in the following was carried out within the main project "Biotechnology Indonesia-Germany" (BTIG), which was started in 1988. Among several other sub-projects, BTIG also included one project on the improvement of the oil palm (Elaeis guineensis Jacq.) which is an agronomically important crop species in Indonesia. The main aim was the application of modem techniques for improving conventional cultivation systems of oil palm in Indonesia.

The research of this study was carried out in collaboration with the Indonesian "Biotechnology Research Unit for Estate Crops" in Bogor and the "Indonesian Oil Palm Research Institute" in Medan, and with the "Institute of Plant Breeding" and the "Institute of Plant Production in the Tropics" of the University of Göttingen in Germany.

The "Indonesian Oil Palm Research Institute" (IOPRI) is the largest oil palm seed producer in Indonesia. IOPRI startet research activities in oil palm tissue culture in 1986. Until 1996, IOPRI had planted about 1.500 ha with clonal oil palms on various locations. Yield advantages of clonal palms in a range of $30 \%$ have been demonstrated in field trials (Ginting et al., 1996).

Tissue culture of palms is time- and labour intensive. The total time required between the sampling of the mother palm and the hardening of the plantlets is 18 month in average (Duval et al., 1995). Because of the high production costs the selling price of clonal plantlets could not be lowered to less than five times the price of selected seeds (2-3 US\$).

One of the acute problems of oil palms multiplied by tissue culture is the survival rate of the young plantlets during the post vitro growth. In this sensitive stage, after micropropagation under sterile controlled conditions and before transplanting to the nursery, plantlets are subject to severe environmental stress, due to poor root and shoot growth and reduced cuticular wax formation. 
During 1992 and 1993 IOPRI has produced 56.401 and 76.612 plantlets, only 63\% and 58\% of these plantlets were sold, respectively. This phenomenon caused by high percentage of mortality (37-42\%) during acclimatization process and after transferring plantlets to the prenursery. The low percentage of plantlet survival is a problem for expanding the commercial planting of clonal oil palms. The technology used for micropropagated plants does not take into consideration the existence of the symbiosis of mycorrhizae and other related plant growth promoting microorganisms like rhizobacteria. The media used are devoid of mycorrhizal propagules, and therefore the plants obtained from this sytems are nonmycorrhizal. These non-mycorrhizal plants obtained from the micropropagation process eventually become mycorrhizal when they are planted to the field soil.

Their omission during micropropagation frequently results in poor development of plants so that their reintroduction during plant production is important. Most natural field soils and nonsterile nursery soils contain indigenous mycorrhizal fungi. The roots of oil palm were colonized by (vesicular-) arbuscular mycorrhizal fungi under natural conditions (Nadarajah 1980; Blal and Gianinazzi-Pearson 1989). A survey of the soil of oil palm plantations in Malaysia revealed species of all six genera of the Glomales (Nadarajah 1980).

Where the indigenous fungi are ineffective, inoculation with effective mycorrhizal fungi may increase plant growth. A decision to introduce mycorrhizal fungi under such conditions depends on the effectiveness of these indigenous fungi, i.e. on their ability to benefit plant growth in comparison with possible introduced fungi.

The usefulness potential of (V)AMF for agricultural production systems, in particular for the recovery and growth of high-value micropropagated plants, has been shown for several temperate species (Morandi et al., 1979; Pons et al., 1983; Gianinazzi et al., 1986; Branzanti et al., 1990; Ravolanirina et al., 1990). In 1993, the "Biotechnology Research Institute for Estate Crops" in Bogor, Indonesia started a greenhouse experiment with the aim to find out how an inoculation with different (V)AM-fungal strains of in vitro multiplied oil palm clones would improve the ingestion, and thus the rise of plant growth. The results of Widiastuti and Tahardi (1993) showed that (V)AMF inoculation increased plant growth and nutrient uptake, specially the P uptake in the shoots of inoculated plantlets increased by $37-44 \%$. The authors concluded that (V)AM seems to enhance the survival and development of the plantlets during the acclimatization phase.

Based on these results the research described in this study was carried out. One of the main aims of this research work was to introduce and establish the mycorrhizal inoculation in an existing micropropagation process and make it possible for practical users. 


\section{State of the Art}

\subsection{The oil palm}

The oil palm belongs to the family Palmaceae and the genus Elaeis. There are two important species in the genus Elaeis, E. guineensis (Jacq.), which is African in origin and E. olifeira, which is South American in origin. This research was done in Indonesia, on Elaeis guineensis. The natural habitat of the oil palm is in the humid tropics, 10' on both side of the equator and in altitudes below $500 \mathrm{~m}$. The optimum temperature lies between $22^{\circ}$ and $32^{\circ} \mathrm{C}$ and rainfall requirement is high (2500-3500 mm year $\left.{ }^{-1}\right)$.

The plant is a monocotyledon of the order Spadiciflorae with a single growing point from which fronds emerge in a regular sequence at a rate of 20-26 fronds per year. It is monoecious, which enforces cross-pollination since it produces separate male and female interflorescences from axillary buds in alternate cycles (Hartley, 1988). The fruits (drupes) are situated on secondary branches and consist of an orange-colored mesocarp which contains 'palm oil', a hard lignified shell (endocarp) and a white kernel containing 'kernel oil'. The number of fruits per bunch varies from 50 to 100 in young palms and up to 1000-3000 in older ones. Individual bunches weight from less than $1 \mathrm{~kg}$ to $20-50 \mathrm{~kg}$. The economic life span of an oil palm plantation is about 20-25 years, beyond which tree height makes the harvesting procedure uneconomic.

The main product is palm oil, which is obtained from the pulp (mesocarp) of the fruit and palm kernel oil, which is extracted from the endosperm of the kernel, considered as a byproduct. Both types of oil have different physical and chemical characteristics so that they are used in different applications. Palm oil mainly contains the saturated palmitic acid and a high quantity of the unsaturated oleic acid, giving it a higher unsaturated acid content than palm kernel or coconut oil. Approximately $90 \%$ of palm oil, which is commercially fractionated into olein and stearin, is used in food products. Its physical properties as a semi-solid vegetable oil make it particularly suitable for margarines, bakery shortenings and some confectionery fats. The remaining $10 \%$ are used as oleochemicals. Recent investigations suggest a potential use of palm oil fatty acid esters as a fuel for combustion engines similar to diesel fuel (Hardon et al., 1997). The oil palm remains a formidable competitor with other vegetable oil crops in terms of yield per hectare. The oil yield from properly maintained oil palms is over ten times larger than oil yields from commercial grown soybean (Mielke, 1991). The energy balance expressed by the ratio of energy output to input is wider for the oil palm (1:10) than other oil crops like rapeseed (1:3) (Wood and Corley, 1991). 


\subsection{Oil palm in Indonesia}

The Southeast Asian countries dominate the world production of palm oil. In the year 2000 18.3 millon tons of palm oil were produced in South East Asia, which is nearly $84 \%$ of the world's palm oil production (FAO, 2000). Malaysia with 10.8 and Indonesia with 6.9 million tons (FAO, 2000) were the two leading producers, with about $97 \%$ of total Asian production. Indonesia is one of the lowest-cost producers of vegetable oil in the world (Larson, 1996). In 1998, the production costs for 1 ton palm oil in this country were about 150 US\$, in Malaysia 250 US\$ (FEER, 1998). Palm oil industries are considered to be important since they are labor-intensive and able to provide employment opportunities for Indonesia's growing population. In 1997, Indonesia's oil palm industry employed more than 2 million people (Arafin and Susila, 1998). With a population of 200 million - which is still rising - Indonesia has a big domestic market for oil and fats. The prolific growth of the oil palm sub-sector has brought important economic benefits. In 1997, 2.9 million tons of palm oil were exported bringing in earnings estimated at 1.4 billion US\$ which accounted for $31 \%$ percent of Indonesia's agricultural export in 1997 (CIFOR, 1998). The main import countries of Indonesian palm oil exports were the Netherlands, Germany and Italy (Oil World, 1999).

The oil palm production has been one of the most dynamic of Indonesia's sub-sectors and its development has attracted much attention in recent years. It is regarded as an important cause of the conversion of Indonesia's natural forest to non-forest uses. From 1967 to 1997, the oil palm sub-sector increased 20-fold in regard to the planted area (from 106.000 ha to 2.516 .000 ha), and crude palm oil production increased 12\% annually (Casson, 1999). Most of the oil palm plantation area is concentrated in Sumatra and West Kalimantan. Government plans drawn up before the economic crash in 1997 called for the plantation area to reach 5.5 million ha by 2000 (Cohen and Hiebert, 1997), and for Indonesia to be the world's biggest palm oil producer by 2005 (McBeth, 1997).

\subsection{Genetic and breeding of oil palm}

The migration of the oil palm from its original growth area toward South America took place from the $16^{\text {th }}$ century onwards. In 1848 , a few individuals were introduced to Asia from Reunion via Amsterdam. They were planted as ornamental palms at the Bogor Botanical Garden in Indonesia. The last of the original trees died in 1993 but offspring of these mother plants can be found all over South East Asia. These palms have been the base material for the first plantations at the beginning of the $20^{\text {th }}$ century. 
Breeding and selection started around 1920, when the oil palm was initially developed as a plantation crop in Sumatra, Malaysia and Zaire. The first commercial plantings in Indonesia were established between 1911 and 1920 on Sumatra's east coast. This population is referred to as 'Deli-dura' characterised by a high production potential. This was followed by selection for high number of bunches and single bunch weight. Until the early 1960's the dura palms, with characteristic thick shells, were the main source of planting material. A mayor contribution was the research of the genetics of three naturally occurring botanical fruit types, Dura characterized by a thick shell, Tenera with a thin shell and Pisifera, without any shell at all and a high-sterility rate among female trees. A significant effect in increasing oil yield was the discovery by Beirnaert and Vanderweyen (1941) that the inheritance of shell thickness is controlled by a single gene. The homozygous dominant, thick-shelled Dura $\left(\mathrm{sh}^{+} \mathrm{sh}^{+}\right)$was crossed with the homozygous recessive shelless Pisifera ( $\mathrm{sh}^{-} \mathrm{sh}^{-}$), and a $100 \%$ heterozygous thin shelled Tenera $\left(\mathrm{sh}^{+} \mathrm{sh}^{-}\right)$was produced. Tenera fruits have relatively more oil bearing mesocarp (60-90\% per fruit weight) than Duras (20-65\% per fruit weight). From 1962 to 1988, the oil yield increased from an average of 5 to $9,6 \mathrm{t} / \mathrm{ha} / \mathrm{y}$ (Lee, 1991). The population of 'Deli-Dura' is most commonly used around the world as a female line for the production of seeds (Nampoothiri, 1998).

The oil palm is an outcrossing species, hence individual palms are highly heterozygous and vary widely in yield, oil quality and disease resistance. In Indonesia, under highly favourable environmental conditions the average oil production per palm per annum was $44.3 \mathrm{~kg}(6.3$ tons per hectare) but the individual production varied between $21 \mathrm{~kg}$ and $77 \mathrm{~kg}$ or between 3 and 11 tons per hectare per annum (Noiret et al., 1985). The sexual breeding cycle in oil palm is very long, as a result of the performance and oil yield of the progeny it can be predicted only after 15-20 years. The variation in vigor and productivity is often observable only many years after field planting. The generation time in a breeding program of oil palm is about 8 years and makes breeding for new lines a very long-term project. Clonal oil palms offer the potential for greater productivity because it is possible to establish uniform tree stands comprising identical clones of a limited number of highly productive oil palms.

\subsection{Micropropagation of oil palm}

Research on oil palm tissue culture was started in 1970 by UNILEVER, England and CIRAD$\mathrm{CP}$ in France. Vegetative propagated al palms were reported for the first time by Jones in 1974 and Corley in 1976. They used root tips as the source of tissue (explant). Rabechauld and Martin (1976) reported the use of young leaf tissue as explant (Durand et al., 1989). In the 1980 's, research and development of oil palm micropropagation expanded to South East Asia. 
The "Indonesian Oil Palm Research Institute" (IOPRI) started research on activities in oil palm tissue culture in 1986 by adopting the technology of the French Institute de Recherches et pour les Huiles et Oleagineux (IRHO). In the mid of 1986 the tissue culture laboratory of IOPRI at Marihat, North Sumatra, produced the first oil palm clone (Lubis et al., 1996). The propagated clones were selected from the best Tenera crosses in terms of oil yield and other related characters, and until now more than 400 ortet have been cultured. From 1985 to the end of 1994 more than 300.000 plants derived from 168 clones which had been distributed to estates, covering an area of ca. 1.532 ha (Ginting et al., 1993). The results of field trials from 10 locations of clones produced by IOPRI showed that the yield (FFB) of clones at the average was $27.8 \%$ higher than that of commercial tenera seedlings (Lubis et al., 1993). Since the clonal plants are more uniform in flowering and setting fruits, the clonal plants can be harvested earlier (24-28 month) compared to seedling (30-34 month) (Lubis et al., 1996).

Oil palm tissue culture has become commercially important. An oil palm has an economic productive life of over 20 years. The price of crude palm oil fluctuated in the period 19951998 between U\$ 500 and U\$ 700 per ton (World Bank). Oil palm clones show a 20-30\% increased yield compared to seedling material (Lubis et al., 1993) providing an added benefit per palm of U\$ 75-U\$ 100 during the economic life span.

The oil palm as a monocotyledon is growing from one primary shoot meristem and has no obvious morphological base for vegetative propagation. Cloning of oil palm is performed by somatic embryogenesis on calli of leaf origin according the method of CIRAD-CP in France which was developed by Pennetier et al. (1981). The source of explant are young leaves from selected mature ortet palms which are still enclosed by leaf bases and inflorescence within the spathes. They can be sampled without destroying the mother palm because the apex is not damaged (for more details see chapter: Material and methods). The main criteria for selecting the 10-15 years old ortets are oil yield $>7.5 \mathrm{t} / \mathrm{ha} / \mathrm{y}$ or fresh fruit bunch (FFB) yield $>30 \mathrm{t} / \mathrm{ha} / \mathrm{y}$ and a moderate growth rate (Ginting et al., 1993). After field testing the best performing clones will further be multiplied and distributed to the consumers (Duval et al., 1995).

Tissue culture of palms is in general a time-consuming and very labour intensive procedure. The total time necessary between the sampling of the mother palm and the hardening of the first batch of plantlets is 18 month in average (Duval et al, 1995). This has a negative impact on production costs. The selling price of clonal plantlets (US\$ 2-3) cannot be lowered to less than five times the price of selected seeds. The success of micropropagation depends on the ability to transfer plantlets out of culture on a large scale at low cost, and with a high survival rate (Preece and Sutter, 1991; Debergh, 1991). 
One of the acute problems is that plantlets derived from tissue culture have been observed to be less vigorous than those obtained by seeds. Before plantlets can be transferred to the nursery it is necessary to include an acclimatization process to improve the survival and growth of the plantlets. In the case of micropropagated oil palm the percentage of mortality is about $30 \%$ during this phase and further $10 \%$ of the plantlets do not survive the transfer to the pre-nursery.

\subsection{The problem of acclimatization}

Several problems among which the transfer of in vitro plantlets to ex vitro conditions is the most critical limit the widespread use of micropropagation. For many species losses from 50 to $90 \%$ of in vitro propagated plantlets have occurred when transferring them to the soil (Sutter, 1985; Ziv, 1986).

The micropropagated plants have been continuously exposed to a unique microenvironment that had been selected to provide minimal stress and nearly optimal conditions for plant multiplication. Plantlets grow heterotrophic, and develop within culture vessels under conditions which are characterized by a saturated atmosphere, relative low light intensity

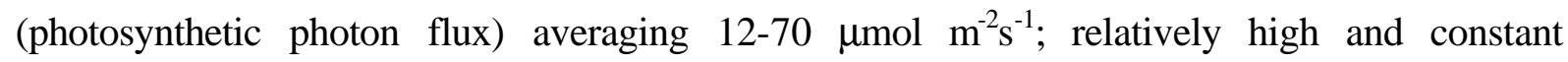
temperature $\left(20-28^{\circ} \mathrm{C}\right)$, low rates of gas exchange between the containers and high concentrations of carbohydrate and exogenous growth regulators in the medium. These factors often induce physiological, anatomical and morphological abnormalities which interfere with the acclimatization subsequent to transplanting resulting in low survival rates $e x$ vitro (Ziv, 1991; Puthur et al., 1998).

In vitro plantlets are invariably diminutive and much smaller than greenhouse grown plants (Donelly and Tisdall, 1993). The percentage of water content is increased and the dry matter accumulation per unit area is reduced compared to greenhouse grown plants (Brainerd and Fuchigami, 1981; Donelly and Vidaver, 1984). This is reflected in fragile organs with reduced mechanical support tissue and thin cell walls. Relatively low light levels and a saturated internal atmosphere promote leaves in vitro that anatomically resemble shade leaves (Brainerd and Fuchigami, 1981; Lee and Wetzstein, 1988; Marin and Gella, 1988) and hydrophytic plant leaves (Grout and Aston, 1978). They often have reduced or absent epicuticular or cuticular wax, which can lack the characteristic crystalline structure or differ in chemical composition from the control plants (Grout, 1975; Grout and Aston, 1977; Sutter, 1984, 1985; Short et al., 1987). In vitro stomata have slow response times and due to an impaired function they do not close in response to stimuli such as darkness, abscisic acid application or when exposed to high levels of carbon dioxide (Brainerd and Fuchigami, 1982; Wardle and Short, 
1983; Wetzstein and Sommer, 1983; Ziv et al., 1987). In vitro plants principally require sugar as a carbon source (Conner and Thomas, 1982), and the $\mathrm{CO}_{2}$ uptake capability is low (Donelly and Vidaver, 1984). Consequently when transplanted out of the culture vessel, plantlets suffer from severe environmental stresses and substantial losses may occur (Van Huylenbroeck and Debergh, 1996).

Difficulties in transplanting tissue cultured plantlets to soil are well documented (Puthur et al., 1998; Subhan et al., 1998). They appear to be a direct result of the culture-induced phenotype which reflects adaptation to in vitro conditions but have a harmful effect when plantlets are transferred to the greenhouse or field where the relative humidity tends to be less than $100 \%$, the ambient light levels are much higher than in culture, the temperatures are fluctuating and the substrate has a much higher water potential. The transfer of plantlets cultivated in vitro is one of the most important steps in the structural and physiological adaptation during the preparation of plantlets. During this time, plantlets must increase their absorption of water and minerals and their photosynthetic rate (Grattapaglia and Machado, 1990). To promote ex vitro survival and physiological competence, especially to protect them against water stress and encourage autotrophy, a transitional environment is usually supplied for the acclimatization interval, ranging from one to several weeks (Brainerd and Fuchigami, 1982; Grout and Millam, 1985; Fabbri et al., 1986). In this transitional environment the relative humidity is kept in the range of $70-100 \%$ via tending and the light level is regulated by shading against direct sunlight. Gradually, as the plantlets acclimatize the relative humidity can be decreased and the light levels can be increased towards ambient conditions. The stage of acclimatization is the beginning of the autotrophic existence of the plant, including the initiation of the physiological processes necessary for survival.

A number of studies have been published to improve the survival and first growth of shootlets at transplant time. These research works were performed mostly under greenhouse conditions and have focused on controlling environmental conditions. The methods were based on $\mathrm{CO}_{2}$ enrichment (Kozai and Iwanami, 1988; Laforge et al., 1990) increased light intensity and the use of mist or fog, plastic tunnels and application of fungizides, but with only limited success. Manipulating of acclimatization condition prior to or upon transplanting usually reduced losses (Donnelly et al., 1985; Desjardins et al., 1988; Preece and Sutter, 1991; Dejardins, 1995; Van Huylenbroeck and Debergh, 1996), however, at additional costs to the producer.

\subsection{The role of mycorrhizal symbiosis}

The ability of the root systems to establish beneficial symbiotic relationships with soil microorganisms represents one of the most successful strategies that land plants have 
developed to cope with abiotic and biotic stresses imposed during the colonization of terrestrial ecosystems (Allen, 1996). These beneficial components of soil biota include mycorrhizae, which are mutualistic associations occurring between the roots of most plant species and certain groups of fungi. The term 'mycorrhiza', created by Frank (1885), refers to an association between fungi (mycor) and root (rhiza) as a mutualistic symbiosis where the host plant receives mineral nutrients via fungal mycelium (mycotrophism) while the heterotrophic fungus obtains carbon compounds from the photosynthesis of the host (Mukerji, 1996).

Seven types of mycorrhizal associations are namely known, (vesicular-) arbuscular mycorrhiza, ectomycorrhiza, ectenmycorrhiza, arbutoid-, monotropoid-, ericoid- and orchidoid mycorrhiza. Types of mycorrhizas are categorized on the basis of taxonomic groups of fungi and plants involved and the alteration in the morphogenesis of fungi and roots, which occurs during the development of the new structure that is mycorrhiza (Harley and Smith, 1987).

The (vesicular-) arbuscular mycorrhiza or (V)AM are the most intensively studied types of mycorrhizae because they are present in most agricultural and natural ecosystems and play an important role in plant growth, health and productivity (Harley and Smith, 1983; Gianinazzi et al. 1990; Lovato et al., 1995). There are only a few genera belonging to Cruciferae; Chenopodiaceae and Cyperaceae where they are not found due to the presence of glucosinolates and their hydrolysis products isothiocyanates in and around the roots (Glenn et al., 1988), which are toxic to the growth of fungi.

(V)AM fungi belong to the class Zygomycotina, order Glomales (Walker, 1992; Morton et al., 1995) whose origin has been dated 353-452 million years ago (Simon et al., 1993). About 150 species of the genera Acaulospora, Enthrophospora, Gigaspora, Glomus, Sclerocystis and Scutellospora have up to now been recognized as forming symbiotic associations with plants. These fungi form morphologically distinct resting spores in the soil and can be multiplied in the presence of a hostplant. Some of these spores can be surface sterilized and used to produce new spores in axenic seedlings or root organ culture (Mosse and Hepper, 1975; Arnaud, et al., 1996). The close relationship of (V)AM fungi with their host plants is mirrored by their obligatory biotrophic status. In absence of a host, their growth is limited to a relatively short time (20-30 days) after which many modifications in fungal morphology point to a cessation of hyphal growth. Presence of the root allows development of vegetative mycelium, which, under favorable conditions, can colonize $60-90 \%$ of the length of the root system (Becard and Piche, 1989; Bonfante and Bianciotto, 1995). 
Mycorrhizal colonization begins with the hyphae that arise from soil-borne propagules, large resting spores of the (V)AMF or mycorrhizal root fragments. The fungal hyphae penetrate the root between the epidermal cells and form an appressorium in the first cell layers. This stage marks the autotrophic growth of the fungus. The colonizing hyphae pass through the intercellular spaces and then enter the root tissues spreading between and through cells of the cortical root layers. Once the hyphae have reached the inner cortex they grow into the cells and form tree-like structures called 'arbuscules'. These branched hyphae are closely surrounded by the intact host plasmalemma and represent a large surface of cellular contact between both symbionts. These facilitates the exchange of metabolites between host and fungus. The arbuscules are probably the main transfer site of mineral nutrients, mainly phosphorus, from the fungus to the plant and of carbon compounds to the fungus (Smith and Gianinazzi-Pearson, 1988; Smith and Smith, 1990; Bonfante and Bianciotto, 1995). As internal colonization spreads, the extraradical hyphae ramify, and grow along the root surface forming more penetration points. They also grow outwards into the surrounding soil, thus developing an extensive tri-dimensional network of mycelium which interfaces with soil particles. Smith and Gianinazzi-Pearson (1988) indicate that the length of the external hyphae growing in soil associated with mycorrhizal roots reaches an average of $1 \mathrm{~m} \mathrm{~cm}^{-1}$ root, but values of up to $10-14 \mathrm{~m} \mathrm{~cm}^{-1}$ root have also been recorded. These mycelial network can extend several centimeters outwards from the root surface, bridging over the zone of nutrient depletion around roots to absorb low-mobile ions from the bulk soil (mineral nutrients). In return the plant provides the fungus with sugars, amino acids and vitamins essential for its growth (Harley and Smith, 1983).

The colonized plant is better nourished and better adapted to its environment. It obtains increased protection against environmental stresses (Sylvia and Williams, 1992), cold (Charest et al., 1993; Paradis et al., 1995), salinity (Davis and Young, 1985) and pollution (Leyval et al., 1994; Shetty et al., 1995). In addition, the symbiosis tends to reduce the incidence of root diseases and minimizes the harmful effect of certain pathogenic agents (StArnaud et al., 1995). In agriculture, the increased uptake of soil minerals by colonized plants means that it is possible to consider reducing substantially the application of fertilizers and pesticides, and at the same time obtain equivalent or even higher crop yields (Abbott and Robson, 1992).

The fact that colonized plants are better able to obtain their nourishment from the soil and resist environmental stresses gives fungal symbionts a biofertilizing and crop protecting role. Maximum benefits will only be obtained from inoculation with efficient mycorrhizal fungi and careful selection of compatible host/fungus/substrate combinations. The performance of 
micropropagated plants may be greatly improved by ensuring a suitable mycorrhizal establishment at outplanting. In particular woody plants which are difficult to root in vitro have been shown to improve their survival rate and quality when inoculated with (V)AM fungi.

\subsection{Mycorrhizae and micropropagation}

The technique of micropropagation eliminates all microorganisms, including mycorrhizal fungi, which are naturally an integral part of the plant, assuring satisfactory growth and development in microbial-rich and nutrient-poor environments. The post vitro acclimatization is a critical step in the micropropagation cycle and the lack of microorganisms can affect survival and growth of in vitro produced plantlets. Previous studies have shown that inoculation with endomycorrhizal fungi at the time of transplanting the micropropagated plantlets from axenic to ex vitro conditions significantly improves survival and growth due to improved absorption of nutrients and water, and to increased stress tolerance (Azcon-Aguilar et al., 1997; Jaizme-Vega et al., 1997). Therefore, there is a high potential for introducing (V)AMF into the micropropagation system of high valued plants.

Experiments of Vestberg (1992) and Verma and Adholeya (1996) and showed an improved vegetative growth of micropropagated strawberry after mycorrhizal inoculation. Significant increases in leaf area have been reported of three micropropageted pineapple varieties inoculated with five different (V)AM fungi (Guillemin et al., 1994). Blocking of shoot apical growth after transplanting Allium porrum (Berta at al., 1990), apple and plum rootstocks (Fortuna, et al., 1992) and Leucaena leucocephala (Naqvi and Mukerji, 1998) could be prevented by (V)AMF inoculation. Mycorrhizal fungal inoculation has also been found to influence root morphology of micropropagated grapevine (Schellenbaum et al., 1991). Inoculation with Glomus mosseae induced a more branched root system into micropropagated plum rootstock (Giovanetti et al., 1996). Endomycorrhizal inoculation is also reported to have a positive influence on the homogeneity of micropropagated apple (Branzanti et al., 1992) and shortened their culture time a quarter to one third compared to uninoculated plants (Uosukkainen and Vestberg, 1994).

The application of (V)AM fungi also offers the opportunity to reduce fertilizer inputs (mainly of phosphorus) as well as the limit use of pesticides (Hooker et al., 1994). Williams et al. (1992) found that fertilizer inputs can be reduced in mycorrhizal micropropagated strawberry to levels considerably lower than those used in commercial practice and yet plant development was equivalent to that of non-mycorrhizal plants receiving full fertilizer inputs. Increase in phosphate concentration and content has been recorded in micropropagated 
Anthyllis after mycorrhizal inoculation (Salamanca et al., 1992). In Gerbera jamesonii plantlets mycorrhizal inoculation with Glomus etunicatum increased P, K, Zn and $\mathrm{Cu}$ uptake besides increasing the dry weight of plants. (V)AMF inoculation also advanced flowering by 16 days as compared with the control (Chiluan et al., 1994). Improvement of survival rate has been observed in micropropagated avocado (Azcón-Aguilar et al., 1994), Anthyllis (Salamanca et al., 1992), jackfruit (Sivaprasad et al., 1995) and in Leucaena leucocephala (Naqvi and Mukerji, 1998). (V)AM inoculation reduced the acclimatization period by about 8 weeks in Anthyllis cystisoides (Salamanca et al., 1992). There are also reports on the effect of (V)AM fungal inoculation on the plant tolerance to fungal pathogenes like Phytophthora (Vestberg et al., 1994; Guillemin at al., 1994).

Mycorrhiza are also known to occur in several palm genera including Elaeis (Blal et al. 1990) after artificial inoculation in the nursery. Blal et al. (1990) reported that micropropagated oil palms increased the coefficient of fertilizer utilization four to five fold after mycorrhization, in particular with rock phosphate. (V)AMF from oil palm plantations were described by Nadarajah (1993) and a beneficial effect of mycorrhizal inoculation on oil palm seedlings has been reported by Loh (1980).

Experiments of Widiastuti and Tahardi (1993) showed that (V)AMF inoculation increased plant growth and nutrient uptake of oil palm plantlets. Especially the $\mathrm{P}$ uptake in the shoots of inoculated plantlets increased by $37-44 \%$. The authors concluded that (V)AMF seemed to enhance the survival and development of the plantlets during the acclimatization phase.

\subsection{Working with mycorrhiza}

Micropropagation involves two main stages, an in vitro and an ex vitro and mycorrhizal inoculation can be done at either of these two stages. The rooting of micropropagated plants is commonly done in agar medium supplemented with auxins. Extensive studies have been done on the germination of (V)AM fungal spores and early stages of growth of mycelium. Results indicate that most mycorrhizal fungal spores require low nutrient content media for rapid germination. High concentration of nutrients particularly phosphorus has a inhibitory effect on spore germination and growth (Green et al., 1976). (V)AM fungal spore inoculation in vitro at the root initiation stage has been succesfully obtained by Becard and Fortin (1988), Diop et al. (1992), Verma and Adholeya (1995, 1996) to establish (vesicular-) arbuscular mycorrhizal symbiosis. At this stage for each plant and fungus combination appropriate medium for the growth of both the micropropagated plant and (V)AM fungus is required. Pons et al. (1983) achieved in vitro inoculation of Prunus avium using Gigaspora margarita. Ravolanirinana et al. (1989) also reported a functional mycorrhizal symbiosis in Vitis vinifera 
in the rooting medium with surface sterilized spores of Gigaspora margarita, Glomus caledonium and Glomus mosseae. Elmeskaoui et al. (1995) obtained an in vitro system for culturing Glomus intraradices with 4 Ri T-DNA-transformed carrot roots or non-transformed tomato roots which were used as a potential active source of inoculum for colonization of micropropagated strawberry plantlets after root induction in growth chambers. Colonized plantlets were reported to have more extensive root system and better shoot growth than control plants. In vitro inoculation of micropropagated plants with (V)AM fungal spores is possible but it is a cumbersome process which involves technical expertise. This technique therefore is not practically feasible on commercial scale and is limited to research studies only.

The inoculation at the ex vitro stage can be achieved either at the beginning or at the end of the acclimatization stage, before the start of the hardening phase. A number of references are available on ex vitro inoculation studies of micropropagated plants like strawberry (Vestberg et al., 1972), grapevine (Ravolanirina et al., 1989), avocado (Azcon-Aguilar et al., 1992; Vidal et al., 1992), kiwifruit (Schubert et al., 1992), apple (Branzanti et al., 1992; Vosukainen, 1992), plum (Fortuna et al., 1992), pineapple (Guillemin et al., 1992, 1994, 1995), jackfruit (Sivaprasad et al., 1995) and banana (Naqvi and Mukerji, 1998). Different workers have inoculated micropropagated plants at various stages. In Pistacia integenima, (V)AM inoculation was done after the acclimatization stage (Schubert and Martinelli, 1988). Vidal et al. (1992) inoculated avocado both at the onset of the acclimatization stage and at the beginning of the hardening phase. Their results revealed that although (V)AM symbiosis could be established at both stages but the inoculation at the beginning of the hardening stage showed better results. The greatest effect of (V)AM fungi on plant growth of Annona cherimola plants was observed when they were inoculated after the acclimatisation period, before starting the hardening under greenhouse conditions (Azcón-Aguilar et al., 1994).

The substrate used for ex vitro growth of micropropagated plants are important for growth of plants and development of (V)AM symbiosis. The most common substrates used in plant tissue culture are peat based without soil and synthetic substrates like perlite or vermiculite. Studies have revealed that different gowth substrates have varying effects on development of (V)AM fungi. In investigations of Vidal et al. (1992) a soil-sand mix was found better for (V)AM fungal colonization of micropropagated avocado plants as compared to a peat-sand mix. Schubert et al. (1990) reported that (V)AM colonized roots of micropropagated grapevine in peat-based media but significant growth response was noted when soil was added to the substrate. 
The inoculum can be used in different forms like mixture of soil-based inoculum and mycorrhizal roots (Naqvi and Mukerji, 1998; Schubert et al., 1990), mycorrhizal root only or surface sterilized mycorrhizal roots (Ponton et al., 1990).

\section{Materials and Methods}

\subsection{Location and climate of the experimental site}

All experiments of this study were conducted in the greenhouse of the biotechnological research unit of the "Indonesian Oil Palm Research Institute" (IOPRI) which is located in Marihat, on North Sumatra, southern of Medan. (Figure 1).

The climate of Indonesia is predominantly tropical and is characterized by two tropical seasons, which vary with the equatorial air circulation (The Walker Circulation) and the meridian air circulation (The Hardley Circulation). The displacement of the latter follows the north-south movement of the sun and its relative position form the earth, in particular from the continents of Asia and Australia, at certain periods of the year. These factors contribute to the displacement and instensity of the Inter-Tropical Convergence Zone (ITCZ) which is an equatorial trough of low pressure that produces rain. Thus, the west and east monsoons, or the rainy and dry seasons, are a prevalent feature of the tropical climate.

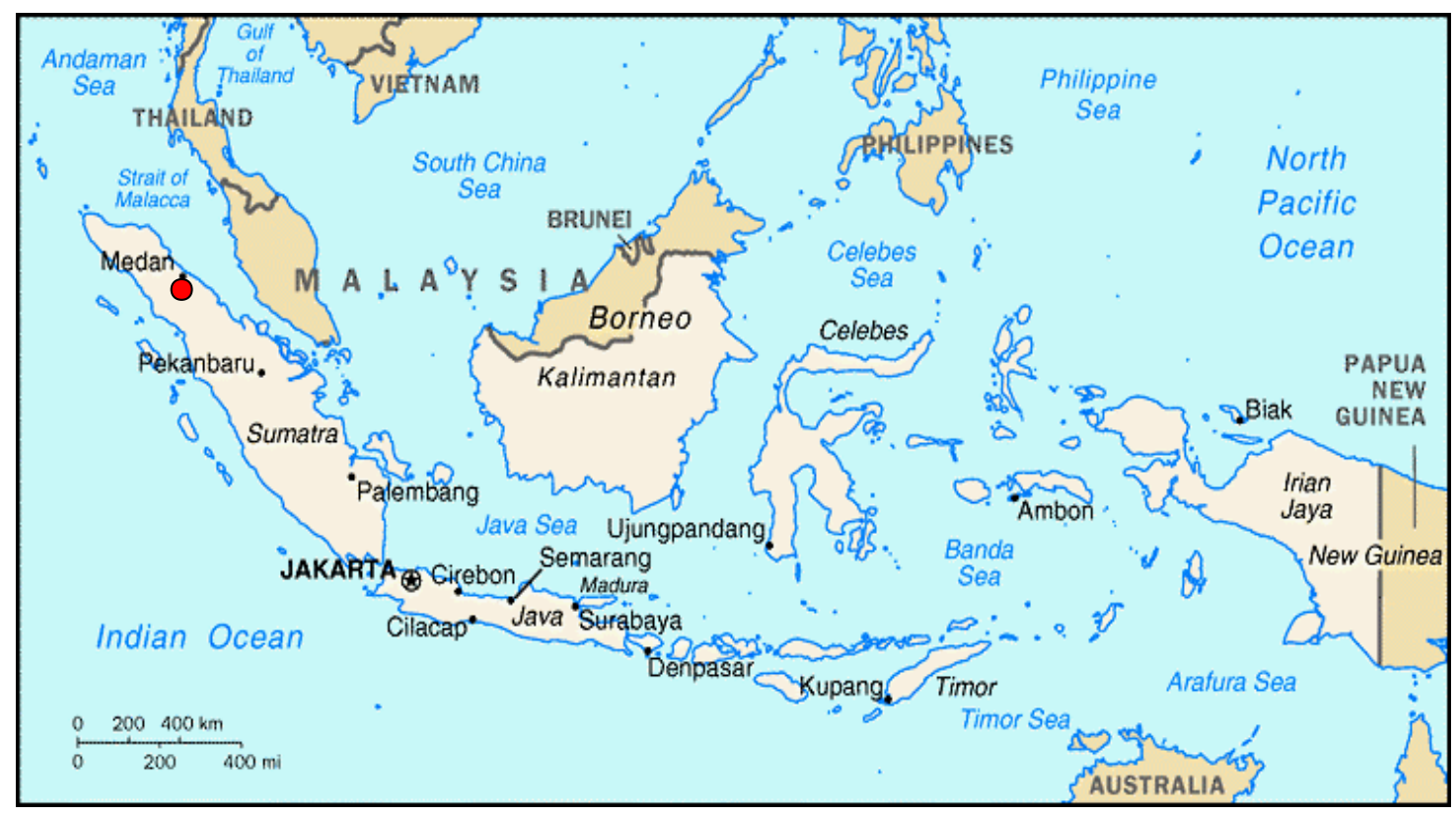

Figure 1: Map of Indonesia (World Fact Book, 2001), location ( 9 of the experimental site.

The East Monsoon lasts from June to September and is characterized by dry weather, especially towards the east. The West Monsoon, which runs from December to March brings 
heavy rainfall especially towards the west. Even outside the West Monsoon period, the rainfall is generally high (1.100-3.400 mm/year) in the western islands ie Sumatra and Kalimantan. The area's relative humidity ranges between 70 and $90 \%$.

Due to the large number of islands and mountains in the country, average temperatures may be classified as follows: coastal plains: $28^{\circ} \mathrm{C}$ inland and mountain areas: $26^{\circ} \mathrm{C}$ higher mountain areas: $23^{\circ} \mathrm{C}$, varying with the altitude.

\subsection{Plant material and maintenance}

\subsubsection{In vitro culture}

Micropropageted oil palm plantlets (Elaeis guineensis Jacq.) were obtained from the biotechnological research unit of the Indonesian Oil Palm Research Institute (IOPRI). Cloning of oil palm was performed by somatic embryogenesis (Figure 2) on calli of leaf origin according the method of CIRAD-CP in France which was developed by Pennetier et al. (1981).

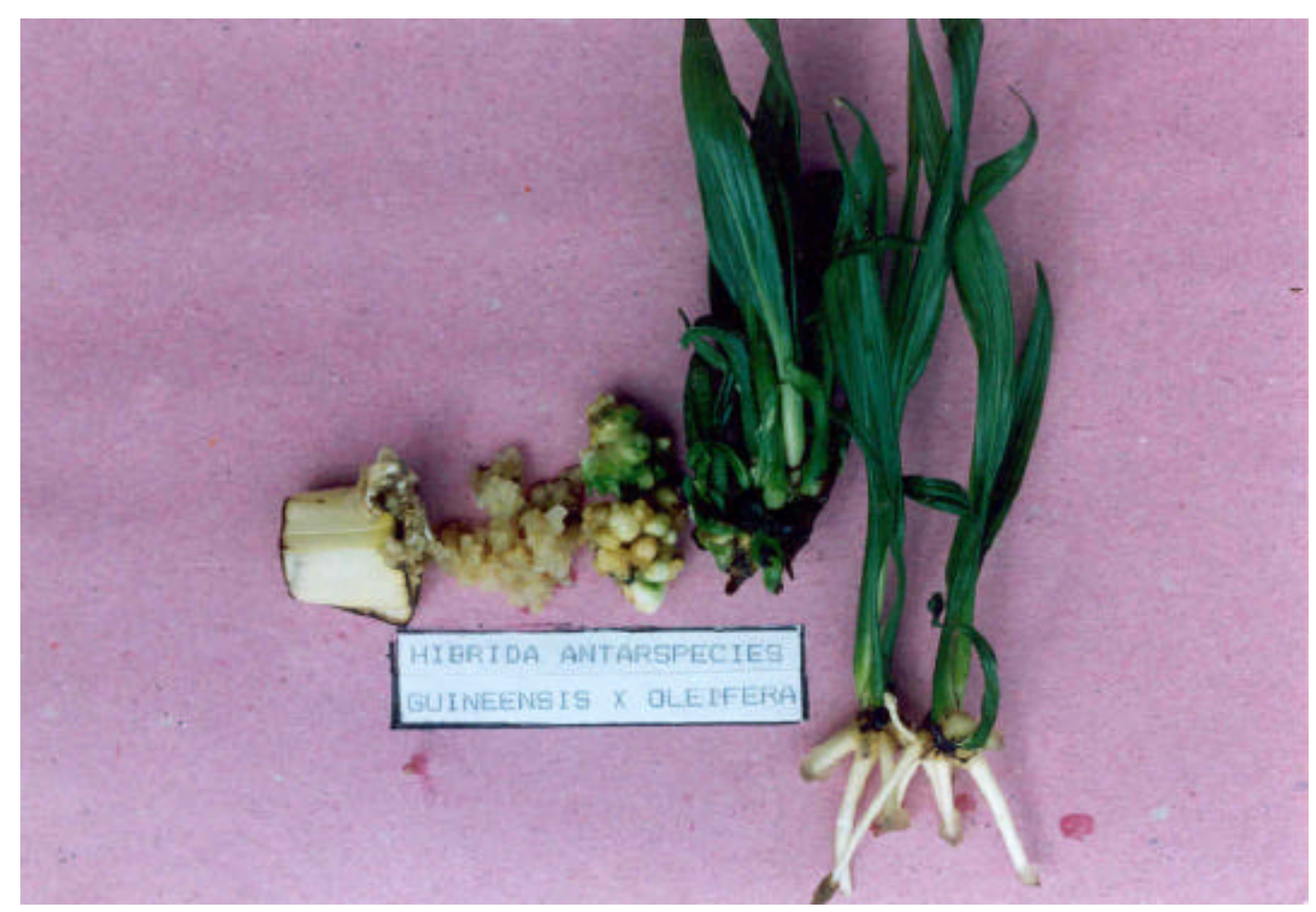

Figure 2: Cultural steps of somatic embryogenesis of oil palm.

The source of explant were young leaves from selected mature ortet palms which were still enclosed by leaf bases and inflorescence within the spathes. The outer surface of leaf bases or spathes were decontaminated and cut into $1 \mathrm{~cm}^{2}$ fragments. The explants were cultured on modified culture media (Murashige and Skoog, 1964), supplemented with growth regulators 
to promote callus induction. Exact media formulation was not available because of intense commercial interest in oil palm tissue culture. The explants were kept in the dark at a temperature around $26^{\circ} \mathrm{C}$. After 46 months callusses were observed and then recultured into media with auxins or cytokinins or both in combination to promote embryogenic process. The embryoids were formed after 4 to 12 months and transferred to embryoid poliferation media to initiate secondary embryogenesis. The embryoids germinated into shoots in the same media and when they are large enough $(\geq 5 \mathrm{~cm})$ they were transferred into rooting media, incorporated with auxins or hormon-free media. Embryoid poliferation, germination and rooting were done under fluorescent light at $27^{\circ} \mathrm{C} \pm 2^{\circ} \mathrm{C}$ temperature. Time requirement from taking ortet up to obtaining plantlets is around 12-18 months. The obtained clones which were used in the experiment were different according origin and yield (Table 1).

Table 1: Characterization of micropropagated oil palm clones by cross (D: Dura; T: Tenera; P: Pisifera; BJ: Bah Jambi; LM: La Mé (Ivory Coast); DS: Dolole Limmusbah; DA: Dabe; MA: Marihat; PA: Pabatu),yield and code (code number in each experiment).

\begin{tabular}{l|l|c|c}
\hline Clone & Cross & Yield & Code \\
\hline \hline Experiment 1 & PA 131 D x MA 321 P & $8-9 \mathrm{t} / \mathrm{ha}$ & 1 \\
MK 96 & TI 221 D x RS 004 T & $9-11 \mathrm{t} / \mathrm{ha}$ & 2 \\
MK 104 & BJ 126 D x LM 002 T & $9-11 \mathrm{t} / \mathrm{ha}$ & 3 \\
MK 124 & LM 2742 D x LM 2399 P & $9-9 \mathrm{t} / \mathrm{ha}$ & 4 \\
MK 203 & DS 029 D x LM 002 T & $9-11 \mathrm{t} / \mathrm{ha}$ & 5 \\
MK 237 & BJ 13 D x LM 7 T & \\
\hline Experiment 2 & LM 268 D x LM 7 T & $9-11 \mathrm{t} / \mathrm{ha}$ & 1 \\
MK 154 & LM 2742 D x LM 2399 P & $8-9 \mathrm{t} / \mathrm{ha}$ & 2 \\
MK 313 & DS 139 D x MA 840T & $8-9 \mathrm{t} / \mathrm{ha}$ & 4 \\
MK 323 & MA 284 D x DS 76 P & $9-11 \mathrm{t} / \mathrm{ha}$ & 5 \\
MK 363 & PA 151 D x RS 8 T & $9-11 \mathrm{t} / \mathrm{ha}$ & 1 \\
MK 339 & DS 300 D x LM 7 T & $8-9 \mathrm{t} / \mathrm{ha}$ & 2 \\
\hline Experiment 3 & LM 2742 D x LM 2399 P & $8-9 \mathrm{t} / \mathrm{ha}$ & 3 \\
MK 164 & LM 270 D x LM 238 T & $8-9 \mathrm{t} / \mathrm{ha}$ & 5 \\
MK 295 & MA 284 D x DS 76 P & $9-11 \mathrm{t} / \mathrm{ha}$ & \\
MK 323 & & \\
MK 359 & & & \\
MK 339 & & & \\
\hline \hline
\end{tabular}

\subsubsection{Post vitro culture - transfer to greenhouse conditions}

After micropropagation the used plantlets were taken from the agar medium and washed with water to remove nutrient agar medium and sugar from the roots. Plantlets were transplanted into sterile sandbeds and were kept in the greenhouse under a semi-shaded plastic tunnel and 
were misted twice daily during the two first weeks to maintain a saturated air humidity. The relative humidity was $90-100 \%$ in the first week after transplanting and was gradually reduced to $60-70 \%$ during the following week. This phase lasted 10-14 days. Such treatments were of great importance for the survival of the plantlets, as it significantly reduces water losses and transpiration demand and avoids photodegradation of chlorophyll by excessive light (Debergh, 1991). Shading (50-90\%) during the first four weeks of acclimatization is necessary for micropropagated oil palm as for other species ( Preece and Sutter, 1991).

This study was carried out when plantlets were transplanted into polybags containing $200 \mathrm{~g}$ of the soil-sand mixture. All polybags were arranged randomly on greenhouse benches and maintained under natural light/dark conditions. The greenhouse was covered by glass and the side walls were made of wire. These conditions creates an nearly natural environment were plants were sheltered against direct sunlight and rainfall. The temparature ranged from max. $34^{\circ} \mathrm{C}$ during the day and min. $21^{\circ} \mathrm{C}$ during the night. Humidity varied between 40 and $70 \%$ during the experimental period. The plantlets were watered as required.

\subsection{Soil preparation}

The plantlets were cultivated in a mixture of native surface soil, from the oil palm plantation, and sand $(1: 1, \mathrm{v}: \mathrm{v})$, which was applied to improve the soil texture. The characteristics of the soil were discribed in Table 2.

Table 2: Chemical characteristics of the experimental soil, analysis of IOPRI (1997).

\begin{tabular}{c|c|c}
\hline Soil characteristics & Unit & Analysis \\
\hline \hline $\mathrm{pH} \mathrm{H} \mathrm{H}_{2} \mathrm{O}$ & & 5.9 \\
$\mathrm{pH} \mathrm{KCl}$ & $\%$ & 4.3 \\
$\mathrm{C}$ org. & $\%$ & 1.18 \\
$\mathrm{~N}$ & & 0.08 \\
$\mathrm{C} / \mathrm{N}$ & $\mathrm{mg} / 100 \mathrm{~g}$ & 14.47 \\
$\mathrm{P}_{2} \mathrm{O}_{5}(\mathrm{HCl} 25 \%)$ & $\mathrm{mg} / 100 \mathrm{~g}$ & 2.62 \\
$\mathrm{MgO}(\mathrm{HCl} \mathrm{25 \% )}$ & $\mathrm{mg} / 100 \mathrm{~g}$ & 46.13 \\
$\mathrm{~K}_{2} \mathrm{O}(\mathrm{HCl} \mathrm{25 \% )}$ & $\mathrm{mg} / 100 \mathrm{~g}$ & 43.47 \\
$\mathrm{CaO}(\mathrm{HCl} \mathrm{25 \% )}$ & $\mathrm{me} / 100 \mathrm{~g}$ & 14.07 \\
$\mathrm{CEC}$ & $\mathrm{me} / 100 \mathrm{~g}$ & 4.72 \\
$\mathrm{~K}$ exch & $\mathrm{me} / 100 \mathrm{~g}$ & 0.38 \\
$\mathrm{Mg}$ exch & $\mathrm{me} / 100 \mathrm{~g}$ & 0.26 \\
$\mathrm{Ca}$ exch & $\mathrm{me} / 100 \mathrm{~g}$ & 3.64 \\
$\mathrm{Na}_{\text {exch }}$ & $\mathrm{me} / 100 \mathrm{~g}$ & 8.39 \\
$\mathrm{Fe}_{\text {exch }}$ & $\mathrm{me} / 100 \mathrm{~g}$ & 0.003 \\
$\mathrm{Al}$ exch & $\mathrm{me} / 100 \mathrm{~g}$ & 0.4 \\
$\mathrm{Mn}_{\text {exch }}$ & $\mathrm{ppm}$ & 0.27 \\
$\mathrm{P}-\mathrm{Bray} \mathrm{II}$ & & 23.64 \\
\hline
\end{tabular}


Prior to potting the substrate was sieved $(2 \mathrm{~cm})$ to remove bigger soil particels and plant material. The substrate in Experiment 1 and 2 was non-sterilized. Experiment 3 included treatments with sterilized and non-sterilized soil. Soil sterilization was done by heating, at $95^{\circ} \mathrm{C}$ for three days, to kill native endophytes.

\subsection{Inoculum production and (V)AMF inoculation}

The used mycorrhizal fungal species (Table 3), representing a broad range of endomycorrhizal species, were obtained from the (V)AMF culture collection of the 'Institute of Plant Production in the Tropics', University of Göttingen, Germany. All mycorrhizal fungi were originated from various tropical locations, have been isolated and characterized and were propagated under greenhouse conditions in pure pot cultures of different host plants (Table 3).

Table 3: Characterization of the tested (V)AMF isolates by strain, host plant and origin.

\begin{tabular}{|c|c|c|c|}
\hline (V)AMF & Strain & Host plant & Origin \\
\hline Acaulospora appendicula & GOE 1-1 & Rib grass & Colombia \\
\hline Acaulospora mellea & GOE 5-1 & Rib grass & Colombia \\
\hline Acaulospora morowiae & GOE 6-1 & Sorghum & Colombia \\
\hline Acaulospora rehmii & GOE 8-1 & Sorghum & Brazil \\
\hline Enthrophospora columbiana & GOE $41-2$ & Sorghum & Colombia \\
\hline Gigaspora gigantea & GOE 51-1 & Sorghum & Brazil \\
\hline Glomus clarum & GOE 74-1 & Sorghum & Brazil \\
\hline Glomus manihot & GOE $78-1$ & Bahia grass & Colombia \\
\hline Glomus occultum & GOE $82-1$ & Sorghum & Colombia \\
\hline Glomus mosseae & GOE $85-1$ & Sorghum & Zaire \\
\hline Scutellispora heterogama & GOE $210-1$ & Sorghum & Brazil \\
\hline Scutellispora pellucida & GOE 211-1 & Sorghum & Colombia \\
\hline
\end{tabular}

The inoculum was prepared from the pure pot cultures described in Table 3. The pots were harvested and the infested soil, containing infected root fragments, extramatrical mycelium and fungal spores as infective propagules, was checked for purity by wet sieving and sucrose centrifugation according the method of Daniels and Skipper (1982) and Sieverding (1991). From each pot 1 spoon of soil and root material was taken and suspendet with 11 water. After 
heavier soil particles settled the suspension was decandet over a series of soil sieves. The mesh size of the sieves used were chosen according to spore size of the (V)AMF species. The first sieve with the biggest mesh size $(355 \mu \mathrm{m})$ separates the roots from soil and organic matter. The obtained roots were carefully transferred with water to a petri dish and kept separately for staining.

The fungal spores passed throught the medium sieve $(125 \mu \mathrm{m})$ and remain on the finest sieve $(45 \mu \mathrm{m})$ from where they were transferred with $\max .50 \mathrm{ml}$ water to a $100 \mathrm{ml}$ centrifuge tube. $30-40 \mathrm{ml}$ of a sucrose solution (1000 g sugar/700ml water) was injected into the bottom of the tube, so a gradient was established in the centrifuge tube. The samples were centrifuged for 2 minutes at 2000 revolutions per min. During this process the soil particles settled and the spores remain on the surface of the sugar gradient. The spores were separated in a $45 \mu \mathrm{m}$ sieve, rinsed with water to remove the sugar solution and were carefully transferred to a petri dish. The spores were observed under a stereomicroscope (x 40 magnification) and were separated into individual groups according to morphological features (size, colour and surface characteristics) counted and checked for purity.

The remained roots were stained with $0,05 \%$ trypan blue in lactic acid (modified from Phillips and Haymann, 1970), to detect mycorrhizal infection. The percentage of mycorrhizal colonisation was assessed using the grid-line intersect method (Giovanetti and Mosse, 1980).

After the pots were checked for purity isolates which were used for inoculum production were selected. The inoculum was produced by cutting roots into segments of $2 \mathrm{~cm}$ length and mixed with rhizosphere soil, containing spores and hyphae. The inoculum potentials of the different fungal species was balanced by using a quantity of $10 \mathrm{~g}$ inoculum (fresh weight), 5\% of the polybag substrate (200 g). Inoculation was done when plantlets were transferred from sandbed to soil. The inoculum was placed in the planting hole closed to the root system. The non-inoculated (NI) control plantlets received the same amount of autoclaved inoculum to provide similar physical and chemical conditions in all experiments.

\subsection{Design of the research}

\subsubsection{Experiment 1: Screening}

Micropropagated plants were transplanted to polybags containing $200 \mathrm{~g}$ of the soil-sand mixture (Table 2). Plantlets were inoculated with 12 different mycorrhizal fungal strains (Table 3). The non-inoculated (NI) control plantlets received the same amount of inoculum, but autoclaved. The plantlets received no fertilisation in this experiment. 
The five different oil palm clones (Table 1) were equally distributed over the treatments. Each treatment consisted of 12 replications and each replication consisted of one plant per polybag. The polybags were arranged randomly on the greenhouse bench. Three months after the plants were transferred to the polybags the harvest was carried out on the remaining plants.

Table 4: (V)AMF isolates used in Experiment 1 (Code: number used in the experiments).

\begin{tabular}{l|c|l|c}
\hline (V)AMF & Code & (V)AMF & Code \\
\hline \hline Glomus manihot & M1 & Gigaspora gigantea & M7 \\
Enthrophospora columbiana & M2 & Glomus clarum & M8 \\
Acaulospora mellea & M3 & Glomus occultum & M9 \\
Acaulospora appendicula & M4 & Glomus mosseae & M10 \\
Acaulospora morowiae & M5 & Scutellispora heterogama & M11 \\
Acaulospora rehmii & M6 & Scutellispora pellucida & M12 \\
\hline \hline
\end{tabular}

\subsubsection{Experiment 2}

The plantlets were inoculated at time of transferring to soil with four mycorrhizal fungi which were selected for their effectiviness on survival and plant development based on the results of the initial screening in experiment 1. These were Glomus manihot (M1), Enthrophospora columbiana (M2), Acaulospora mellea (M3) and Acaulospora appendicula (M4) (Table 3). The non-inoculated (NI) control plantlets received the same amount of inoculum, but autoclaved.

The fertilization was oriented on the traditional practice of plant nutrition which was implemented at the 'International Oil Palm Research Institute' (IOPRI) to provide nourishment of the young oil palms. IOPRI uses 'BAYFOLAN' (BAY) a commercially available liquid complete foliar fertilizer (Table 5).

Table 5: Nutrient content ( in \% by volume) of 'BAYFOLAN'.

\begin{tabular}{lc|ll}
\hline \multicolumn{4}{c}{ Nutrient content ( in \% by volume) } \\
\hline \hline & 11 & $\mathrm{Fe}$ & 0.020 \\
$\mathrm{~N}$ & 8 & $\mathrm{Mn}$ & 0.016 \\
$\mathrm{P}_{2} \mathrm{O}_{5}$ & $\mathrm{Zn}$ & 0.006 \\
$\mathrm{~K}_{2} \mathrm{O}$ & $\mathrm{Cu}$ & 0.008 \\
$\mathrm{Mg}$ & 6 & $\mathrm{~B}$ & 0.010 \\
$\mathrm{Ca}$ & - & $\mathrm{Mo}$ & 0.001 \\
$\mathrm{~S}$ & - & & \\
\hline \hline
\end{tabular}


'BAYFOLAN' was applied until the first harvest in the $3^{\text {rd }}, 4^{\text {th }}$ and $5^{\text {th }}$ week after transplanting, and until the second harvest in weekly intervals from the $7^{\text {th }}$ to the $11^{\text {th }}$ week. Plants were not fertilized in the $6^{\text {th }}$ and $12^{\text {th }}$ week to avoid traces of nutrients (especially $\mathrm{P}$ ), which could disturb the chemical anlysis of shoots of the first and second harvest.

As an alternative to 'BAYFOLAN', hydroxy-apatite (HA), a tri-calciumphosphate $\left(\mathrm{Ca}_{3}\right.$ $\left.\left(\mathrm{PO}_{4}\right)_{2}\right)$, as a slow P-release fertilizer ( $\left.90 \mathrm{~kg} \mathrm{P} / \mathrm{ha}\right)$, was added to the soil prior to transplanting. The control plants (FO) received no fertilization.

The five different oil palm clones (Table 1) were equally distributed over the treatments. Each treatment consisted of 30 replications and each replication consisted of one plant per polybag. The plants were arranged randomly on the greenhouse bench. After six weeks of post vitro growth the first harvest was carried out on 10 plants per treatment to investigate the plant growth effects and mycorrhizal development. The remaining plants were maintained for the following six weeks and were harvested at the end of the 12-weeks experimental period.

\subsubsection{Experiment 3}

Micropropagated plantlets were transferred to polybags containing $200 \mathrm{~g}$ sterilized (S) or nonsterilized soil (NS). Soil sterilization was done by heating, at $95^{\circ} \mathrm{C}$ for 3 days, to kill native endophytes. The plantlets were inoculated at transplanting with three mycorrhizal fungi which were selected for their effectiveness on survival and plant development based on the results of the initial screening in experiment 1. These were Glomus manihot (M1), Enthrophospora columbiana (M2) and Acaulospora mellea (M3) (Table 3). The non-inoculated (NI) control plantlets received the same amount of inoculum, but autoclaved.

Polybags were surrounded with a plastic screen, open to the top, or maintained individually in special plastic bags, 'Sunbags' (Sigma, USA), to avoid external contamination. Control plants grew without any protection measurement (Figure 3).

'Sunbag's were obtained from the 'Sigma Chemical Company Ltd.'. The bag consisted of a transparent autoclavable material, in which a micro-pore panel $(0.02 \mu \mathrm{m}$ pore size $)$ is incorporated to allow exchange of gases (including water vapour). The panel's small size restricted (though does not eliminate) water loss, resulting in high humidity within the bags.

The five different clones were equally distributed over the treatments (Table 1). Each treatment consited of 10 replications and each replication consisted of one plant per polybag. The polybags were arranged randomly on the greenhouse bench. Three months after the plants were transferred to the polybags the harvest was carried out on the remaining plants. 


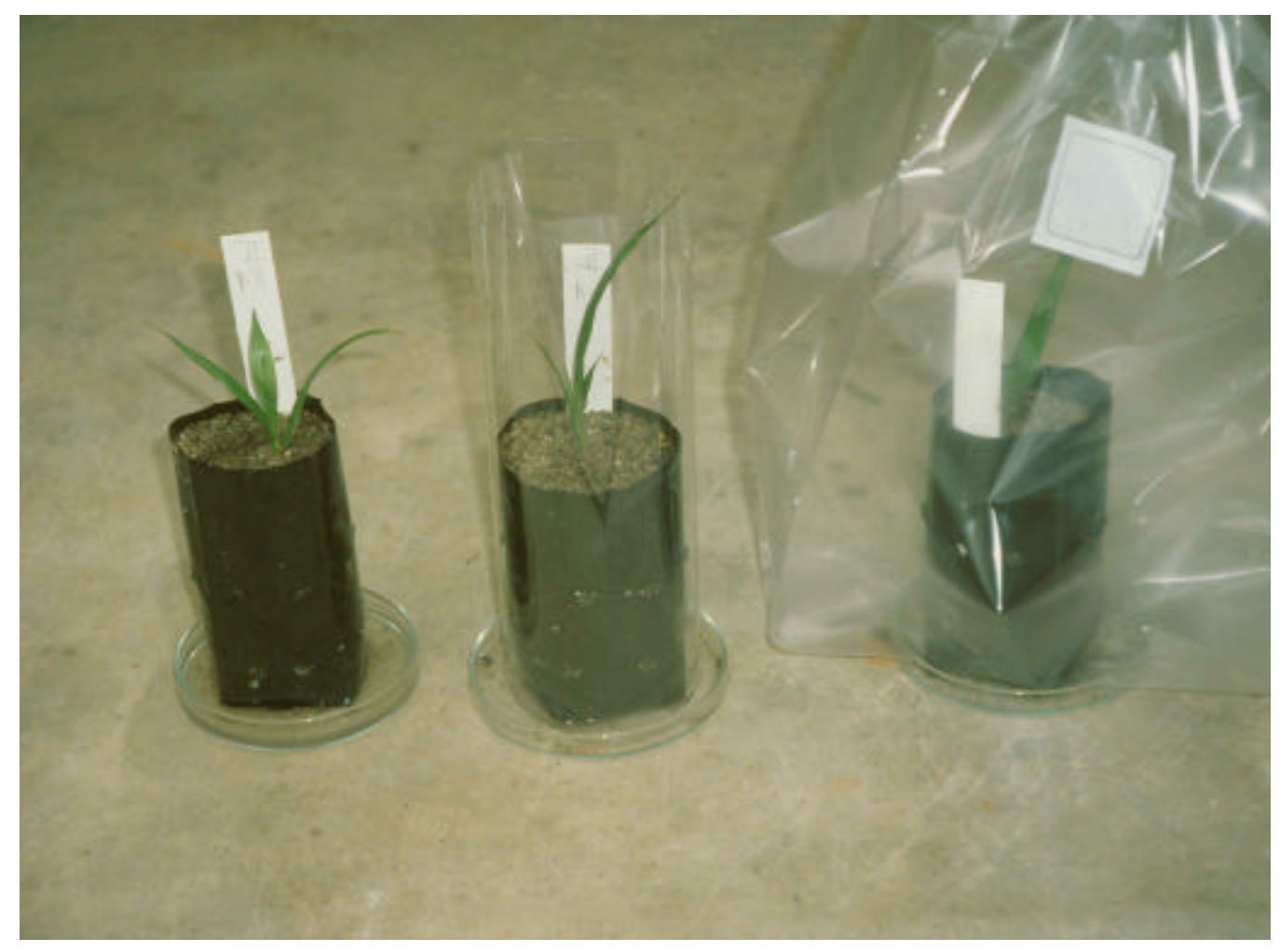

Figure 3: Protection measures in Experiment 3: control (left), plastic screen (middle), 'sunbag' (right).

\subsection{Growth parameters}

The plantlets consisted of a stem and leaves with no laterals. The performance of the plantlets (both inoculated and non-inoculated) was evaluated in regular intervals by measuring various parameters during a 3-months-period of ex vitro growth. This period was choosen because it is usually considered in commercial pre-nursery conditions as being the time necessary for in vitro propagated oil palm plantlets to attain the same developmental status as seedlings and therefore to be treated in the same way (Rival et al.,1998).

\subsubsection{Survival and growth measurements}

Survival of plants was controlled each day. The date of mortality was reported for each plant which died. The survival rate $(\%)$ was calculated on the end of the experimental period.

Plant growth during the experimental period was determined every second week, the shoot length $(\mathrm{cm})$ was taken from the leaf base to the top of the highest leaf and the number of expanded leaves was reported at the same time.

Relative growth as the ratio of the difference between final and initial shoot height $(\mathrm{cm})$ to initial height was calculated according to Hunt (1990). 
The relative growth rate $\left(\mathrm{RGR} \mathrm{cm} \mathrm{day}{ }^{-1}\right)$ of shoots was calculated between two-weeks intervals, and over the whole experimental period as average values by using the formula:

$\mathrm{RGR}=\left(\ln \mathrm{TSL}_{2}-\ln \mathrm{TSL}_{1}\right) /\left(\mathrm{t}_{2}-\mathrm{t}_{1}\right)$

(where $\ln =$ natural logarithm; $\mathrm{TSL}_{2}=$ total shoot lenght at final measurement; $\mathrm{TSL}_{1}=$ total shoot length at initial measurement; $\mathrm{t}_{2}-\mathrm{t}_{1}=$ days between measurements)

\subsubsection{Plant analysis}

\subsubsection{Shoot analysis}

At each harvest shoot fresh weights $(\mathrm{g})$, shoot height $(\mathrm{cm})$ and number of leaves were recorded. Shoots were separated from the roots and washed with distilled water and dried to constant weight at $65^{\circ} \mathrm{C}$ for $42 \mathrm{~h}$. Dry weights were taken and shoots were ground before taking out sub-samples for nutrient analysis, in a plant mill to pass a 20 -mesh screen. Three macro-elements were determined in foliar tissue at harvest .

Samples of the dried ground plant material (0.5-0.55 g) were wet digested with a mixture of Hydrochloric-perchloric-nitric-acid (Juo, 1982). Total phosphorus content of the digest was determined colorimetrically with the Vanado-Molybdate method on the Technicon Model II Autoanalyzer (Pulse Instrumentation Lts, Sakatoon, Canada). The reference material was a dry powdered corn bran (RM8433, NIST).

Concentrations of potassium in foliar tissue was measured by a atom absorption spectrometer (PU 9200 x, Phillips).

The total $\mathrm{N}$ and $\mathrm{C}$ content was determined directly on a ground subsample with a Carlo Erba NA 1500 gas chromatograph.

\subsubsection{Root analysis}

At each harvest root fresh weights $(\mathrm{g})$ were recorded. The roots were separeted from the shoots, rinsed, blotted dry and their fresh weights were recorded. Until staining for histochemical studies the fresh roots were stored in a solution of ethanol (99\%) and acetic acid $(60 \%)(3: 1)$.

The preserved roots were rinsed in tap water and cleared in $10 \% \mathrm{KOH}$ at about $90^{\circ} \mathrm{C}$ for $1 \mathrm{~h}$. Dark roots were bleached in hydrogen peroxide for $20 \mathrm{Min}$. All roots were acidified with $\mathrm{HCl}$ and stained with 0,05\% trypan blue in lactic acid (modified from Phillips and Haymann, 1970). Individual roots were examined at $x 40-100$ magnification for the presence of arbuscules, coils, vesicles, internal hyphae and external hyphae of (V)AM fungi. Mycorrhizal colonization was estimated using the grid-line intersect method (Giovanetti and Mosse, 1980). 
Samples in which root colonization was difficult to quantify due to low amount of root material were mounted on a slide for more detailed observation using a compound microscope (Dodd and Jeffries 1986).

\subsection{Statistics}

The experiments were set up according to randomized complete block designs. However, missing data occurred due to loss of plantlets in most experiments. Therefore, results were analysed with the General Linear Model routine of SYSTAT software as Completely Randomized Designs and clones were used as covariate to control random variation.

In the case of variables which were expressed as percentages, data were transformed by the arcsin square-root procedure prior to ANOVA to ensure homogeneity of variances (Sachs, 1992).

For all characteristics studied the statistical significance of differences between means were determined using the least significant difference (LSD), (Steel and Torrie) or Tukey-test at $P=0.05$.

\section{Results and Discussion}

\section{$5.1 \quad$ Experiment 1}

\section{Screening of 12 different mycorrhizal fungal species for their effectiveness on post vitro development of micropropagated oil palms}

The first step in any inoculation program is to obtain isolates which are both infective, able to penetrate and spread in the roots, and effective, able to enhance growth and stress tolerance of the host. Individual isolates of mycorrhizal fungi vary widely in these properties, so screening trials are important to select isolates that will perform successfully. For future application of endomycorrhizal inoculation in the existing micropropagation process of oil palms, screening under actual cropping conditions is best because indigenous mycorrhizal fungi, pathogens, and soil chemical and physical properties will influence the results. The first experiment of this study was conducted as an initial screening. Twelve different mycorrhizal isolates (Table 3), representing a broad range of endomycorrhizal fungi, were tested for their effectiveness on survival and development of micropropagated oil palms during twelve weeks of post vitro growth. 


\subsubsection{Survival rate}

Mycorrhizal inoculation at the transplanting stage affected the percentage of survival during the three-month period significantly (Table 6). The effect of the clones and the interactions of the two main factors (inoculation, clones) studied were not significant regarding plant survival rate during this plant stage.

Table 6: ANOVA of main factors and their interaction on the survival rate (\%) of micropropagated oil palms after a three-month period of post vitro growth.

\begin{tabular}{l|c|c|c}
\hline \hline ANOVA & DF & MQ & P \\
\hline Inoculation & 12 & 3974.28 & $\mathbf{0 . 0 0 2}$ \\
Clone & 4 & 1247.32 & 0.488 \\
Inoculation x Clone & 48 & 761.64 & 0.994 \\
Error & 131 & 1444.93 & \\
\hline \hline
\end{tabular}

After three months of post vitro growth, the percentage of plant survival differed between the treatments. From the twelve mycorrhizal isolates which were tested in this initial screening, eleven fungi improved the survival rate significantly to $83-100 \%$ (Figure 4), helping the plantlets to resist the environmental stress induced when transplanting them from axenic conditions to normal cultivation in open pots. In contrast, only $55 \%$ of the non-inoculated control plants survived this critical growth stage during the three-month experimental period.

Significant differences in plant survival between the tested (V)AMF isolates were only found with plantlets inoculated with Acaulospora rehmii (M6), which showed the lowest survival rate $(67 \%)$. The most effective fungal isolates were Acaulospora mellea (M3) and Glomus mosseae (M4) resulting in survival rates of $100 \%$.

Recent investigations on value crops such as grape, apple, plum, pineapple, avocado, strawberry, raspberry and cherry have shown that early mycorrhizal inoculation and colonization of the tissue-cultured plantlets reduced transplant shock during acclimatization, thus increasing plant survival and establishment rates (Azcón-Aguilar et al., 1994; Lovato et al., 1994; Rapparini et al., 1994).

Several authors recommend screening various strains of mycorrhizal fungi to identify beneficial ones. Wang et al. (1993) reported variation in the survival of transplanted micropropagated Gerbera, Nephrolepis and Syngonium plantlets depending on the isolate of tested mycorrhizal fungi. Azcon-Aguilar et al. (1992) also stressed the need to identify the endomycorrhizal fungus best used for maximum benefits of the symbiosis. 


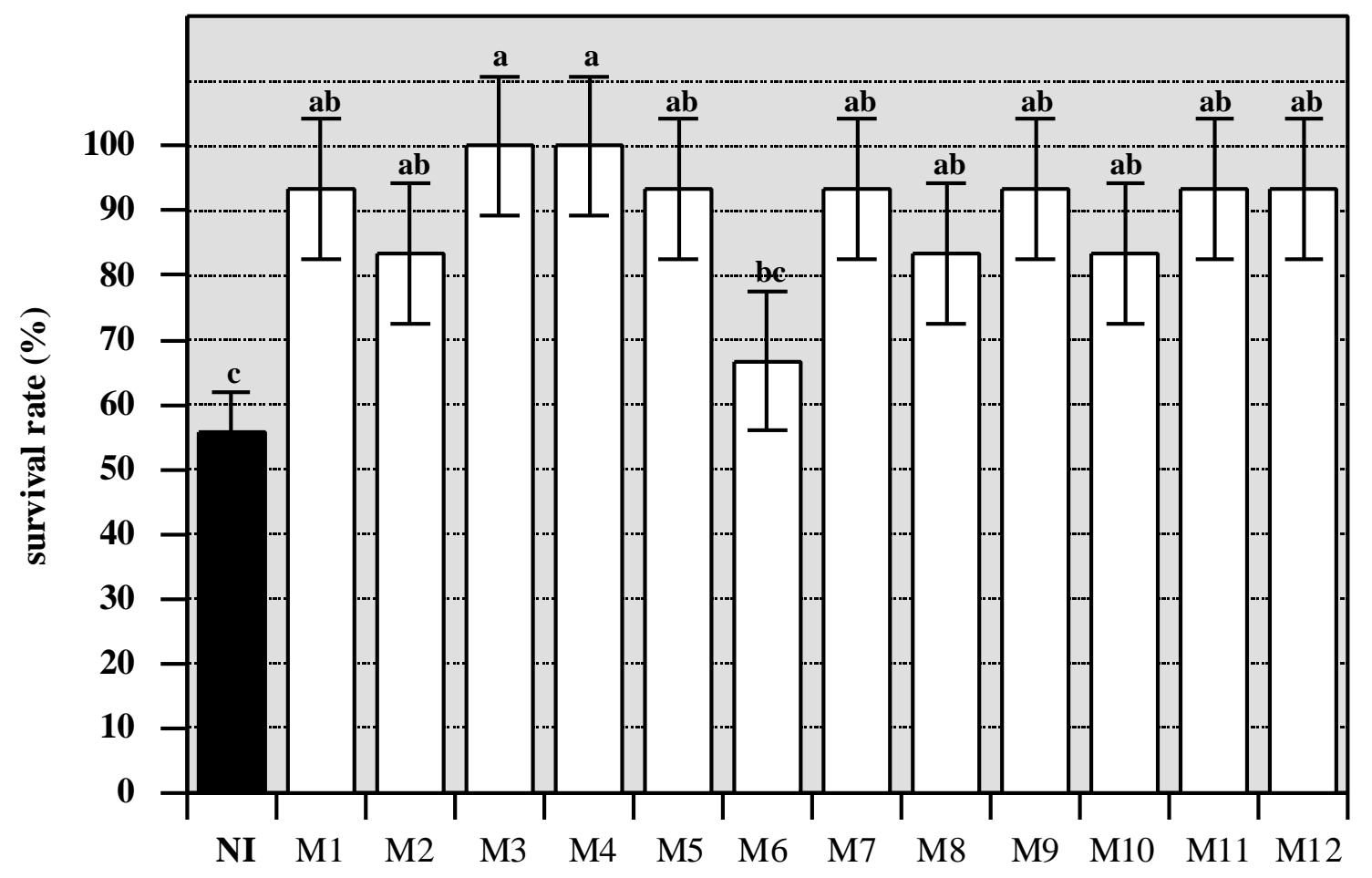

Figure 4: Survival rate (\%) of micropropagated oil palm plantlets after 3 months of post vitro growth, non-inoculated (NI) or inoculated with 12 mycorrhizal fungi (M1-M12).Vertical bars represent standard errors of the mean. Columns with different letters are significantly different at $P=0.05$ as indicated by LSD-test.

\subsubsection{Date of mortality}

The date of plant mortality is a very important factor for post vitro establishment of micropropagated plants. If plants died during the twelve-week experimental period, the date of mortality was recorded. Mortality of plantlets was mainly observed in the first six weeks after transplanting and grouped together according to inoculated mycorrhizal fungi and date of plant mortality (Figure 5). All plantlets of group A, which were inoculated with Acaulospora mellea (M3) and Acaulospora appendicula (M4), survived the twelve-week period. In groups $\mathrm{B}$ and $\mathrm{D}$, less than $10 \%$ of the plantlets died during the $2^{\text {nd }}(\mathrm{D})$ or $5^{\text {th }}(\mathrm{B})$ week. In group $\mathrm{C}, 14 \%$ of the inoculated plantlets died between the $2^{\text {nd }}$ and $3^{\text {rd }}$ week. The exception was group E, where 33\% of the plantlets, which were inoculated with Acaulospora rehmii (M6), died in the $4^{\text {th }}$ week. The non-inoculated (NI) control plantlets showed the highest mortality; $45 \%$ of the plantlets died between the $1^{\text {st }}$ and the $5^{\text {th }}$ week. Six weeks after mycorrhizal inoculation, the remaining plantlets appeared adapted to ex vitro conditions. 


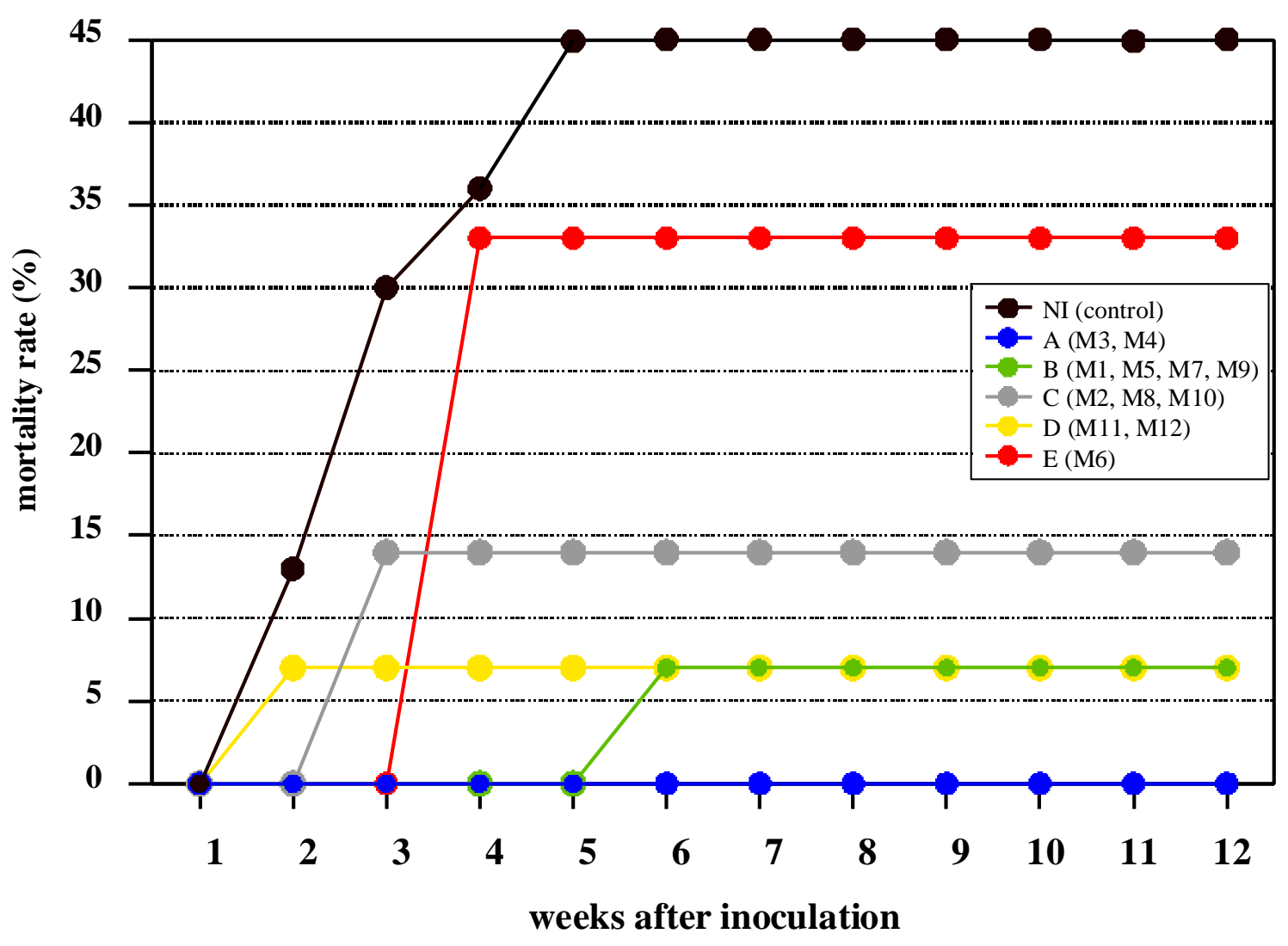

Figure 5: Mortality rate (\%) of oil palm clones during 12 weeks of post vitro stage, noninoculated (NI) or inoculated with 12 different mycorrhizal fungi (M1-M12).

\subsubsection{Post vitro plant development}

The effect of mycorrhizal inoculation on the plant development of oil palm plantlets during post vitro growth was characterized by different growth measurements. During twelve weeks of post vitro growth, the shoot length was measured and the number of leaves counted in twoweek intervals from the day of transplanting to harvesting.

\subsubsection{Shoot length}

Mycorrhizal inoculation had significantly affected shoot length 6 weeks after mycorrhizal inoculation and the effect persisted up to the $12^{\text {th }}$ week when the plants were harvested (Table 7). The used clones showed no significant differences in shoot length and there was no significant interaction between the two factors. 
Table 7: ANOVA* of main factors and their interaction on the shoot length increase $(\mathrm{cm})$ of micropropagated oil palms measured in two-week intervals and calculated for the three-month period of post vitro growth. The table represents effects when $\mathrm{P}$ values became significant.

\begin{tabular}{|c|c|c|c|c|c|c|c|c|c|c|c|}
\hline \multirow{3}{*}{$\begin{array}{l}\text { ANOVA } \\
\end{array}$} & \multirow[b]{3}{*}{ DF } & \multicolumn{8}{|c|}{ Weeks after transplanting } & \multirow{2}{*}{\multicolumn{2}{|c|}{ Total }} \\
\hline & & \multicolumn{2}{|c|}{6} & \multicolumn{2}{|c|}{8} & \multicolumn{2}{|c|}{10} & \multicolumn{2}{|c|}{12} & & \\
\hline & & MQ & $\mathbf{P}$ & MQ & $\mathbf{P}$ & MQ & $\mathbf{P}$ & MQ & $\mathbf{P}$ & MQ & $\mathbf{P}$ \\
\hline Inoculation (1) & 12 & 13.59 & 0.038 & 17.90 & 0.009 & 24.90 & 0.001 & 26.60 & 0.000 & 23.51 & 0.000 \\
\hline Clone (2) & 4 & 19.90 & 0.288 & 17.60 & 0.060 & 12.20 & 0.205 & 11.90 & 0.209 & 1.47 & 0.829 \\
\hline $1 \times 2$ & 48 & 8.99 & 0.148 & 9.40 & 0.172 & 8.70 & 0.374 & 8.60 & 0.369 & 4.13 & 0.423 \\
\hline Error & 103 & 7.00 & & 7.50 & & 8.10 & & 7.90 & & 3.97 & \\
\hline
\end{tabular}

*Complete ANOVA, see Annex (Table A1)

After transplanting to ex vitro conditions in the greenhouse, oil palm plantlets showed a slow initial growth during the first four weeks with only marginal shoot growth. In most of the inoculated plantlets a significantly increased shoot length was observed after six weeks of post vitro growth (Table 8). At the end of the experimental period, inoculated plantlets were significantly taller than the non-inoculated controls, except plantlets which were inoculated with Gigaspora gigantea (M7). After this growth period, most of the inoculated plantlets were 2-2.5 times taller than the non-inoculated control plantlets.

Table 8: Mycorrhizal inoculation (M1-M12) as a main effect on shoot length (cm) of micropropagated oil palms during the period from the $6^{\text {th }}$ to $12^{\text {th }}$ week of post vitro growth and calculated as total increment for the whole experimental period. NI: non-inoculated plants. Means in each column followed by different letters are significantly different $P=0.05$ as indicated by LSD-test.

\begin{tabular}{l|cccc|c}
\hline \hline \multirow{2}{*}{ Inoculation } & $\mathbf{6}$ & Weeks after transplanting & 12 & Total \\
\hline NI & $11.0 \mathrm{~b}$ & $11.6 \mathrm{~b}$ & $12.0 \mathrm{c}$ & $12.9 \mathrm{c}$ & $\mathbf{2 . 9} \mathbf{c}$ \\
M1 & $11.8 \mathrm{ab}$ & $13.2 \mathrm{ab}$ & $14.2 \mathrm{ab}$ & $15.2 \mathrm{ab}$ & $\mathbf{5 . 9} \mathbf{~ b}$ \\
M2 & $12.3 \mathrm{ab}$ & $13.7 \mathrm{a}$ & $15.2 \mathrm{a}$ & $16.2 \mathrm{a}$ & $\mathbf{6 . 9} \mathbf{~ a}$ \\
M3 & $12.8 \mathrm{a}$ & $14.1 \mathrm{a}$ & $15.5 \mathrm{a}$ & $16.4 \mathrm{a}$ & $\mathbf{6 . 3} \mathbf{~ a}$ \\
M4 & $12.9 \mathrm{a}$ & $14.6 \mathrm{a}$ & $16.1 \mathrm{a}$ & $17.1 \mathrm{a}$ & $\mathbf{5 . 6} \mathbf{~ b}$ \\
M5 & $13.3 \mathrm{a}$ & $14.1 \mathrm{a}$ & $14.9 \mathrm{a}$ & $15.9 \mathrm{a}$ & $\mathbf{5 . 4} \mathbf{b}$ \\
M6 & $13.9 \mathrm{a}$ & $15.0 \mathrm{a}$ & $15.6 \mathrm{a}$ & $16.6 \mathrm{a}$ & $\mathbf{5 . 6} \mathbf{b}$ \\
M7 & $10.7 \mathrm{ab}$ & $11.6 \mathrm{~b}$ & $12.5 \mathrm{bc}$ & $13.5 \mathrm{bc}$ & $\mathbf{4 . 8} \mathbf{c}$ \\
M8 & $13.2 \mathrm{a}$ & $14.0 \mathrm{a}$ & $15.0 \mathrm{a}$ & $15.9 \mathrm{a}$ & $\mathbf{5 . 9} \mathbf{~ b}$ \\
M9 & $13.7 \mathrm{a}$ & $14.5 \mathrm{a}$ & $15.1 \mathrm{a}$ & $16.1 \mathrm{a}$ & $\mathbf{5 . 8} \mathbf{~ b}$ \\
M10 & $13.8 \mathrm{a}$ & $14.7 \mathrm{a}$ & $15.4 \mathrm{a}$ & $16.3 \mathrm{a}$ & $\mathbf{6 . 9} \mathbf{~ a b}$ \\
M11 & $12.6 \mathrm{ab}$ & $14.1 \mathrm{a}$ & $15.9 \mathrm{a}$ & $16.8 \mathrm{a}$ & $\mathbf{7 . 4} \mathbf{~ a}$ \\
M12 & $12.8 \mathrm{ab}$ & $13.9 \mathrm{a}$ & $14.8 \mathrm{ab}$ & $15.7 \mathrm{ab}$ & $\mathbf{5 . 7} \mathbf{~ b}$ \\
\hline \hline
\end{tabular}


These results are consistent with data obtained from other micropropagated species. Granger et al. (1983), Vidal et al. (1992), Lovato et al. (1996) and Rapparini et al. (1996) reported increases in plant height of 1.5 to 3.0 times in the case of mycorrhiza with micropropagated apple, avocado, grapevine, common ash, and pear plants, respectively.

Especially mycorrhizal fungal species of the genera Acaulospora and Glomus led to increased growth in this experiment. The growth curves below (Figure 6) show the shoot development of these plants in comparison to the non-inoculated control plants for the whole experimental period.
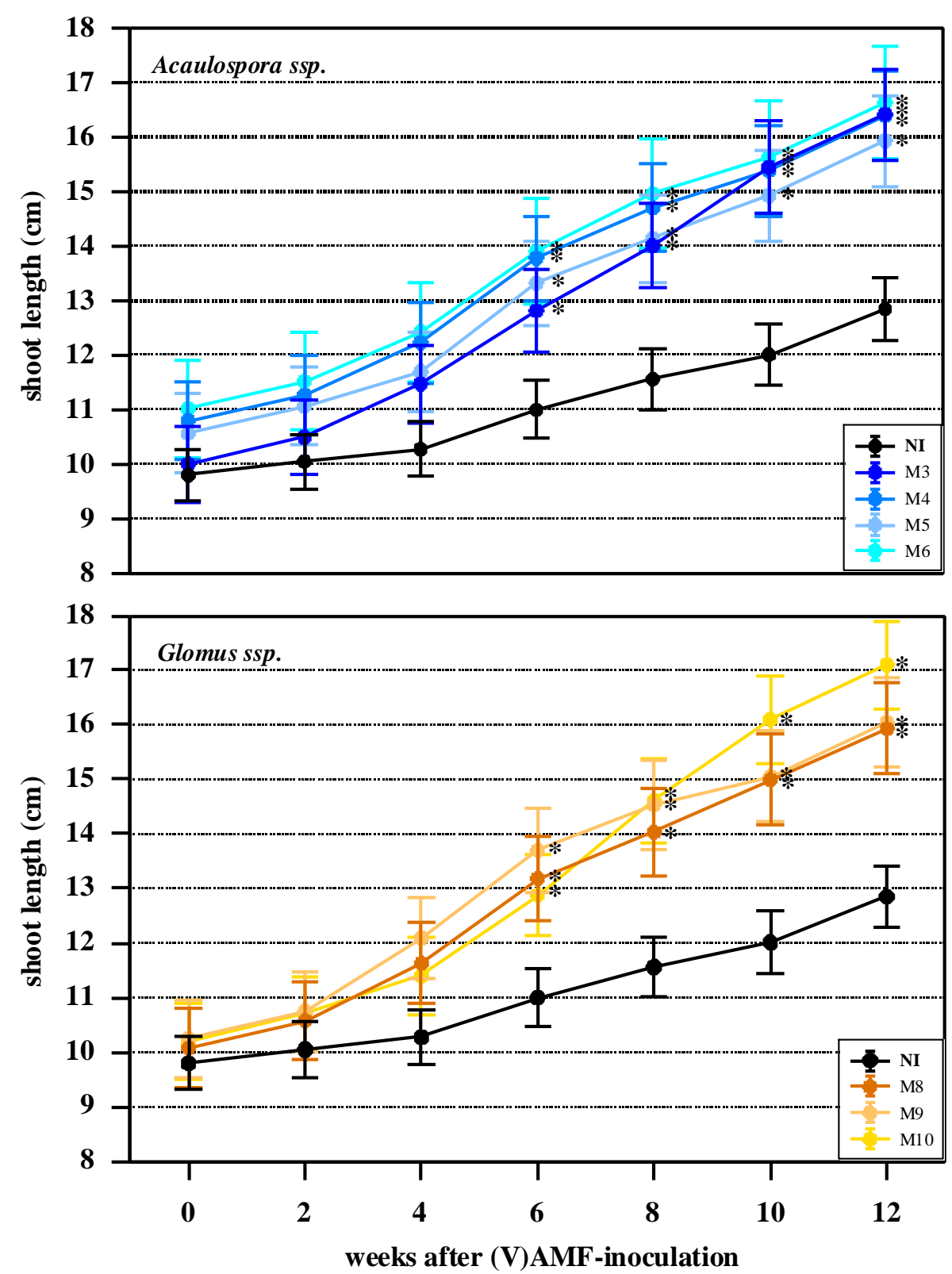

Figure 6: Effect of mycorrhizal inoculation on shoot length of micropropagated oil palm plantlets during 12 weeks of post vitro growth. The curves represent the most effective (V)AMF strains (M3-M10). Vertical bars represent standard errors of the mean. Growth curves of inoculated plants with one asterisk are significantly different from the noninoculated control plants (NI) at $P=0.05$ as indicated by LSD-test. 
At the beginning of the experiment, all plants were uniform in size with a shoot length of 10 $\pm 1.2 \mathrm{~cm}$ (Figure 6). Significantly different shoot lengths were first measured six weeks after transplanting in plantlets inoculated with Acaulospora mellea (M3), Acaulospora. appendicula (M4), Acaulospora morowiae (M5), Acaulospora rehmii (M6), Glomus clarum (M8), Glomus occultum (M9) and Glomus mosseae (M10).

\subsubsection{Relative growth rate}

The relative growth rate $\left(\mathrm{RGR} \mathrm{cm} \mathrm{day}{ }^{-1}\right)$ of total shoot length $(\mathrm{cm})$ was monitored every second week. Plantlets were not homogenous in their morphological structure at the time of transplanting. Mycorrhizal inoculation significantly affected both, the RGR of shoots at 8, 10 and 12 weeks after inoculation, and the average RGR calculated over the total experimental period (Table 9). The clones and the interactions of the two main factors studied had no significant effect on the RGR during this growth period.

Table 9: ANOVA* of main factors and their interaction on the relative growth rate $(\mathrm{RGR} \mathrm{cm}$ day $^{-1}$ ) of micropropagated oil palms measured in two-week intervals during a three-month period of post vitro growth and calculated as average values. The table represents effects when $\mathrm{P}$ values became significant.

\begin{tabular}{lc|cc|cc|cc|cc}
\hline \hline & & \multicolumn{6}{|c|}{ Weeks after transplanting } & \multicolumn{2}{c}{} \\
& & \multicolumn{2}{|c|}{$\mathbf{8}$} & \multicolumn{2}{c}{$\mathbf{1 0}$} & \multicolumn{2}{c}{ Average } \\
\hline ANOVA & DF & MQ & $\mathbf{P}$ & MQ & $\mathbf{P}$ & MQ & P & MQ & P \\
\hline Inoculation (1) & 12 & 0.000 & $\mathbf{0 . 0 3 5}$ & 0.000 & $\mathbf{0 . 0 3 3}$ & 0.000 & $\mathbf{0 . 0 0 0}$ & 0.000 & $\mathbf{0 . 0 0 4}$ \\
Clone (2) & 4 & 0.000 & 0.922 & 0.000 & 0.586 & 0.000 & 0.179 & 0.000 & 0.087 \\
1 x 2 & 48 & 0.000 & 0.368 & 0.000 & 0.759 & 0.000 & 0.365 & 0.000 & 0.558 \\
& & & & & & & & & \\
Error & 103 & 0.000 & & 0.000 & & 0.000 & & 0.000 & \\
\hline \hline
\end{tabular}

*Complete ANOVA, see Annex (Table A2)

After transplanting ex vitro, oil palm plantlets generally showed a slow initial growth during the first two weeks (Table 10). In most of the inoculated plants the RGR was higher after 4 weeks. Significant differences compared to the control plants of the RGR were observed 8 weeks after transplanting in plantlets which were inoculated with Glomus manihot (M1), Enthrophospora columbiana (M2), Acaulospora appendicula (M4), and Scutellispora heterogama (M11). The growth-promoting effect continued in most of the inoculated plantlets till the end of the experimental period. From the $10^{\text {th }}$ to $12^{\text {th }}$ week, all inoculated plantlets showed a significantly higher shoot growth compared to the non-inoculated (NI) control plants. The average relative growth calculated over the whole experimental period confirmed the growth improvement through mycorrhizal inoculation. The most effective mycorrhizal 
fungi were Enthrophospora columbiana (M2) and Scutellispora heterogama (M11). Plants inoculated, however, with Glomus manihot (M1), Acaulospora mellea (M3), Acaulospora appendicula (M4), Glomus clarum (M8), and Scutellispora pellucida (M12) showed a significantly higher relative growth rate compared to the control plants (NI).

Table 10: Main effect of mycorrhizal inoculation on relative growth rate (RGR $\mathrm{cm}^{-1}$ day ${ }^{-1}$ of micropropagated oil palm shoots during 12 weeks of plant establishment. NI: non-inoculated control plants. Means in each column followed by different letters are significantly different $P=0.05$ as indicated by LSD-test; ns: not significant.

\begin{tabular}{|c|c|c|c|c|c|c|c|}
\hline \multirow[b]{2}{*}{ Inoculation } & \multicolumn{6}{|c|}{ Weeks after transplanting } & \multirow[b]{2}{*}{ Average } \\
\hline & 2 & 4 & 6 & 8 & 10 & 12 & \\
\hline NI & $0.004 \mathrm{~ns}$ & $0.004 \mathrm{~ns}$ & $0.006 \mathrm{~ns}$ & $0.003 \mathrm{c}$ & $0.002 \mathrm{c}$ & $0.003 \mathrm{c}$ & $0.004 \mathrm{c}$ \\
\hline M1 & $0.004 \mathrm{~ns}$ & $0.007 \mathrm{~ns}$ & $0.009 \mathrm{~ns}$ & $0.008 \mathrm{ab}$ & $0.005 \mathrm{ab}$ & $0.005 \mathrm{~b}$ & $0.006 \mathrm{ab}$ \\
\hline M2 & $0.004 \mathrm{~ns}$ & $0.005 \mathrm{~ns}$ & $0.010 \mathrm{~ns}$ & $0.008 \mathrm{ab}$ & $0.007 \mathrm{a}$ & $0.005 \mathrm{~b}$ & $0.007 \mathrm{a}$ \\
\hline M3 & $0.004 \mathrm{~ns}$ & $0.005 \mathrm{~ns}$ & $0.010 \mathrm{~ns}$ & $0.006 \mathrm{abc}$ & $0.007 \mathrm{a}$ & $0.005 \mathrm{~b}$ & $0.006 \mathrm{ab}$ \\
\hline M4 & $0.003 \mathrm{~ns}$ & $0.006 \mathrm{~ns}$ & $0.008 \mathrm{~ns}$ & $0.009 \mathrm{a}$ & $0.004 \mathrm{ab}$ & $0.005 \mathrm{~b}$ & $0.006 \mathrm{ab}$ \\
\hline M5 & $0.003 \mathrm{~ns}$ & $0.004 \mathrm{~ns}$ & $0.009 \mathrm{~ns}$ & $0.004 \mathrm{bc}$ & $0.004 \mathrm{bc}$ & $0.005 \mathrm{~b}$ & $0.005 \mathrm{bc}$ \\
\hline M6 & $0.003 \mathrm{~ns}$ & $0.006 \mathrm{~ns}$ & $0.008 \mathrm{~ns}$ & $0.006 \mathrm{abc}$ & $0.003 \mathrm{bc}$ & $0.005 \mathrm{~b}$ & $0.005 \mathrm{bc}$ \\
\hline M7 & $0.004 \mathrm{~ns}$ & $0.004 \mathrm{~ns}$ & $0.007 \mathrm{~ns}$ & $0.005 \mathrm{bc}$ & $0.006 \mathrm{a}$ & $0.006 \mathrm{a}$ & $0.005 \mathrm{bc}$ \\
\hline M8 & $0.004 \mathrm{~ns}$ & $0.007 \mathrm{~ns}$ & $0.009 \mathrm{~ns}$ & $0.004 \mathrm{bc}$ & $0.004 \mathrm{ab}$ & $0.005 \mathrm{~b}$ & $0.006 \mathrm{ab}$ \\
\hline M9 & $0.004 \mathrm{~ns}$ & $0.008 \mathrm{~ns}$ & $0.008 \mathrm{~ns}$ & $0.005 \mathrm{bc}$ & $0.003 \mathrm{bc}$ & $0.005 \mathrm{~b}$ & $0.005 \mathrm{bc}$ \\
\hline M10 & $0.004 \mathrm{~ns}$ & $0.005 \mathrm{~ns}$ & $0.009 \mathrm{~ns}$ & $0.005 \mathrm{bc}$ & $0.007 \mathrm{a}$ & $0.004 \mathrm{~b}$ & $0.005 \mathrm{bc}$ \\
\hline M11 & $0.004 \mathrm{~ns}$ & $0.008 \mathrm{~ns}$ & $0.010 \mathrm{~ns}$ & $0.008 \mathrm{ab}$ & $0.009 \mathrm{a}$ & $0.004 \mathrm{~b}$ & $0.007 \mathrm{a}$ \\
\hline M12 & $0.004 \mathrm{~ns}$ & $0.004 \mathrm{~ns}$ & $0.009 \mathrm{~ns}$ & $0.006 a b c$ & $0.005 \mathrm{ab}$ & $0.005 \mathrm{~b}$ & $0.006 \mathrm{ab}$ \\
\hline
\end{tabular}

\subsubsection{Number of leaves}

The development of leaves was affected by mycorrhizal inoculation (Table 11). This positive effect on leaf number became significant from the fourth week after inoculation. At the end of the experimental period, calculation of the total number of leaves which had developed during the three months confirmed the significant effect of mycorrhiza on plant growth during this plant stage. The clones differed significantly in their number of leaves from the onset of the experiment (Annex Table A6). The interaction of the two main factors studied showed no significance. 
Table 11: ANOVA* of main factors and their interaction on the leaf number of micropropagated oil palms in two-week intervals and calculated for the three-month period of post vitro growth. The table represents effects when $\mathrm{P}$ values became significant.

\begin{tabular}{|c|c|c|c|c|c|c|c|c|c|}
\hline \multirow[b]{2}{*}{ ANOVA } & \multirow[b]{2}{*}{ DF } & \multicolumn{7}{|c|}{ Weeks after transplanting } & \multirow[b]{2}{*}{ Total } \\
\hline & & $\mathbf{0}$ & 2 & 4 & 6 & 8 & 10 & 12 & \\
\hline Inoculation (1) & 12 & 0.683 & 0.623 & 0.000 & 0.002 & 0.001 & 0.006 & 0.001 & 0.000 \\
\hline Clone (2) & 4 & 0.017 & 0.004 & 0.002 & 0.008 & 0.005 & 0.002 & 0.001 & 0.013 \\
\hline $1 \times 2$ & 48 & 0.305 & 0.133 & 0.243 & 0.130 & 0.273 & 0.309 & 0.541 & 0.602 \\
\hline
\end{tabular}

* Complete ANOVA, see Annex (Table A3)

At the time of transplanting, all plantlets had generally the same number of leaves (Table 12). Emergence of the first new leaves, developed ex vitro, could be observed 2 weeks after transplanting in some of the inoculated plants, but these effects were statistically not significant. Most of the inoculated plantlets developed the first new leaves 4 weeks after transplanting in contrast to the non-inoculated plants (NI) where the first new leaves were formed after 6 weeks. This significant effect on leaf development due to mycorrhizal inoculation persists up to the end of the experimental period and is reflected in the total increase in number of leaves developed during the measured 12 weeks of post vitro growth (Table 12).

Table 12: Effect of mycorrhizal inoculation (M1-M12) on leaf development of micropropagated oil palm plantlets during 12 weeks of post vitro growth. The total number of leaves developed during the experimental period was calculated and tested for significant difference. NI: non-inoculated control plants. Values with different letters are significantly different at $P=0.05$ as indicated by LSD-test; ns: not significant.

\begin{tabular}{|c|c|c|c|c|c|c|c|c|}
\hline \multirow[b]{2}{*}{ Inoculation } & \multicolumn{7}{|c|}{ "Weeks after transplanting } & \multirow[b]{2}{*}{ Total } \\
\hline & $\mathbf{0}$ & 2 & 4 & 6 & 8 & 10 & 12 & \\
\hline NI & $3.3 \mathrm{~ns}$ & $3.3 \mathrm{~ns}$ & $3.5 \mathrm{~d}$ & $4.0 \mathrm{c}$ & $4.3 \mathrm{c}$ & $4.9 \mathrm{~b}$ & $5.3 \mathrm{~b}$ & $2.0 \mathrm{~b}$ \\
\hline M1 & $3.0 \mathrm{~ns}$ & $3.2 \mathrm{~ns}$ & $3.8 \mathrm{~cd}$ & $4.3 \mathrm{bc}$ & $4.4 \mathrm{c}$ & $4.8 \mathrm{~b}$ & $5.3 \mathrm{~b}$ & $2.2 \mathrm{~b}$ \\
\hline M2 & $3.3 \mathrm{~ns}$ & $3.3 \mathrm{~ns}$ & $3.9 \mathrm{bcd}$ & $4.2 \mathrm{bc}$ & $4.6 \mathrm{bc}$ & $5.2 \mathrm{~b}$ & $5.9 \mathrm{ab}$ & $2.7 \mathrm{a}$ \\
\hline M3 & $3.3 \mathrm{~ns}$ & $3.3 \mathrm{~ns}$ & $4.2 \mathrm{bc}$ & $4.4 \mathrm{bc}$ & $4.7 \mathrm{bc}$ & $5.2 \mathrm{~b}$ & $5.7 \mathrm{~b}$ & $2.4 \mathrm{~b}$ \\
\hline M4 & $3.4 \mathrm{~ns}$ & $3.4 \mathrm{~ns}$ & $4.8 \mathrm{a}$ & $5.1 \mathrm{a}$ & $5.4 \mathrm{a}$ & $6.0 \mathrm{a}$ & $6.6 \mathrm{a}$ & $3.2 \mathrm{a}$ \\
\hline M5 & $3.3 \mathrm{~ns}$ & $3.4 \mathrm{~ns}$ & $4.0 \mathrm{~cd}$ & $4.5 \mathrm{bc}$ & $4.5 \mathrm{bc}$ & $5.0 \mathrm{~b}$ & $5.5 \mathrm{~b}$ & $2.2 \mathrm{~b}$ \\
\hline M6 & $3.4 \mathrm{~ns}$ & $3.4 \mathrm{~ns}$ & $4.6 \mathrm{a}$ & $5.0 \mathrm{a}$ & $5.0 \mathrm{~b}$ & $5.7 \mathrm{ab}$ & $6.6 \mathrm{a}$ & $3.2 \mathrm{a}$ \\
\hline M7 & $3.4 \mathrm{~ns}$ & $3.4 \mathrm{~ns}$ & $4.0 \mathrm{bcd}$ & $4.4 \mathrm{bc}$ & $4.7 \mathrm{bc}$ & $5.1 \mathrm{~b}$ & $5.6 \mathrm{~b}$ & $2.2 \mathrm{~b}$ \\
\hline M8 & $3.4 \mathrm{~ns}$ & $3.4 \mathrm{~ns}$ & $4.3 \mathrm{ab}$ & $4.9 \mathrm{ab}$ & $5.2 \mathrm{a}$ & $5.9 \mathrm{a}$ & $6.3 \mathrm{a}$ & $3.2 \mathrm{a}$ \\
\hline M9 & $3.2 \mathrm{~ns}$ & $3.4 \mathrm{~ns}$ & $4.0 \mathrm{bcd}$ & $4.7 \mathrm{ab}$ & $4.9 \mathrm{bc}$ & $5.6 \mathrm{ab}$ & $6.1 \mathrm{ab}$ & $2.9 \mathrm{a}$ \\
\hline M10 & $3.5 \mathrm{~ns}$ & $3.5 \mathrm{~ns}$ & $4.7 \mathrm{a}$ & $5.2 \mathrm{a}$ & $5.7 \mathrm{a}$ & $6.1 \mathrm{a}$ & $6.7 \mathrm{a}$ & $3.1 \mathrm{a}$ \\
\hline M11 & $3.5 \mathrm{~ns}$ & $3.7 \mathrm{~ns}$ & $4.5 \mathrm{ab}$ & $4.7 \mathrm{ab}$ & $5.0 \mathrm{~b}$ & $5.5 \mathrm{ab}$ & $5.9 \mathrm{ab}$ & $2.4 \mathrm{~b}$ \\
\hline M12 & $3.3 \mathrm{~ns}$ & $3.4 \mathrm{~ns}$ & $4.4 \mathrm{ab}$ & $4.7 \mathrm{ab}$ & $5.0 \mathrm{~b}$ & $5.7 \mathrm{ab}$ & $6.3 \mathrm{a}$ & $3.1 \mathrm{a}$ \\
\hline
\end{tabular}


The most effective (V)AMF species on leaf development were Enthrophospora columbiana (M2), Acaulospora appendicula (M4), Acaulospora rehmii (M6), Glomus clarum (M8), Glomus occultum (M9), Glomus mosseae (M10), and Scutellispora pellucida (M12) (Table 12).

At the end of the experiment, the growth promoting effect of mycorrhiza resulted in a greater total shoot length, accompanied by a higher number of expanded leaves in most of the inoculated treatments compared to the non-inoculated plants (Table 12). These results are consistent with data obtained from other micropropagated species. Fortuna et al. (1995) observed these growth-promoting effects during the post vitro acclimatization phase of micropropagated plum and apple plants which were inoculated with different mycorrhizal fungi. Subhan et al. (1998) reports that, at any given time during a 16-week experimental period, the ex vitro growth in terms of shoot height and number of leaves of inoculated Sesbania sesban plantlets was superior to that of non-inoculated control plants.

\subsubsection{Plant growth parameters after harvesting}

\subsubsection{Shoot and root fresh weight, root:shoot fresh weight ratio}

The shoot and root fresh weights and the root:shoot fresh weight (R:S) ratios were strongly affected by mycorrhizal inoculation (Table 13). The used clones showed significant differences only in the root fresh weights. There was no significant interaction between mycorrhizal inoculation and clones.

Table 13: ANOVA of main factors and their interaction on the shoot and root fresh weight $(\mathrm{g})$ and root:shoot fresh weight $(\mathrm{R}: \mathrm{S})$ ratio of micropropagated oil palms after three months of post vitro growth.

\begin{tabular}{lc|cc|cc|cc}
\hline \hline & & \multicolumn{2}{|c|}{ Shoot fresh weight } & \multicolumn{2}{|c|}{ Root fresh weight } & \multicolumn{2}{c}{ R:S ratio } \\
\hline ANOVA & DF & MQ & $\mathbf{P}$ & MQ & P & MQ & P \\
\hline Inoculation (1) & 12 & 4.13 & $\mathbf{0 . 0 0 0}$ & 0.14 & $\mathbf{0 . 0 0 2}$ & 0.009 & $\mathbf{0 . 0 0 3}$ \\
Clone (2) & 4 & 0.95 & 0.068 & 0.16 & $\mathbf{0 . 0 1 3}$ & 0.006 & 0.133 \\
1 x 2 & 48 & 0.59 & 0.086 & 0.06 & 0.178 & 0.003 & 0.406 \\
& & & & & & & \\
Error & 99 & 0.42 & & 0.049 & & 0.003 & \\
\hline \hline
\end{tabular}

After twelve weeks of post vitro growth, all tested (V)AMF significantly increased shoot fresh weights compared to the non-inoculated (NI) control plants (Table 14). Plantlets inoculated with Acaulospora appendicula (M4) produced more than two times higher shoot fresh weights than that of the non-inoculated control plants. Also, the root systems of 
mycorrhizal plants were, in general, well developed compared to the non-inoculated plantlets. Significantly higher root fresh weights compared to the control plants were measured in plantlets inoculated with Acaulospora appendicula (M4), Glomus clarum (M8), Glomus occultum (M9), Glomus mosseae (M10), and Scutellispora pellucida (M12).

An increase in the fresh weight of the shoots and the roots in plantlets inoculated with mycorrhizal fungi was also observed in avocado (Schubert et al., 1989). Sbrana et al. (1994) demonstrated that the inoculation of micropropagated plantlets of apple, peach and plum resulted in improved overall growth besides increasing the survival rate.

The root:shoot fresh weight (R:S) ratios were modified by inoculation with (V)AMF and were generally lower in the inoculated treatments (Table 14). The lowest R:S ratio was observed in plantlets inoculated with Glomus manihot (M1). Significant differences compared with the non-inoculated control plants were observed in all inoculated treatments, except Glomus occultum (M9).

Since relatively less energy is directed to root formation, endomycorrhizal plants showed a greater shoot production. According to Azcón-Aguilar and Barea (1997), mycorrhizacolonized plants have a lower root:shoot ratio in response to a greater increment of shoot mass relative to root mass.

Table 14: Shoot and root fresh weight $(\mathrm{g})$ and root:shoot fresh weight $(\mathrm{R}: \mathrm{S})$ ratio of noninoculated (NI) and inoculated (M1-M12) oil palm plantlets after 12 weeks of post vitro growth. Means in each column followed by different letters are significantly different at $P=0.05$ as indicated by LSD-test.

\begin{tabular}{c|c|c|c}
\hline \hline Inoculation & Shoot fresh weight (g) & Root fresh weight $(\mathbf{g})$ & R:S ratio \\
\hline NI & $1.84 \mathrm{~d}$ & $0.43 \mathrm{c}$ & $0.23 \mathrm{c}$ \\
M1 & $2.95 \mathrm{bc}$ & $0.40 \mathrm{c}$ & $0.12 \mathrm{a}$ \\
M2 & $3.20 \mathrm{~b}$ & $0.54 \mathrm{bc}$ & $0.17 \mathrm{ab}$ \\
M3 & $2.93 \mathrm{bc}$ & $0.57 \mathrm{bc}$ & $0.19 \mathrm{~b}$ \\
M4 & $4.05 \mathrm{a}$ & $0.80 \mathrm{a}$ & $0.19 \mathrm{~b}$ \\
M5 & $2.99 \mathrm{bc}$ & $0.50 \mathrm{bc}$ & $0.16 \mathrm{ab}$ \\
M6 & $3.19 \mathrm{bc}$ & $0.55 \mathrm{bc}$ & $0.17 \mathrm{ab}$ \\
M7 & $2.61 \mathrm{c}$ & $0.50 \mathrm{bc}$ & $0.18 \mathrm{~b}$ \\
M8 & $3.62 \mathrm{a}$ & $0.59 \mathrm{~b}$ & $0.16 \mathrm{ab}$ \\
M9 & $3.32 \mathrm{~b}$ & $0.69 \mathrm{a}$ & $0.20 \mathrm{bc}$ \\
M10 & $3.55 \mathrm{~b}$ & $0.64 \mathrm{a}$ & $0.18 \mathrm{~b}$ \\
M11 & $3.08 \mathrm{bc}$ & $0.53 \mathrm{bc}$ & $0.17 \mathrm{~b}$ \\
M12 & $3.31 \mathrm{~b}$ & $0.61 \mathrm{a}$ & $0.19 \mathrm{~b}$ \\
\hline \hline
\end{tabular}


At the end of the experimental period the inoculated plants were better developed than the non-inoculated control plants (Figure 7).

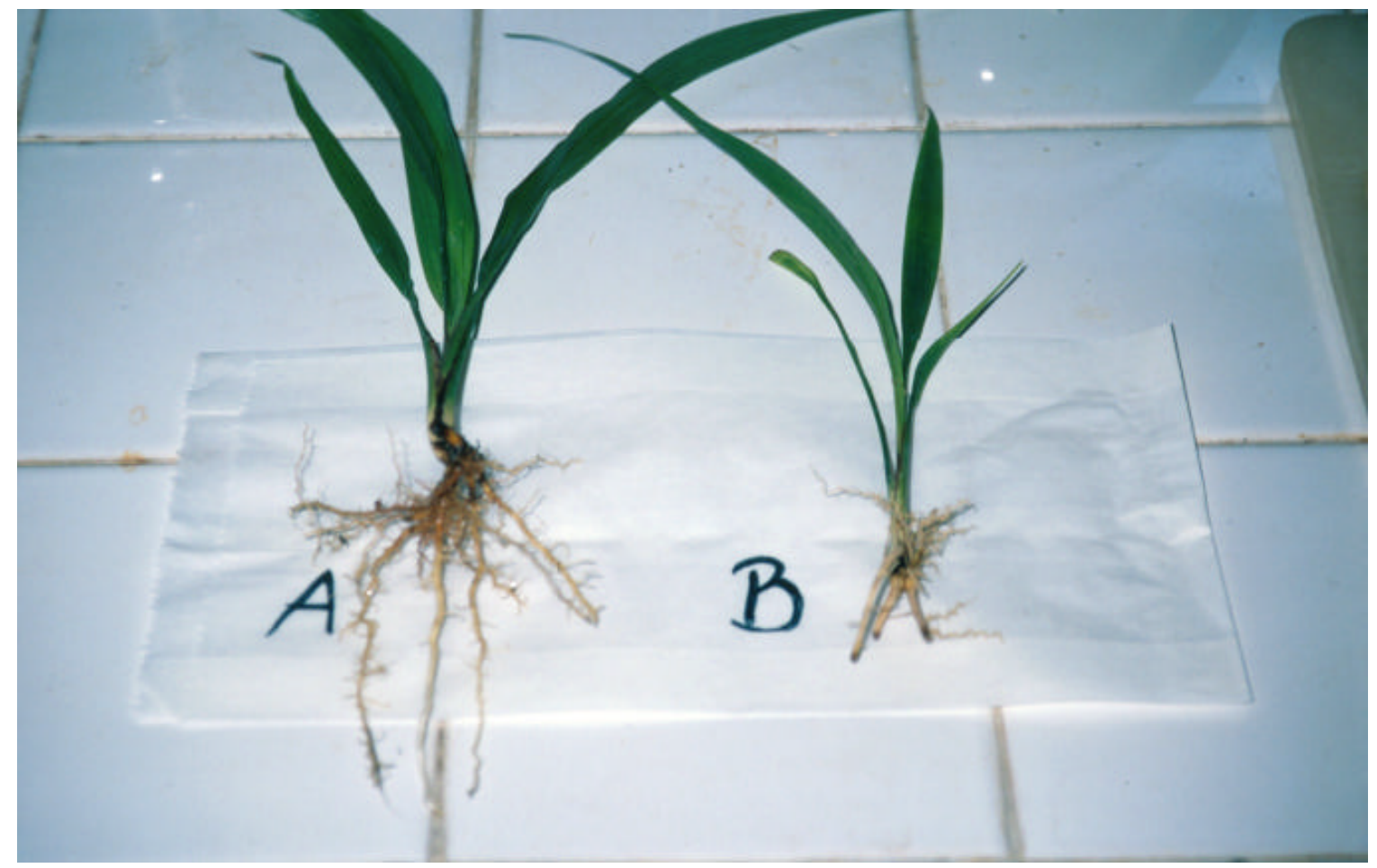

Figure 7: Development of inoculated (A) and non-inoculated (B) oil palm plantlets after 3 month of post vitro growth

\subsubsection{Dry matter}

The mycorrhizal fungi had a highly significant effect on shoot dry weights of the oil palm plantlets (Table 16). The clones and the interactions of the two main factors showed no significant differences in dry matter accumulation at this growth stage.

Table 16: ANOVA of main factors and their interaction on the shoot dry weight $(\mathrm{g})$ of micropropagated oil palms after a three-month period of post vitro growth.

\begin{tabular}{l|c|c|c}
\hline \hline ANOVA & DF & MQ & P \\
\hline Inoculation & 12 & 0.083 & $\mathbf{0 . 0 0 0}$ \\
Clone & 4 & 0.031 & 0.251 \\
Inoculation x Clone & 48 & 0.028 & 0.171 \\
Error & 100 & 0.023 & \\
\hline \hline
\end{tabular}

Results obtained in this experiment showed that most of the tested mycorrhizal fungi were effective in promoting plant growth, with little difference in the effectiveness of the (V)AMF 
species. Figure 8 illustrates the main effect of inoculation on dry matter accumulation of oil palm plantletsm Most of the used mycorrhizal fungi increased the shoot dry weights significantly compared to the non-inoculated (NI) control plants, as a consequence of better growth due to improved shoot and leaf development. Especially in the case of Acaulospora appendicula (M4), the dry weight of shoots was two times that of the control plants. Differences in the effectiveness of mycorrhizal fungi were also observed. As discussed above, A. appendicula, but also Acaulospora rehmii (M6), Glomus clarum (M8), Glomus mosseae (M10) and Scutellispora pellucida (M12) were the most effective fungal isolates promoting dry matter accumulation in shoots. Gigaspora gigantea (M7) and Scutellispora pellucida (M11) were significantly less effective among all investigated isolates.

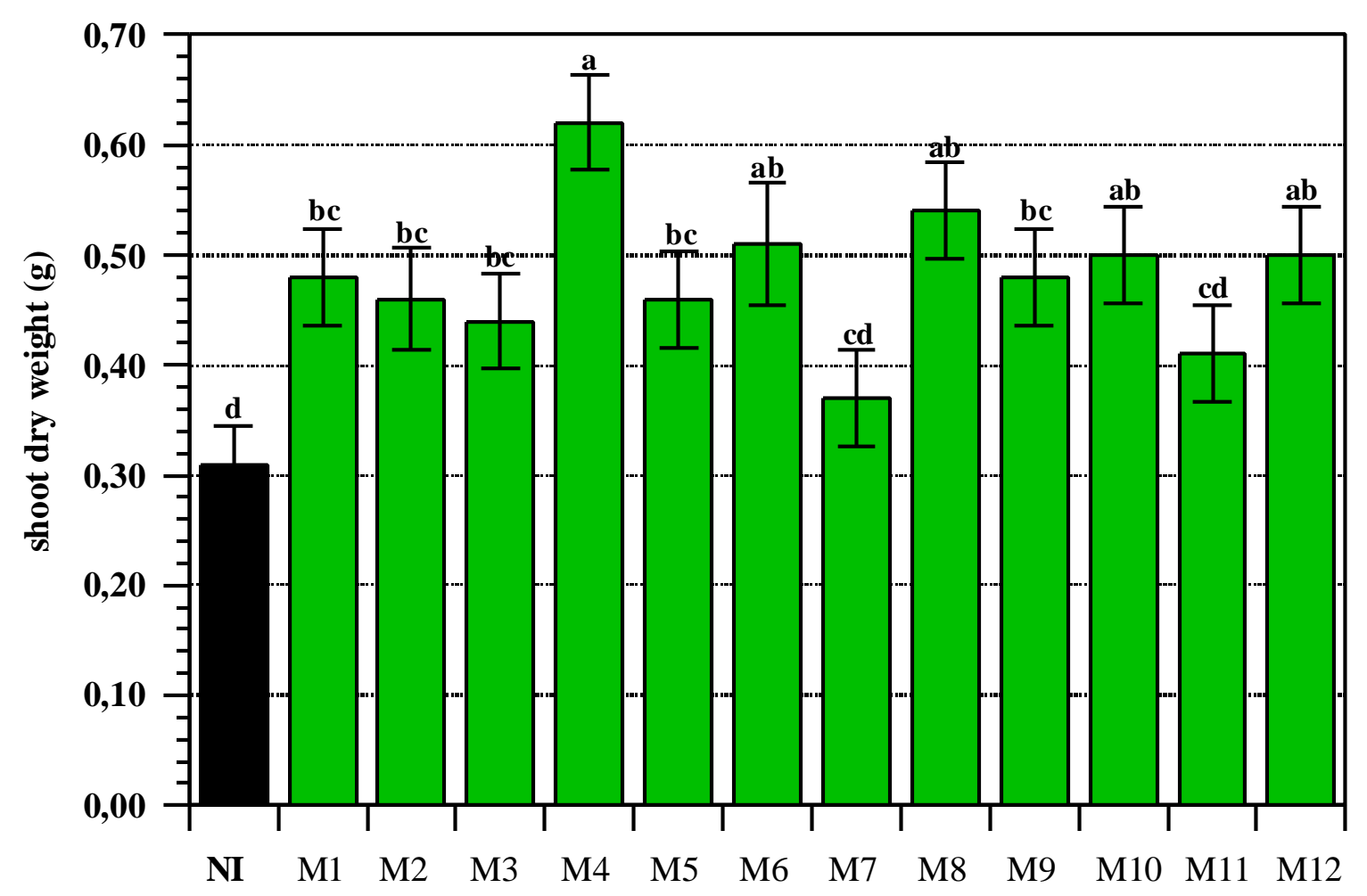

Figure 8: Mycorrhizal inoculation (M1-M12) as a main effect on shoot dry weight (g) of micro-propagated oil palms after 12 weeks of post vitro growth. NI: non-inoculated control plants. Vertical bars represent standard errors of the mean. Columns with different letters are significantly different at $\mathrm{P}=0.05$ as indicated by LSD-test.

Declerck et al. (1995) investigated the growth response of micropropagated banana plants to (V)AM inoculation. The authors report that inoculation with Glomus mosseae and Glomus geosporum resulted in significantly higher shoot fresh and dry weights as compared to the control plants. Fortuna et al. (1992) observed large differences in the fresh and dry mass between inoculated and non-inoculated plum plants as a result of differences in the growth behaviour of the plants. According to Branzanti et al. (1992), and Azcón-Aguilar and Barea 
(1997), mycorrhiza enhances growth of plantlets of selected species and causes earlier resumption in shoot apical growth. Vestberg (1992) found that only 3 of 6 fungal strains tested with 10 strawberry cultivars were highly efficient with regard to significant growth improvement.

\subsubsection{Nutrient concentration and uptake}

\subsection{Phosphorus}

Mycorrhizal inoculation significantly affected the phosphorus concentration and uptake of plant shoots (Table 16). The clones showed no differences in $\mathrm{P}$ absorption in this study. Interactions between the two main factors were also not significant.

Table 16: ANOVA of main factors and their interaction on the $P$ concentration $(\mathrm{mg} / \mathrm{g})$ and $P$ uptake (mg/plant) of micropropagated oil palms after three months of post vitro growth.

\begin{tabular}{lr|cc|cc}
\hline \hline & & \multicolumn{2}{|c|}{ P (mg/g) } & \multicolumn{2}{c}{ P (mg/plant) } \\
\hline ANOVA & DF & MQ & P & MQ & P \\
\hline Inoculation (1) & 12 & 0.193 & $\mathbf{0 . 0 0 0}$ & 0.358 & $\mathbf{0 . 0 0 0}$ \\
Clone (2) & 4 & 0.072 & 0.170 & 0.084 & 0.294 \\
1 x 2 & 48 & 0.044 & 0.286 & 0.092 & 0.091 \\
& & & & & \\
Error & 100 & 0.039 & & 0.067 & \\
\hline \hline
\end{tabular}

Mycorrhizal inoculation significantly increased the phosphorus content of the shoots compared with the non-inoculated (NI) control plants (Figure 9).

There were no significant differences in the $\mathrm{P}$ concentration in shoots of plants inoculated with the tested fungal isolates. Estrada-Luna et al. (2000) reports that mycorrhizal inoculation alters the nutrient uptake of micropropagated guava plantlets; especially the leaf-elemental concentration of $\mathrm{P}$ was significantly higher in mycorrhizal plants. The growth stimulation of oil palm plantlets reported in this study was associated with the increased phosphorus concentration in shoots.

The increase in absorption of phosphorus by (V)A mycorrhizal plants in this study may be due to increased physical exploration of the soil as a consequence of a better-developed mycorrhizal root system in most of the inoculated plants (Table 15). Berta et al. (1990) reported that mycorrhizal inoculation at the weaning stage produces plants with a more effective root system for uptake of $\mathrm{P}$ and other nutrients. 


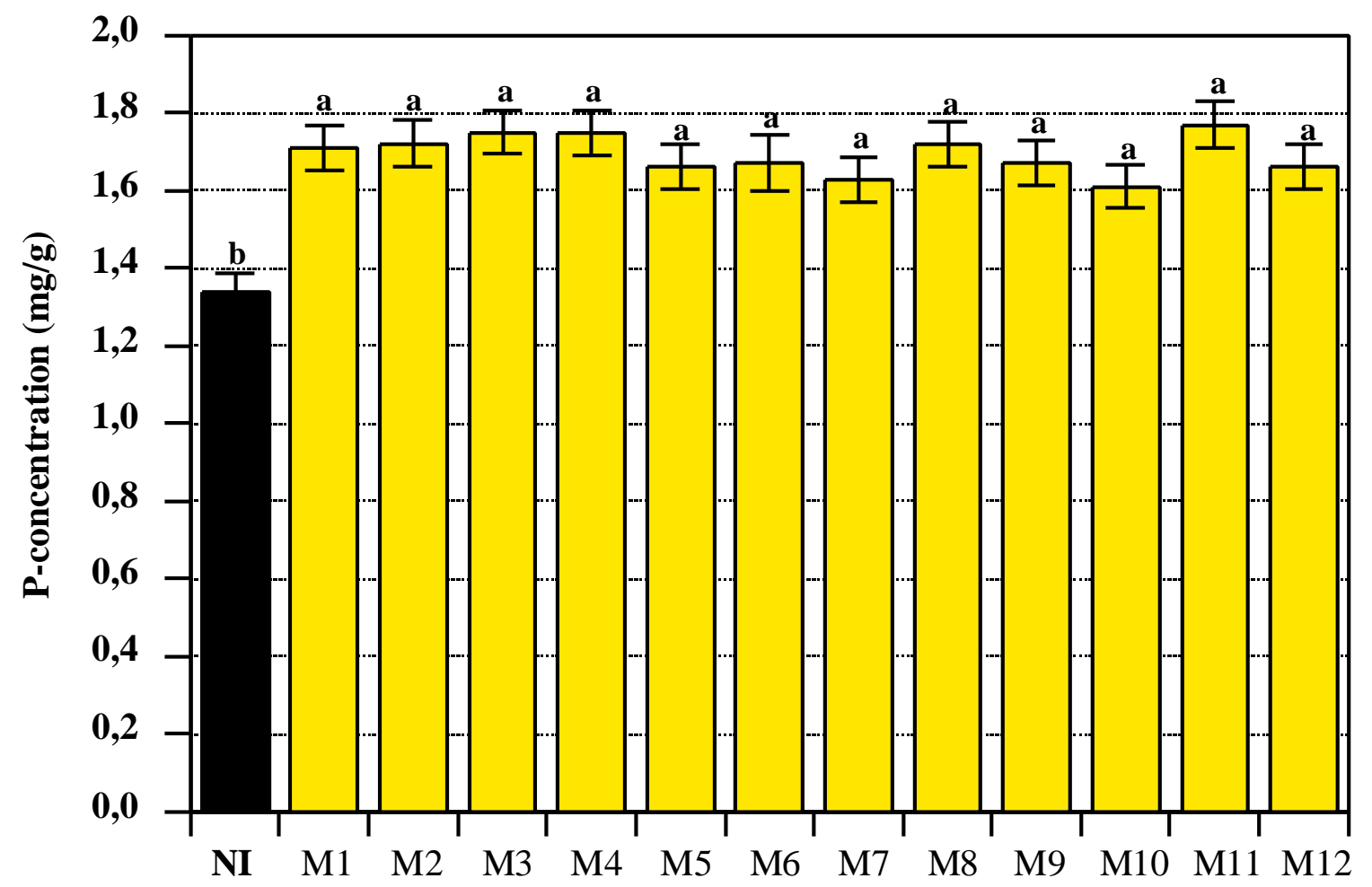

Figure 9: Mycorrhizal inoculation (M1-M12) as a main effect on phosphate concentrations $(\mathrm{mg} / \mathrm{g})$ of micropropagated oil palms after 12 weeks of post vitro growth. NI: non-inoculated control plants. Vertical bars represent standard errors of the mean. Columns with different letters are significantly different at $P=0.05$ as indicated by LSD-test.

The phosphorus uptake of all inoculated plants was significantly higher than that of the control plants (Figure 10), except in plantlets which were inoculated with Gigaspora giganthea (M7).

According to Haymann and Mosse (1972) and Gianinazzi-Pearson et al. (1981) is the positive role of (V)AMF in phosphate uptake mainly due to the capacity of mycorrhizal roots to exploit the labile pool of available soil phosphate more efficiently. 


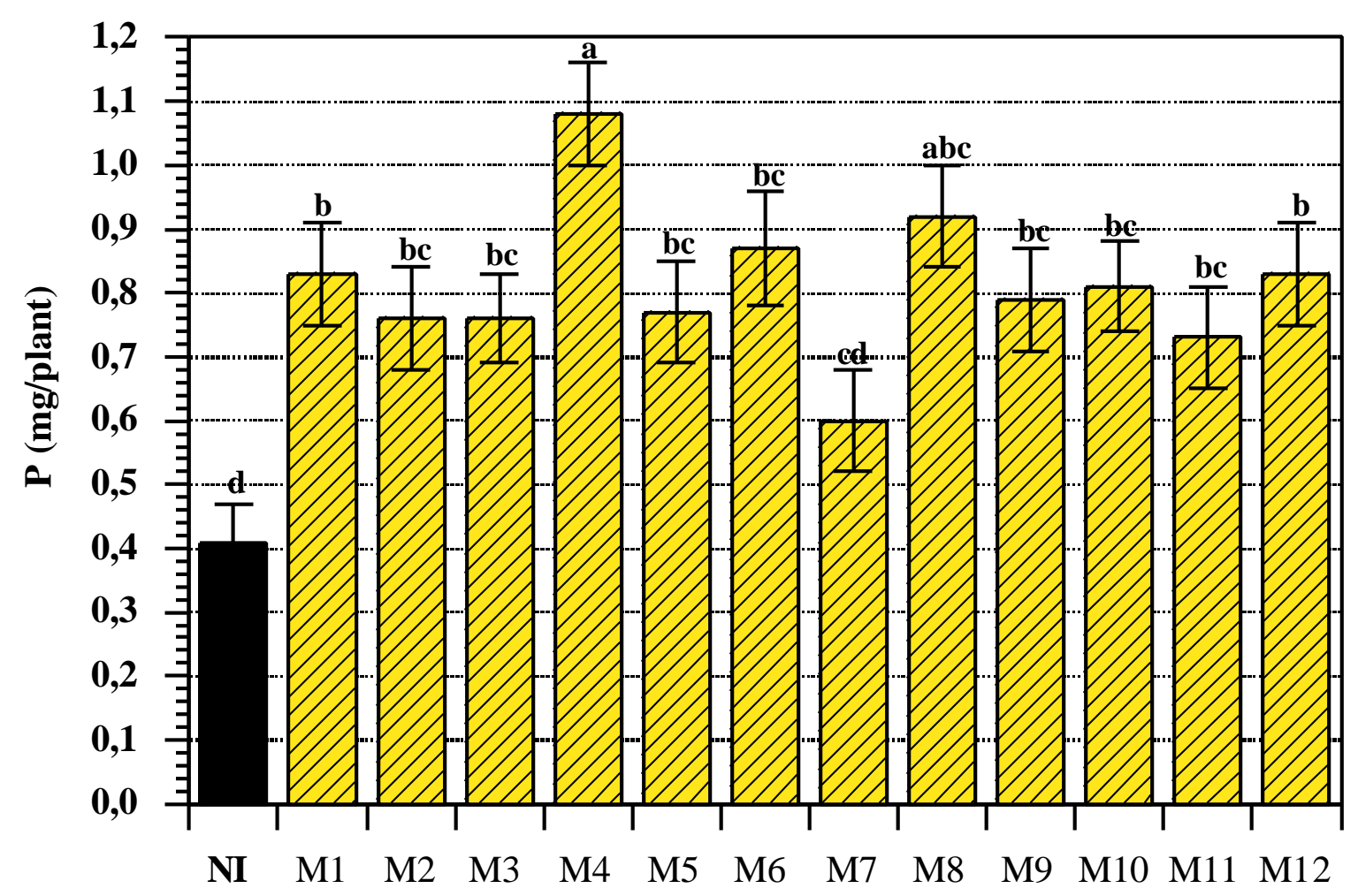

Figure 10: Mycorrhizal inoculation (M1-M12) as a main effect on phosphate uptake (mg/plant) of micropropagated oil palms after 12 weeks of post vitro growth. NI: noninoculated control plants. Vertical bars represent standard errors of the mean. Columns with different letters are significantly different at $P=0.05$ as indicated by LSD-test.

\subsection{Potassium}

Mycorrhizal inoculation was a highly significant factor enhancing the potassium concentration and uptake in plant shoots (Table 17). The clones showed no differences in $\mathrm{K}$ concentration and uptake. Interactions of the two main factors were not detected in this study.

Table 17: ANOVA of main factors and their interaction on the $\mathrm{K}$ concentration $(\mathrm{mg} / \mathrm{g})$ and $\mathrm{K}$ uptake (mg/plant) of micropropagated oil palms after three months of post vitro growth.

\begin{tabular}{lc|cc|cc}
\hline \hline & & \multicolumn{2}{|c|}{ K (mg/g) } & \multicolumn{2}{c}{ K (mg/plant) } \\
\hline ANOVA & DF & MQ & P & MQ & P \\
\hline & & & & & \\
Inoculation (1) & 12 & 20.16 & $\mathbf{0 . 0 1 7}$ & 18.04 & $\mathbf{0 . 0 0 2}$ \\
Clone (2) & 4 & 7.25 & 0.534 & 2.66 & 0.794 \\
$1 \times 2$ & 48 & 7.17 & 0.827 & 5.62 & 0.673 \\
Error & & & & & \\
\hline \hline
\end{tabular}

A significant increase in the $\mathrm{K}$ concentration compared to the non-inoculated (NI) control plants was observed in plantlets inoculated with Glomus manihot (M1), Enthrophospora 
columbiana (M2), Acaulospora mellea (M3), Acaulospora appendicula (M4), and Scutellispora pellucida (M11), (Table 18). As a consequence of better growth, the inoculated plantlets took up more $\mathrm{K}$ than the non-inoculated control plants except when inoculated with Gigaspora giganthea (M7).

Table 18: Main effect of mycorrhizal inoculation (M1-M12) on K concentration (mg/g) and $\mathrm{K}$ uptake (mg/plant) of micropropagated oil palms after 12 weeks of post vitro growth. NI: non-inoculated control plants. Means in each column followed by different letters are significantly different $P=0.05$ as indicated by LSD-test.

\begin{tabular}{l|c|c}
\hline \hline Inoculation & K $(\mathbf{m g} / \mathbf{g})$ & $\mathbf{K}(\mathbf{m g} / \mathbf{p l a n t})$ \\
\hline NI & $13.74 \mathrm{c}$ & $4.45 \mathrm{c}$ \\
M1 & $16.92 \mathrm{ab}$ & $8.02 \mathrm{a}$ \\
M2 & $16.87 \mathrm{ab}$ & $7.73 \mathrm{ab}$ \\
M3 & $17.63 \mathrm{a}$ & $7.47 \mathrm{ab}$ \\
M4 & $17.34 \mathrm{a}$ & $9.22 \mathrm{a}$ \\
M5 & $15.66 \mathrm{abc}$ & $7.14 \mathrm{ab}$ \\
M6 & $13.43 \mathrm{c}$ & $6.74 \mathrm{~b}$ \\
M7 & $15.64 \mathrm{abc}$ & $5.67 \mathrm{bc}$ \\
M8 & $14.51 \mathrm{bc}$ & $7.70 \mathrm{ab}$ \\
M9 & $15.21 \mathrm{abc}$ & $6.99 \mathrm{ab}$ \\
M10 & $14.90 \mathrm{bc}$ & $8.43 \mathrm{a}$ \\
M11 & $16.72 \mathrm{ab}$ & $6.80 \mathrm{~b}$ \\
M12 & $15.36 \mathrm{abc}$ & $7.62 \mathrm{ab}$ \\
\hline \hline
\end{tabular}

The better nutritional status of mycorrhizal plants in this study is primarily due to more efficient P absorption (Cooper, 1984; Rizardi, 1990). Declerck et al. (1995) also observed significantly higher shoot $\mathrm{P}$ and $\mathrm{K}$ contents in banana plants inoculated with Glomus mosseae and Glomus geosporum. The authors concluded that the higher $\mathrm{P}$ content could be related to various mechanisms, including a larger soil volume, which reduces the distance of ion diffusion to the plant roots, and rhizosphere modifications. (V)AM fungi might also increase the uptake of other nutrients that move to the root surface, primarily by diffusion (Abbott and Robson, 1984).

\subsection{Nitrogen}

Nitrogen concentration and uptake in plant shoots was strongly affected by mycorrhizal inoculation (Table 19) The clones showed no differences in $\mathrm{N}$ absorption in this study. Interactions between the two main factors were also not significant. 
Table 19: ANOVA of main factors and their interaction on the $\mathrm{N}$ concentration $(\mathrm{mg} / \mathrm{g})$ and $\mathrm{N}$ uptake (mg/plant) of micropropagated oil palms after three months of post vitro growth.

\begin{tabular}{lc|cc|cc}
\hline \hline & & \multicolumn{2}{|c|}{$\mathbf{N}(\mathbf{m g} / \mathbf{g})$} & \multicolumn{2}{c}{$\mathbf{N}$ (mg/plant) } \\
\hline ANOVA & DF & MQ & P & MQ & P \\
\hline Inoculation (1) & 12 & 21.81 & $\mathbf{0 . 0 0 1}$ & 51.83 & $\mathbf{0 . 0 0 0}$ \\
Clone (2) & 4 & 7.83 & 0.344 & 9.21 & 0.526 \\
1 x 2 & 48 & 8.91 & 0.141 & 12.78 & 0.319 \\
& & & & & \\
Error & 100 & 6.89 & & 11.45 & \\
\hline \hline
\end{tabular}

In most of the inoculated plantlets, except Acaulospora morowiae (M5) and Glomus mosseae (M10), a significantly higher $\mathrm{N}$ concentration was determined in the shoots (Table 20). The inoculated plantlets had a significant higher $\mathrm{N}$ uptake compared to the non-inoculated control plants (NI).

Table 20: Main effect of mycorrhizal inoculation (M1-M12) on $\mathrm{N}$ concentration $(\mathrm{mg} / \mathrm{g})$ and $\mathrm{N}$ uptake (mg/plant) of micropropagated oil palms after 12 weeks of post vitro growth. NI: non-inoculated control plants. Means in each column followed by different letters are significantly different $P=0.05$ as indicated by LSD-test.

\begin{tabular}{l|c|c}
\hline \hline Inoculation & $\mathbf{N}(\mathbf{m g} / \mathbf{g})$ & $\mathbf{N}(\mathbf{m g}$ /plant $)$ \\
\hline NI & $21.88 \mathrm{c}$ & $6.63 \mathrm{~d}$ \\
M1 & $26.43 \mathrm{a}$ & $12.54 \mathrm{ab}$ \\
M2 & $25.60 \mathrm{a}$ & $11.63 \mathrm{ab}$ \\
M3 & $24.50 \mathrm{ab}$ & $10.60 \mathrm{bc}$ \\
M4 & $24.53 \mathrm{ab}$ & $13.97 \mathrm{a}$ \\
M5 & $23.53 \mathrm{bc}$ & $10.83 \mathrm{bc}$ \\
M6 & $24.13 \mathrm{ab}$ & $12.28 \mathrm{ab}$ \\
M7 & $25.77 \mathrm{a}$ & $9.36 \mathrm{c}$ \\
M8 & $23.88 \mathrm{~b}$ & $12.68 \mathrm{ab}$ \\
M9 & $24.32 \mathrm{ab}$ & $11.17 \mathrm{bc}$ \\
M10 & $23.11 \mathrm{bc}$ & $11.94 \mathrm{ab}$ \\
M11 & $24.97 \mathrm{ab}$ & $10.33 \mathrm{bc}$ \\
M12 & $25.79 \mathrm{a}$ & $12.79 \mathrm{ab}$ \\
\hline \hline
\end{tabular}

\subsection{5 (V)AMF infection rate}

Mycorrhizal inoculation significantly affected the (V)AMF infection rate in the roots of oil palms (Table 21). The clones and the interaction of the two main factors did not influence the (V)AMF infection rate of the plantlets during this growth stage. 
Table 21: ANOVA of main factors and their interaction on the (V)AMF infection rate of micropropagated oil palms after three months of post vitro growth.

\begin{tabular}{l|c|c|c}
\hline \hline ANOVA & DF & MQ & P \\
\hline Inoculation & 12 & 273.59 & $\mathbf{0 . 0 0 0}$ \\
Clone & 4 & 150.65 & 0.095 \\
Inoculation x Clone & 48 & 83.36 & 0.303 \\
Error & 99 & 73.86 & \\
\hline \hline
\end{tabular}

All mycorrhizal fungi tested in this initial screening formed mycorrhizas with the oil palm plantlets. Levels of infection observed after trypan blue staining differed between isolates and ranged in most cases between 17-23\% (Figure 11). Plants inoculated with Glomus mosseae (M4) showed the highest infection rate (27\%), while the lowest was observed in roots of plantlets inoculated with Glomus clarum (M8), although inoculation with both fungi improved plant growth significantly.

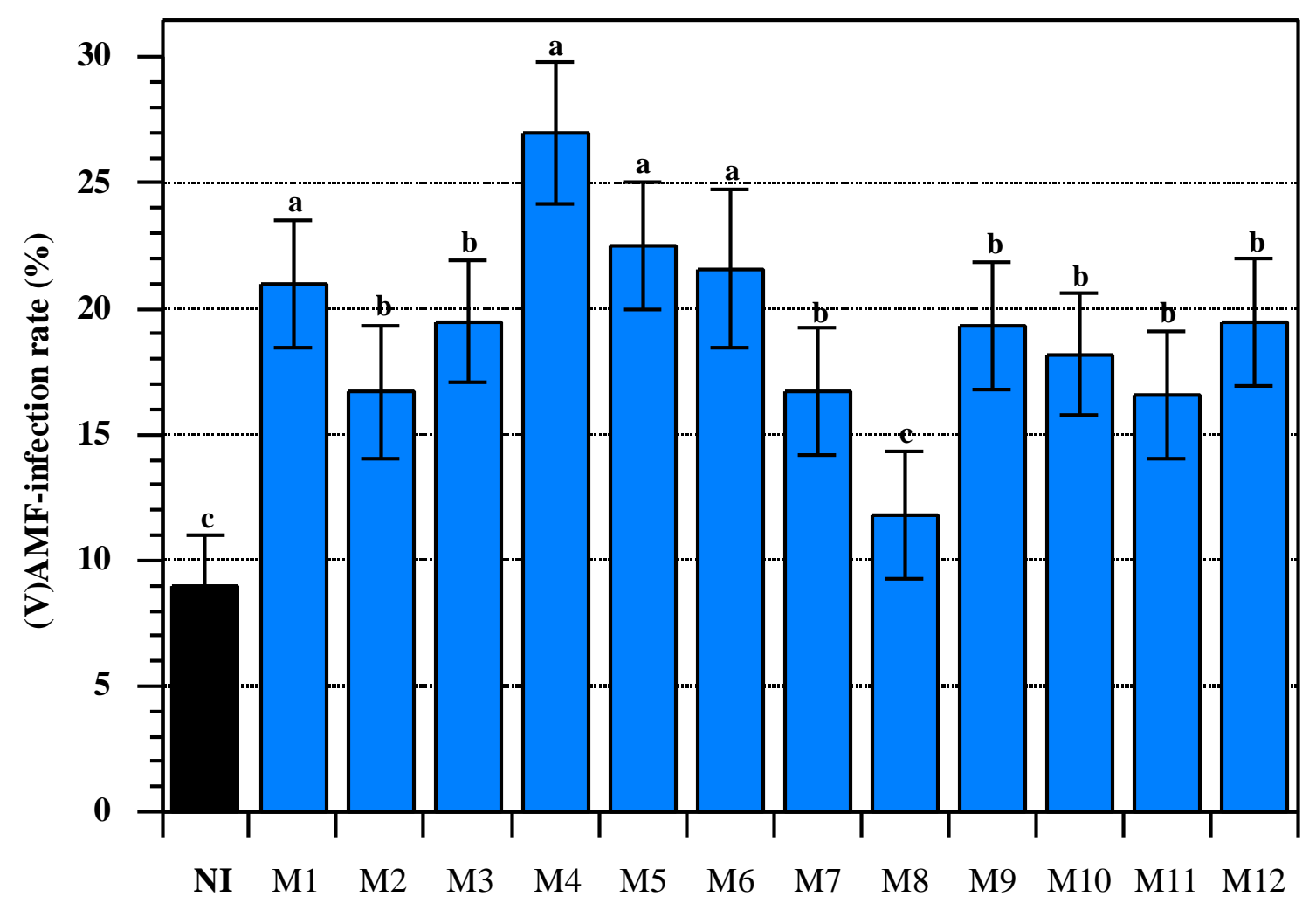

Figure 11: Main effect of mycorrhizal inoculation (M1-M12) on (V)AMF infection rate (\%) of micropropagated oil palms after 12 weeks of post vitro growth. NI: non-inoculated control plants. Vertical bars represent standard errors of the mean. Columns with different letters are significantly different at $P=0.05$ as indicated by LSD-test. 
Pinochet et al. (1997) reported that the percentage of mycorrhizal colonization of Glomus interadices was relatively low at $27 \%$, although plant growth response in mycorrhizal treatments was significantly higher compared with the non-mycorrhizal treatments for all growth characteristics (plant height, number of leaves and fresh and dry weights).

This study demonstrates that (V)AM fungi can establish a symbiotic association with the oil palm clones and that an early endomycorrhizal inoculation ensures maximum survival and growth of the young oil palms after they have been transferred to the soil. Chavez and Ferrera-Cerrato (1990) measured the response of 4 micropropagated strawberry cultivars to root colonization by (V)AMF. They found that plant yields differed significantly depending on the (V)AMF species tested and that yield was unrelated to percentage of root colonization. Some plant cultivar/fungus combinations resulted in improved growth while others did not.

The weak mycorrhizal formation $(9 \%)$ in the roots of control plants (NI) grown in the nonsterilized soil (Figure 11) in this study indicated the natural levels of infection, which occur in plant roots under 'normal' nursery conditions. The low effectiveness of these fungi on plant survival and development was evident in this experiment. These results indicate that the early inoculation of micropropagated oil palms with more effective (V)AM fungi greatly improves the tolerance to the stress situation after transplanting to post vitro conditions.

\subsubsection{Assessment of plant development}

At the end of the experimental period, the remaining plants were visually classified as of 'good quality', which is an important factor for successful marketing of oil palm plantlets. The young plants were classified according to a scheme which is generally used at the 'Indonesian Oil Palm Research Institute' (IOPRI) when plantlets reach this growth stage and are to be sold to the planters or transferred to the nursery for further cultivation. This assessment is based on the three categories, which are presented in Figure 12: (Class A: Best quality, plantlets are ready for selling; Class B: Good quality, plantlets are expected for future selling (after some weeks); Class C: Plantlets will be discarded, due to stunted or abnormal growth). 


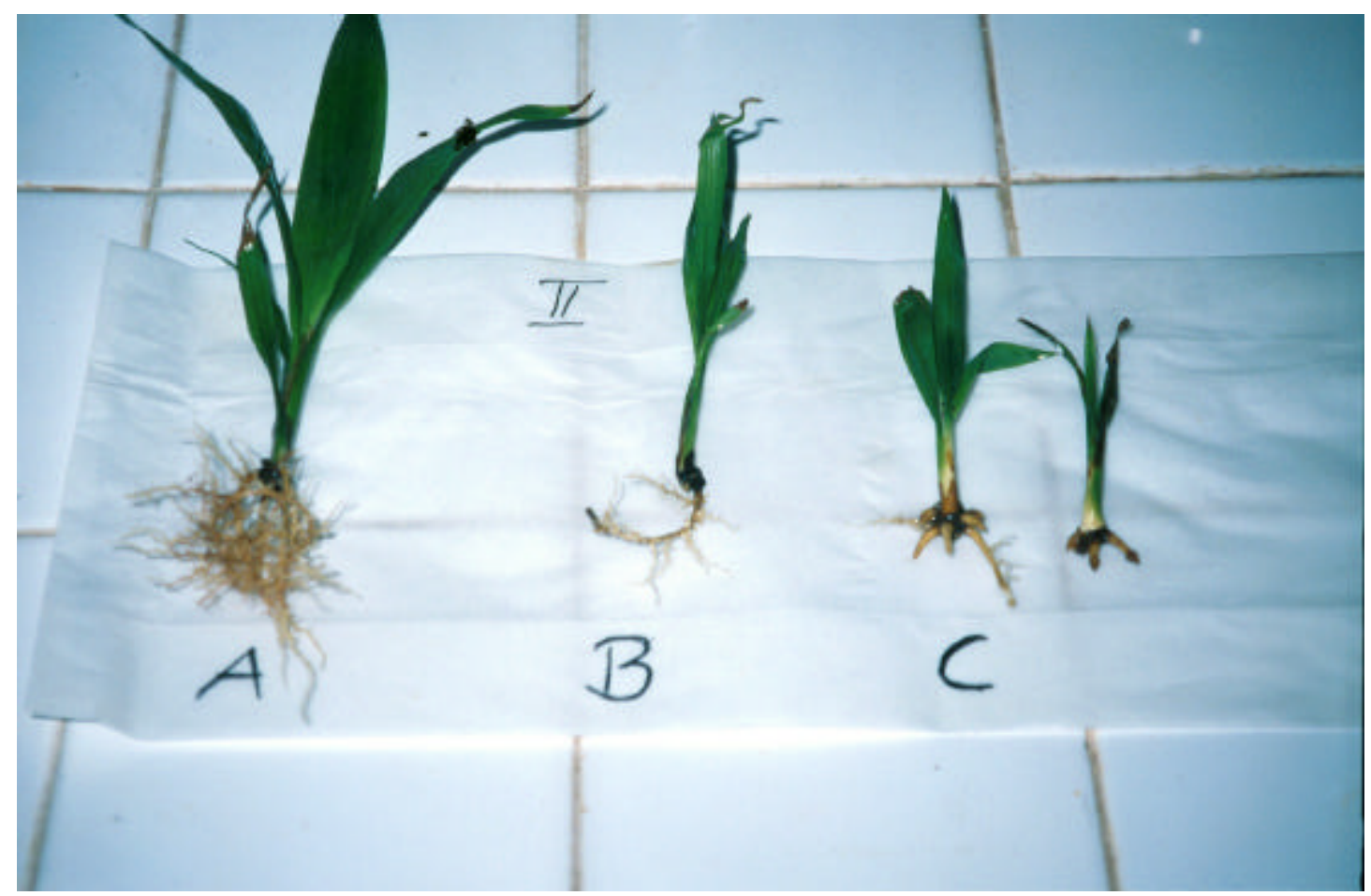

Figure 12: Categories of micropropagated oil palms after 3 months of post vitro growth. (A: Class A: Best quality, plantlets are ready for selling; B: Class B: Good quality, plantlets are expected for future selling (after some weeks); C: Class C: Plantlets will be discarded, due to stunted or abnormal growth).

Table 22 presents the classification of all remaining plants which survived during the experimental period. Plantlets of Class $\mathrm{C}$, which were discarded, and the plantlets which died during the experimental period were summarized as total losses.

Without inoculation, $45 \%$ of the non-inoculated (NI) control plants died during the experimental period and $7.5 \%$ of the remaining control plants were assessed for Class $\mathrm{C}$ which resulted in $52.5 \%$ total losses. This confirms further the low effectiveness of the soilindigenous mycorrhizal fungi which colonized the roots of the control plants.

The percentage of total losses could be markedly lowered by mycorrhizal inoculation as is shown in this study (Table 22). Most of the inoculated plantlets were more vigorous and showed better growth performance during post vitro development. The total losses in most of the inoculated treatments could be markedly reduced to $7.7-15.4 \%$, except in plantlets inoculated with Acaulospora rehmii (M6) and Glomus clarum (M8), where the total losses amounted to $30.6 \%$ and $23.1 \%$, respectively. 
Table 22: Assessment of survived plants (\%) 12 weeks after post vitro growth according plant stage for selling. (Class A: Best quality, plantlets are ready for selling; Class B: Good quality, plantlets are expected for future selling (after some weeks); Class C: Plantlets will be discarded, due to stunted or abnormal growth).

\begin{tabular}{l|ccc|c|c}
\hline \hline Inoculation & \multicolumn{3}{|c|}{ Plant class (\%) } & Dead plants (\%) & $\begin{array}{c}\text { Total loss (\%) } \\
\text { (Stage C+dead } \\
\text { plants) }\end{array}$ \\
& & & & & \\
NI & A & B & C & & 52.5 \\
M1 & 30.0 & 17.5 & 7.5 & 45.0 & 15.4 \\
M2 & 69.2 & 15.4 & 7.7 & 7.7 & 15.4 \\
M3 & 76.9 & 7.7 & 0 & 15.4 & 7.7 \\
M4 & 84.6 & 7.7 & 7.7 & 0 & 7.7 \\
M5 & 84.6 & 7.7 & 7.7 & 0 & 15.4 \\
M6 & 76.9 & 7.7 & 7.7 & 7.7 & 30.8 \\
M7 & 61.5 & 7.7 & 0 & 30.8 & 15.4 \\
M8 & 46.2 & 38.5 & 7.7 & 7.7 & 23.1 \\
M9 & 69.2 & 7.7 & 7.7 & 15.4 & 7.7 \\
M10 & 84.6 & 7.7 & 0 & 7.7 & 15.4 \\
M11 & 76.9 & 7.7 & 0 & 15.4 & 7.7 \\
M12 & 84.6 & 7.7 & 0 & 7.7 & 15.4 \\
\hline \hline
\end{tabular}

\subsubsection{Conclusions of Experiment 1}

The main aim of this research work was to investigate the effectiveness of (V)AMF on survival rate and post vitro development of oil palm clones by introducing endomycorrhizal inoculation in the existing micropropagation process. The first step in any inoculation program is to obtain isolates which are both infective and effective on plant development. Screening trials are important to select isolates that will perform successfully. Based on these terms, the first experiment of this study was conducted as an initial screening of twelve different mycorrhizal isolates, representing a broad range of endo-mycorrhizal fungal genera and species. (V)AM fungi are known to colonize roots of a wide variety of host plants belonging to different families. In general, the (V)AM fungi are not host-specific but for the inoculation of micropropagated plants selection of appropriate fungal partners is essential to derive maximum benefit of mycorrhizal symbiosis.

Most of the tested fungal isolates used for inoculation were highly effective for post vitro development of micropropagated oil palm plantlets, which indicates that the introduction of 
selected fungal isolates could be a biological tool to improve post vitro survival and development of E. guineensis plantlets.

Based on the results of this initial screening, four mycorrhizal fungi which were the most effective in terms of plant survival, shoot and leaf development were selected for further investigations. These were Glomus manihot (M1), Enthrophospora columbiana (M2), Acaulospora mellea (M3) and Acaulospora appendicula (M4). In Table 23 the effectiveness of these fungal isolates on post vitro survival and development of oil palm plantlets is summarized.

Table 23: Parameters of the most efficient (V)AMF isolates (Glomus manihot (M1), Enthrophospora columbiana (M2), Acaulospora mellea (M3), and Acaulospora appendicula (M4)).

\begin{tabular}{|c|c|c|c|c|}
\hline \multirow[b]{2}{*}{ Parameter } & \multicolumn{4}{|c|}{$\begin{array}{l}\text { (V)AMF } \\
\text { (VMF }\end{array}$} \\
\hline & M1 & M2 & M3 & M4 \\
\hline Survival rate $(\%)$ & 93 & 83 & 100 & 100 \\
\hline $\begin{array}{l}\text { Shoot length } \\
\text { (became significant) }\end{array}$ & after $8^{\text {th }}$ week & after $8^{\text {th }}$ week & after $6^{\text {th }}$ week & after $6^{\text {th }}$ week \\
\hline Shoot length (total) & $\mathrm{S} 2 *$ & $\mathrm{~S} 1 *$ & $\mathrm{~S} 1 *$ & $\mathrm{~S} 2 *$ \\
\hline Emergence $1^{\text {st }}$ leaf & $4^{\text {th }}$ week & $4^{\text {th }}$ week & $4^{\text {th }}$ week & $4^{\text {th }}$ week \\
\hline No. of leaves & S2* & $\mathrm{S} 1 *$ & $\mathrm{~S} 2 *$ & $\mathrm{~S} 1 *$ \\
\hline
\end{tabular}

*S1 the significantly most highly effective fungal isolate

*S2 significantly highly effective

\subsection{Experiment 2}

Experiment 2 was conducted to compare the application of traditional plant nutrition, which is practiced at the 'International Oil Palm Research Institute' (IOPRI), with the beneficial effect of mycorrhizal inoculation during the sensitive post vitro stage of clonal oil palms. Because of the weakly developed roots of the oil palm plantlets, 'BAYFOLAN' (BAY), a commercially available liquid, complete-foliar spray, was applied. As an alternative to 'BAYFOLAN', hydroxy-apatite (HA), a slow P-release fertilizer, was added to the soil and the influence of these two methods of fertilization was compared with non-fertilized control plants (FO). 
Based on the results of the initial screening in Experiment 1, plantlets were inoculated with four endomycorrhizal fungi which were selected for their effectiveness on plant survival and development. These were Glomus manihot (M1), Enthrophospora columbiana (M2), Acaulospora mellea (M3), and Acaulospora appendicula (M4).

In this experiment, plants were harvested at two different growth stages to investigate the effect of mycorrhizal inoculation and fertilization on the post vitro plant development. The first harvest was carried out 6 weeks and the second harvest 12 weeks after transplanting.

\subsubsection{Survival rate}

Inoculation with the selected (V)AMF at the transplanting stage was highly effective in securing plant survival during the three-month growth period (Table 24) and confirmed the results of the first experiment. Both mycorrhizal inoculation and fertilization as main factors, but also the interaction between these two factors, affected plant survival significantly. The clones as a main factor and the interactions of the three factors studied were not significant.

Table 24: ANOVA of main effects and their interactions on the survival rate (\%) of micropropagated oil palms after a three-month period of post vitro growth.

\begin{tabular}{l|c|c|c}
\hline \hline ANOVA & DF & MQ & P \\
\hline Inoculation & 4 & 14716.67 & $\mathbf{0 . 0 0 0}$ \\
Fertilization & 2 & 4933.33 & $\mathbf{0 . 0 1 7}$ \\
Clone & 4 & 2883.33 & 0.149 \\
& & & \\
Inoculation x Fertilization & 8 & 2516.67 & $\mathbf{0 . 0 3 5}$ \\
Inoculation x Clone & 16 & 320.83 & 0.998 \\
Fertilization x Clone & 8 & 433.34 & 0.938 \\
Inoculation x Fertilization x Clone & 32 & 620.83 & 0.985 \\
Error & & 1188.89 & \\
\hline \hline
\end{tabular}

The interactions between the two main factors inoculation and fertilization regarding plant survival during three months of post vitro growth are represented in Figure 13. The lowest percentage of plant survival $(45 \%)$ was observed in the non-inoculated (NI) control plants which were either non-fertilized (FO) or in soil fertilized with hydroxy-apatite (HA). The survival rate was significantly improved by mycorrhizal inoculation with either of the tested (V)AMF: up o $75-95 \%$ in the non-fertilized, and up to $85-100 \%$ in the HA-fertilized plants, respectively. 
Significantly more $(80 \%)$ of the non-inoculated control plants survived during the post vitro growth period when 'BAYFOLAN' (BAY) fertilization was applied. This effect of BAYfertilization observed in the control plants of this experiment does not correspond with the survival data of 60-70\%, which were recorded by IOPRI in the past years (Ginting 1993).

Mycorrhizal inoculation with either of the (V)AM fungi improved plant survival of the BAYfertilized plants up to $85-100 \%$, but this increase was not significantly different from the BAY-fertilized, non-inoculated control plants. The most effective (V)AM fungi concerning plant survival were Glomus manihot (M1) and Acaulospora mellea (M3) in the HA-fertilized treatments and Acaulospora appendicula (M4) in the BAY-fertilized treatments.

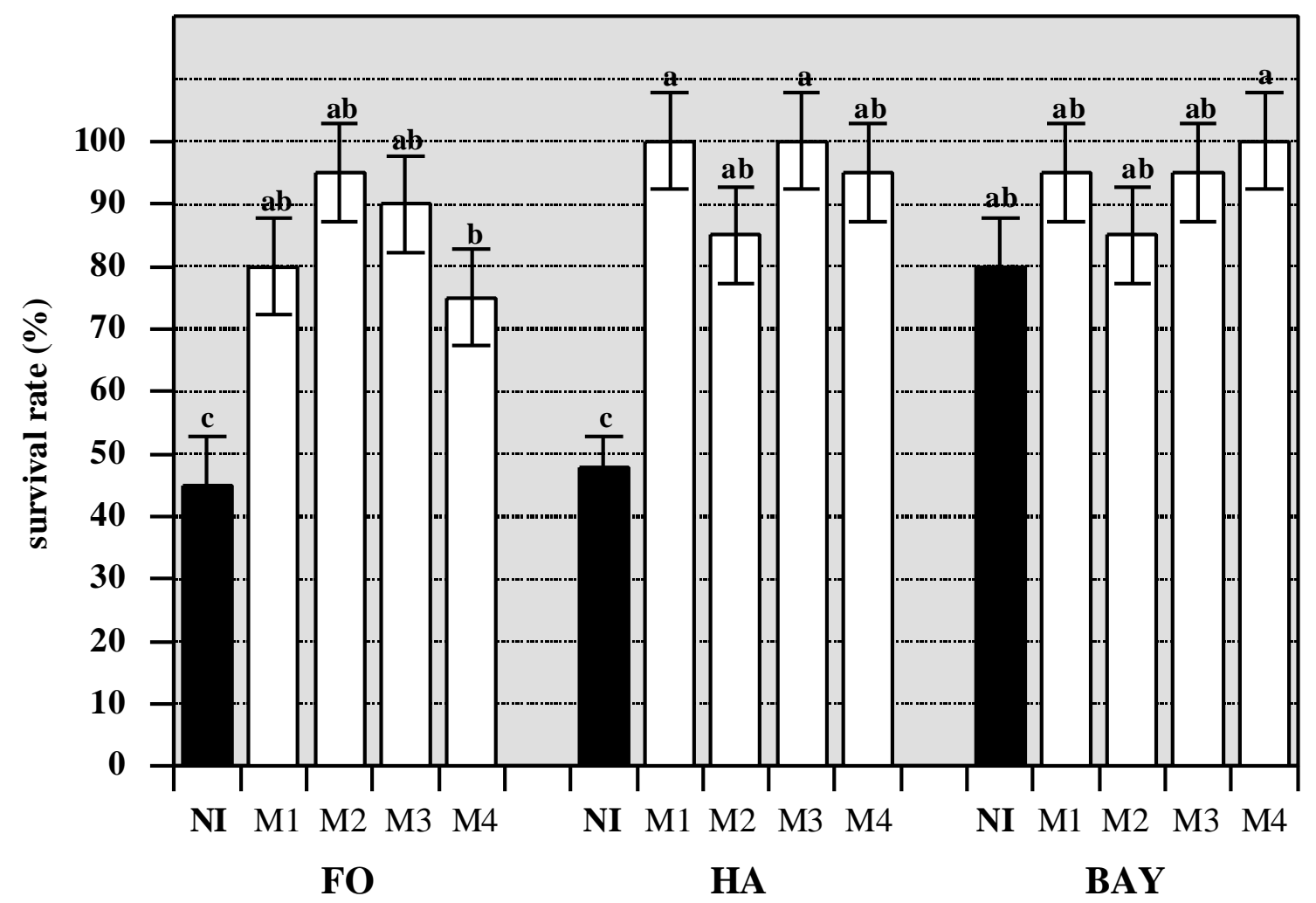

Figure 13: Interaction between (V)AMF inoculation (M1-M4) and fertilization (FO, HA, BAY) on the survival rate (\%) of oil palm plantlets after 3 months of post vitro growth. NI: non-inoculated plantlets. Vertical bars represent standard errors of the mean. Columns with different letters are significantly different at $P=0.05$ as indicated by LSD-test.

The positive effect of (V)AMF was not eliminated in plantlets which were able to obtain adequate plant nutrients from a fertilizer. In the case of hydroxy-apatite fertilization, mycorrhizal inoculation was highly effective in improving survival of the plants. The application of 'BAYFOLAN' increased the survival rate of the control plants; this effect was, however, improved when plants were inoculated. 
These results underscore the importance of an early inoculation and establishment of the symbiosis with mycorrhizal fungi for post vitro growth of the oil palm plantlets, even when these plants were fertilized with the complete soluble foliar 'BAYFOLAN'.

\subsubsection{Date of mortality}

The curves in Figure 14 represent the date of plant mortality during the 12-week experimental period, influenced by different (V)AM fungal isolates and fertilization treatments. The highest mortality rates $(55 \%)$ were observed in the non-inoculated control plants (NI), either nonfertilized (FO) or soil fertilized with hydroxy-apatite (HA). Plant mortality was reduced to 5$25 \%$ by the mycorrhizal inoculation in the non-fertilized treatments. The lowest mortality rates in this experiment were observed in the inoculated plantlets fertilized with HA. None of the plantlets inoculated with Glomus manihot (M1) and Acaulospora mellea (M3), respectively, died in this treatment. Two weeks after inoculation, 5\% and $15 \%$ of the plantlets inoculated with Acaulospora appendicula (M4) and Enthrophospora columbiana (M2), respectively, died. No further mortality of the inoculated plants in this treatment was observed after the second week of post vitro growth.

Receiving 'BAYFOLAN', 20\% of the non-inoculated control plants died up to the $6^{\text {th }}$ week. All inoculated plantlets in this treatment showed reduced mortality rates. Especially inoculation with Acaulospora appendicula (M4,) but also with Glomus manihot (M1) and Acaulospora mellea (M3), resulted in reduced plant mortality.

As discussed in Experiment 1, plant mortality was only observed during the first six weeks after transplanting. After this growth period, plantlets became more adapted to post vitro conditions. These results were also confirmed in this experiment, especially for the noninoculated (NI) control plants, independent of fertilization. In contrast, the date of mortality of all inoculated plants in this experiment was limited to the first three weeks after plants were transferred to polybags. During this period, (V)AM infection was initiated and fungi colonized the plants. Several studies on the early stages of post vitro acclimatization have reported this phase to be a critical step in the micropropagation cycle, at which the lack of beneficial microorganisms can adversely affect survival and growth of the micropropagated plantlets (Pons et al., 1983). 


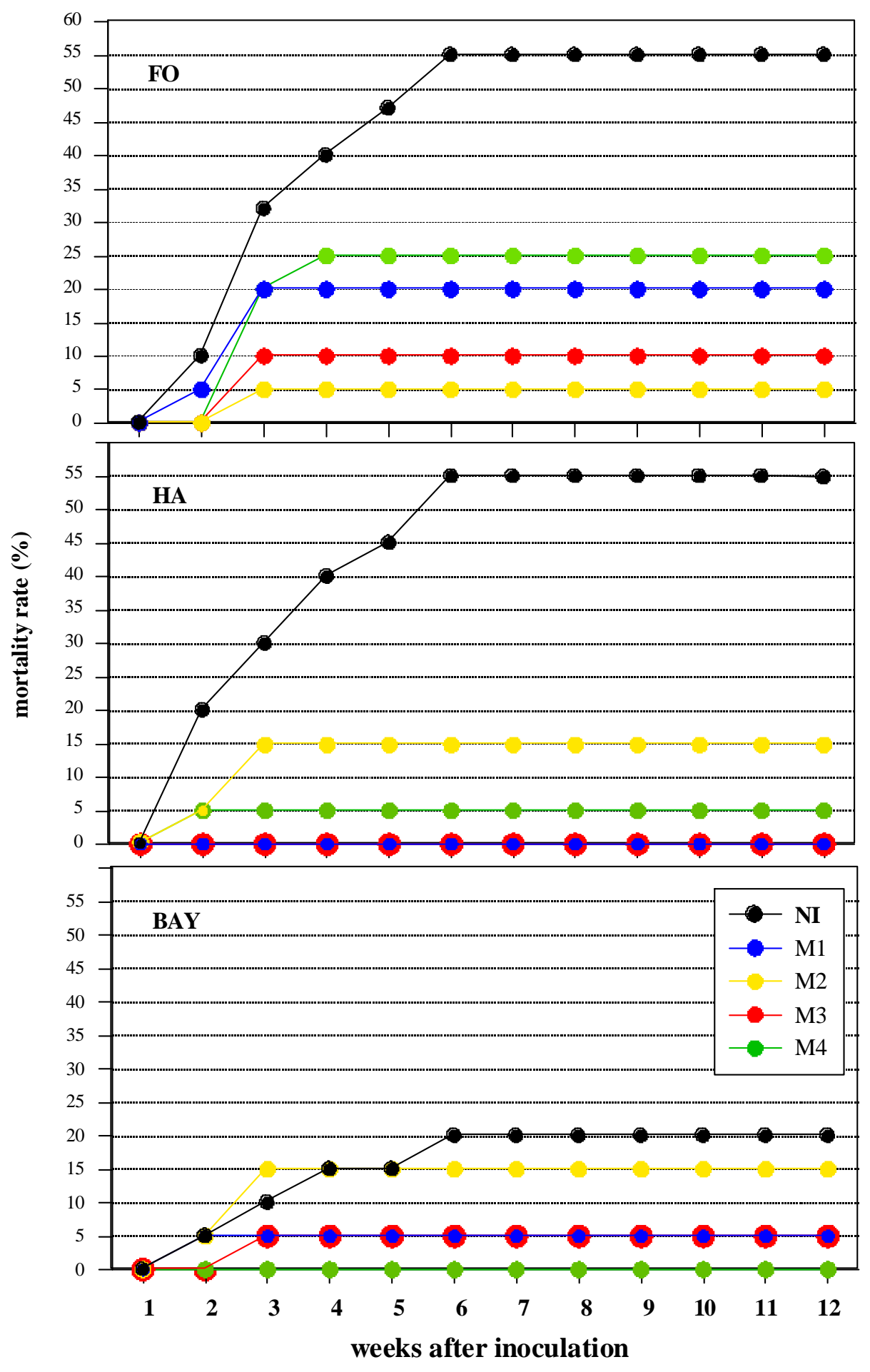

Figure 14: Effect of (V)AMF inoculation (M1-M4) and fertilization (FO, HA, BAY) on the mortality rate $(\%)$ of oil palm plantlets during 12 weeks of post vitro growth. NI: noninoculated plantlets.

\subsubsection{Post vitro plant development}

The effect of mycorrhizal inoculation on the post vitro development of oil palm plantlets was characterized by monitoring the shoot length and number of leaves at two-week intervals during the experimental period. The most important results are discussed in the following. 


\subsubsection{Shoot length}

The (V)AMF inoculation significantly affected shoot length increase in this experiment (Table 25). The main effect of inoculation became significant from the $8^{\text {th }}$ week after plants were transplanted and lasted until the end of the experiment. Fertilization significantly affected the shoot length during the last two weeks of the experiment. No interaction was observed between these two factors. The clones showed no significant differences in shoot length.

The total increase of shoot length, which was calculated for 3 months, confirmed that inoculation and fertilization were highly effective in promoting shoot development of the plantlets (Table 25). The interactions of these two main factors studied were also highly significant during this growth stage. Significant differences between the clones, either as a main factor or as interaction with the other two main factors, could not be found.

Table 25: ANOVA* of main effects and their interactions on the shoot length increase $(\mathrm{cm})$ of micropropagated oil palms measured at two-week intervals and calculated for the threemonth period of post vitro growth. The table represents effects when $\mathrm{P}$ values became significant

\begin{tabular}{|c|c|c|c|c|c|c|c|c|c|}
\hline \multirow{3}{*}{$\begin{array}{l}\text { ANOVA } \\
\end{array}$} & \multirow[b]{3}{*}{ DF } & \multicolumn{6}{|c|}{ Weeks after transplanting } & \multirow{2}{*}{\multicolumn{2}{|c|}{ Total growth }} \\
\hline & & \multicolumn{2}{|c|}{8} & \multicolumn{2}{|c|}{10} & \multicolumn{2}{|c|}{12} & & \\
\hline & & MQ & $\mathbf{P}$ & MQ & $\mathbf{P}$ & MQ & $\mathbf{P}$ & MQ & $\mathbf{P}$ \\
\hline Inoculation (1) & 4 & 43.3 & 0.008 & 64.6 & 0.000 & 104.5 & 0.000 & 82.04 & 0.000 \\
\hline Fertilization (2) & 2 & 32.5 & 0.066 & 59.6 & 0.005 & 111.4 & 0.000 & 96.34 & 0.000 \\
\hline Clone (3) & 4 & 10.4 & 0.467 & 8.4 & 0.528 & 4.4 & 0.761 & 10.19 & 0.052 \\
\hline $1 \times 2$ & 8 & 4.2 & 0.938 & 4.1 & 0.921 & 5.4 & 0.801 & 10.40 & 0.015 \\
\hline $1 \times 3$ & 16 & 8.4 & 0.757 & 6.8 & 0.830 & 6.9 & 0.755 & 3.9 & 0.489 \\
\hline $2 \times 3$ & 8 & 15.2 & 0.246 & 12.3 & 0.327 & 12.4 & 0.253 & 5.0 & 0.287 \\
\hline $1 \times 2 \times 3$ & 32 & 6.3 & 0.969 & 5.6 & 0.975 & 5.1 & 0.975 & 3.4 & 0.689 \\
\hline Error & 75 & 11.5 & & 10.5 & & 9.5 & & 4.0 & \\
\hline
\end{tabular}

*complete ANOVA, see Annex Table A4

Table 26 shows the mycorrhizal inoculation as a main effect on post vitro shoot development. At the beginning, the plantlets were not uniform in size but these differences were not significant. Until the second week after inoculation, all plants showed a similar shoot growth. From the $4^{\text {th }}$ to the $6^{\text {th }}$ week, shoot growth was improved in the inoculated treatments. Significant differences were detected for the first time 8 weeks after inoculation and lasted till the $12^{\text {th }}$ week. At the end of the experimental period, the inoculated plantlets were $19-24 \%$ taller than the non-inoculated control plants (NI). 
The total increase in shoot length, which was calculated for the whole 3-month experimental period, showed that the growth of inoculated plants in terms of shoot length was superior to that of the control plants (Table 26). Shoots of oil palms, which were inoculated with Glomus manihot (M1), Acaulospora mellea (M3) or Acaulospora appendicula (M4), were 63-70\% taller than the non-inoculated control plants. Plantlets inoculated with Enthrophospora columbiana (M2) showed a 55\% increase of shoot length.

Table 26: Mycorrhizal inoculation (M1-M4) as main effect on the shoot length $(\mathrm{cm})$ of oil palm plantlets during 12 weeks of post vitro growth. NI: non-inoculated control plants. Mean values in each column followed by different letters are significantly different at $P=0.05$ as indicated by LSD-test; ns: not significant.

\begin{tabular}{l|ccccccc|c}
\hline \hline & \multicolumn{7}{|c|}{ Weeks after transplanting } & \multirow{2}{*}{ Inoculation } \\
& $\mathbf{0}$ & $\mathbf{2}$ & $\mathbf{4}$ & $\mathbf{6}$ & $\mathbf{8}$ & $\mathbf{1 0}$ & $\mathbf{1 2}$ & Total \\
\hline NI & $13.5 \mathrm{~ns}$ & $14.2 \mathrm{~ns}$ & $15.0 \mathrm{~ns}$ & $15.9 \mathrm{~ns}$ & $17.0 \mathrm{~b}$ & $17.9 \mathrm{~b}$ & $19.1 \mathrm{~b}$ & $\mathbf{5 . 6} \mathbf{b}$ \\
$\mathbf{M 1}$ & $13.7 \mathrm{~ns}$ & $14.5 \mathrm{~ns}$ & $15.9 \mathrm{~ns}$ & $17.6 \mathrm{~ns}$ & $19.1 \mathrm{a}$ & $20.7 \mathrm{a}$ & $22.8 \mathrm{a}$ & $\mathbf{9 . 1} \mathbf{a}$ \\
$\mathbf{M 2}$ & $14.4 \mathrm{~ns}$ & $15.7 \mathrm{~ns}$ & $16.8 \mathrm{~ns}$ & $18.4 \mathrm{~ns}$ & $19.8 \mathrm{a}$ & $21.1 \mathrm{a}$ & $23.1 \mathrm{a}$ & $\mathbf{8 . 7} \mathbf{a}$ \\
$\mathbf{M 3}$ & $13.4 \mathrm{~ns}$ & $14.9 \mathrm{~ns}$ & $16.3 \mathrm{~ns}$ & $18.1 \mathrm{~ns}$ & $19.4 \mathrm{a}$ & $21.0 \mathrm{a}$ & $23.0 \mathrm{a}$ & $\mathbf{9 . 5} \mathbf{a}$ \\
$\mathbf{M 4}$ & $14.3 \mathrm{~ns}$ & $15.3 \mathrm{~ns}$ & $16.5 \mathrm{~ns}$ & $18.3 \mathrm{~ns}$ & $19.9 \mathrm{a}$ & $21.5 \mathrm{a}$ & $23.8 \mathrm{a}$ & $\mathbf{9 . 5} \mathbf{~ a}$ \\
\hline \hline
\end{tabular}

Effects of fertilization on shoot length as a main factor were observed 10 weeks after inoculation (Table 27). Plantlets in soil which was fertilized with sparingly soluble hydroxyapatite (HA) or soluble foliar 'BAYFOLAN' (BAY) were significantly taller than the nonfertilized oil palms (FO). Significant differences between plantlets fertilized with HA or BAY could not be found in this study. The total increase in shoot length, which was calculated for the whole experimental period, confirmed that plant growth was improved by HA or BAY fertilization.

Table 27: Fertilization (FO, HA, BAY) as main effect on the shoot length $(\mathrm{cm})$ of oil palm plantlets during 12 weeks of post vitro growth. Mean values in each column followed by different letters are significantly different at $P=0.05$ as indicated by LSD-test; ns: not significant.

\begin{tabular}{l|ccccccc|c}
\hline \hline & \multicolumn{7}{|c|}{ Weeks after transplanting } & \multirow{2}{*}{ Total } \\
\hline Fertilization & $\mathbf{0}$ & $\mathbf{2}$ & $\mathbf{4}$ & $\mathbf{6}$ & $\mathbf{8}$ & $\mathbf{1 0}$ & $\mathbf{1 2}$ & ( \\
\hline HO & $13.7 \mathrm{~ns}$ & $14.7 \mathrm{~ns}$ & $15.8 \mathrm{~ns}$ & $17.1 \mathrm{~ns}$ & $18.1 \mathrm{~ns}$ & $19.2 \mathrm{~b}$ & $20.6 \mathrm{~b}$ & $\mathbf{6 . 9} \mathbf{b}$ \\
HA & $14.0 \mathrm{~ns}$ & $15.1 \mathrm{~ns}$ & $16.5 \mathrm{~ns}$ & $18.0 \mathrm{~ns}$ & $19.6 \mathrm{~ns}$ & $21.2 \mathrm{a}$ & $23.2 \mathrm{a}$ & $\mathbf{9 . 2} \mathbf{a}$ \\
BAY & $13.9 \mathrm{~ns}$ & $14.9 \mathrm{~ns}$ & $16.1 \mathrm{~ns}$ & $17.9 \mathrm{~ns}$ & $19.5 \mathrm{~ns}$ & $20.9 \mathrm{a}$ & $23.2 \mathrm{a}$ & $\mathbf{9 . 3} \mathbf{a}$ \\
\hline \hline
\end{tabular}


The interaction between inoculation and fertilization on total shoot length increase $(\mathrm{cm})$ is demonstrated in Figure 15. The significantly lowest increase in shoot length during the 3month growth period was observed in the non-inoculated control plants (NI) which were nonfertilized (FO) or had received hydroxy-apatite (HA). Control plants, which were fertilized with 'BAYFOLAN' (BAY), showed an increased shoot growth which was significantly higher than that of the non-fertilized, non-inoculated (NI) plants.

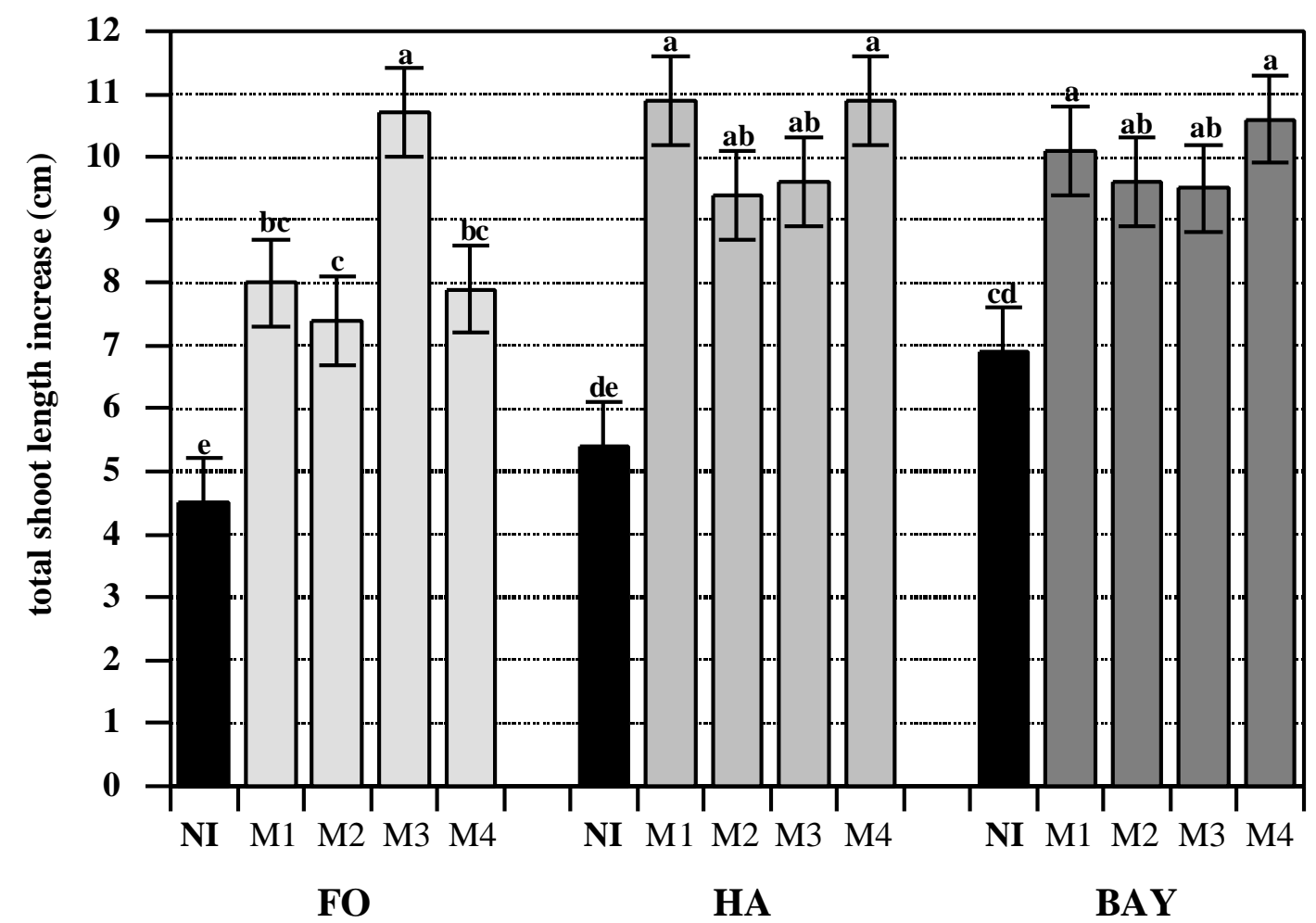

Figure 15: Interactions between fertilization (FO, HA, BAY) and inoculation (M1-M4) on the total shoot length increase $(\mathrm{cm})$ of oil palm plantlets after 12 weeks of post vitro growth. NI: non-inoculated plantlets. Vertical bars represent standard errors of the mean. Columns with different letters are significantly different at $P=0.05$ as indicated by LSD-test.

Mycorrhizal inoculation of the young plants resulted in improved shoot development (Figure 15). The shoot length of the non-fertilized plantlets was significantly increased by mycorrhizal inoculation. Especially plantlets which were inoculated with Acaulospora mellea (M3) showed an increase in shoot length which was similar to that of most inoculated plants in the HA- and BAY-fertilized treatments. This effect confirmed the high efficiency of Acaulospora mellea.

The highest increment in shoot length was observed in plants which received HA-fertilization and were either inoculated with Glomus manihot (M1) or Acaulospora appendicula (M4). (V)AMF inoculation of the 'BAYFOLAN' fertilized plants resulted in significantly higher 
shoot length increment. In the presence of HA or BAY, the (V)AMF species all performed similarly.

\subsubsection{Number of leaves}

Mycorrhizal inoculation significantly influenced the leaf development 6 weeks after inoculation until the end of the experimental period (Table 28). Slight differences in the number of leaves in the fertilization treatments were detected from the $4^{\text {th }}$ until the $10^{\text {th }}$ week. Interaction between these factors was observed between 10 and 12 weeks after transplanting.

The total increase in number of leaves during the experimental period confirmed the positive effect of mycorrhizal inoculation as a main factor as well as the interaction with fertilization regarding plant development. The clones showed no significant differences in the number of leaves during this growth period.

Table 28: $\mathrm{P}$ values of the ANOVA* of main effects and their interactions on the number of leaves of micropropagated oil palms measured at two-week intervals and calculated as total value for the three-month period of post vitro growth.

\begin{tabular}{lc|ccccccc|c}
\hline \hline & & \multicolumn{7}{|c|}{ Weeks after transplanting } & \\
ANOVA & DF & $\mathbf{0}$ & $\mathbf{2}$ & $\mathbf{4}$ & $\mathbf{6}$ & $\mathbf{8}$ & $\mathbf{1 0}$ & $\mathbf{1 2}$ & Total \\
\hline & & & & & & & & & \\
Inoculation (1) & 4 & 0.385 & 0.152 & 0.056 & $\mathbf{0 . 0 2 8}$ & $\mathbf{0 . 0 0 5}$ & $\mathbf{0 . 0 0 7}$ & $\mathbf{0 . 0 0 0}$ & $\mathbf{0 . 0 0 0}$ \\
Fertilization (2) & 2 & 0.463 & 0.959 & $\mathbf{0 . 0 2 5}$ & $\mathbf{0 . 0 0 0}$ & $\mathbf{0 . 0 0 0}$ & $\mathbf{0 . 0 0 4}$ & 0.121 & 0.226 \\
Clone (3) & 4 & 0.433 & 0.273 & 0.307 & 0.190 & 0.140 & 0.453 & 0.107 & 0.473 \\
& & & & & & & & & \\
1 x 2 & 8 & 0.240 & 0.350 & 0.056 & 0.059 & 0.084 & $\mathbf{0 . 0 4 8}$ & $\mathbf{0 . 0 1 3}$ & $\mathbf{0 . 0 1 9}$ \\
1 x 3 & 16 & 0.100 & 0.146 & 0.466 & 0.481 & 0.616 & 0.964 & 0.845 & 0.801 \\
2 x 3 & 8 & 0.091 & 0.054 & 0.518 & 0.832 & 0.597 & 0.490 & 0.940 & 0.740 \\
& & & & & & & & & \\
1 x 2 x 3 & 32 & 0.384 & 0.256 & 0.333 & 0.885 & 0.958 & 0.850 & 0.84 & 0.354 \\
\hline \hline
\end{tabular}

*complete ANOVA, see Annex Table A5

As ist is seen in Table 29 all plants had nearly the same number of leaves at time of transplanting. The leaf development during the first two weeks of the experimental period was in general minor, but some of the inoculated plants developed new leaves after the $2^{\text {nd }}$ and $4^{\text {th }}$ week. Significant differences in leaf development between inoculated and non-inoculated (NI) plants were estimated after six weeks of post vitro growth. This positive effect of mycorrhizal inoculation lasted until the end of the experimental period. 
Table 29: Mycorrhizal inoculation (M1-M4) as a main effect on leaf number of micropropagated oil palms during 12 weeks of post vitro growth. NI: non-inoculated control plants. Means in each column followed by different letters are significantly different at $(P=0,05)$ as indicated by LSD-test; ns:not significant.

\begin{tabular}{l|ccccccc|c}
\hline \hline \multirow{2}{*}{ Inoculation } & $\mathbf{0}$ & $\mathbf{2}$ & $\mathbf{4}$ & $\mathbf{6}$ & $\mathbf{8}$ & $\mathbf{1 0}$ & $\mathbf{1 2}$ & Total \\
\hline NI & $\mathbf{3 . 9} \mathbf{~ n s}$ & $\mathbf{3 . 9} \mathbf{~ n s}$ & $\mathbf{4 . 0} \mathbf{~ n s}$ & $\mathbf{4 . 2} \mathbf{b}$ & $\mathbf{4 . 4} \mathbf{b}$ & $\mathbf{4 . 7} \mathbf{~ b}$ & $\mathbf{4 . 8} \mathbf{~ b}$ & $\mathbf{0 . 9} \mathbf{~ b}$ \\
$\mathbf{M 1}$ & $4.0 \mathrm{~ns}$ & $4.1 \mathrm{~ns}$ & $4.4 \mathrm{~ns}$ & $4.7 \mathrm{a}$ & $5.0 \mathrm{a}$ & $5.3 \mathrm{a}$ & $6.1 \mathrm{a}$ & $2.0 \mathrm{a}$ \\
$\mathbf{M 2}$ & $3.9 \mathrm{~ns}$ & $3.9 \mathrm{~ns}$ & $4.4 \mathrm{~ns}$ & $4.6 \mathrm{a}$ & $4.8 \mathrm{a}$ & $5.3 \mathrm{a}$ & $6.1 \mathrm{a}$ & $2.2 \mathrm{a}$ \\
$\mathbf{M 3}$ & $3.9 \mathrm{~ns}$ & $4.1 \mathrm{~ns}$ & $4.4 \mathrm{~ns}$ & $4.6 \mathrm{a}$ & $4.8 \mathrm{a}$ & $5.1 \mathrm{a}$ & $6.1 \mathrm{a}$ & $2.1 \mathrm{a}$ \\
$\mathbf{M 4}$ & $3.8 \mathrm{~ns}$ & $4.0 \mathrm{~ns}$ & $4.3 \mathrm{~ns}$ & $4.5 \mathrm{ab}$ & $4.7 \mathrm{ab}$ & $5.2 \mathrm{a}$ & $6.0 \mathrm{a}$ & $2.1 \mathrm{a}$ \\
\hline \hline
\end{tabular}

At the end of the experimental period, the development of a significantly higher number of leaves due to mycorrhizal inoculation was observed in all fertilization treatments (Figure 16) Plantlets which received hydroxy-apatite (HA) and were also inoculated with Enthrophospora columbiana (M2) or Acaulospora mellea (M3) produced the highest number of leaves during this growth period.

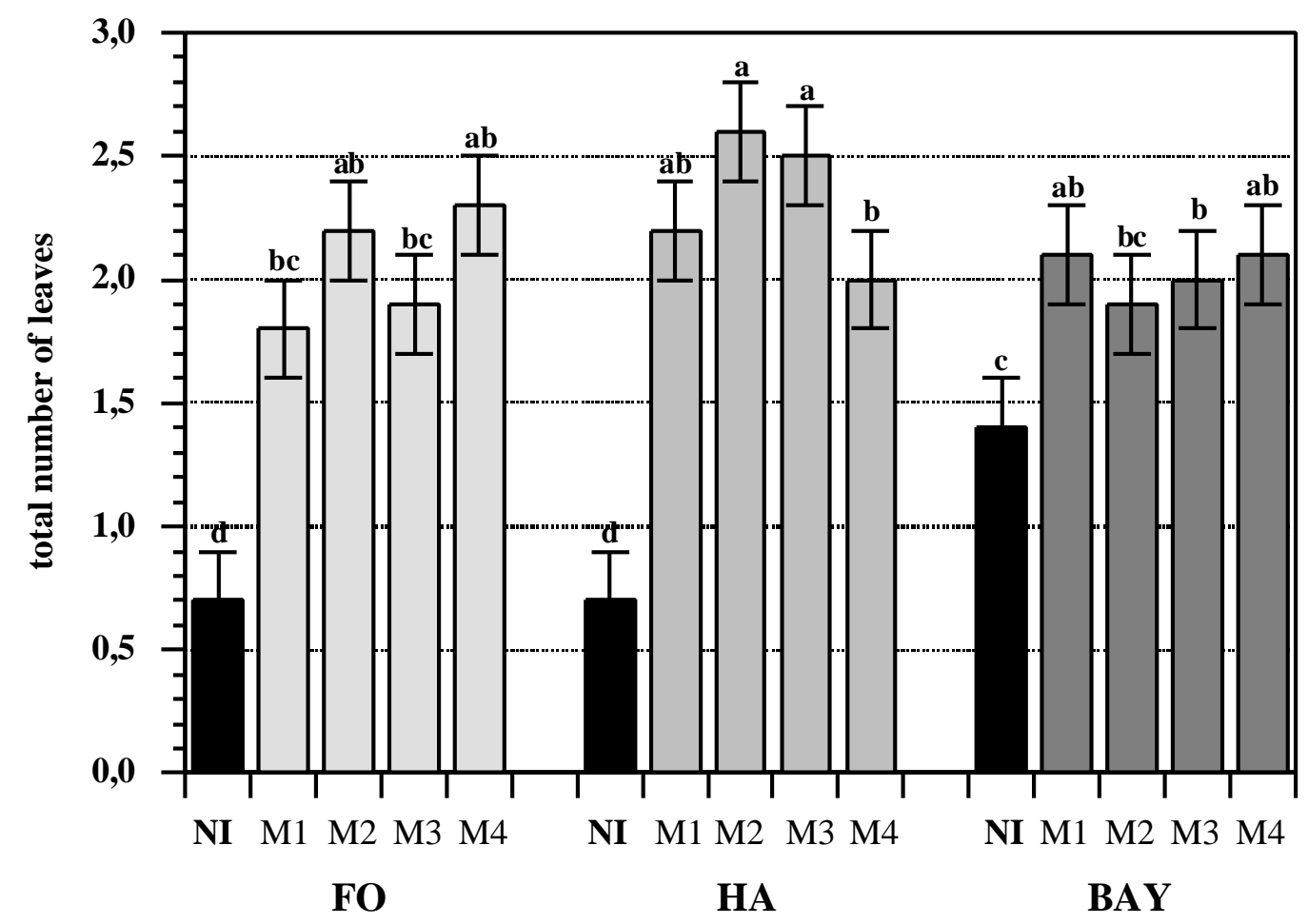

Figure 16: Interactions between fertilization (FO, HA, BAY) and inoculation (M1-M4) on the leaf number of micropropagated oil palms during 12 weeks of post vitro growth. NI: noninoculated control plants. Vertical bars represent standard errors of the mean. Columns with different letters are significantly different at $P=0.05$ as indicated by LSD-test. 
The calculation of the total increase in leaf number of the non-inoculated control plants confirmed the greater benefit of mycorrhizal inoculation for post vitro leaf development compared with fertilization. 'BAYFOLAN' foliar fertilization, which is used at IOPRI for the nourishment of the young palms, significantly improved leaf development of the noninoculated (NI) control plants. As in the case of shoot length, mycorrhizal inoculation with either of the fungal isolates was more effective on leaf development than fertilization, which resulted in 2 to 3 times more leaves on the HA- and nearly 50\% more leaves on the BAYfertilized plants.

\subsubsection{Plant growth parameter after harvesting}

In this experiment plants were harvested at two different growth stages to investigate the effect of mycorrhizal inoculation and fertilization on the post vitro plant development. The first harvest was carried out 6 weeks and the second harvest 12 weeks after transplanting. The results of these investigations were discussed in the following according to the date of harvest. ANOVA tables of the first harvest are presented in the Annex.

\subsubsection{Shoot and root fresh weight root:shoot fresh weight ratio}

After six weeks of post vitro growth the shoot fresh weight was highly affected by mycorrhizal inoculation (Table 30). At this early growth stage all inoculated oil palm plantlets showed significantly higher shoot fresh weight compared to the non-inoculated (NI) control plants.

The root fresh weight and the R:S ratio were not affected by either of the experimental factors at this growth stage (Table A7). The five different clones were treated as covariates and showed no significant differences in either of the growth parameters.

Table 30: Mycorrhizal inoculation (M1-M4) as a main effect on the shoot fresh weight (g) of oil palm plantlets after 6 weeks of post vitro growth. NI: non-inoculated plantlets. Means with different letters are significantly different at $(P=0,05)$ as indicated by LSD-test.

\begin{tabular}{l|ccccc}
\hline \hline & NI & M1 & M2 & M3 & M4 \\
\hline SFW (g) & $0.89 \mathrm{~b}$ & $1.23 \mathrm{a}$ & $1.11 \mathrm{a}$ & $1.10 \mathrm{a}$ & $1.18 \mathrm{a}$ \\
& & & & & \\
\hline \hline
\end{tabular}

After 12 weeks of post vitro growth the shoot fresh weight and the R:S ratio were highly influenced by mycorrhizal inoculation (Table A8). The root fresh weight was not affected by either of the experimental factors in this study. There were no significant interactions between 
the main factors. The clones showed no significant differences in either of the measured parameters.

Table 31: Mycorrhizal inoculation (M1-M4) as a main effect on the shoot fresh weight (g) and root:shoot (R:S) ratio of oil palm plantlets after 12 weeks of post vitro growth. NI: noninoculated plantlets. Means in each column with different letters are significantly different at $(P=0,05)$ as indicated by LSD-test.

\begin{tabular}{l|c|c}
\hline \hline Inoculation & Shoot fresh weight $(\mathbf{g})$ & R:S ratio \\
\hline NI & $\mathbf{1 . 7 4 ~ b}$ & $\mathbf{0 . 3 2} \mathbf{~ b}$ \\
M1 & $2.83 \mathrm{a}$ & $0.20 \mathrm{a}$ \\
M2 & $2.85 \mathrm{a}$ & $0.20 \mathrm{a}$ \\
M3 & $2.87 \mathrm{a}$ & $0.23 \mathrm{a}$ \\
M4 & $2.97 \mathrm{a}$ & $0.19 \mathrm{a}$ \\
\hline \hline
\end{tabular}

At the end of the experimental period all (V)AMF which were used for inoculation significantly increased shoot fresh weight compared to the non-inoculated (NI) plants (Table 31). The root:shoot (R:S) ratio was modified by inoculation with (V)AMF and was generally lower in the inoculated treatments (Table 31). The lowest R:S ratio was observed in plantlets inoculated with Acaulospora appendicula (M4). Significant differences compared to the noninoculated control plants were observed in all inoculated treatments. According to AzcónAguilar and Barea (1997) have mycorrhizal colonized plants a lower root:shoot ratio in response to a greater increment of shoot mass relative to root mass.

\subsubsection{Dry matter}

Six weeks after transplanting, mycorrhizal inoculation increased the dry matter accumulation (Figure 17). The interaction between the two main factors, inoculation and fertilization methods, were not significant at that stage of plant development. The used clones were treated as covariates and showed no significant differences concerning plant dry weight (Table A9).

The most effective (V)AM fungus was Glomus manihot (M1) (Figure 17). Acaulospora mellea (M3) and Acaulospora appendicula (M4), however, also significantly improved shoot dry weight compared to the non-inoculated (NI) control plants at that growth stage. Enthrophospora columbiana (M2) also increased shoot growth but this fungus was significantly less effective than Glomus manihot. 


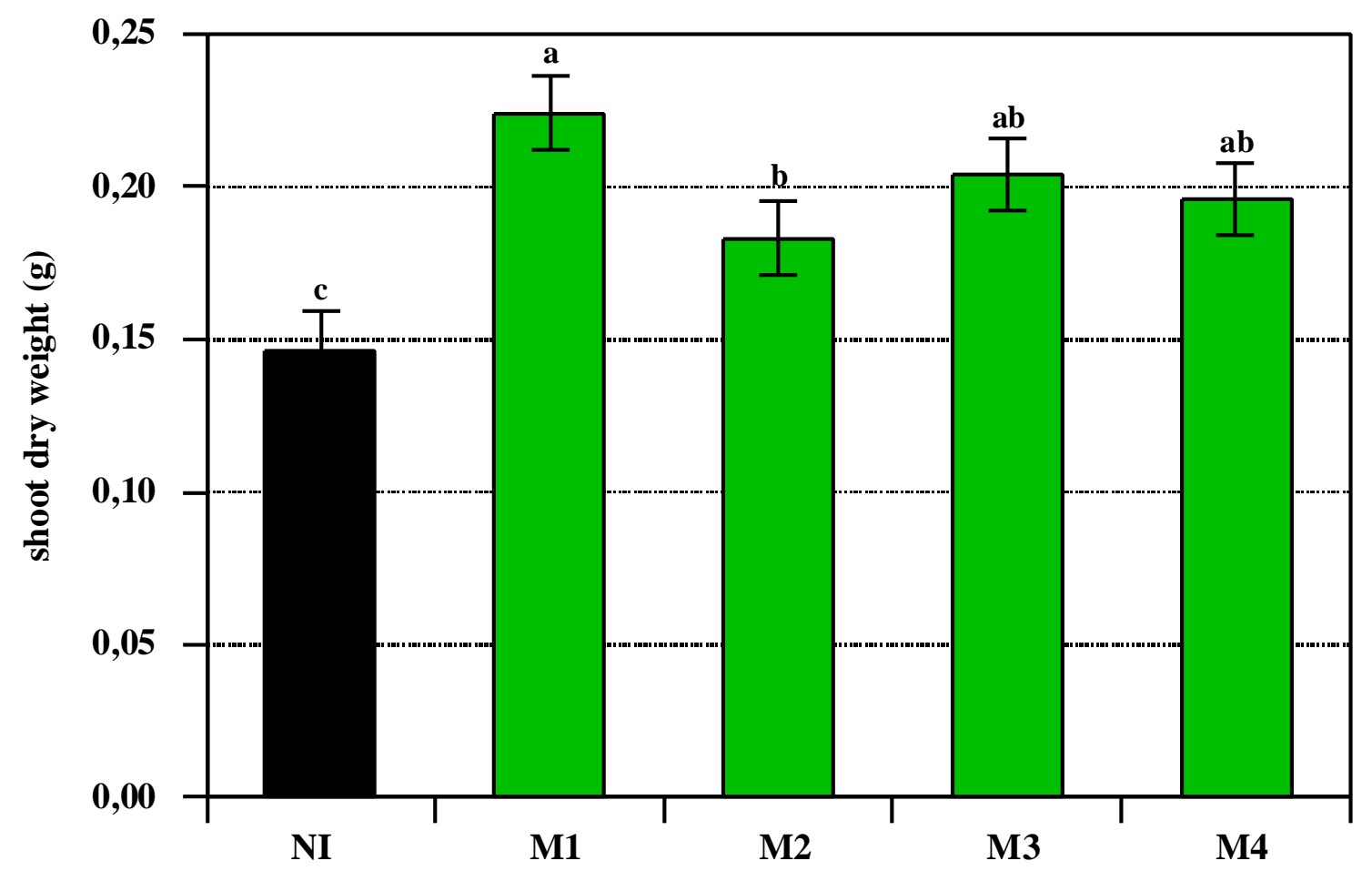

Figure 17: Mycorrhizal inoculation (M1-M4) as a main effect on shoot dry weight (g) of oil palm plantlets after 6 weeks of post vitro growth. NI: non-inoculated plantlets. Vertical bars represent standard errors of the mean. Columns with different letters are significantly different at $P=0.05$ as indicated by LSD-test.

After 12 weeks of post vitro growth, mycorrhizal inoculation and fertilization methods were highly effective in increasing the dry matter formation (Table 32). The interactions between these two factors also increased the dry weight of shoots significantly. Differences between the used clones were not detected. The interactions of the three main factors studied were not significant, either.

Table 32: ANOVA of main effects and their interaction on the shoot dry weight $(\mathrm{g})$ of micropropagated oil palms after 12 weeks of post vitro growth.

\begin{tabular}{l|c|c|c}
\hline \hline ANOVA & DF & MQ & P \\
\hline Inoculation & 4 & 0.243 & $\mathbf{0 . 0 0 0}$ \\
Fertilization & 2 & 0.115 & $\mathbf{0 . 0 0 0}$ \\
Clone & 4 & 0.013 & 0.101 \\
& & & \\
Inoculation x Fertilization & 8 & 0.017 & $\mathbf{0 . 0 1 1}$ \\
Inoculation x Clone & 16 & 0.005 & 0.689 \\
Fertilization x Clone & 8 & 0.007 & 0.403 \\
Inoculation x Fertilization x Clone & 32 & 0.005 & 0.746 \\
Error & 74 & 0.006 & \\
\hline \hline
\end{tabular}


The interactions between mycorrhizal inoculation and fertilization regarding plant growth are demonstrated in Figure 17. Without mycorrhizal inoculation and fertilization the plants grew very poorly. The lowest shoot dry weight was observed in the non-inoculated (NI) plants of all fertilization treatments. 'BAYFOLAN' (BAY), as a soluble foliar fertilization, improved the dry weight of the non-inoculated plants significantly compared to the control plants of the non-fertilized (FO) or hydroxy-apatite (HA) fertilized treatments.

The shoot growth was highly improved by (V)AMF inoculation in all fertilization treatments compared to the non-inoculated control plants (Figure 17). The only exceptions were Enthrophospora columbiana (M2) and Acaulospora mellea (M3) inoculated plantlets of the non-fertilized treatments (FO). The dry weight of these plants was not significantly improved to that of the non-inoculated control plants which received "BAYFOLAN".

The highest and most similar shoot dry weight was found in the inoculated plantlets which were fertilized either with hydroxy-apatite (HA) or "BAYFOLAN" (Figure 17). Mycorrhizal inoculation together with fertilization ensured maximum growth of the oil palm plantlets. Reports that (V)AM fungi respond strongly to soil fertilization by tricalcium phosphate seem to indicate an improved use of $\mathrm{P}$ from this relatively insoluble fertilizer (Cabala-Rosand and Wild, 1982; Bolan et al., 1987; Lange-Ness and Vlek, 2000).

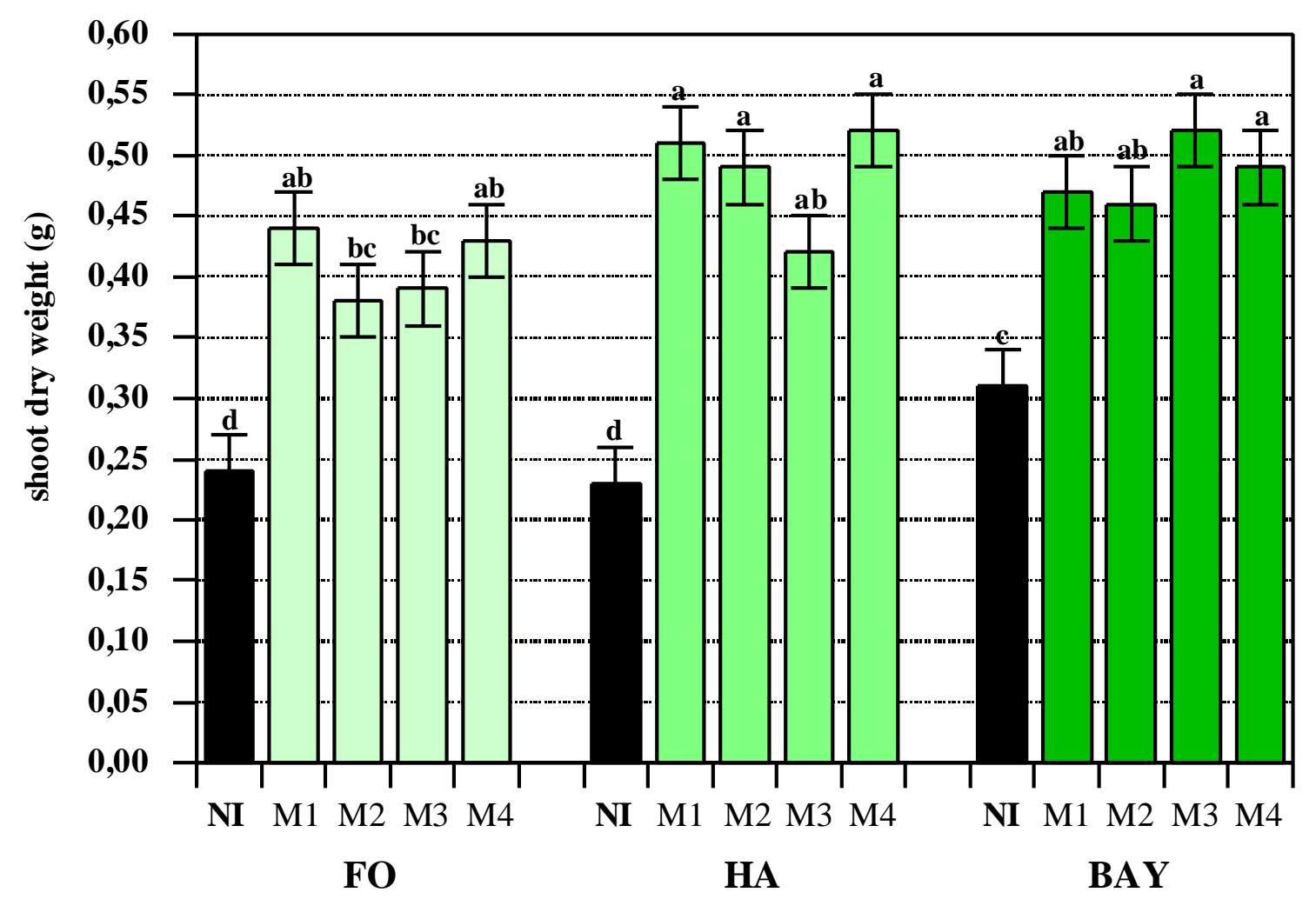

Figure 17: Interaction between inoculation (M1-M4) and fertilization (FO, HA, BAY) on the shoot dry weight $(\mathrm{g})$ of oil palm plantlets after 12 weeks of post vitro growth. NI: noninoculated plantlets. Vertical bars represent standard errors of the mean. Columns with different letters are significantly different at $P=0.05$ as indicated by LSD-test. 
The increase in oil palm growth obtained in this experiment by the combination of mycorrhizal inoculation and fertilization compaired to the non-inoculated plants reflected the low P uptake capacity of the oil palm roots and the high mycorrhiza dependency of the oil palms. In experiments of Blal et al. (1990) micropropagated oil palms grew very poorly in two tropical, acid P-fixing soils without mycorrhizal infection, although adding phosphate fertilizers to the non-inoculated control plants led to a significant increase in dry matter production. However, the authors concluded that this fertilization effect on plant growth was not as important as that of (V)AMF inoculation without fertilization. The combination of mycorrhiza and fertilization resulted in maximum growth of the oil palms.

The growth of plants which received "BAYFOLAN" fertilization was also significantly improved by mycorrhizal inoculation. 'BAYFOLAN', a foliar spray, was directly applied to the shoots. The results of this experiment indicate that the beneficial effect of inoculation was not reduced by BAY fertilization. This may be due to the shoot application of this fertilizer. There are no literature reports for comparison with these results.

The growth promoting effect of mycorrhizal inoculation on shoot and leaf development already mentioned in this study resulted in significantly higher shoot dry weights in most of the inoculated oil palm plantlets. The percentage of root infection by the tested (V)AM fungi was relatively low, but the effect on growth improvement was significant. Pinochet et al. (1997) also reports that the percentage of mycorrhizal colonization of Gl. interadices was relatively low at $27 \%$, although plant growth in mycorrhizal treatments was significantly stronger than in non-mycorrhizal treatments for all growth characteristics (in terms of shoot length, number of leaves, fresh and dry weights).

\subsubsection{Nutrient concentration and uptake}

\subsection{Phosphorus}

After six weeks of post vitro growth, the P concentration (mg/g plant) and uptake (mg/plant) were increased by mycorrhizal inoculation (Table 33). The fertilization as a main factor and the interaction between the two main factors had no significant effect on P concentration and uptake at this growth stage (Table A 10). For the analysis of variance of the first harvest, the clones were treated as co-variates and no differences were detected.

As a consequence of better growth (Figure 17, shoot dry weights, $1^{\text {st }}$ harvest) the phosphate uptake of the inoculated plants was about 2 times higher compared with the non-inoculated (NI) control plants (Table 33). 
Table 33: Mycorrhizal inoculation (M1-M4) as a main effect on $\mathrm{P}$ concentration $(\mathrm{mg} / \mathrm{g})$ and $\mathrm{P}$ uptake (mg/plant) in shoots of oil palm plantlets after 6 weeks of post vitro growth. NI: noninoculated plantlets. Columns with different letters are significantly different at $P=0.05$ as indicated by LSD-test.

\begin{tabular}{l|c|c}
\hline \hline Inoculation & P concentration $(\mathbf{m g} / \mathbf{g})$ & P uptake $(\mathbf{m g} /$ plant) \\
\hline NI & $1.46 \mathrm{~b}$ & $0.22 \mathrm{~b}$ \\
M1 & $2.07 \mathrm{a}$ & $0.45 \mathrm{a}$ \\
M2 & $2.28 \mathrm{a}$ & $0.41 \mathrm{a}$ \\
M3 & $2.13 \mathrm{a}$ & $0.43 \mathrm{a}$ \\
M4 & $2.26 \mathrm{a}$ & $0.44 \mathrm{a}$ \\
\hline \hline
\end{tabular}

After 3 months of post vitro growth, mycorrhizal inoculation and fertilization as main factors as well as their interactions affected the phosphate concentration and uptake of the young oil palms (Table 34). However, there were no differences between the clones concerning the parameters analysed in this experiment.

Table 34: ANOVA of main effects and their interactions on the $\mathrm{P}$ concentration $(\mathrm{mg} / \mathrm{g})$ and $\mathrm{P}$ uptake (mg/plant) of micropropagated oil palm plantlets after 12 weeks of post vitro growth.

\begin{tabular}{|c|c|c|c|c|c|}
\hline \multirow[b]{2}{*}{ ANOVA } & \multirow[b]{2}{*}{ DF } & \multicolumn{2}{|c|}{$\begin{array}{c}\text { P concentration } \\
\text { (mg/g plant) }\end{array}$} & \multicolumn{2}{|c|}{$\begin{array}{l}\text { P uptake } \\
\text { (mg/plant) }\end{array}$} \\
\hline & & MQ & $\mathbf{P}$ & MQ & $\mathbf{P}$ \\
\hline Inoculation (1) & 4 & 2.966 & 0.000 & 2.142 & 0.000 \\
\hline Fertilization (2) & 2 & 0.850 & 0.000 & 1.039 & 0.000 \\
\hline Clone (3) & 4 & 0.056 & 0.439 & 0.093 & 0.089 \\
\hline $1 \times 2$ & 8 & 0,135 & 0.028 & 0.143 & 0.001 \\
\hline $1 \times 3$ & 16 & 0.035 & 0.874 & 0.026 & 0.772 \\
\hline $2 \times 3$ & 8 & 0.041 & 0.682 & 0.064 & 0.107 \\
\hline $1 \times 2 \times 3$ & 32 & 0.039 & 0.890 & 0.039 & 0.406 \\
\hline Error & 74 & 0.058 & & 0.037 & \\
\hline
\end{tabular}

The interactions between mycorrhizal inoculation and fertilization regarding phosphate concentration in oil palm shoots after 12 weeks of post vitro growth showed that the lowest $\mathrm{P}$ concentrations in this study are to be found in the non-inoculated (NI) control plants, independent of fertilization (Figure 18). 'BAYFOLAN' (BAY) fertilization improved the P concentration in the control plants but this increase was not significantly different from that of the non-fertilized (FO) or hydroxy-apatite (HA) fertilized NI plants. 
Mycorrhizal inoculation with either of the fungal isolates resulted in significantly increased phosphate concentrations compared to the non-inoculated (NI) control plants (Figure 18). The P concentrations in inoculated plants, either fertilized with hydroxy-apatite or 'BAYFOLAN', were more or less similar. The highest foliar $\mathrm{P}$ contents were observed in plants which received hydroxy-apatite and were inoculated with Acaulospora appendicula (M4) as well as in plants inoculated with Enthrophospora columbiana (M2), which were either fertilized with HA or 'BAYFOLAN'. The P concentrations in the inoculated oil palms which received no fertilization were lower, but not significantly different from most of the HA-or BAY-fertilized plants.

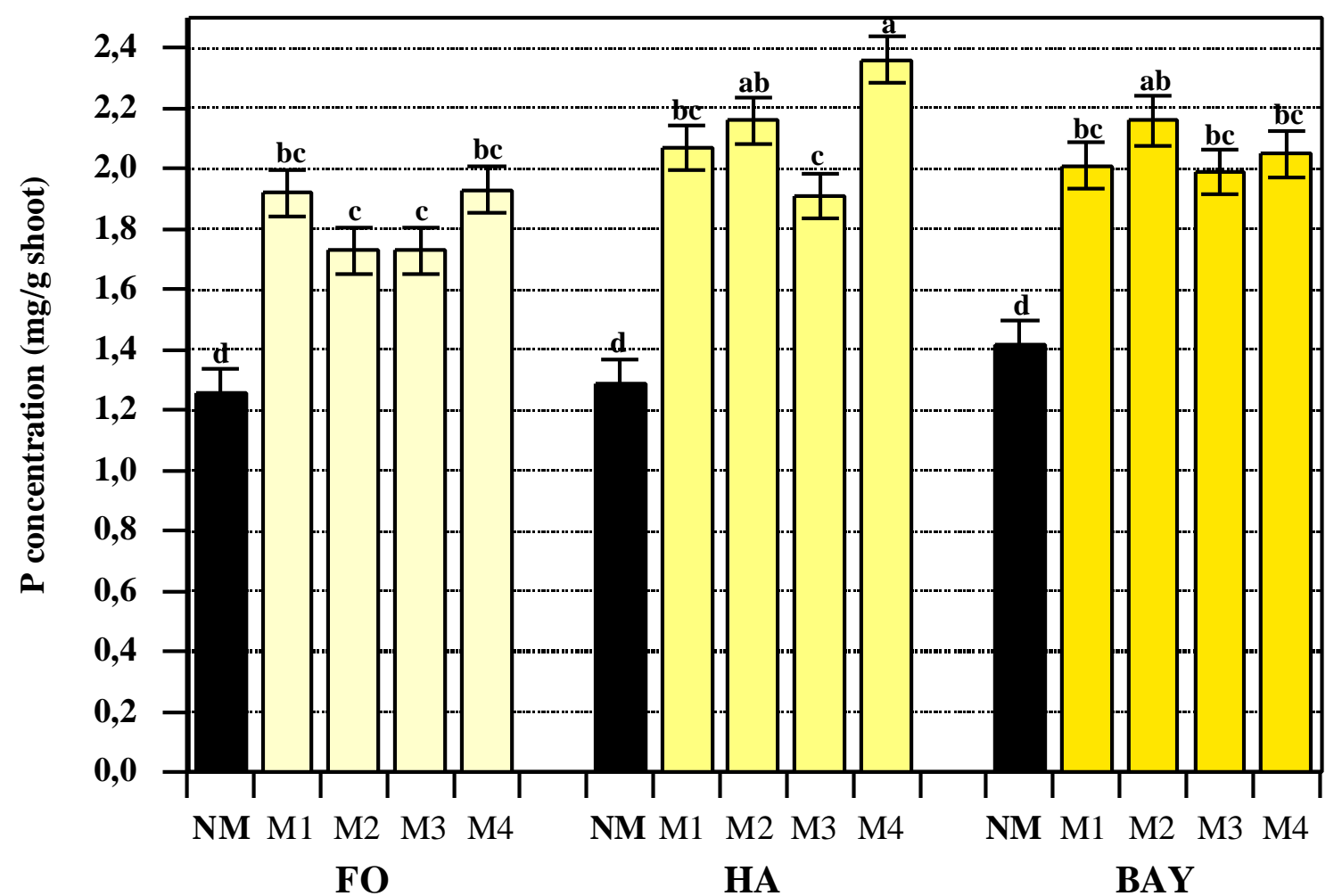

Figure 18: Interaction between inoculation (M1-M4) and fertilization (FO, HA, BAY) on the $\mathrm{P}$ concentration $(\mathrm{mg} / \mathrm{g}$ plant) of oil palm plantlets after 12 weeks of post vitro growth. NI: non-inoculated plantlets. Vertical bars represent standard errors of the mean. Columns with different letters are significantly different at $P=0.05$ as indicated by LSD-test.

Increase in growth following mycorrhization has been attributed to improvement in $\mathrm{P}$ translocation, suggesting that the growth stimulation of mycorrhizal plants can be explained by higher mineral $\mathrm{P}$ accumulation in foliar tissues. This can be seen even in the non-fertilized plants (FO), where dry weight of shoots seems to correlate with the foliar P concentrations of the young oil palms. Especially plants which were inoculated with Glomus manihot (M1) and Acaulospora appendicula (M4) showed higher shoot dry weights and P concentrations, which were comparable to most of the fertilized mycorrhizal plants. 
Mycorrhizal inoculation was also highly effective in improving the phosphate concentration of the hydroxy-apatite or 'BAYFOLAN' fertilized plants, which resulted in significantly higher shoot dry weights. In a study of Gaur et al. (1999), mycorrhizal inoculation at the weaning stage and $\mathrm{P}$ fertilization significantly affected shoot $\mathrm{P}$ content of Syngonium podophylum and Draceana sp., suggesting that the growth stimulation of mycorrhizal plants may be explained by higher mineral concentrations in foliar tissues.

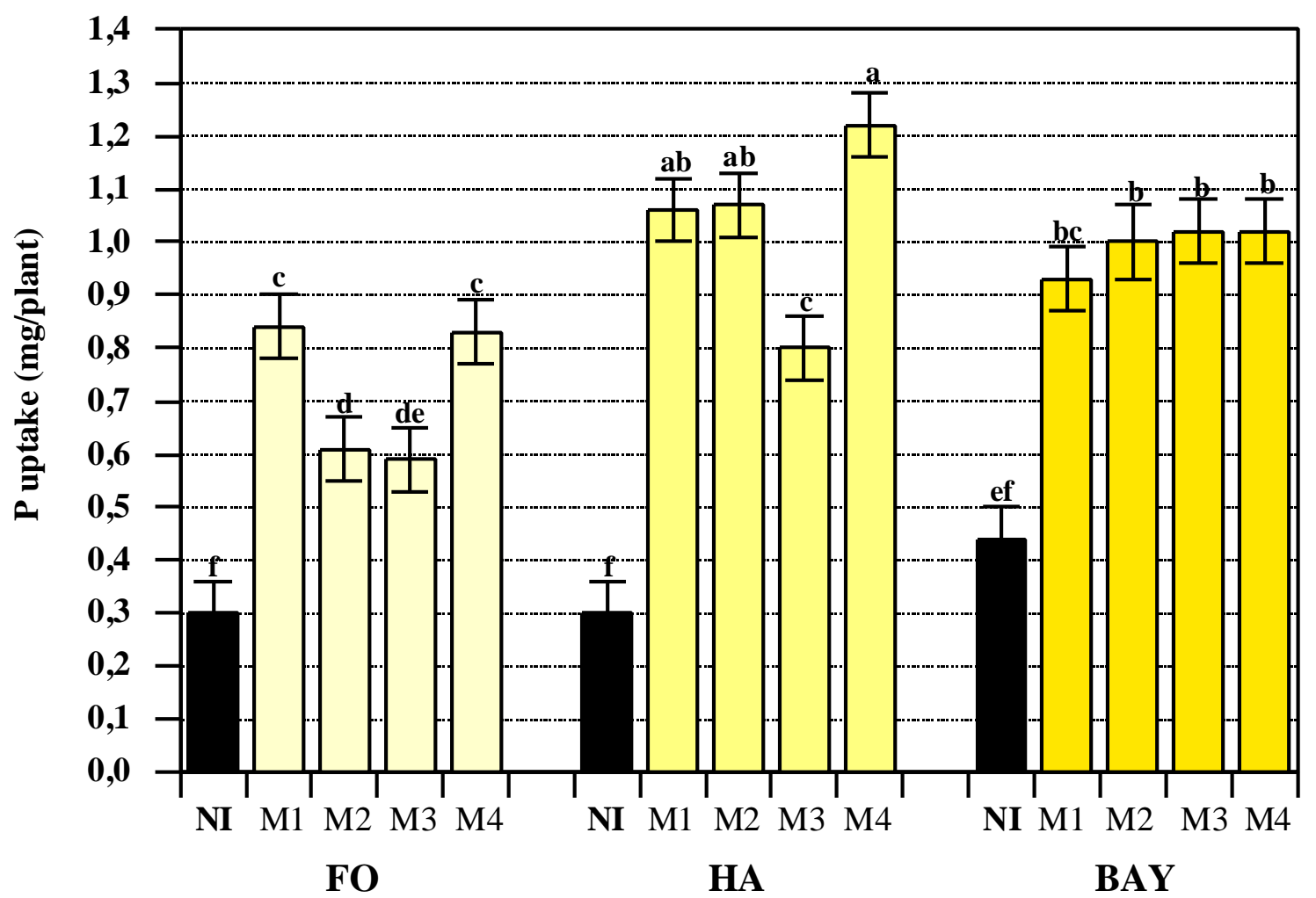

Figure 19: Interaction between inoculation (M1-M4) and fertilization (FO, HA, BAY) on P uptake (mg/ plant) of micropropagated oil palms after 12 weeks of post vitro growth. NI: noninoculated plantlets. Vertical bars represent standard errors of the mean. Columns with different letters are significantly different at $P=0.05$ as indicated by LSD-test.

The interactions between inoculation and fertilization demonstrate the high effectiveness of mycorrhizal inoculation on phosphate uptake (Figure 19). The highest phosphate uptake in this study was observed in the inoculated plants which were fertilized with the hardly soluble hydroxy-apatite (HA). Especially Acaulospora appendicula (M4) significantly increased P uptake of plants compared with all inoculated plants of the non-fertilized (FO) or 'BAYFOLAN' (BAY) fertilized treatments. According to these results it can be concluded that the fungal isolates used for inoculation are most effective on $\mathrm{P}$ uptake when plants are grown in HA-fertilized soil. Lange-Ness and Vlek (2000) demonstrated the ability of (V)AMF to dissolve P from sparingly soluble HA. 
"BAYFOLAN" fertilization improved the P uptake of the plantlets. This increase was not significantly different from the $\mathrm{P}$ uptake of the non-inoculated control plants of all fertilizer treatments. The effect of BAYFOLAN fertilization on $\mathrm{P}$ uptake was low, unless plantlets were inoculated.

\subsection{Potassium}

At the first harvest, main effects or interactions between factors regarding $\mathrm{K}$ concentrations were not observed. The K uptake of plants was highly affected by mycorrhizal inoculation (Table A11). The fertilization or interactions between the main factors considered were not significant regarding $\mathrm{K}$ uptake at this growth stage. The clones were treated as covariates, and showed no differences in the investigated parameters.

The K uptake of the inoculated plants was significantly increased compared to that of the noninoculated (NI) control plants (Table 35). Inoculated plants grew better during the first six weeks of the experimental period as shown in Figure 17. As a consequence of better growth, the $\mathrm{K}$ uptake of the mycorrhizal plants was significantly higher than that of the non-inoculated control plants.

Table 35: Mycorrhizal inoculation (M1-M4) as a main effect on $\mathrm{K}$ uptake (mg/plant) of oil palm plantlets after 6 weeks of post vitro growth. NI: non-inoculated plantlets. Columns with different letters are significantly different at $P=0.05$ as indicated by LSD-test; ns: not significant.

\begin{tabular}{l|ccccc}
\hline \hline & NI & M1 & M2 & M3 & M4 \\
\hline \hline K (mg/plant) & $3.65 \mathrm{~b}$ & $5.68 \mathrm{a}$ & $5.19 \mathrm{a}$ & $5.32 \mathrm{a}$ & $5.42 \mathrm{a}$ \\
& & & & & \\
\hline \hline
\end{tabular}

Twelve weeks after transplanting, the $\mathrm{K}$ concentrations (mg/g plant) and $\mathrm{K}$ uptake $(\mathrm{mg} / \mathrm{g}$ ) of the plants were highly affected by mycorrhizal inoculation and fertilization (Table 36). Interactions between inoculation and fertilization regarding $\mathrm{K}$ uptake were detected. The clones showed no significant differences in $\mathrm{K}$ concentration or uptake of the plants. 
Table 36: ANOVA of main effects and their interaction on the $\mathrm{K}$ concentration $(\mathrm{mg} / \mathrm{g})$ and $\mathrm{K}$ uptake (mg/plant) of micropropagated oil palms after 12 weeks of post vitro growth.

\begin{tabular}{|c|c|c|c|c|c|}
\hline \multirow[b]{2}{*}{ ANOVA } & \multirow[b]{2}{*}{ DF } & \multicolumn{2}{|c|}{$\begin{array}{c}\text { K concentration } \\
(\mathrm{mg} / \mathrm{g} \text { plant })\end{array}$} & \multicolumn{2}{|c|}{$\begin{array}{l}\text { K uptake } \\
\text { (mg/plant) }\end{array}$} \\
\hline & & MQ & $\mathbf{P}$ & MQ & $\mathbf{P}$ \\
\hline Inoculation (1) & 4 & 39.06 & 0.023 & 121.91 & 0.000 \\
\hline Fertilization (2) & 2 & 221.55 & 0.000 & 129.37 & 0.000 \\
\hline Clone (3) & 4 & 5.91 & 0.767 & 7.89 & 0.185 \\
\hline $1 \times 2$ & 8 & 20.86 & 0.135 & 17.87 & 0.000 \\
\hline $1 \times 3$ & 16 & 8.59 & 0.818 & 4.57 & 0.264 \\
\hline $2 \times 3$ & 8 & 9.13 & 0.685 & 5.77 & 0.152 \\
\hline $1 \times 2 \times 3$ & 32 & 13.38 & 0.437 & 6.86 & 0.115 \\
\hline Error & 74 & 12.92 & & 3.70 & \\
\hline
\end{tabular}

The interactions between mycorrhizal inoculation and fertilization regarding $\mathrm{K}$ uptake are presented in Figure 20. The lowest K uptake was detected in the non-inoculated (NI) control plants of the hydroxy-apatite (HA) or non-fertilized (FO) treatments. Fertilization with 'BAYFOLAN' (BAY) significantly increased K uptake of the control plants.

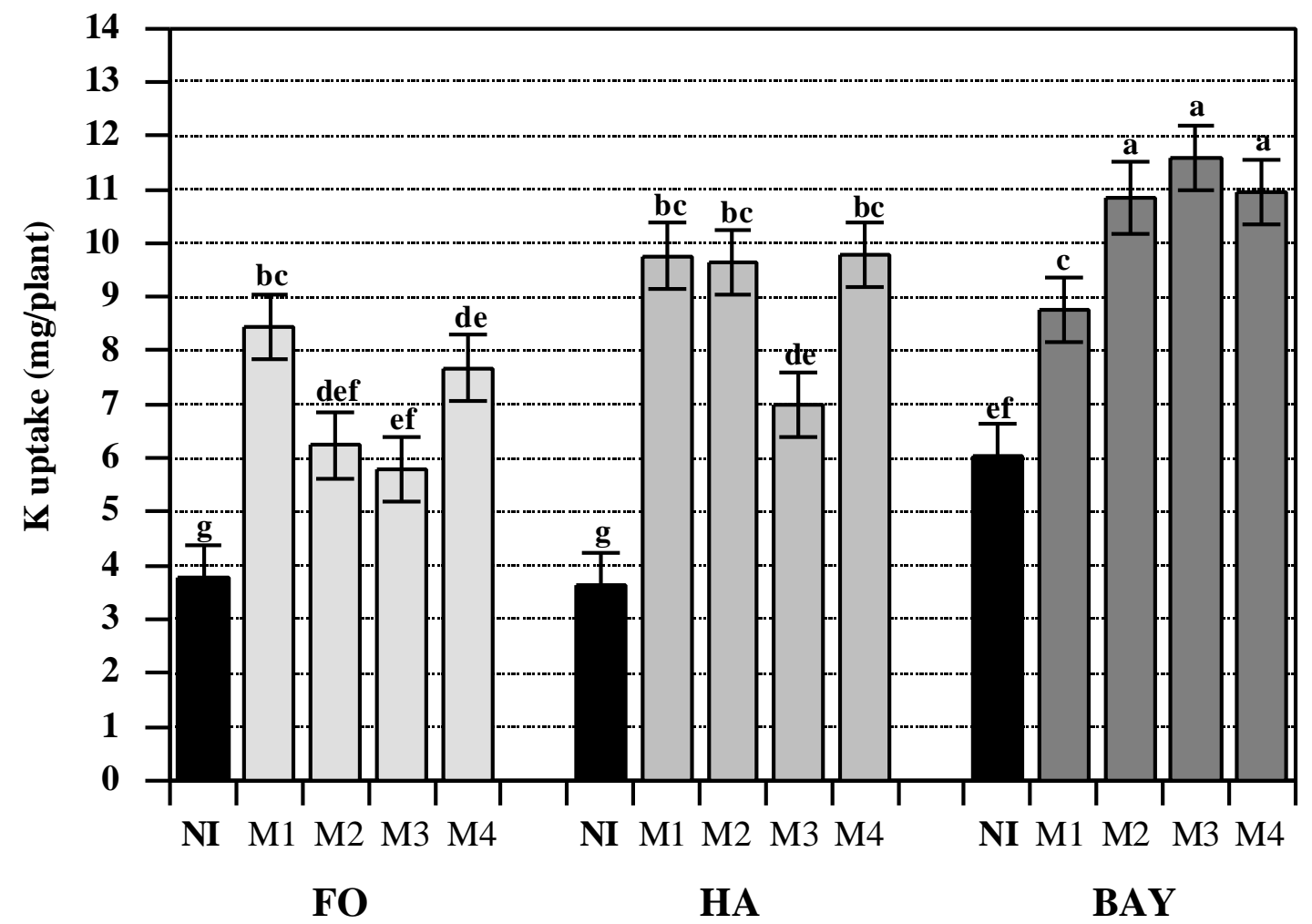

Figure 20: Interactions between inoculation (M1-M4) and fertilization (FO, HA, BAY) on the K uptake (mg/plant) of micropropagated oil palms after 12 weeks of post vitro growth. NI: non-inoculated plantlets. Vertical bars represent standard errors of the mean. Columns with different letters are significantly different at $P=0.05$ as indicated by LSD-test. 
The highest $\mathrm{K}$ uptake was detected in plantlets which received 'BAYFOLAN' (BAY) fertilization and were inoculated with Enthrophospora columbiana (M2), Acaulospora mellea (M3), and Acaulospora appendicula (M4).

The K uptake of the inoculated plants that received hydroxy-apatite (HA) was significantly lower compared to most of the BAY-fertilized plants, but significantly higher compared to the non-inoculated (NI) control plants of all fertilization treatments.

Non-fertilized (FO) plantlets inoculated with Glomus manihot (M1) or Acaulospora appendicula (M4) showed the highest K uptake of the inoculated plants. Acaulospora mellea (M3) showed the lowest $\mathrm{K}$ uptake without fertilization (FO) and the highest P uptake when 'BAYFOLAN' was applied.

\subsection{Nitrogen}

After six weeks of post vitro growth, the $\mathrm{N}$ concentration (mg/g plant) and uptake (mg/plant) of the young oil palms were not affected by either of the main factors considered (Table A12). Significant differences in $\mathrm{N}$ concentrations and uptake of the young plants were observed after 12 weeks of post vitro growth (Table A13). The $\mathrm{N}$ concentration was highly affected by mycorrhizal inoculation. Both, inoculation and fertilization, increased $\mathrm{N}$ uptake of the oil palms. Interactions between the main factors considered regarding $\mathrm{N}$ concentrations or uptake could not be found.

Three months after transplanting all inoculated plants showed significantly increased $\mathrm{N}$ concentrations compared to the non-inoculated (NI) control plants (Table37). At this growth stage, the $\mathrm{N}$ uptake of plants was 2 times higher compared to that of the non-inoculated (NI) control plants, as a consequence of better growth.

Table 37: Mycorrhizal inoculation (M1-M4) as a main effect on $\mathrm{N}$ concentration $(\mathrm{mg} / \mathrm{g}$ ) and $\mathrm{N}$ uptake (mg/plant) of oil palm plantlets after 12 weeks of post vitro growth. NI: noninoculated plantlets. Columns with different letters are significantly different at $P=0,05$ as indicated by LSD-test.

\begin{tabular}{l|c|c}
\hline \hline Inoculation & N concentration (mg/g) & N uptake (mg/plant) \\
\hline NI & $20.99 \mathrm{~b}$ & $5.43 \mathrm{c}$ \\
M1 & $24.85 \mathrm{a}$ & $11.75 \mathrm{ab}$ \\
M2 & $24.44 \mathrm{a}$ & $10.52 \mathrm{~b}$ \\
M3 & $25.86 \mathrm{a}$ & $10.93 \mathrm{ab}$ \\
M4 & $24.78 \mathrm{a}$ & $11.88 \mathrm{a}$ \\
\hline \hline
\end{tabular}


The $\mathrm{N}$ uptake of 'BAYFOLAN' fertilized plants was significantly higher than that of the HA or non-fertilized (PO) plants at this growth stage (Table 38). A significantly higher uptake of $\mathrm{N}$ was also detected in plants which received hydroxy-apatite compared to the non-fertilized plants, as a consequence of a better growth of the BAY- and HA-fertilized plants mainly due to a better nourishment.

Table 38: Fertilization (FO, HA, BAY) as a main effect on $\mathrm{N}$ uptake (mg/plant) of oil palm plantlets after 12 weeks of post vitro growth. Columns with different letters are significantly different at $P=0,05$ as indicated by LSD-test; ns: not significant.

\begin{tabular}{c|ccc}
\hline \hline & FO & HA & BAY \\
\hline \hline $\mathbf{N}(\mathbf{m g} /$ plant) & $8.59 \mathrm{c}$ & $10.24 \mathrm{~b}$ & $11.46 \mathrm{a}$ \\
& & & \\
\hline \hline
\end{tabular}

\subsection{5 (V)AMF infection}

The percentage of (V)AMF root colonization after six weeks of post vitro growth was greatly increased by mycorrhizal inoculation (Figure 20). Main effects of fertilization or interaction between the two main factors considered were not observed (Table A14). The clones, which were analysed as a co-variate, showed no differences in their (V)AMF infection rate.

Acaulospora mellea (M3) inoculated plants showed the highest infection rate (23\%), followed by Acaulospora appendicula (M4) (18\%) and Glomus manihot (M1) (17\%) inoculated plants (Figure 20). The lowest infection (10\%) of the inoculated plants was formed by Enthrophospora columbiana (M2). Differences in the ability of (V)AMF to colonize the root system are well known and may have played a part in the lower percentage of root colonization observed in E. columbiana (M2) inoculated plants six weeks after inoculation. Mycorrhizal infection in the non-inoculated (NI) control plants, due to the soil indigenous mycorrhizal fungi of the non-sterilized soil, was not observed at that growth stage.

These results showed that the oil palms were infected early, during the first six weeks after inoculation, by the used (V)AMF. Despite the relatively low percentage of (V)AMF infection, these colonisations were highly effective in promoting $\mathrm{P}$ concentrations (Table 33) of the inoculated clones, which resulted in improved plant development (Figure 17). Differences in the ability of (V)AMF to colonize the root system are well known and may have played a part in the lower percentage of colonization observed after the first harvest in roots of plants inoculated with E. columbiana (M2). 


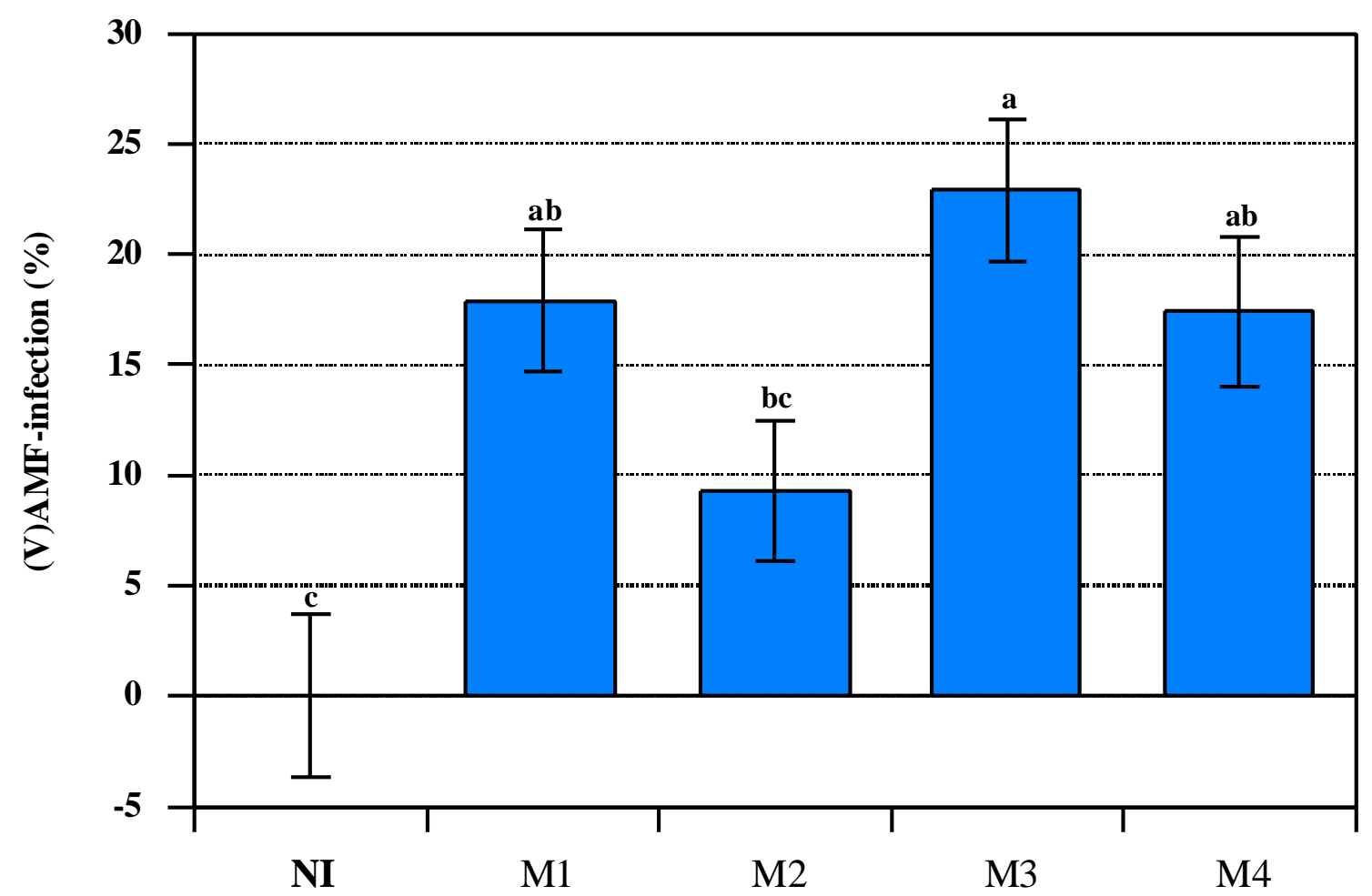

Figure 20: Mycorrhizal inoculation (M1-M4) as a main effect on the (V)AMF-infection rate (\%) of micropropagated oil palms after 6 weeks of post vitro growth. NI: non-inoculated plantlets. Vertical bars represent standard errors of the mean. Columns with different letters are significantly different at $P=0,05$ as indicated by LSD-test.

The results confirm the beneficial effect of mycorrhizal inoculation with effective fungal isolates at the early post vitro stage of the micropropagated oil palms. Little is known about the early stages of (V)AM infection in plants. It has been demonstrated by Ravolanirina et al. (1989) and Gianinazzi et al. (1990) that the early root colonization is very important during the delicate acclimatization phase .

Table 39: ANOVA of main effects and their interaction on the (V)AMF infection rate (\%) of micropropagated oil palms after 12 weeks of post vitro growth.

\begin{tabular}{l|c|c|c}
\hline \hline ANOVA & DF & MQ & P \\
\hline Inoculation & 4 & 1914.06 & $\mathbf{0 . 0 0 7}$ \\
Fertilization & 2 & 260.63 & 0.592 \\
Clone & 4 & 1449.17 & 0.126 \\
& & & \\
Inoculation x Fertilization & 8 & 290.23 & 0.786 \\
Inoculation x Clone & 16 & 323.82 & 0.828 \\
Fertilization x Clone & 8 & 310.99 & 0.751 \\
Inoculation x Fertilization x Clone & 32 & 298.59 & 0.943 \\
Error & & & \\
\hline \hline
\end{tabular}


After twelve weeks of post vitro growth, the percentage of (V)AMF root colonization was greatly enhanced by mycorrhizal inoculation (Figure 21). There was no significant effect of fertilization and its interaction with inoculation (Table 39). The clones, which were analysed as a co-variate, showed no differences in their (V)AMF infection rate.

The percentage of infection in roots of the inoculated plants varied between $28-32 \%$ and was significantly higher than that of the non-inoculated (NI) plants (Figure 21). Compared to the mycorrhizal colonization of plant roots at the first harvest, significant differences between fungal isolates were not observed. In contrast to the first harvest, mycorrhizal fungi colonized the non-inoculated plants after 12 weeks of post vitro growth (Figure 21). The percentage of infection was low (12\%), and was due to indigenous mycorrhizal fungi which were present in the native, non-sterilized soil.

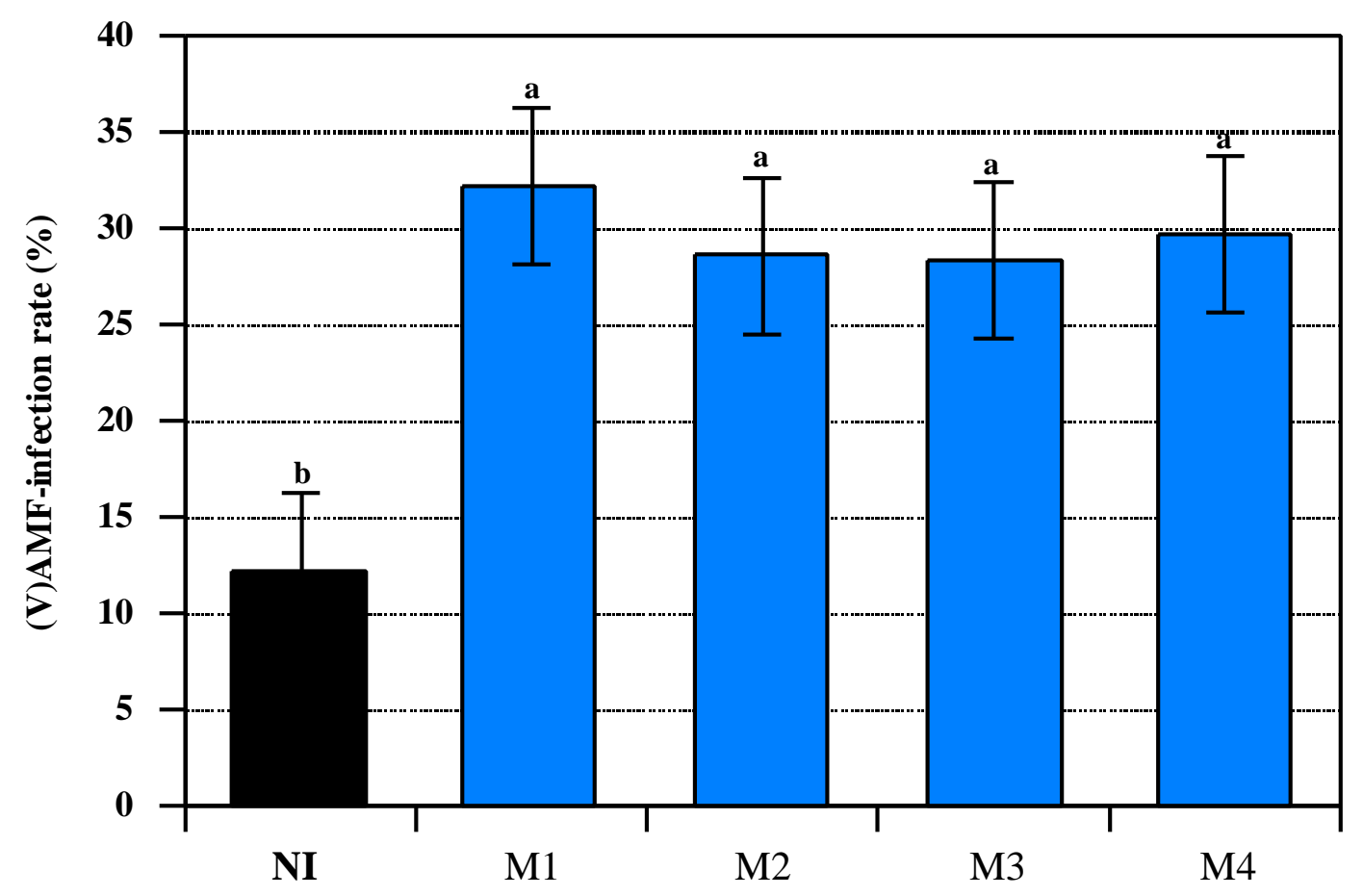

Figure 21: Mycorrhizal inoculation (M1-M4) as a main effect on the (V)AMF-infection rate (\%) of micropropagated oil palms after 12 weeks of post vitro growth. NI: non-inoculated plantlets. Vertical bars represent standard errors of the mean. Columns with different letters are significantly different at $P=0,05$ as indicated by LSD-test.

These results show that indigenous mycorrhizal fungi colonized the plant roots but that the (V)AMF isolates used for inoculation were more effective and able to compete with the native fungi. The used isolates infected the roots earlier and to a greater extent than the indigenous fungi. According to Koomen et al. (1987) are indigenous fungi not always the most effective ones as regards either mycorrhizal development or mycorrhizal growth response. In experiments of Vosatka et al. (2000), it was shown that even inoculation in non-sterile field 
soil could be of a great advantage for further development of mycorrhizal symbiosis despite the presence of native mycorrhizal fungi in the field.

\subsubsection{Conclusions Experiment 2}

The objective of Experiment 2 was to compare the application of traditional plant nutrition with "BAYFOLAN", which is practiced at the "International Oil Palm Research Institute" (IOPRI), with the effect of mycorrhizal inoculation during the sensitive post vitro stage of clonal oil palms. "BAYFOLAN", a foliar spray, is usually applied at IOPRI to supply the oil palms with nutrients via the shoot, as the root system of the plantlets is weakly developed at the time of transplanting. When "BAYFOLAN" fertilization was applied, the percentage of plant survival obtained in this experiment was high (80\%). This observation does not correspond with the survival data of $60-70 \%$, which were recorded by IOPRI during former years. It seems that, under experimental conditions, it was possible to achieve a higher efficiency with "BAYFOLAN" than under commercial conditions. The combination of foliar fertilization and mycorrhizal inoculation resulted in an improved survival rate reaching 85$100 \%$, which was similar to that of hydroxy-apatite fertilized, inoculated plants.

The beneficial effect by the combination of fertilization and inoculation was also found for the post vitro development of the sensitive plants. The growth of non-fertilized or hydroxyapatite fertilized plants was low and not much improved if plants received "BAYFOLAN". Both, fertilization and (V)AMF inoculation, greatly increased dry matter accumulation of the plants.

The increase in oil palm growth obtained by the addition of fertilizer and (V)AMF inoculation reflects the low uptake capacity of oil palm roots and the high mycorrhiza dependency of the plantlets in the initial growth phase. The highest $\mathrm{P}$ uptake was observed in the inoculated plants which were fertilized with the hardly soluble hydroxy-apatite. According to these results, it can be concluded that the fungal isolates used for inoculation were most effective on $\mathrm{P}$ uptake when plants were grown in hydroxy-apatite fertilized soil.

Plantlets were grown in a growth substrate which was of low $\mathrm{pH}$, a fact which frequently occurs in most tropical soils. Under such conditions inoculation with the tested (V)AMF isolates was an important factor in facilitating plant recovery of $\mathrm{P}$ from these fertilizer.

The response to "BAYFOLAN", a complete foliar nutrient containing macro- and micronutrients, was expected to be higher. The use of the cheaper hydroxy-apatite as a $\mathrm{P}$ 
fertilizer in combination with (V)AMF inoculation for improving the efficiency of the symbiosis, offers an alternative to the more expensive "BAYFOLAN" or soluble P fertilizers.

Inoculated plantlets which were harvested after six weeks of post vitro growth showed that all (V)AM fungal isolates significantly increased the foliar phosphate of the inoculated plants. At that early growth stage, the P uptake of mycorrhizal plants was 2 times higher compared to the non-inoculated control plants. A significantly increased nutrient uptake was only found for phosphate, but not for potassium or nitrogen. These results indicate that phosphate is probably the most limiting growth factor during the early post vitro stage of the oil palm clones. Addition of fertilizers does not greatly improve the nutrient status of propagated plants in their early growing stage because of their relatively small root systems and inability to take up nutrients efficiently.

\subsection{Experiment 3}

Experiment 3 was conducted to examine the effects of mycorrhizal inoculation, protection measurements and soil sterilization on the post vitro development of clonal oil palms. The plantlets were inoculated with one of three (V)A mycorrhizal fungi which were selected for their effectiveness on survival and plant development based on the results of the screening in Experiment 1. These were Glomus manihot (M1), Enthrophospora columbiana (M2) and Acaulospora mellea (M3). Plantlets were transferred either to sterilized or non-sterilized soil and were cultivated under 'normal' pre-nursery conditions or with protection against pathogenes by a plastic screen open to the top or covered by special plastic bags ('sunbag').

\subsubsection{Survival rate}

The survival rate of the oil palm plantlets in Experiment 3 was mainly influenced by mycorrhizal inoculation and soil sterilization (Table 40). These two treatments as main effects as well as interactions affected plant survival significantly during the three-month experimental period. The interactions were not significant. The clones were analysed as covariates and showed no significant differences regarding plant survival. 
Table 40: ANOVA of main factors and their interactions on the survival rate (\%) of micropropagated oil palms after three months of post vitro growth.

\begin{tabular}{l|r|r|r}
\hline \hline ANOVA & DF & MQ & \multicolumn{1}{c}{ P } \\
\hline Inoculation & 3 & 32500.00 & $\mathbf{0 . 0 0 0}$ \\
Protection & 2 & 291.67 & 0.823 \\
Sterilization & 1 & 24000.00 & $\mathbf{0 . 0 0 0}$ \\
& & & \\
Inoculation x Protection & 6 & 291.68 & 0.978 \\
Inoculation x Sterilization & 3 & 411.11 & $\mathbf{0 . 0 4 4}$ \\
Protection x Sterilization & 2 & 375.00 & 0.779 \\
Inoculation x Protection x Sterilization & 6 & 152.78 & 0.996 \\
Clone & 1 & 20.83 & 0.906 \\
Error & & 1497.58 & \\
\hline \hline
\end{tabular}

The interactions between mycorrhizal inoculation and soil sterilization on plant survival are demonstrated in Figure 22. The lowest survival rates (40\%) were detected in the noninoculated (NI) control plants which grew either in sterilized or non-sterilized soil. Unless accompanied by mycorrhizal inoculation the effect of soil sterilization on plant survival was minor.

The survival rate of inoculated plantlets grown in non-sterilized soil was significantly improved compared to the control plants. Glomus manihot (M1) was the most effective fungi, increasing plant survival to $83 \%$, followed by Acaulospora mellea (M3) with $73 \%$. The lowest plant survival rate (60\%) was detected with Enthrophospora columbiana (M2).

The (V)AMF isolates showed a higher effectiveness when they were applied to sterilized soil. Survival of the oil palm plantlets significantly increased to $97-100 \%$. Significant differences were specially seen in Enthrophospora columbiana (M2) and Acaulospora mellea (M3) inoculated plantlets. 


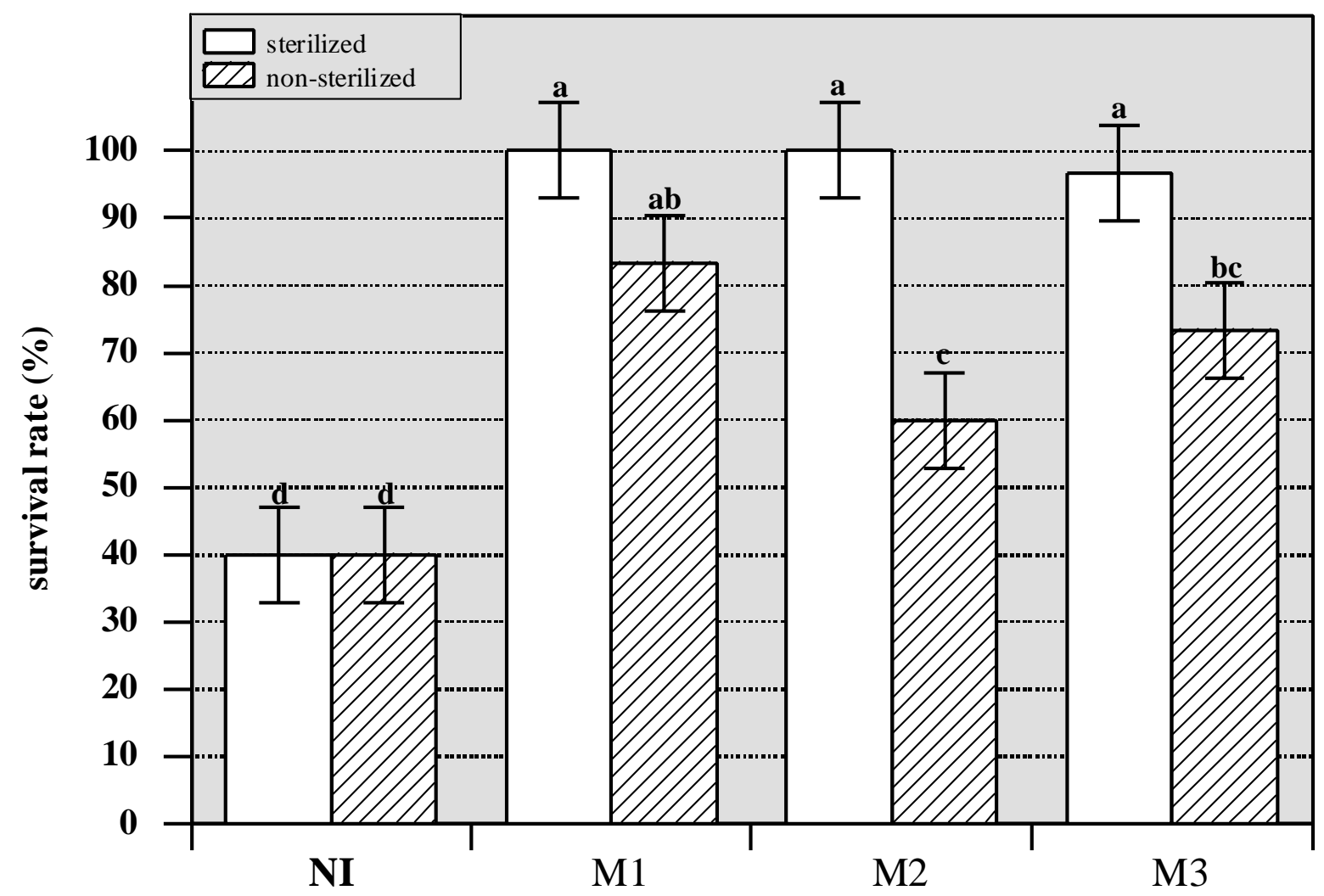

Figure 22: Interactions between mycorrhizal inoculation (M1-M3) and soil sterilization on the survival rate $(\%)$ of oil palm plantlets after 3 months of post vitro growth. NI: noninoculated plantlets. Vertical bars represent standard errors of the mean. Columns with different letters are significantly different at $P=0.05$, as indicated by LSD-test.

\subsubsection{Date of plant mortality}

The curves in Figure 23 demonstrate the influence of soil sterilization and mycorrhizal inoculation on the date of plant mortality. The high mortality rates (60\%), which were observed for the non-inoculated (NI) control plantlets, were maybe due to the size of the plantlets. These were generally smaller compared to the previous experiments.

Mycorrhizal inoculation generally reduced plant mortality, but the (V)AMF isolates were more effective when plants grew in sterilized soil (Figure 23). None of the plantlets which were inoculated with Glomus manihot (M1) or Enthrophospora columbiana (M2) died in this treatment. Three weeks after inoculation, 5\% of the Acaulospora appendicula (M4) inoculated plantlets died. In the non-sterilized soil, the mortality rates of plantlets were decreased by mycorrhizal inoculation to $17-40 \%$. However, the results of this experiment also show that mortality of the plantlets was limited and was observed only during the first three weeks of post vitro growth due to the combination of soil sterilization and mycorrhizal inoculation. 


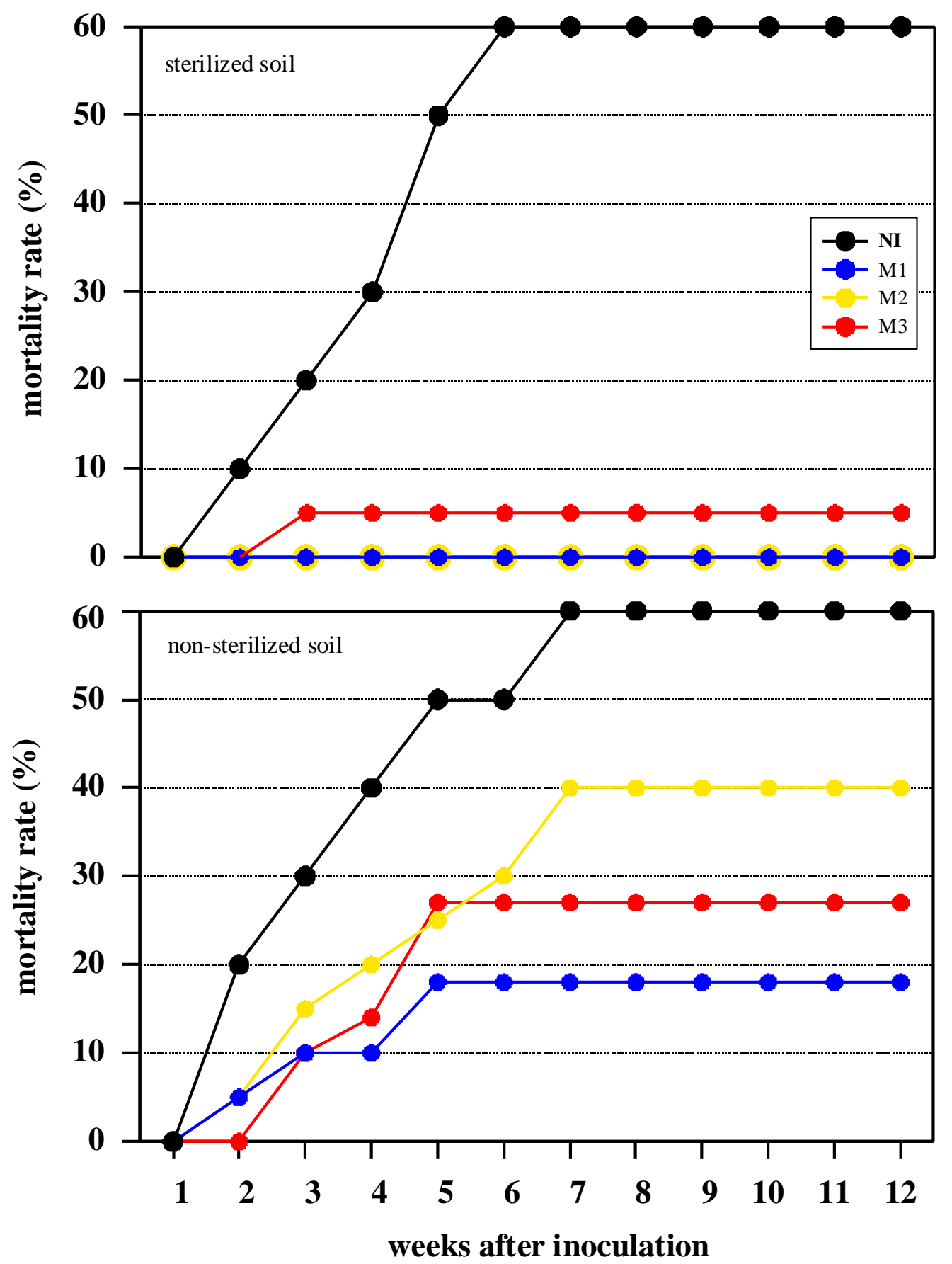

Figure 23: Effect of mycorrhizal inoculation (M1-M3) and soil sterilization on the mortality rate $(\%)$ of oil palm plantlets during 12 weeks of post vitro growth. NI: non inoculated plantlets.

\subsubsection{Post vitro plant development}

The effect of mycorrhizal inoculation, soil sterilization and protection measurements on the post vitro development of oil palm plantlets was characterized by monitoring the shoot length and number of leaves in two-weeks intervals during the experimental period. The most important results are discussed as follows. 


\subsubsection{Shoot length}

Significant effects on shoot development of all treatments were observed during the twelve week growth period (Table 41). The effect of the soil sterilization became significant after 2 weeks, mycorrhizal inoculation and the protection measures 4 weeks after transplanting significant differences persisted up to the $12^{\text {th }}$ week when plants were harvested.

Significant interactions between inoculation and soil sterilization were detected from the $2^{\text {nd }}$ until the $12^{\text {th }}$ week. Also, the interactions between soil sterilization and protection measurements showed significant differences during the last four weeks of the growth period. The calculation of the total shoot length increase during the three-month period showed significant differences in all main factors and between the two-way interactions of these main factors. The clones were analysed as covariates and showed no significant differences in shoot length.

Table 41: ANOVA* of main factors and their interaction on the shoot length increase $(\mathrm{cm})$ of micropropagated oil palms measured at two-week intervals and calculated as total values for the three-month period of post vitro growth. The table represents effects when $\mathrm{P}$ values became significant.

\begin{tabular}{|c|c|c|c|c|c|c|c|c|c|}
\hline \multirow[b]{2}{*}{ ANOVA } & \multirow[b]{2}{*}{ DF } & \multicolumn{7}{|c|}{ Weeks after transplanting } & \multirow[b]{2}{*}{ Total } \\
\hline & & 0 & 2 & 4 & 6 & 8 & 10 & 12 & \\
\hline Inoculation (1) & 3 & 0.603 & 0.105 & 0.000 & 0.000 & 0.000 & 0.000 & 0.000 & 0.000 \\
\hline Protection (2) & 2 & 0.478 & 0.099 & 0.010 & 0.005 & 0.000 & 0.000 & 0.000 & 0.000 \\
\hline Sterilization (3) & 1 & 0.109 & $\mathbf{0 . 0 0 0}$ & 0.000 & 0.000 & 0.000 & 0.000 & 0.000 & 0.000 \\
\hline $1 \times 2$ & 6 & 0.905 & 0.686 & 0.541 & 0.409 & 0.279 & 0.182 & 0.070 & 0.013 \\
\hline $1 \times 3$ & 3 & 0.257 & 0.014 & 0.003 & 0.003 & 0.001 & 0.001 & 0.000 & 0.000 \\
\hline $2 \times 3$ & 2 & 0.383 & 0.079 & 0.058 & 0.107 & 0.114 & 0.043 & 0.004 & 0.001 \\
\hline $1 \times 2 \times 3$ & 6 & 0.817 & 0.648 & 0.374 & 0.398 & 0.311 & 0.304 & 0.259 & 0.302 \\
\hline Clone & 1 & 0.185 & 0.255 & 0.222 & 0.158 & 0.217 & 0.235 & 0.540 & 0.529 \\
\hline
\end{tabular}

* complete ANOVA, see Annex Table A15

The used protection measures influenced shoot development (Table 42). Plants which were grown in 'sunbags' were significantly taller from the $4^{\text {th }}$ to the $12^{\text {th }}$ week after transplanting . The highest shoot length increment was detected when plants were cultivated in 'sunbags'. 
Table 42: Protection measures as main effects on the shoot length increase $(\mathrm{cm})$ of micropropagated oil palms measured at two-week intervals and calculated as total values for the three-month period of post vitro growth. NI: non-inoculated plantlets. Means within collumns of one date, with different letters, are significantly different at $P=0.05$, as indicated by Tukey-test; ns: not significant.

\begin{tabular}{l|ccccccc|c}
\hline \hline & \multicolumn{7}{|c|}{ Weeks after transplanting } & \multirow{2}{*}{ Protection } \\
& $\mathbf{0}$ & $\mathbf{2}$ & $\mathbf{4}$ & $\mathbf{6}$ & $\mathbf{8}$ & $\mathbf{1 0}$ & $\mathbf{1 2}$ & Total \\
\hline Control & $6.5 \mathrm{~ns}$ & $6.5 \mathrm{~ns}$ & $6.8 \mathrm{~b}$ & $7.2 \mathrm{~b}$ & $7.7 \mathrm{~b}$ & $8.2 \mathrm{~b}$ & $8.5 \mathrm{c}$ & $\mathbf{2 . 0} \mathbf{c}$ \\
Plastic screen & $6.6 \mathrm{~ns}$ & $6.9 \mathrm{~ns}$ & $7.4 \mathrm{ab}$ & $7.8 \mathrm{~b}$ & $8.3 \mathrm{~b}$ & $8.9 \mathrm{~b}$ & $9.6 \mathrm{~b}$ & $\mathbf{3 . 0} \mathbf{b}$ \\
'Sunbag' & $6.8 \mathrm{~ns}$ & $6.9 \mathrm{~ns}$ & $7.6 \mathrm{a}$ & $8.2 \mathrm{a}$ & $9.0 \mathrm{a}$ & $9.8 \mathrm{a}$ & $10.5 \mathrm{a}$ & $\mathbf{3 . 8} \mathbf{~ a}$ \\
\hline \hline
\end{tabular}

The interaction between mycorrhizal inoculation and soil sterilization (Table 43) showed that (V)AMF inoculation had a greater effect on plant development when plants were grown in sterilized soil. All fungal isolates used for inoculation significantly improved shoot length two weeks after transplanting. The beneficial effect of (V)AMF lasted until the end of the experimental period. During the three months of post vitro growth, the shoot length increment of all inoculated plants was four times higher than that of the non-inoculated (NI) control plants.

Table 43: Interaction between mycorrhizal inoculation (M1-M3) and soil sterilization on the shoot length increase $(\mathrm{cm})$ of micropropagated oil palms, measured at two-week intervals and calculated for the three-month period of post vitro growth. NI: non-inoculated plantlets. Means within collumns of one date, with different letters, are significantly different at $P=0.05$, as indicated by Tukey-test.

\begin{tabular}{|c|c|c|c|c|c|c|c|c|}
\hline & \multicolumn{7}{|c|}{ Weeks after transplanting } & \multirow[b]{2}{*}{ Total } \\
\hline & $\mathbf{0}$ & 2 & 4 & 6 & 8 & 10 & 12 & \\
\hline \multicolumn{9}{|c|}{ Sterilized soil } \\
\hline NI & $6.4 \mathrm{~ns}$ & $6.5 \mathrm{~b}$ & $6.8 \mathrm{~b}$ & $6.9 \mathrm{~b}$ & $7.1 \mathrm{c}$ & $7.3 \mathrm{c}$ & $7.6 \mathrm{c}$ & $1.2 \mathrm{~cd}$ \\
\hline M1 & $6.9 \mathrm{~ns}$ & $7.4 \mathrm{a}$ & $8.2 \mathrm{a}$ & $9.0 \mathrm{a}$ & $9.8 \mathrm{a}$ & $10.8 \mathrm{a}$ & $11.7 \mathrm{a}$ & $4.7 \mathrm{a}$ \\
\hline M2 & $7.1 \mathrm{~ns}$ & $7.6 \mathrm{a}$ & $8.3 \mathrm{a}$ & $9.2 \mathrm{a}$ & $10.0 \mathrm{a}$ & $10.9 \mathrm{a}$ & $11.6 \mathrm{a}$ & $4.5 \mathrm{a}$ \\
\hline M3 & $6.9 \mathrm{~ns}$ & $7.5 \mathrm{a}$ & $8.2 \mathrm{a}$ & $9.1 \mathrm{a}$ & $10.1 \mathrm{a}$ & $11.0 \mathrm{a}$ & $11.9 \mathrm{a}$ & $4.9 \mathrm{a}$ \\
\hline \multicolumn{9}{|c|}{ Non-sterilized soil } \\
\hline NI & $6.6 \mathrm{~ns}$ & $6.7 \mathrm{ab}$ & $6.7 \mathrm{~b}$ & $6.7 \mathrm{~b}$ & $6.8 \mathrm{c}$ & $7.0 \mathrm{c}$ & $7.4 \mathrm{c}$ & $0.8 \mathrm{~d}$ \\
\hline M1 & $6.6 \mathrm{~ns}$ & $6.8 \mathrm{ab}$ & $7.5 \mathrm{ab}$ & $7.9 \mathrm{ab}$ & $8.3 \mathrm{~b}$ & $8.9 \mathrm{~b}$ & $9.4 \mathrm{~b}$ & $2.8 \mathrm{~b}$ \\
\hline M2 & $6.3 \mathrm{~ns}$ & $6.3 \mathrm{~b}$ & $6.4 \mathrm{~b}$ & $6.7 \mathrm{~b}$ & $7.3 \mathrm{bc}$ & $7.8 \mathrm{bc}$ & $8.3 \mathrm{bc}$ & $1.9 \mathrm{bcd}$ \\
\hline M3 & $6.3 \mathrm{~ns}$ & $6.5 \mathrm{~b}$ & $6.5 \mathrm{~b}$ & $6.6 \mathrm{~b}$ & $7.3 \mathrm{bc}$ & $7.9 \mathrm{bc}$ & $8.4 \mathrm{bc}$ & $2.1 \mathrm{bc}$ \\
\hline
\end{tabular}

Inoculation was also effective when plantlets were growing in non-sterilized soil (Table 43). From the second until the $6^{\text {th }}$ week after transplanting, Enthrophospora columbiana (M2) and 
Acaulospora mellea (M3) inoculated plants were significantly taller than the control plants. From the $8^{\text {th }}$ to the $12^{\text {th }}$ week, significantly longer shoots were observed in plantlets which were inoculated with Glomus manihot (M1). During the three-month growth period, the shoot length increment of the inoculated plants growing in non-sterilized soil was 2 to 3 times higher than that of the non-inoculated plants.

According to these results, it can be concluded that the (V)AMF isolates significantly improve shoot length and that inoculation is more effective when plants are grown in sterilized soil.

\subsubsection{Number of leaves}

Significant, main effects on leaf number development of all treatments were observed during the measured 12-week growth period (Table 44). Significant interactions were only detected between mycorrhizal inoculation and soil sterilization at the end of the experimental period.

Table 44: ANOVA* of main factors and their interactions on the leaf number of micropropagated oil palms measured at two-week intervals and calculated for the three-month period of post vitro growth. The table represents effects when $\mathrm{P}$ values became significant.

\begin{tabular}{|c|c|c|c|c|c|c|c|c|c|}
\hline \multirow[b]{2}{*}{ ANOVA } & \multirow[b]{2}{*}{ DF } & \multicolumn{7}{|c|}{ "Weeks after transplanting } & \multirow[b]{2}{*}{ Total } \\
\hline & & $\mathbf{0}$ & 2 & 4 & 6 & 8 & 10 & 12 & \\
\hline Inoculation (1) & 3 & 0.106 & 0.005 & 0.000 & 0.000 & 0.000 & 0.000 & 0.000 & 0.000 \\
\hline Protection (2) & 2 & 0.000 & 0.000 & 0.000 & 0.000 & 0.000 & 0.000 & 0.000 & 0.000 \\
\hline Sterilization (3) & 1 & 0.000 & 0.000 & 0.000 & 0.000 & 0.000 & 0.000 & 0.000 & 0.000 \\
\hline $1 \times 2$ & 6 & 0.653 & 0.245 & 0.932 & 0.543 & 0.667 & 0.992 & 0.929 & 0.651 \\
\hline $1 \times 3$ & 3 & 0.645 & 0.204 & 0.348 & 0.363 & 0.319 & 0.525 & 0.032 & 0.012 \\
\hline $2 \times 3$ & 2 & 0.015 & 0.118 & 0.034 & 0.373 & 0.061 & 0.047 & 0.131 & 0.522 \\
\hline $1 \times 2 \times 3$ & 6 & 0.494 & 0.558 & 0.622 & 0.738 & 0.504 & 0.719 & 0.425 & 0.998 \\
\hline Clone & 1 & 0.053 & 0.106 & 0.067 & 0.261 & 0.293 & 0.245 & 0.507 & 0.093 \\
\hline
\end{tabular}

* complete ANOVA, see Annex Table A16

The total number of leaves which developed during the three-month period showed significant differences due to all main factors (Table 44). The interactions between protection and soil sterilization were not consistent and are not elaborated here. The clones were analysed as covariates, significant differences were not observed.

The main effects of inoculation, protection measures and soil sterilization on leaf development are demonstrated in Table 45. At time of transplanting, plants had nearly the 
same number of leaves. The development of new leaves generally occurred earlier, when plantlets were inoculated with (V)AMF. Two weeks after transfer to soil, Enthrophospora columbiana (M2) and Acaulospora mellea (M3) inoculated plants developed the first new leaves. In contrast, new leaves of the control plants (NI) emerged after six weeks of post vitro growth. From the $4^{\text {th }}$ until the $12^{\text {th }}$ week, all inoculated plantlets produced double the number of leaves than the non-inoculated (NI) control plants.

Table 45: Mycorrhizal inoculation, soil sterilization and protection measures as main effects on the leaf number of micropropagated oil palms measured at two-week intervals during a three-month period of post vitro growth and calculated as total values. NI: non-inoculated plantlets. Means within collumns of one date, with different letters, are significantly different at $P=0.05$, as indicated by Tukey-test; ns: not significant.

\begin{tabular}{l|ccccccc|c}
\hline \hline & \multicolumn{7}{|c|}{ Weeks after transplanting } & \\
Main effect & $\mathbf{0}$ & $\mathbf{2}$ & $\mathbf{4}$ & $\mathbf{6}$ & $\mathbf{8}$ & $\mathbf{1 0}$ & $\mathbf{1 2}$ & Total \\
\hline Inoculation & & & & & & & & \\
$\mathrm{NI}$ & $3.4 \mathrm{~ns}$ & $3.4 \mathrm{~b}$ & $3.5 \mathrm{~b}$ & $3.8 \mathrm{~b}$ & $4.1 \mathrm{~b}$ & $4.1 \mathrm{~b}$ & $4.6 \mathrm{~b}$ & $\mathbf{1 . 2} \mathbf{~ b}$ \\
M1 & $3.5 \mathrm{~ns}$ & $3.7 \mathrm{~b}$ & $4.3 \mathrm{a}$ & $4.6 \mathrm{a}$ & $5.1 \mathrm{a}$ & $5.3 \mathrm{a}$ & $6.0 \mathrm{a}$ & $\mathbf{2 . 5} \mathbf{~ a}$ \\
$\mathrm{M} 2$ & $3.6 \mathrm{~ns}$ & $3.8 \mathrm{a}$ & $4.3 \mathrm{a}$ & $4.7 \mathrm{a}$ & $5.2 \mathrm{a}$ & $5.3 \mathrm{a}$ & $6.0 \mathrm{a}$ & $\mathbf{2 . 4} \mathbf{~ a}$ \\
M3 & $3.6 \mathrm{~ns}$ & $3.9 \mathrm{a}$ & $4.4 \mathrm{a}$ & $4.8 \mathrm{a}$ & $5.2 \mathrm{a}$ & $5.4 \mathrm{a}$ & $6.1 \mathrm{a}$ & $\mathbf{2 . 5} \mathbf{~ a}$ \\
\hline Soil sterilization & & & & & & & & \\
Sterilized & $3.5 \mathrm{~ns}$ & $3.9 \mathrm{a}$ & $4.4 \mathrm{a}$ & $4.7 \mathrm{a}$ & $5.2 \mathrm{a}$ & $5.3 \mathrm{a}$ & $6.1 \mathrm{a}$ & $\mathbf{2 . 4} \mathbf{~ a}$ \\
Non-sterilized & $3.4 \mathrm{~ns}$ & $3.5 \mathrm{~b}$ & $3.9 \mathrm{~b}$ & $4.3 \mathrm{~b}$ & $4.7 \mathrm{~b}$ & $4.8 \mathrm{~b}$ & $5.3 \mathrm{~b}$ & $\mathbf{1 . 9} \mathbf{~ b}$ \\
\hline Protection & & & & & & & & \\
Control & $3.4 \mathrm{~ns}$ & $3.4 \mathrm{~b}$ & $4.0 \mathrm{~b}$ & $4.1 \mathrm{c}$ & $4.5 \mathrm{c}$ & $4.7 \mathrm{~b}$ & $5.3 \mathrm{~b}$ & $\mathbf{1 . 9} \mathbf{~ b}$ \\
Plastic screen & $3.4 \mathrm{~ns}$ & $3.7 \mathrm{~b}$ & $4.0 \mathrm{~b}$ & $4.4 \mathrm{~b}$ & $4.8 \mathrm{~b}$ & $5.0 \mathrm{~b}$ & $5.5 \mathrm{~b}$ & $\mathbf{2 . 0} \mathbf{~ b}$ \\
'Sunbag' & $3.5 \mathrm{~ns}$ & $4.1 \mathrm{a}$ & $4.5 \mathrm{a}$ & $5.0 \mathrm{a}$ & $5.4 \mathrm{a}$ & $5.5 \mathrm{a}$ & $6.3 \mathrm{a}$ & $\mathbf{2 . 5} \mathbf{~ a}$ \\
\hline \hline
\end{tabular}

The sterilization of the soil substrate strongly influenced leaf production (Table 45). From the $2^{\text {nd }}$ until the $12^{\text {th }}$ week, plantlets which were grown in sterilized soil developed significantly more leaves.

The protection measurements also influenced the number of newly developed leaves. Significantly more leaves were developed when plantlets were cultivated in 'sunbags' (Table 45).

The beneficial effects of mycorrhizal inoculation and soil sterilization were evident from the total number of leaves which had developed during the 12 weeks of the post vitro growth (Figure 24). The sterilization of the growth substrate did not influence leaf growth of the control plants (NI). The inoculation with either of the (V)AMF isolates resulted in the development of significantly more leaves. The effictiveness of the fungal isolates was 
increased by the sterilization of the growth substrate. This was specially seen in Glomus manihot (M1) and Enthrophospora columbiana (M2) inoculated plants.

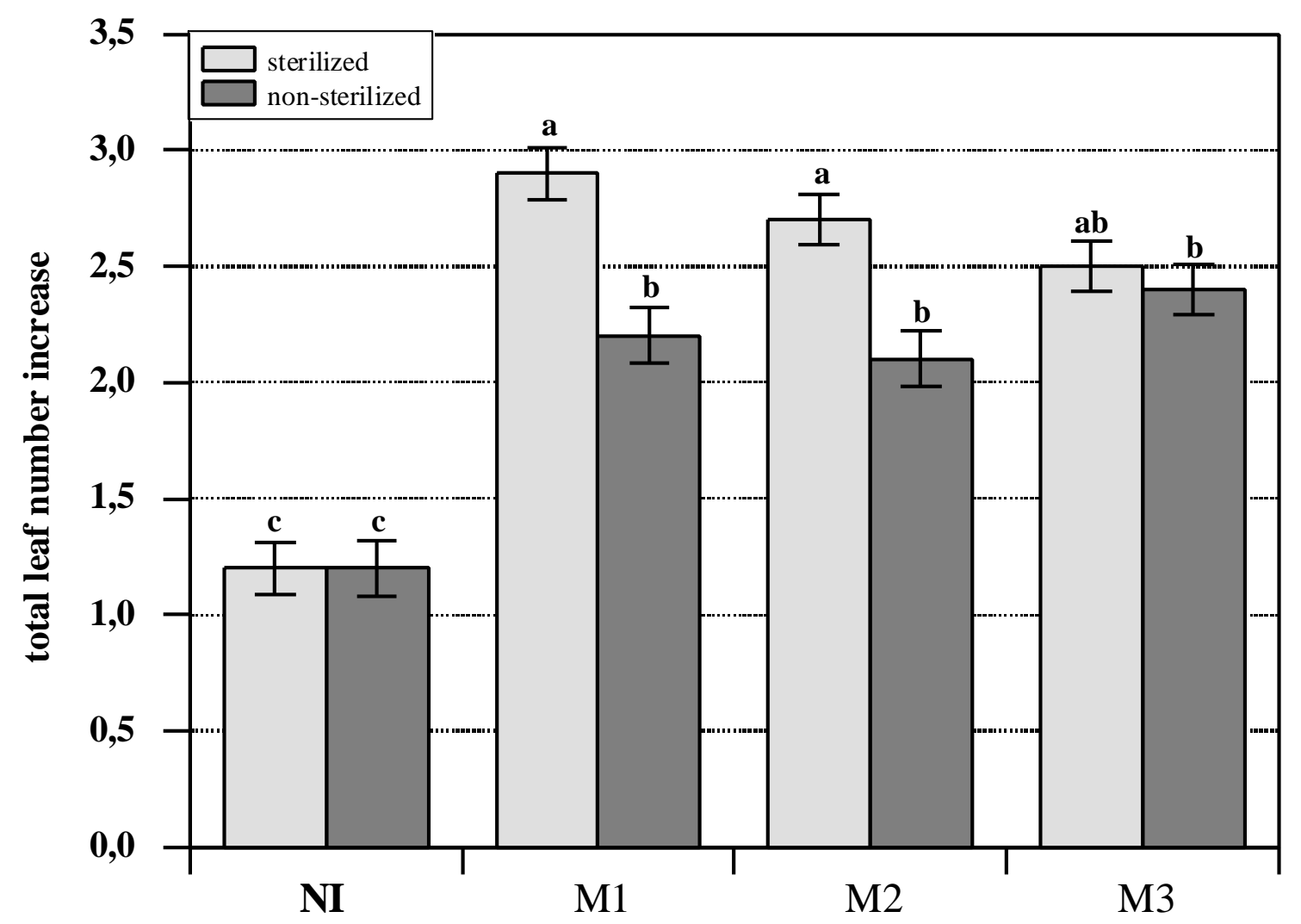

Figure 24: Interaction between mycorrhizal inoculation (M1-M3) and soil sterilization on the total leaf number increase of micropropagated oil palms during 12 weeks of post vitro growth. NI: non-inoculated plantlets. Vertical bars represent standard errors of the mean. Columns followed by different letters are significantly different $P=0.05$ as indicated by Tukey-test.

\subsubsection{Plant growth parameters after harvesting}

\subsubsection{Shoot and root fresh weight; root:shoot fresh weight ratio}

At the end of the experimental period the shoot and root fresh weights and the root:shoot fresh weight ratios (R:S) were highly affected by all investigated treatments (Table 46). Significant interactions between inoculation and soil sterilization and between protection and soil sterilization were measured for shoot fresh weight. The root fresh weights were significantly influenced by the interaction between inoculation and soil sterilization. The clones were analysed as covariates and showed no significant differences of the studied parameters. 
Table 46: ANOVA of main factors and their interactions on the shoot and root fresh weights (g) and root:shoot fresh weight $(\mathrm{R}: \mathrm{S})$ ratio of micropropagated oil palms after three months of post vitro growth.

\begin{tabular}{l|c|cc|cc|cc}
\hline \hline & & \multicolumn{2}{|c|}{ Shoot fresh weight } & \multicolumn{2}{c|}{ Root fresh weight } & \multicolumn{2}{c}{ R:S ratio } \\
\hline ANOVA & DF & MQ & $\mathbf{P}$ & MQ & P & MQ & P \\
\hline Inoculation (1) & 3 & 4.88 & $\mathbf{0 . 0 0 0}$ & 0.179 & $\mathbf{0 . 0 0 1}$ & 0.163 & $\mathbf{0 . 0 0 0}$ \\
Protection (2) & 2 & 3.73 & $\mathbf{0 . 0 0 0}$ & 0.235 & $\mathbf{0 . 0 0 1}$ & 0.139 & $\mathbf{0 . 0 0 0}$ \\
Sterilization (3) & 1 & 18.38 & $\mathbf{0 . 0 0 0}$ & 1.369 & $\mathbf{0 . 0 0 0}$ & 0.008 & 0.400 \\
& & & & & & & \\
1 x 2 & 6 & 0.016 & 0.993 & 0.046 & 0.181 & 0.020 & 0.185 \\
1 x 3 & 3 & 0.697 & $\mathbf{0 . 0 0 1}$ & 0.084 & $\mathbf{0 . 0 4 4}$ & 0.009 & 0.573 \\
2 x 3 & 2 & 1.62 & $\mathbf{0 . 0 0 0}$ & 0.074 & 0.092 & 0.005 & 0.680 \\
1 x 2 x 3 & 6 & 0.032 & 0.958 & 0.027 & 0.501 & 0.008 & 0.745 \\
Clone & 1 & 0.279 & 0.143 & 0.116 & 0.054 & 0.039 & 0.091 \\
Error & 183 & 0.129 & & & & & \\
\end{tabular}

The root:shoot fresh weight (R:S) ratio was decreased by endomycorrhizal infection because inoculated plants showed a greater shoot than root production (Table 47). Such modifications in biomass distribution have often been observed in mycorrhizal plants.

The R:S ratios of plantlets which were cultivated in 'sunbags' were lower compared to plants which were surrounded by a plastic screen or to the control plants, which grew under 'normal' pre-nursery conditions (Table 47). The decrease of the R:S ratio was a consequence of better shoot growth in relation to root growth.

Table 47: Mycorrhizal inoculation and protection measures as main effects on the root:shoot fresh weight ratio of oil palm plantlets after 3 months of post vitro growth. NI: non-inoculated plantlets. Columns with different letters are significantly different at $P=0.05$, as indicated by Tukey-test.

\begin{tabular}{ll|ll}
\hline \hline Inoculation & & Protection & \\
\hline \hline NI & $0.39 \mathrm{~b}$ & Control & $0.33 \mathrm{~b}$ \\
M1 & $0.27 \mathrm{a}$ & Plastic screen & $0.33 \mathrm{~b}$ \\
M2 & $0.28 \mathrm{a}$ & 'Sunbag' & $0.25 \mathrm{a}$ \\
M3 & $0.28 \mathrm{a}$ & & \\
\hline \hline
\end{tabular}

The influence of mycorrhizal inoculation and soil sterilization on plant growth was demonstrated by the interactions between these two factors studied (Table 48). The lowest shoot fresh weights were observed in the non-inoculated (NI) control plants. The shoot 
growth of the control plants was significantly improved when they were cultivated in sterilized soil.

The combination of (V)AMF inoculation and soil sterilization resulted in significantly increased shoot fresh weights. The effectiveness of the (V)AMF isolates was generally higher when plants were grown in sterilized soil. Mycorrhizal inoculation also significantly improved shoot growth when plantlets grew in non-sterilized soil, as seen in comparison to the control plants of this treatment, but the isolates were less effective.

Table 48: Interaction between mycorrhizal inoculation (M1-M3) and soil sterilization on the shoot fresh weight $(\mathrm{g})$ of oil palm plantlets after 3 months of post vitro growth. NI: noninoculated plantlets. Means with different letters are significantly different at $P=0.05$, as indicated by Tukey-test.

\begin{tabular}{|c|c|c|c|c|}
\hline & NI & M1 & M2 & M3 \\
\hline Sterilized & $1.00 \mathrm{~b}$ & $1.87 \mathrm{a}$ & $1.93 \mathrm{a}$ & $1.73 \mathrm{a}$ \\
\hline Non-sterilized & $0.67 \mathrm{c}$ & $1.19 \mathrm{~b}$ & $1.06 \mathrm{~b}$ & $1.06 \mathrm{~b}$ \\
\hline
\end{tabular}

The influence of the protection measurements on plant growth was low, unless accompanied by soil sterilization as is seen in the interactions between these two factors (Table 49). The sterilization of the growth substrate generally resulted in improved shoot growth. The highest shoot fresh weights were obtained when plantlets were grown in sterilized soil and were cultivated under 'sunbags'.

Table 49: Interaction between soil sterilization and protection measures on the shoot fresh weight $(\mathrm{g})$ of oil palm plantlets after 3 months of post vitro growth. NI: non-inoculated plantlets. Means with different letters are significantly different at $P=0.05$, as indicated by Tukey-test.

\begin{tabular}{l|ccc}
\hline \hline & Control & Plastic screen & 'Sunbag' \\
\hline \hline Sterilized & $1.22 \mathrm{c}$ & $1.58 \mathrm{~b}$ & $1.96 \mathrm{a}$ \\
\multirow{2}{*}{ Non-sterilized } & $0.87 \mathrm{~d}$ & $1.08 \mathrm{~cd}$ & $1.03 \mathrm{~cd}$ \\
\hline \hline
\end{tabular}

Significant differences in the root fresh weights were observed with regard to the interaction between inoculation and soil sterilization (Figure 25). The lowest root fresh weights were obtained in the non-inoculated control plants (NI), which were either grown in sterilized or non-sterilized soil. The plantlets developed more roots due to inoculation with the (V)AM 
fungal isolates and cultivation in sterilized soil. Especially Enthrophospora columbinana (M2) and Acaulospora mellea (M3) inoculated plants showed significantly higher root fresh weights than the non-inoculated controls or the mycorrhizal plants of the non-sterilized treatments.

The effectiveness of the fungal isolates on root growth was in general lower when plants were grown in non-sterilized soil. (V)AMF inoculation of these plants had no significant effect on the root growth.

Observations of Subhan et al. (1998) showed that the roots of inoculated Sesbania sesban plantlets were found to be healthier/stronger than those of non-mycorrhizal plants. The authors reported that sixteen weeks after transplanting, the fresh weights of roots were found to be $50 \%$ higher than those of the control plants.

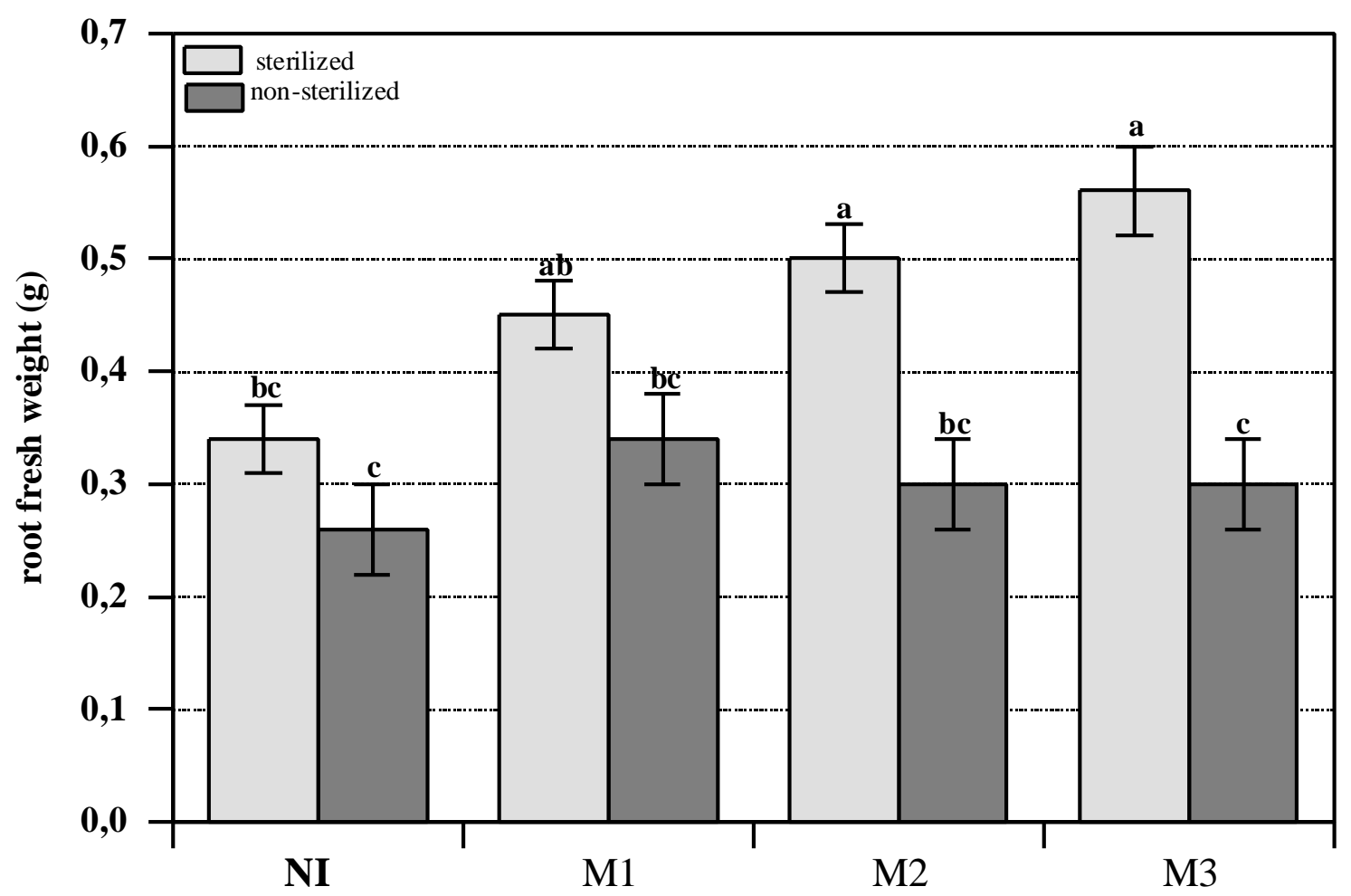

Figure 25: Interaction between mycorrhizal inoculation (M1-M3) and soil sterilization on the root fresh weight $(\mathrm{g})$ of oil palm plantlets after 3 months of post vitro growth. NI: noninoculated plantlets. Vertical bars represent standard errors of the mean. Columns with different letters are significantly different at $P=0.05$, as indicated by Tukey-test.

\subsubsection{Dry matter}

The used (V)AM fungi, the protection measures and the soil sterilization significantly influenced shoot dry weights of the oil palm plantlets (Table 50). Interactions between soil sterilization and inoculation or protection measurements significantly affected plant growth. 
Interactions between inoculation and protection or between all main factors were not significant. The clones were analysed as covariates and showed no differences in dry matter.

Table 50: ANOVA of main factors and their interactions on the shoot dry weight $(\mathrm{g})$ of micropropagated oil palms after three months of post vitro growth.

\begin{tabular}{l|c|c|c}
\hline \hline ANOVA & DF & MQ & P \\
\hline Inoculation & 3 & 0.116 & $\mathbf{0 . 0 0 0}$ \\
Protection & 2 & 0.013 & $\mathbf{0 . 0 2 0}$ \\
Sterilization & 1 & 1.310 & $\mathbf{0 . 0 0 0}$ \\
& & & 0.767 \\
Inoculation x Protection & 6 & 0.002 & $\mathbf{0 . 0 0 0}$ \\
Inoculation x Sterilization & 3 & 0.071 & $\mathbf{0 . 0 0 0}$ \\
Protection x Sterilization & 2 & 0.025 & 0.105 \\
Inoculation x Protection x Sterilization & 6 & 0.006 & 0.697 \\
Clone & 1 & 0.000 & \\
Error & 168 & 0.003 & \\
\hline \hline
\end{tabular}

The influence of mycorrhizal inoculation and soil sterilization on plant growth was demonstrated by the interactions between these two factors (Figure 26). The lowest shoot dry weights were observed in the non-inoculated (NI) control plants, either grown in sterilized or non-sterilized soil. The soil sterilization was not effective in enhancing shoot dry matter accumulation unless accompanied by endomycorrhizal fungi.

The inoculation with either of the (V)AMF isolates generally led to increased shoot dry weights. The effectiveness of the fungal isolates on dry matter accumulation was greatly increased by the sterilization of the growth substrate. The highest shoot dry weights were obtained when plantlets were inoculated and cultivated in sterilized soil. The significant effect of mycorrhizal inoculation on plant growth was lower if plants grew in non-sterilized soil. 


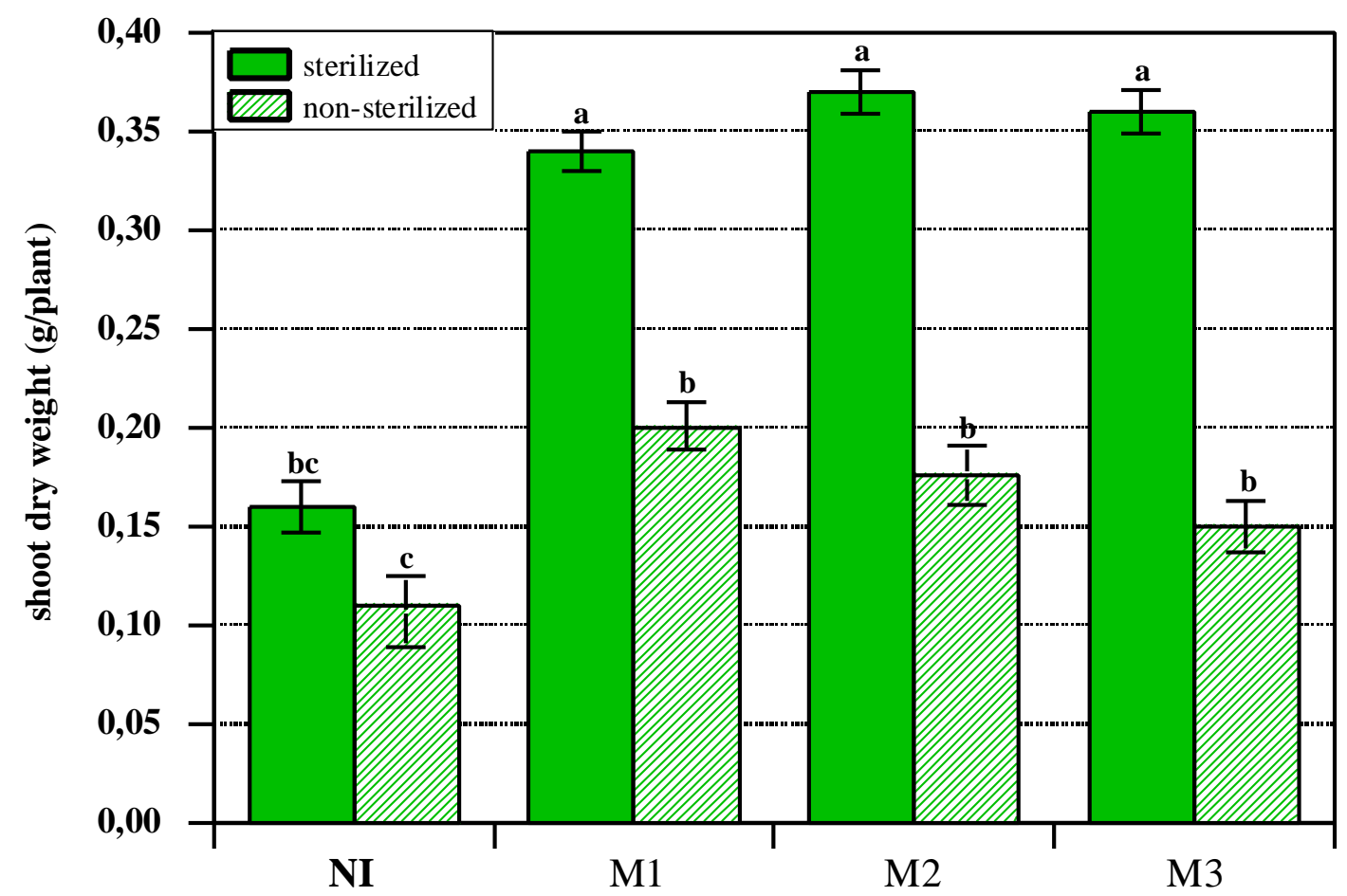

Figure 26: Interactions between mycorrhizal inoculation (M1-M3) and soil sterilization on the shoot dry weight $(\mathrm{g})$ of oil palm plantlets after 3 months of post vitro growth. NI: noninoculated plantlets. Vertical bars represent standard errors of the mean. Columns with different letters are significantly different at $P=0.05$, as indicated by Tukey-test.

The influence of soil sterilization and the protection measures on shoot growth was demonstrated by the interaction between these two factors (Table 51). The effects of the protection measures were low when plantlets were cultivated in non-sterilized soil. Especially the use of 'sunbags' does not improve the dry matter accumulation of plants in this treatment. The highest shoot dry weights were observed when plants were grown in sterilized soil and cultivated under 'sunbags'. The growth of plants which were only surrounded by a plastic screen was not much lower than that of the plants which were grown under 'sunbags'. The growth-promoting effect of this interaction was dominated by the sterilization of the soil.

Table 51: Interaction between soil sterilization and protection measures on the shoot dry weight $(\mathrm{g})$ of oil palm plantlets after 3 months of post vitro growth. Means with different letters are significantly different at $(P=0,05)$ as indicated by Tukey-test.

\begin{tabular}{l|ccc}
\hline \hline & Control & Plastic screen & 'Sunbag' \\
\hline \hline Sterilized & $0.27 \mathrm{~b}$ & $0.31 \mathrm{ab}$ & $0.34 \mathrm{a}$ \\
\multirow{2}{*}{ Non-sterilized } & $0.14 \mathrm{c}$ & $0.14 \mathrm{c}$ & $0.13 \mathrm{c}$ \\
\hline \hline
\end{tabular}




\subsubsection{Nutrient concentration and uptake}

\subsection{Phosphorus}

Mycorrhizal inoculation and soil sterilization were highly significant factors increasing phosphorus concentration and uptake of plant shoots (Table 52). The interactions between inoculation and soil sterilization were highly effective regarding $\mathrm{P}$ concentration as well as $\mathrm{P}$ uptake of plant shoots. The phosphate uptake was also influenced by the interactions between protection measures and soil sterilization. Interaction between the three main factors regarding $\mathrm{P}$ concentration or $\mathrm{P}$ uptake were not detected. The clones were analysed as covariates and showed no significant differences regarding the studied parameters.

Table 52: ANOVA of main factors and their interactions on the $P$ concentration $(\mathrm{mg} / \mathrm{g})$ and $P$ uptake of micropropagated oil palms after three months of post vitro growth.

\begin{tabular}{l|c|cc|cc}
\hline \hline & & \multicolumn{2}{|c|}{ P (mg/g) } & \multicolumn{2}{c}{ P (mg/plant) } \\
\hline ANOVA & DF & MQ & P & MQ & P \\
\hline Inoculation (1) & 3 & 2.58 & $\mathbf{0 . 0 0 0}$ & 0.725 & $\mathbf{0 . 0 0 0}$ \\
Protection (2) & 2 & 0.32 & 0.058 & 0.005 & 0.730 \\
Sterilization (3) & 1 & 1.11 & $\mathbf{0 . 0 0 1}$ & 5.50 & $\mathbf{0 . 0 0 0}$ \\
& & & & & \\
1 x 2 & 6 & 0.18 & 0.085 & 0.014 & 0.430 \\
1 x 3 & 3 & 0.36 & $\mathbf{0 . 0 1 2}$ & 0.349 & $\mathbf{0 . 0 0 0}$ \\
2 x 3 & 2 & 0.07 & 0.470 & 0.078 & $\mathbf{0 . 0 0 5}$ \\
$1 \times 2 \times 3$ & 6 & 0.08 & 0.529 & 0.015 & 0.387 \\
Clone & 1 & 0.36 & 0.062 & 0.023 & 0.212 \\
Error & 166 & 0.096 & & 0.015 & \\
\hline \hline
\end{tabular}

The foliar P concentrations of the non-inoculated (NI) control plants were similar, either cultivated in sterilized or non-sterilized soil, and were significantly lower than those of the mycorrhizal plants (Figure 27). The inoculation with (V)AMF isolates resulted in significantly increased P concentrations. Differences of the efficiency among fungal isolates due to the sterilization of the soil were specially observed with Glomus manihot (M1). If these plants were cultivated in sterilized soil, the shoot $\mathrm{P}$ concentrations were significantly higher. The phosphate concentrations with Enthrophospora columbiana (M2) and Acaulospora mellea (M3) were similar and not influenced by soil sterilization.

The significantly increased $\mathrm{P}$ concentrations observed in the mycorrhizal plants resulted in improved growth of the oil palm plantlets. Differences of the efficiency in promoting plant growth between the (V)AMF isolates were not observed. 


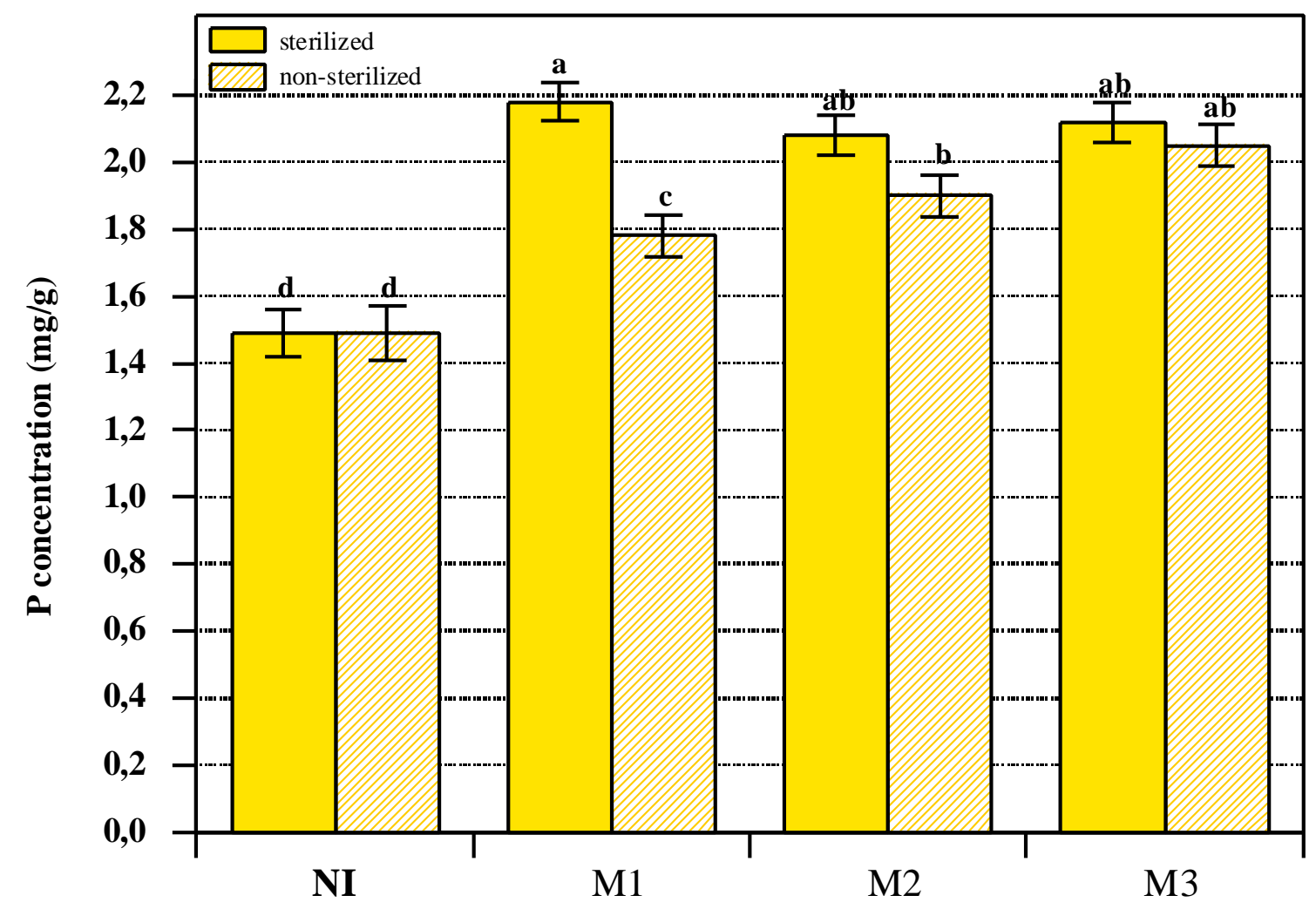

Figure 27: Interaction between mycorrhizal inoculation (M1-M3) and soil sterilization on the P concentration (mg/g) of oil palm plantlets after 3 months of post vitro growth. NI: noninoculated plantlets. Vertical bars represent standard errors of the mean. Columns with ifferent letters are significantly different at $P=0.05$, as indicated by Tukey-test.

The influence of mycorrhizal inoculation and soil sterilization on phosphate uptake is demonstrated in Figure 28. The lowest $\mathrm{P}$ uptake was observed in the non-inoculated (NI) control plants, either grown in sterilized or non-sterilized soil. The P uptake of control plants which grew in sterilized soil was higher but not significant increased.

(V)AMF inoculation significantly improved $\mathrm{P}$ uptake of the oil palm plantlets. The efficiency of the fungal isolates was far greater with sterilization of the growth substrate. The effect of mycorrhizal inoculation on P uptake was lower, but still significantly improved if plants grew in non-sterilized soil. The highly improved $\mathrm{P}$ uptake of the mycorrhizal plants which were cultivated in sterilized soil was mainly due to a better growth of the oil palm plantlets in this treatment. 


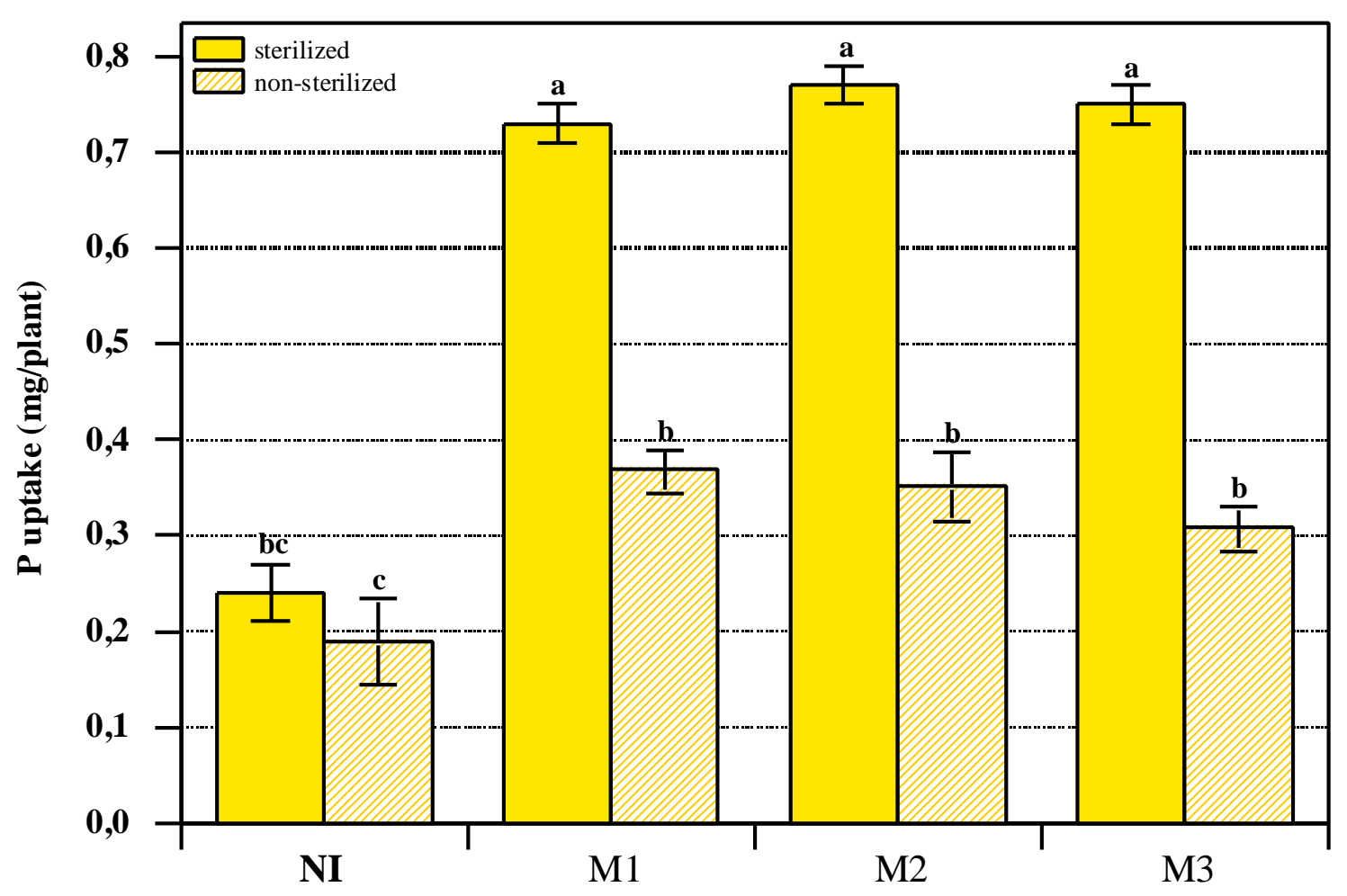

Figure 28: Interaction between mycorrhizal inoculation (M1-M3) and soil sterilization on the $\mathrm{P}$ uptake (mg/plant) of oil palm plantlets after 3 months of post vitro growth. NI: noninoculated plantlets. Vertical bars represent standard errors of the mean. Columns with differentl etters are significantly different at $P=0.05$, as indicated by Tukey-test.

The interaction between soil sterilization and protection measures showed that the $\mathrm{P}$ uptake of plants was generally higher when the growth substrate was sterilized (Table 53). The increased $\mathrm{P}$ uptake due to soil sterilization was improved when plantlets were cultivated in 'sunbags'. As a consequence of poor growth, which was observed when plants were grown in the non-sterilized soil, the P uptake was low and not affected by the protection measures.

Table 53: Interaction between soil sterilization and protection measures on the $\mathrm{P}$ uptake (mg/plant) of oil palm plantlets after 3 months of post vitro growth. Means with different letters are significantly different at $P=0.05$ as indicated by Tukey-test.

\begin{tabular}{l|ccc}
\hline \hline & Control & Plastic screen & 'Sunbag' \\
\hline \hline Sterilized & $0.59 \mathrm{a}$ & $0.61 \mathrm{ab}$ & $0.67 \mathrm{~b}$ \\
Non-sterilized & $0.24 \mathrm{c}$ & $0.26 \mathrm{c}$ & $0.30 \mathrm{c}$ \\
\hline \hline
\end{tabular}

\subsection{Potassium}

Mycorrhizal inoculation and soil sterilization were highly significant factors regarding potassium concentration and uptake of the oil palm plantlets (Table 54). The used protection 
measures showed significant differences in $\mathrm{K}$ uptake. The interactions between inoculation and soil sterilization and between protection measures and soil sterilization were highly significant. Interaction between the three main factors regarding $\mathrm{K}$ concentration or $\mathrm{K}$ uptake were not detected. The clones were analysed as covariates and showed no significant differences regarding the studied parameters.

Table 54: ANOVA of main factors and their interactions on the $\mathrm{K}$ concentration $(\mathrm{mg} / \mathrm{g})$ and $\mathrm{K}$ uptake (mg/plant) of micropropagated oil palms after three months of post vitro growth.

\begin{tabular}{l|c|cc|cc}
\hline \hline & & \multicolumn{2}{|c|}{ K (mg/g) } & \multicolumn{2}{c}{ K (mg/plant) } \\
\hline ANOVA & DF & MQ & $\mathbf{P}$ & MQ & P \\
\hline Inoculation (1) & 3 & 70.95 & $\mathbf{0 . 0 0 0}$ & 67.15 & $\mathbf{0 . 0 0 0}$ \\
Protection (2) & 2 & 13.40 & 0.063 & 5.58 & 0.056 \\
Sterilization (3) & 1 & 100.43 & $\mathbf{0 . 0 0 0}$ & 604.67 & $\mathbf{0 . 0 0 0}$ \\
& & & & & \\
$1 \times 2$ & 6 & 4.53 & 0.461 & 0.33 & 0.958 \\
1 x 3 & 3 & 9.45 & 0.119 & 36.47 & $\mathbf{0 . 0 0 0}$ \\
2 x 3 & 2 & 9.37 & 0.143 & 17.48 & $\mathbf{0 . 0 0 0}$ \\
$1 \times 2 \times 3$ & 6 & 4.05 & 0.534 & 2.59 & 0.072 \\
Clone & 1 & 10.46 & 0.140 & 1.10 & 0.360 \\
Error & 170 & 4.77 & & & \\
\hline \hline
\end{tabular}

The $\mathrm{K}$ concentration of the plants was significantly increased by (V)AMF inoculation (Table 55). The oil palm plantlets showed a significantly higher $\mathrm{K}$ concentration and uptake when they were cultivated in the sterilized growth substrate.

Table 55: Mycorrhizal inoculation and soil sterilization as main effects on the $K$ concentration $(\mathrm{mg} / \mathrm{g})$ of oil palm plantlets after 3 months of post vitro growth. NI: noninoculated plantlets. Columns with different letters are significantly different at $P=0.05$ as indicated by Tukey-test.

\begin{tabular}{ll|lc}
\hline \hline Inoculation & & Soil sterilization & \\
\hline \hline & & & \\
NI & $17.62 \mathrm{~b}$ & Sterilized & $20.48 \mathrm{a}$ \\
M1 & $20.34 \mathrm{a}$ & & \\
M2 & $20.43 \mathrm{a}$ & Non-sterilized & $18.99 \mathrm{~b}$ \\
M3 & $20.52 \mathrm{a}$ & & \\
& & & \\
\hline \hline
\end{tabular}

The interaction between inoculation and soil sterilization on $\mathrm{K}$ uptake of the plants are demonstrated in Table 56. The $\mathrm{K}$ uptake was greatly increased in the inoculated plantlets which were transferred to sterilized soil. Due to poor growth of the inoculated plants which 
were cultivated in non-sterilized soil, the potassium uptake in these treatments was significantly lower, and, with the exception of Glomus manihot (M1), similar to that of the non-inoculated (NI) control plants.

Table 56: Interaction between mycorrhizal inoculation (M1-M3) and soil sterilization on the $\mathrm{K}$ uptake (mg/plant) of oil palm clones after 3 months of post vitro growth. NI: noninoculated plantlets. Means with different letters are significantly different at $P=0.05$, as indicated by Tukey-test.

\begin{tabular}{l|cccc}
\hline \hline & NI & M1 & M2 & M3 \\
\hline \hline Sterilized & $2.94 \mathrm{bc}$ & $7.34 \mathrm{a}$ & $7.88 \mathrm{a}$ & $7.62 \mathrm{a}$ \\
\multirow{2}{*}{ Non-sterilized } & $2.18 \mathrm{c}$ & $3.39 \mathrm{~b}$ & $3.06 \mathrm{bc}$ & $2.46 \mathrm{bc}$ \\
\hline \hline
\end{tabular}

The effects of soil sterilization and protection measures on $\mathrm{K}$ uptake are demonstrated in Table 57. The highest $\mathrm{K}$ uptake was detected in plants which were cultivated in sterilized soil. This effect was improved when plantlets were grown in 'sunbags'. The P uptake of plants which were transferred to non-sterilized soil was low due to poor shoot growth and was not improved by either of the protection measures.

Table 57: Interactions between soil sterilization and protection measures on the $\mathrm{K}$ uptake (mg/plant) of oil palm clones after 3 months of post vitro growth. Means with different letters are significantly different at $P=0,05$ as indicated by Tukey-test.

\begin{tabular}{l|ccc}
\hline \hline & Control & Plastic screen & 'Sunbag' \\
\hline \hline Sterilized & $5.59 \mathrm{c}$ & $6.44 \mathrm{~b}$ & $7.30 \mathrm{a}$ \\
\multirow{2}{*}{ Non-sterilized } & $3.04 \mathrm{~d}$ & $2.72 \mathrm{~d}$ & $2.56 \mathrm{~d}$ \\
\hline \hline
\end{tabular}

\subsection{Nitrogen}

Mycorrhizal inoculation and soil sterilization were highly significant main factors regarding nitrogen concentration and uptake of plants (Table 57). However, the interactions between inoculation and soil sterilization and between protection measures and soil sterilization were highly significant regarding $\mathrm{N}$ uptake. Interactions between the three main factors as regards $\mathrm{N}$ concentration or $\mathrm{N}$ uptake were not detected. The clones were analysed as covariates and showed no significant differences with regard to the studied parameters. 
Table 58: ANOVA of main factors and their interactions on the $\mathrm{N}$ concentration $(\mathrm{mg} / \mathrm{g})$ and $\mathrm{N}$ uptake (mg/plant) of micropropagated oil palms after three months of post vitro growth.

\begin{tabular}{l|c|cc|cc}
\hline \hline & & \multicolumn{2}{|c|}{$\mathbf{N}(\mathbf{m g} / \mathbf{g})$} & \multicolumn{2}{c}{$\mathbf{N}$ (mg/plant) } \\
\hline ANOVA & DF & MQ & $\mathbf{P}$ & MQ & $\mathbf{P}$ \\
\hline Inoculation (1) & 3 & 106.34 & $\mathbf{0 . 0 0 1}$ & 113.09 & $\mathbf{0 . 0 0 0}$ \\
Protection (2) & 2 & 114.52 & 0.053 & 0.42 & 0.866 \\
Sterilization (3) & 1 & 104.83 & $\mathbf{0 . 0 2 1}$ & 963.22 & $\mathbf{0 . 0 0 0}$ \\
& & & & & \\
1 x 2 & 6 & 21.63 & 0.356 & 2.87 & 0.433 \\
1 x 3 & 3 & 40.99 & 0.100 & 55.18 & $\mathbf{0 . 0 0 0}$ \\
2 x 3 & 2 & 16.66 & 0.426 & 17.74 & $\mathbf{0 . 0 0 3}$ \\
$1 \times 2 \times 3$ & 6 & 20.15 & 0.402 & 7.25 & 0.054 \\
Clone & 1 & 6.78 & 0.555 & 0.61 & 0.647 \\
Error & & & & & \\
\hline \hline
\end{tabular}

The $\mathrm{N}$ concentration of the inoculated oil palm plantlets was significantly higher than that of the non-inoculated control plants (Table 59). The sterilization of the soil also significantly increased the $\mathrm{N}$ concentration of the oil palm plantlets.

Table 59: Mycorrhizal inoculation (M1-M3) and soil sterilization as main effects on the $N$ concentration $(\mathrm{mg} / \mathrm{g})$ of oil palm plantlets after 3 months of post vitro growth. NI: noninoculated plantlets. Columns with different letters are significantly different at $(P=0,05)$ as indicated by Tukey-test.

\begin{tabular}{ll|lc}
\hline \hline Inoculation & Soil sterilization & \\
\hline \hline & & & \\
NI & $23.89 \mathrm{~b}$ & Sterilized & $26.88 \mathrm{a}$ \\
M1 & $26.58 \mathrm{a}$ & & \\
M2 & $27.84 \mathrm{a}$ & Non-sterilized & $25.63 \mathrm{~b}$ \\
M3 & $26.67 \mathrm{a}$ & & \\
& & & \\
\hline \hline
\end{tabular}

The uptake of nitrogen was affected as a consequence of differences in plant growth (Table 60). The inoculated plantlets grown in sterilized soil showed the highest shoot growth and took up significantly more $\mathrm{N}$ than the non-inoculated (NI) control plants. In the non-sterilized soil, inoculation did not significantly change $\mathrm{N}$ uptake. 
Table 60: Interactions between mycorrhizal inoculation (M1-M3) and soil sterilization on the $\mathrm{N}$ uptake (mg/plant) of oil palm clones after 3 months of post vitro growth. NI: noninoculated plantlets. Means with different letters are significantly different at $P=0.05$, as indicated by Tukey-test.

\begin{tabular}{l|cccc}
\hline \hline & NI & M1 & M2 & M3 \\
\hline \hline Sterilized & $3.95 \mathrm{~b}$ & $9.41 \mathrm{a}$ & $10.51 \mathrm{a}$ & $9.59 \mathrm{a}$ \\
& & & & \\
Non-sterilized & $2.94 \mathrm{~b}$ & $4.36 \mathrm{~b}$ & $4.26 \mathrm{~b}$ & $3.37 \mathrm{~b}$ \\
\hline \hline
\end{tabular}

The interactions between soil sterilization and protection measures are demonstrated in Table 61. The significantly highest $\mathrm{N}$ uptake was obtained when plants were cultivated in sterilized soil. As a consequence of poor growth, which was observed when plants were grown in the non-sterilized soil, the $\mathrm{N}$ uptake was low in this treatment. Differences in the nitrogen uptake of the oil palm plantlets were not affected by the protection measures.

Table 61: Interaction between soil sterilization and protection measurements on the $\mathrm{N}$ uptake (mg/plant) of oil palm clones after 3 months of post vitro growth. Means with different letters are significantly different at $P=0.05$, as indicated by Tukey-test.

\begin{tabular}{l|ccc}
\hline \hline & Control & Plastic screen & 'Sunbag' \\
\hline \hline Sterilized & $7.70 \mathrm{~b}$ & $8.59 \mathrm{a}$ & $8.12 \mathrm{a}$ \\
Non-sterilized & $4.29 \mathrm{~b}$ & $3.70 \mathrm{bc}$ & $3.21 \mathrm{c}$ \\
\hline \hline
\end{tabular}

\subsection{5. (V)AMF infection}

Mycorrhizal inoculation and soil sterilization were highly significant factors in the percentage of (V)AMF infection (Table 62). The interactions between inoculation and soil sterilization and between protection measures and soil sterilization were also highly significant. Interactions between the three main factors regarding percentage of (V)AMF infection were not detected. The clones were analysed as covariates and showed no significant differences as regards the studied parameter. 
Table 62: ANOVA of main factors and their interactions on the (V)AMF infection rate (\%) of micropropagated oil palms after three months of post vitro growth.

\begin{tabular}{l|c|c|c}
\hline \hline ANOVA & DF & MQ & P \\
\hline Inoculation & 3 & 9492.22 & $\mathbf{0 . 0 0 0}$ \\
Protection & 2 & 658.86 & 0.055 \\
Sterilization & 1 & 3771.43 & $\mathbf{0 . 0 0 0}$ \\
& & & \\
Inoculation x Protection & 6 & 396.91 & $\mathbf{0 . 0 4 9}$ \\
Inoculation x Sterilization & 3 & 1414.96 & $\mathbf{0 . 0 0 0}$ \\
Protection x Sterilization & 2 & 183.92 & 0.371 \\
Inoculation x Protection x Sterilization & 6 & 162.79 & 0.510 \\
Clone & 1 & 174.65 & 0.332 \\
Error & & & \\
\hline \hline
\end{tabular}

The effects of mycorrhizal inoculation and soil sterilization on (V)AMF infection rates are demonstrated in Figure 29. Non-inoculated (NI) control plants grown in sterilized soil were not colonized by mycorrhizal fungi. According to Munro et al. (1999), the absence of mycorrhizal infection indicates that there was no ingress of infective particles during the experiment. It also reflects the negative impact of soil sterilization on mycorrhizal infection and growth in the absence of inoculation.

A low percentage of mycorrhizal inoculation (4\%) was observed in the non-inoculated (NI) control plants grown in non-sterilized soil. This small degree of mycorrhizal formation was due to indigenous fungi which were present in the non-sterilized soil. The inoculation with (V)AMF isolates significantly increased the infection rate of the oil palm plantlets.

The infectivity of the mycorrhizal fungi varied between fungal isolates and was highly affected by the sterilization of the growth substrate. The infection rates were in general higher when the inoculated plantlets were cultivated in sterilized soil, significantly so for Glomus manihot (M1). The infection rate of these plants ranged around $23 \%$ if plants were grown in non-sterilized soil, and increased to $43 \%$ when cultivated in sterilized soil, may be due to a failure of competiveness with indigeneous fungi present in the native soil. Significant differences in the infectivity of Enthrophospora columbiana (M2) and Acaulospora mellea (M3) were not observed. 


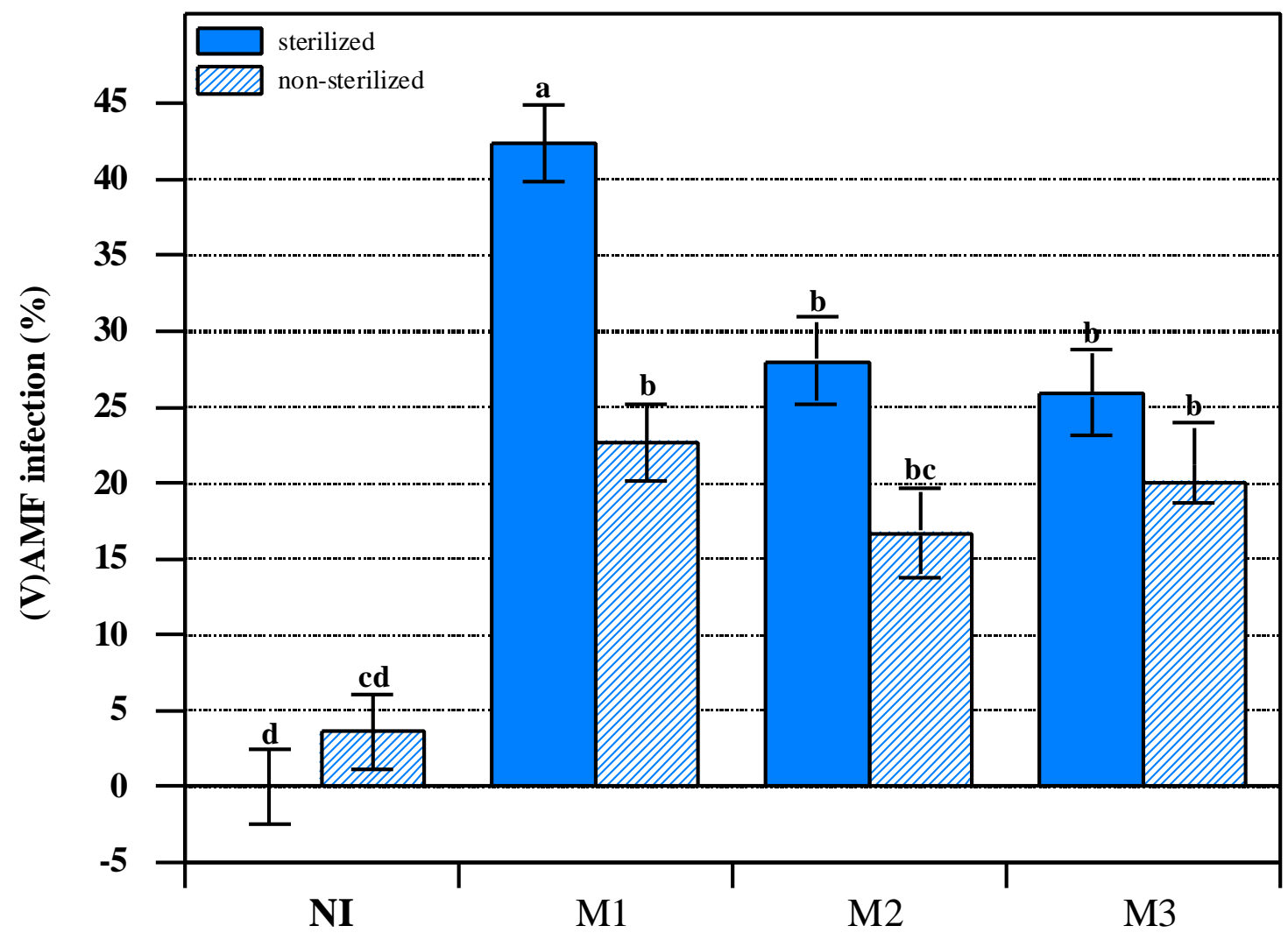

Figure 29: Interactions between mycorrhizal inoculation (M1-M3) and soil sterilization on the(V)AMF infection rate $(\%)$ of oil palm plantlets after 3 months of post vitro growth. NI: non-inoculated plantlets. Vertical bars represent standard errors of the mean. Columns with different letters are significantly different at $P=0.05$, as indicated by Tukey-test.

The (V)AMF colonization differed among the inoculated treatments in this experiment. The increased plant growth was not related to differences in the infection rates of the fungal isolates. The positive effects of the investigated factors were mainly influenced by mycorrhizal inoculation and soil sterilization. Unless plants were accompanied by (V)AMF, growth was poor. The growth-promoting effect of mycorrhizal inoculation was mainly improved when plants were cultivated in sterilized soil due to an increased efficiency of the (V)AMF.

\subsubsection{Conclusions of Experiment 3}

In this experiment, plants were grown in sterilized or non-sterilized soil. Sterilization was carried out to investigate the pathogenic potential of the soil and to eliminate indigenous mycorrhizal propagules.

The lowest survival rates were observed in the non-inoculated control plants which were grown either in sterilized or non-sterilized soil soil. According to these results, it seems that the sterilization of the soil could not be considered as a measure for reducing the problem of 
plant mortality due to pathogens or other reasons. The effect of soil sterilization alone was low, unless plants were inoculated with the (V)AMF isolates. Due to the effectiveness of the endomycorrhizal fungi, the combination of these two treatments was the most effective in promoting plant survival and development, especially when the plantlets were not well developed at the time of transfer to the soil.

Heating or partial sterilization of soil alters the biological and chemical properties of the soil in addition to eliminating microorganisms. It can be concluded that soil sterilization leads to a combined effect of mineralization and mobilization of nutrients, thus promoting plant growth, and failure of competition with soil own microorganisms.

The plant growth promoting effect through cultivation in 'sunbags' was probably due to the development of a special microclimate in this semi-closed system. These conditions were more similar to in vitro conditions and more favourable for plant development than 'normal' pre-nursery conditions. It is doubtful if this protection makes sense, because the main aim of the post vitro growth period in the greenhouse is the hardening of the sensitive micropropagated plantlets. The question is still open whether the later adaptation of the plantlets to normal conditions will be successful if plants are grown in this protected environment. Moreover, the cost of 'sunbags' is not low and would be additional to the production costs. From the viewpoint of commercialisation and according to the results obtained in this experiment, the implementation of these measures cannot be recommended.

\section{General discussion}

Over the past few years the use of in vitro micropropagation techniques for multiplication of a wide range of plantation crops, ornamentals, fruits, vegetables and forest trees, has increased rapidly. One of the main objectives of such a technique is to obtain a large number of identical plants from a selected mother plant. For this purpose, tissue-culture techniques are being developed rapidly. However, little attention has been given to acclimatisation and adaptation of in vitro propagated plants to greenhouse and/or field.

The high mortality and poor development of micropropagated oil palms experienced at the "Indonesian Oil Palm Research Institute" (IOPRI) after plantlets were transferred to ex vitro conditions is a major problem for expanding clonal oil palm production commercially. It could be possible to improve plant survival and development after transplanting by introducing a beneficial microbial population into the growth substrate.

Mycorrhizal fungi are known to have beneficial effects on growth and development of many micropropagated species (Ponders, 1984; Douds and Chaney, 1986; Lovato et al., 1994, 1996; 
Azcón-Aguilar and Barea, 1996, 1997) through improvement of mineral nutrition, induction of root system modifications (Berta et al., 1995) and increased resistance to pathogens (Guillemin et al., 1992; Lindermann, 1994). Their elimination during micropropagation frequently results in poor development of plants so that their reintroduction during plant production is important. Based on these facts, the research described in this study was carried out. One of the main aims of this research work was to introduce and establish the mycorrhizal inoculation in an existing micropropagation process with a view to future practical applications. A further objective of this research was to determine whether (vesicular-) arbuscular mycorrhiza could enhance transplanting success and plantlet acclimatisation as indicated by the main plant-growth parameters such as survival rate, plant growth properties, and nutrient uptake.

\subsection{Effect of (V)A mycorrhiza on the post vitro survival of micropropagated oil palms}

The transfer of in vitro plantlets to ex vitro conditions is one of the most critical steps in the micropropagation process. High mortality rates are recorded for certain micropropagated plant species upon transfer to ex vitro conditions due to the plantlets' limited ability to resist the transplant stress. At IOPRI, the percentage of mortality of micropropagated oil palms is high, $30-40 \%$ of the oil palms dying after being transferring ex vitro to the pre-nursery. The main aim of this study was to investigate whether the introduction of (V)AM fungi in the micropropagation system of oil palms can reduce mortality and improve the tolerance of the sensitive plants to the transplanting stress.

The survival of micropropagated oil palms was remarkably improved with mycorrhizal inoculation in all experiments of this study. From the twelve mycorrhizal isolates tested in the initial screening of Experiment 1, eleven fungi were able to improve the survival rate significantly to $83-100 \%$, helping the plantlets to resist the environmental stress induced through transplanting from axenic conditions to normal cultivation in open pots. In contrast, only $55 \%$ of the non-inoculated control plants survived during the three-month experimental period. Inoculation with (V)AM fungi appears to be critical for the survival of micropropagated oil palms. Several investigations have shown that early mycorrhizal inoculation and colonisation of tissue-cultured plantlets of other plant species reduce transplant shock during acclimatisation, and increase plant survival and establishment rates (Varma and Schüepp, 1995; Fortuna et al., 1996; Lovato et al., 1996; Azc?n-Aguilar and Barea, 1997). Azc?n-Aguilar et al. (1997) reported that the survival rate of micropropagated cassava plants, inoculated with Glomus deserticola at the beginning of the acclimatisation stage, was significantly improved by mycorrhizal inoculation. Subhan et al. (1998) used the 
(vesicular-) arbuscular mycorrhizal fungus Glomus fasciculatum for inoculation of micropropagated Sesbania sesban plantlets. All of the inoculated plants survived transplanting in contrast to the non-inoculated control plants, where only $30 \%$ of the plants survived.

In the second and third experiment, four and three out of the twelve tested (V)AMF isolates, respectively, were selected and further investigations were carried out concerning their effectiveness on plant survival.

Experiment 2 investigated the effect of (V)AMF on the survival of oil palm plantlets in combination with different fertilisation methods. The question here was whether the (V)AMF effect described above could also be achieved in plantlets that were able to obtain adequate plant nutrients provided by fertilisation. The lowest percentage of plant survival (45\%) was observed in the non-inoculated control plants growing either in non-fertilised soil or in soil fertilised with poorly soluble hydroxy-apatite (HA). These low survival rates were significantly improved by mycorrhizal inoculation with the tested (V)AMF to $75-95 \%$ in the non-fertilised, and up to $85-100 \%$ in the HA-fertilised plants, respectively.

Significantly more $(80 \%)$ of the non-inoculated control plants survived during the post vitro growth period when 'BAYFOLAN', a completely soluble foliar fertiliser, was applied; (V)AMF inoculation, however, further improved plant survival of these plants to $85-100 \%$. This effect of the 'BAYFOLAN' fertilisation observed in the control plants of this experiment does not correspond with the survival data of $60-70 \%$ recorded by IOPRI in the past years (Ginting 1996). These results underscore the importance of an early inoculation and the establishment of the symbiosis with mycorrhizal fungi for post vitro growth of the oil palm plantlets, even when they are fertilised with a foliar spray fertiliser.

Mycorrhizal infection often reduces susceptibility or increases tolerance of roots to soil-borne pathogens like fungi or nematodes (Powell and Bagyaraj, 1984; Cordier et al., 1996). In the third experiment, the role of pathogens, which are supposed to be the main cause of plant mortality (Ginting, personal communication), was investigated. Plants were transplanted to sterilised or non-sterilised soil and grew with special protection measures to prevent pathogenic contamination. The lowest survival rates (40\%) were detected in the noninoculated plants which grew either in sterilised or non-sterilised soil. These results show that soil sterilisation has no effect on plant survival, suggesting a lack of soil-borne pathogens. (V)AMF inoculation highly increased plant survival in both soils, and the efficiency of the fungal isolates was enhanced by soil sterilisation. If the inoculated plants were grown in nonsterilised soil, survival improved to $60-83 \%$, which increased to $97-100 \%$ when the soil was sterilised. The positive effect of soil sterilisation on the efficiency of the (V)AMF was 
possibly due to the decrease of indigenous mycorrhizal fungi which are normally present in native soil and would have competed with the inoculated (V)AMF.

It was observed in this study, that the first six weeks after transplanting were the most critical for the survival of the sensitive oil palm plantlets. Most of the plants died during this period. In Experiment 2, plants were harvested twice, at six and twelve weeks after inoculation and transplanting, to investigate the effect of mycorrhiza during the early stages of post vitro development. The results show that during this period (V)AMF infection was initiated and fungi colonised the host, so that the reduced mortality in (V)AMF inoculated plants was possibly due to the early mycorrhizal colonisation of the plants.

Several other studies on the early stages of post vitro acclimatisation have reported this phase to be critical in the micropropagation cycle, during which the lack of beneficial microorganisms can adversely affect survival and growth of the micropropagated plantlets (Pons et al., 1983). In contrast, in a study of Wang et al. (1993), (V)AMF infection was not recorded in the first 4 weeks following inoculation of S. podophyllum, Gerbera or Nephroleptis sp. The authors concluded that mycorrhizal fungi do not affect survival of micropropagated plants.

In this study, the post vitro inoculation with endomycorrhizal isolates increased the survival percentage markedly, a result which is in line with previous studies which show that endomycorrhizal inoculation at the time of transplanting from axenic to in vivo conditions significantly improve survival and growth of micropropagated plantlets (Ravolanirina et al., 1989; Branzanti et al., 1992; Sbrana et al., 1994). Different explanations have been proposed for this phenomenon. (V)AM fungi were suggested to promote renewed shoot apical growth of micropropagated plants (Fortuna, 1998). Inoculation at the weaning stage produces plants with a more effective root system for uptake of $\mathrm{P}$ and other nutrients (Bertha et al., 1990) as well as making them more resistant to transplant stress (Cordier et al., 1996).

\subsection{Effect of (V)A mycorrhiza on post vitro plant development during the experimental period}

The vitality and post vitro development of the oil palms during the experimental period was characterised by the shoot length and number of leaves, which were measured at two-week intervals. The increase in shoot length and emergence of new leaves are signs of adaptation to ex vitro conditions.

After transplanting, initial development of the oil palm plantlets during the first weeks was generally slow with only marginal shoot growth. Micropropagated plants frequently show blocked apical growth just after transplanting, described as 'transplant shock'. Renewed 
growth occurs after different periods, depending on nutritional and environmental conditions as, for example, reported for peach plants (Morini and Concetti, 1984).

The inoculation of the plantlets with (V)AMF isolates initiated an earlier shoot growth compared to the non-inoculated plants. This effect was observed in all experiments. In experiments carried out by Fortuna et al. (1992), plum plants showed a similar behaviour, but with mycorrhizal inoculation most plants showed renewed apical growth during the first month after transplanting, whilst non-inoculated controls did not actively grow and apices remained blocked up to the end of the 3-month experimental period. The authors concluded that probably additional effects other than nutrition, such as hormone balance modifications, are produced by the symbiosis. This was also suggested by Allen et al. $(1980,1982)$.

The beneficial effect of inoculation on shoot growth resulted in 2-3 times taller shoots compared to the non-inoculated control plants. This observation is consistent with data on other micropropagated species. Granger et al. (1983), Vidal et al. (1992), Lovato et al. and Rapparini et al. (1996) report increases in plant height of 1.5 to 3.0 times when mycorrhizae were applied to micropropagated apple, avocado, grapevine, common ash, and pear plants.

The results of Experiment 2 indicate that mycorrhizal inoculation is more effective on shoot growth than fertilisation. The shoot length of the non-fertilised plantlets was significantly increased by mycorrhizal inoculation. The highest increment in shoot length was observed in most of the inoculated plants growing in soil fertilised with hydroxy-apatite. (V)AMF inoculation of the 'BAYFOLAN' fertilised plants resulted in significantly higher shoot lengths.

Experiment 3 confirmed the beneficial effect of mycorrhizal inoculation on shoot growth especially when the plantlets were cultivated in sterilised soil.

At the end of each investigated post vitro period in this study, plants with mycorrhizal inoculation developed stronger and more vigorous shoots than plants without. Root infection by mycorrhizal fungi can enhance the growth of plantlets of selected species as reported by Branzanti et al. (1992) and Azcón-Aguilar and Barea (1997), and cause earlier resumption of shoot apical growth in apple (Fortuna et al., 1992, 1996) and plum rootstock (Azcón-Aguilar et al. 1994). In an investigation of Berta et al. (1995), it was demonstrated that the presence of this association avoids blocking of shoot apical growth at transplanting of Prunus cerasifera, a fact which is of great importance. In experiments of Cordier et al. (1996), blocked apical shoot growth was also frequent in control plants after transplanting, while this did not occur in the mycorrhizal Prunus avium plants. This has also been observed for other woody plants like micropropagated fruit rootstocks (Fortuna et al., 1992; Sbrana et al., 1994). The influence of (V)AM on shoot apical growth of these micropropagated fruit trees was reported; however, 
the mechanisms involved were not investigated. Fortuna concluded that mycorrhizal inoculation in nursery production may present a useful tool to overcome both inhibition of apical activity and stunted growth of plantlets and allows the reduction of chemical inputs during the acclimatisation phase of micropropagated fruit trees.

In addition to the cumulative growth of shoots, the leaf development of the oil palm plantlets was generally stimulated by mycorrhizal inoculation. The emergence of the first new leaves, developed ex vitro, could be observed between 2 and 4 weeks after transplanting in contrast to the non-inoculated plants, where the first new leaves did not emerge until 6 weeks after transplanting. The development of new leaves during acclimatisation is considered to be important for the vigorous growth of the plants. During acclimatisation, leaves present as primordial leaves in vitro assume an intermediate character between leaves grown in vitro and greenhouse- or field-grown plants. Only new leaves that form completely after removal from culture resemble greenhouse-grown leaves (Grout and Aston, 1978; Brainerd and Fuchigami, 1981; Wetzstein and Sommer, 1982; Donelly et al., 1985).

The leaves formed in vitro are thin and have underdeveloped leaf mesophyll and a very low chlorophyll content. These factors make the plantlets photosynthetically less efficient or even inactive ( Desjardins et al., 1994; Ziv, 1995). In many plant species, the leaves formed in vitro are unable to develop further under ex vitro conditions, and they are replaced by newly formed leaves (Preece and Sutter, 1991; Diettrich et al., 1992).

At the end of the experimental period, the growth-promoting effect of mycorrhiza resulted in higher total shoot length, accompanied by a higher number of expanded leaves in most of the inoculated treatments compared to the non-inoculated plants.

\subsection{Effect of (V)A mycorrhiza on the root development of micropropagated oil palm clones after 12 weeks of post vitro growth}

A weakly developed root system is considered to be a main cause of the high plant mortality observed at IOPRI at the time of transplanting to ex vitro conditions. In vitro plantlets taken from an aseptic environment, where temperature, light and high relative humidity were controlled, are extremely fragile. The plantlets photosynthesise very little, if at all, and do not have enough roots. Consequently, plantlets suffer from severe environmental stress, and substantial losses may occur (Preece and Sutter, 1991; Van Huylenbroeck and Deberg, 1996).

Acclimatisation of micropropagated oil palms corresponds to a transition period when roots become adapted to a substrate with less available nutrients and to an autotrophic condition.

In this study, the root system of inoculated plants was in general better developed than that of the non-inoculated plantlets after 12 weeks of post vitro growth. This was specially seen in 
Experiment 1 and 3, where significantly higher root fresh weights were estimated in the inoculated plants.

Improvement of rooting and root function due to mycorrhizal inoculation have also been observed in several micropropagated species (Schellenbaum et al., 1991), along with greater tolerance of environmental stress (Varma and Schüepp, 1995). There is increased evidence that the role of mycorrhizal fungi in enhancing the survival rates of micropropagated plantlets is based on the development of a stronger root system and enhancement in root functions (Elmeskaoui et al., 1995). Berta et al. (1990) reported that mycorrhizal inoculation at the weaning stage produces plants with a more effective root system for uptake of $\mathrm{P}$ and other nutrients. At this stage the presence of mycorrhizas increases the availability of limiting nutrients such as phosphorus and nitrogen by facilitating their absorption.

In this study, the symbiosis with mycorrhizal fungi enhanced both root and shoot growth and resulted in significantly lower root:shoot fresh weight ratios for mycorrhizal plants than for control plants. This is in line with results obtained by Azcón-Aguilar and Barea (1997). Plants forming mycorrhizae tend to have a lower root:shoot (R:S) ratio, which means a greater biomass efficiency, since less energy is directed to root formation. Using micropropagated pineapple, Guillemin et al. (1991) were even able to demonstrate the existence of a negative correlation between the mycorrhizal effect on root and shoot development. According to the authors, the higher the root:shoot ratio, the less efficient the system for shoot production. This mycorrhizal effect on root development is partly due to architectural changes in the root system, as has been demonstrated in particular for micropropagated woody species such as grapevine (Schellenbaum et al., 1991) and Prunus (Berta et al., 1994). These studies show that mycorrhiza formation changes root topology from a herringbone pattern to a more dichotomous pattern, the latter being more efficient for scavenging of the soil nutrients. Pacovisky et al. (1986) reported that P-deficient plants lacking (V)AM symbiosis tend to have a high root:shoot ratio, which is usually associated with nutrient-stressed plants.

\subsection{Dry matter accumulation}

The role of mycorrhizae in improving the growth and productivity of seed-grown plants as a natural symbiont has been well established (Srivastava et al., 1996). During the last few years, the mycorrhizal technology has been used in a number of micropropagated plant species in order to improve plant growth (Varma and Schuepp, 1994; Puthur et al., 1998; Subhan et al., 1998).

The growth-promoting effect of mycorrhizal inoculation on shoot and leaf development already mentioned in this study resulted in significantly higher shoot dry weights in most of 
the inoculated oil palm plantlets. Sbrana et al. (1994) demonstrated that the inoculation of micropropagated plantlets of apple, peach and plum resulted in improved overall growth besides increasing the survival rate.

The screening of twelve (V)AMF species showed that ten mycorrhizal fungi were highly effective in promoting plant growth, even when plantlets received no fertilisation. The most effective (V)AMF isolates were selected and further investigated in their effect on plant development. Experiment 2 investigated whether the growth-promoting effect of (V)AMF could be achieved in plantlets that were able to obtain adequate plant nutrients by fertilisation. The shoot growth was generally improved by (V)AMF inoculation compared to that of noninoculated control plants. The highest shoot dry weight was found in the inoculated plantlets which were fertilised either with hydroxy-apatite or 'BAYFOLAN'. Significant differences in the shoot dry weight of the inoculated plants in both fertilisation treatments could not be found in this experiment. The application of both, mycorrhizal inoculation and fertilisation, ensured maximum growth of the oil palm plantlets.

The effect of soil fertilisation with slowly soluble hydroxy-apatite on plant growth in Experiment 2 was low unless accompanied by mycorrhizal inoculation. Plantlets were grown in a growth substrate which was of low $\mathrm{pH}$, which is typical for most tropical soils. Under such conditions inoculation with the tested (V)AMF isolates was an important factor in facilitating plant recovery of $\mathrm{P}$ from these fertiliser and therefore fertiliser efficiency (LangeNess and Vlek, 2000).

Blal et al. (1990) compared the influence of (vesicular-) arbuscular mycorrhizae on the efficiency of triple superphosphate and rock phosphate fertilisers in two tropical, acid, Pfixing soils from the Ivory Coast in which available $\mathrm{P}$ was labelled with ${ }^{32} \mathrm{P}$. Both soils were planted with micropropagated oil palms. Both fertilisers were equally available to the plants but the growth responses to the fertiliser applications were low unless accompanied by (V)AM inoculation. The oil palms grew very poorly in both soils without mycorrhizal infection, although adding phosphate fertilisers to the non-inoculated control plants led to a significant increase in dry matter production.

The increase in oil palm growth obtained in this experiment by the combination of mycorrhizal inoculation and fertilisation compared to the non-inoculated plants reflected the low P-uptake capacity of the oil palm roots and the high mycorrhiza dependency of the oil palms.

The growth-promoting effect of (V)AMF observed in this study was also confirmed in Experiment 3. The effectiveness of the (V)AMF isolates was highly improved if the oil palms were grown in sterilised soil. 
In this study, there were large differences in growth between inoculated and non-inoculated plants, confirming the importance of mycorrhizal inoculation for micropropagated oil palms, as reported for micropropagated fruit trees (Branzanti et al., 1994) and cassava plantlets (Azcón-Aguilar and Barea, 1997). The shoot dry weight was higher in mycorrhizal oil palm plantlets as a consequence of the better nutritional status and active growth of inoculated plantlets.

In investigations of Azcón-Aguilar et al. (1994), Lovato et al. (1994) and Rapparini et al. (1994), it was reported that micropropagated plantlets which were inoculated with mycorrhizal fungi had enhanced plant quality, nutrient uptake and plant growth. The inoculation of plants with (V)AM fungi increases the growth of plants by several fold, and generally most of the growth enhancement effects observed in root colonisation with (V)AM fungi are caused by increased P absorption (Bagyaraj and Varma, 1995).

\subsection{Effect of (V)A mycorrhiza on nutrient concentration and uptake of oil palm plantlets}

\subsubsection{Phosphorus}

In this study, the inoculation with (V)AMF isolates significantly increased phosphorus concentration and uptake of the oil palm plantlets compared to the non-inoculated controls. The role of (V)AM fungi in uptake of nutrients, particularly $\mathrm{P}$, is well documented (Bolan, 1991; Marschner and Dell, 1994; Smith et al., 1998). Estrada-Luna et al. (2000) reported that mycorrhizal inoculation altered the nutrient uptake of micropropagated guava plantlets, especially the leaf elemental concentration of $\mathrm{P}$ was significantly higher in mycorrhizal plants. It was seen in Experiment 1 and 3 that inoculated plants showed increased P uptake even when they were not fertilised.

The growth stimulation of mycorrhizal plants in this study may be explained by higher mineral P concentrations in foliar tissues. Koch and Johnson (1984) and Fitter (1988) reported that net photosynthesis of mycorrhizal plants can increase as a result of improved plant nutritional status. Plants with an optimal P concentration should be more vigorous with high net photosynthesis $(A)$ and stomatal conductance $\left(\mathrm{g}_{\mathrm{s}}\right)$ than plants with limiting $\mathrm{P}$ (Radin and Eidenbock, 1986). Low P can also reduce the concentration and activity of RubisCO, and slow down the regeneration of intermediate substances in the Calvin cycle (Lauer et al. 1989). The interaction between inoculation and fertilisation in Experiment 2 demonstrated the high effectiveness of mycorrhizal inoculation on $\mathrm{P}$ uptake. The highest $\mathrm{P}$ uptake in this experiment was observed in the inoculated plants which were fertilised with the slowly soluble hydroxy- 
apatite (HA). Especially Acaulospora appendicula significantly increased P uptake of plants compared with all inoculated plants of the non-fertilised or 'BAYFOLAN' fertilised treatments. Mycorrhizal fungi often have access to forms of nutrients which are not directly available to plants (Lange-Ness and Vlek, 2000), as well as being able to acquire nutrients which are spatially separated from roots. However, it is now evident that these associations have a greater benefit when phosphorus is present in less-soluble forms (Bolan 1991, Tarafdar \& Marschner 1994, Kahiluoto \& Vestberg 1998, Lange-Ness and Vlek, 2000).

The results of Experiment 2 also indicate that mycorrhizal inoculation has a greater effect on $\mathrm{P}$ uptake of shoots than fertilisation. A comparison between all non-inoculated control plants shows that the fertilisation with the complete foliar 'BAYFOLAN', which is practised at IOPRI, or fertilisation with hydroxy-apatite, does not significantly increase the $\mathrm{P}$ uptake of the plants, unless accompanied by (V)AMF. The combination of both, inoculation and fertilisation, resulted in a highly improved $\mathrm{P}$ uptake by the plants.

According to the results of this study, the first six weeks after transplanting to soil seem to be the most critical for the survival and growth of the sensitive oil palm plantlets. Inoculated plantlets of Experiment 2 harvested after six weeks of post vitro growth showed significantly increased $\mathrm{P}$ concentration and uptake. At this early growth stage, the P uptake of mycorrhizal plants was 2 times higher compared to the non-inoculated control plants. A significantly increased nutrient concentration at that growth stage was only found for phosphorus, but not for potassium or nitrogen. These results indicate that $\mathrm{P}$ seems to be the most limiting growth factor during the early post vitro stage of the oil palm clones. Addition of fertilisers does not greatly improve the nutrient status of propagated plants in their early growing stage because of their relatively small root systems and inability to take up nutrients efficiently.

In Experiment 3, the beneficial effect of (V)AMF inoculation on P uptake of the plants was confirmed. The effectiveness of the fungal isolates was far greater with soil sterilisation. The effect of inoculation on P uptake was lower, but still significantly improved if plants grew in non-sterilised soil. The higher effectiveness of the (V)AMF isolates may be due to the mobilisation of nutrients, particularly $\mathrm{P}$, and/or the decreased competition between native and introduced mycorrhizal fungi, as a result of the soil sterilisation.

The mycorrhizal dependency of oil palm plantlets on $\mathrm{P}$ uptake during the critical post vitro phase was illustrated in this study. The improvement of plant nutrition, especially phosphate, is a physiological factor that can be used to evaluate the functioning of the endomycorrhizal symbiosis.

According to a wide spectrum of research work documented in literature, phosphorus is recognised as being the most important plant-growth limiting factor which can be supplied by 
mycorrhizal associations, because of the many abiotic and biotic factors which can restrict its mobility in soils (Harley \& Smith 1983, Hayman 1983, Marschner 1986, Bolan 1991, etc.).

\subsubsection{Potassium and Nitrogen}

(V)AM fungi might also increase the uptake of other nutrients that move to the root surface primarily by diffusion (Abbott and Robson, 1984). This could explain the higher K uptake of the inoculated oil palms in this study.

Nevertheless, no direct mycorrhizal effect on K uptake has been demonstrated to date (Harley and Smith, 1993). Considering the importance of $\mathrm{P}$ and $\mathrm{K}$ during the early growth stages of micropropagated plants, the better growth response in mycorrhizal plants was probably due to the increased uptake of these two nutrients.

Matos et al. (1996) investigated the effect of endomycorrhizal inoculation on the growth of micropropagated pineapple plants. After 12 months of growth, the mycorrhizal plants showed significantly greater dry matter accumulation of leaves than the controls. It was also observed that in the mycorrhizal treatments, the $\mathrm{P}$ and $\mathrm{K}$ concentrations in the leaves were higher. These data indicate that mycorrhizal plants showed a greater vigour and a better nutritional status when compared to the non-mycorrhizal plants. The better nutritional status of mycorrhizal plants is primarily due to the improved plant growth as a result of increased $\mathrm{P}$ uptake (Cooper, 1984; Rizardi, 1990).

Declerck et al., (1995) investigated the growth response of micropropagated banana plants to (V)AM inoculation. Inoculation with Glomus mosseae and Glomus geosporum resulted in significantly higher shoot fresh and dry weights as compared to the control plants. Shoot $\mathrm{P}$ and $\mathrm{K}$ contents were also significantly higher in inoculated plants. The authors concluded that the higher $\mathrm{P}$ content could be related to various mechanisms, including the larger soil volume which reduces the distance of ion diffusion to the plant roots, and rhizosphere modifications (Bolan, 1991). (V)AM fungi might also increase the uptake of other nutrients that move to the root surface, primarily by diffusion (Abbott and Robson, 1984).

Improvement of the nitrogen status of the host is one of the ecologically significant consequences of mycorrhizal associations. (V)AM fungal hyphae have the ability to extract nitrogen and transport it from the soil to the plant due to the increased absorption surface provided by the mycorrhizal fungi. Nitrogen exists in many forms, namely free nitrogen, nitrate, nitrite, ammonium ions and organic nitrogen. Ammonium constitutes a significant proportion of the inorganic nitrogen pool at a low $\mathrm{pH}$ level. Ammonium is less mobile in soil because it is fixed in lattice of clay minerals and absorbed to negatively charged clay 
minerals. (V)A mycorrhiza hyphae transport this immobile ammonium to the plant roots (Bowen, 1987).

This study shows that inoculation with efficient (V)AMF isolates leads to an improved plant nutritional status which is probably the cause of improved plant development and consequently reduces plant mortality. Several authors report that (V)AM fungal colonisation of horticultural plants improves growth by increasing uptake of $\mathrm{P}$ and other minerals (Gianinazzi and Gianinazzi-Pearson, 1986; Sieverding, 1991; Pearson and Jakobsen, 1993), thus increasing transplanting uniformity which resulted in reduced plant mortality (Biermann and Linderman, 1983) and injury (Menge et al., 1978).

\section{6 (V)AMF infectivity and effectiveness}

In (VA)MF symbiosis, the ability of a fungal species to infect a host plant rapidly plays an important role in determining the success of the relationship. The main parameters, which can be utilised to measure this type of host affinity, are fungal infectivity and the growthpromoting ability of (V)AM fungi.

All mycorrhizal fungi tested in the initial screening of Experiment 1 had been shown to form mycorrhizas with the oil palm plantlets. Levels of infection observed after trypan blue staining differed between isolates and ranged in most cases between 17-23\%. Plants inoculated with Glomus mosseae (M4) showed the highest infection rate (27\%) while the lowest infection rate was observed in roots of plantlets inoculated with Glomus clarum (M8), although inoculation with both fungi improved plant growth significantly. This would suggest that Gl. clarum is a highly effective symbiont in this mycorrhiza-host association, even when root infection is weak. Despite the low percentage of root infection by the tested (V)AM fungi, the effectiveness on plant survival and on growth improvement was significant in this study. Pinochet et al. (1997) also reported that the percentage of mycorrhizal colonisation of Gl. interadices was relatively low at $27 \%$, although plant growth in mycorrhizal treatments was significantly better than in non-mycorrhizal treatments for all growth characteristics (in terms of shoot length, number of leaves, fresh and dry weights).

Investigations of Lovato et al. (1992) showed that the growth of micropropagated grapevine plants was improved due to inoculation with different commercial arbuscular endomycorrhizal fungal inoculates. The authors reported that the infection levels were low (30\%) and concluded that the intensity of infection is a relative parameter (Abbot and Robson, 1978). According to Douds et al. (1998), the physiological response of a plant is the result of the interactions between environment, plant, and fungus genotype. Increases in the growth rate are not always related to colonisation (Guillemin et al., 1992), but may be 
influenced by other factors such as extension of the external mycelium and transport of nutrients from the soil to the host.

In Experiment 2, the oil palms were infected early, during the first six weeks after inoculation, by the used (V)AMF. Despite the relatively low percentage of (V)AMF infection (9-23\%), which varied between the fungal isolates, the colonisation was highly effective in promoting $\mathrm{P}$ concentration of the inoculated clones at that early growth stage, which resulted in improved plant development. Differences in the ability of (V)AMF to colonise the root system are well known and may have played a part in the lower percentage of root colonisation observed in $E$. columbiana (M2) inoculated plants after the first harvest.

Little is known about the early stages of (V)AM infection in micropropagated plants, through early root colonisation has been demonstrated to be very important during the delicate acclimatisation phase (Ravolanirina et al., 1990; Gianinazzi et al., 1990).

The infectivity of the mycorrhizal fungi was highly affected by the sterilisation of the growth substrate as could be seen in Experiment 3. The assessment of the root colonisation at this plant stage showed that the soil sterilisation influenced the degree to which the fungi colonised the root. In the sterilised soil, colonisation of the roots was $27-42 \%$, while in the non-sterilised soil the colonisation was only $17-23 \%$. The sterilisation of the soil reduced the indigenous fungal population of the soil, an effect that led to a decreased competition between the native and the introduced fungi.

Non-inoculated control plants of Experiment 3 grown in sterilised soil were not infected by mycorrhizal fungi. According to Munro et al. (1999) the absence of mycorrhizal infection indicates that there was no ingress of infective propagules during the experiment; this is also indicative of the negative impacts of soil sterilisation on mycorrhizal infection and growth in the absence of inoculation.

Weak mycorrhizal formation in the non-inoculated control plants, which occurred in all experiments after twelve weeks of post vitro growth, was due to indigenous fungi which were present in the native, non-sterilised soil. These colonisations indicated the natural levels of infection, which occur in plant roots under 'normal' nursery conditions. The low effectiveness of these fungi on plant survival and development was evident in this study. The (V)AMF isolates were able to compete with the native fungi and infected the roots earlier (see $1^{\text {st }}$ harvest) and to a higher extent than the indigenous fungi, showing that they were more effective in the development of a well functioning symbiosis.

In experiments of Vosatka et al. (2000), it was shown, as has already been stated, that the indigenous (V)AMF are not always the most effective fungi as regards either mycorrhizal 
development or mycorrhizal growth response tested on strawberry plants (Koomen et al., 1988).

It can be concluded that in soils containing infective but inefficient mycorrhizal fungi, growth of micropropagated oil palms can be greatly improved by inoculation with introduced fungal isolates. The results of this study indicate that although mycorrhizal fungi are present in the soil, and that the roots are eventually colonised with the native endophytes, the early inoculation of micropropagated oil palms with selected more effective (V)AM fungi greatly improves the resistance of the plants to the stress situation after transplanting to post vitro conditions.

\subsection{Specific effects of experimental factors and measures}

\subsubsection{Efficiency of the selected (V)AMF}

The results of this study confirmed the different efficiencies of (V)AMF isolates to be utilized. The selected species were highly efficient for improving the survival and development of micropropagated oil palms during the sensitive post vitro period.

\subsubsection{Role of the applied $P$ form}

In Experiment 2 two methods of fertilization and their effect on plant survival and development were compared. Hydroxy-apatite a slowly soluble P fertilizer was applied to the soil. "BAYFOLAN", a foliar spray, traditionally used by IOPRI to supply the plantlets with nutrients via shoot, due to weakly developed roots.

"BAYFOLAN", which was directly applied on the plant shoots does not interfere with the colonization process of mycorrhizal fungi which can be observed when soil fertilizers were applied. Nevertheless, there are no comparable results in the literature yet.

It is to be recommended that fertilizing the soil, specially with hardly soluble P forms, like hydroxy-apatite, was highly efficient when combined with (V)AM inoculation.

Similar results have been obtained with other several fertilizers in the production of commercially micropropagated strawberry in the United Kingdom and in Finland. These studies confirm that fertilizer inputs can be reduced with mycorrhizal inoculation of micropropagated plants, whilst maintaining high production levels. 


\subsubsection{Effect of soil sterilization}

Some treatments with sterilized soil were involved in Experiment 3 to investigate the role of its pathogenic potential and to eliminate indigenous (V)AM propagules. It could not be found that the sterilization of the soil could be a measure to reduce the mortality of oil palm plantlets. However, soil sterilization increased the infectivity and the effectiveness of the used (V)AMF isolates. The soil sterilization gave these introduced isolates the advantage of no competition with indigenous microorganisms, including (V)AMF, of the non-sterilized experimental soil.

On the other side, heating or partial sterilization of soil causes physical, biological and chemical changes (Wolf and Skipper, 1994). It is to be exspected that the soil sterilization leds to a combined effect of mineralisation and mobilization of nutrients, such as $\mathrm{P}$.

\subsubsection{Role of protection measures}

The use of protection measures in order to prevent pathogenic contamination did not influence plant survival. The cultivation in 'sunbags', positively influenced plant growth compared to control plants which were grown under 'normal' pre-nursery conditions. The plant growth promoting effect by the cultivation in 'sunbags' was probably due to the development of a special micro-climate by this semi-closed system. These conditions were more similar to in vitro conditions. Nevertheless, this protective measure cannot be recommended due to additional costs, beside the sensitive reaction of the plantlets to be exspected after shifting to the nursery.

\section{Final conclusions and perspectives}

This study contributed to the idea that the application of the mycorrhizal biotechnology can benefit the production of micropropagated plantlets of target crops. Micropropagation is a technique of increasing importance for the mass multiplication of quality and disease free plants of many commercial crops. The technique focuses on the major problem of a low survival rate of these plants and their poor growth performance.

The results of this study confirm that the biotechnology of using selected (V)AMF isolates to improve the survival and post vitro development of oil palm plantlets appears to be a promising way to optimize the production of micropropagated oil palms.

The increase in oil palm growth achieved through the combination of mycorrhizal inoculation and fertilization reflects the low $\mathrm{P}$ uptake capacity of the oil palm roots and the high 
mycorrhiza dependency of the oil palm plantlets in the weaning stage. The mechanisms of enhancement of survival and growth of the clonal oil palms seems to be due to the ability of the mycorrhizal fungi in increasing plant nutrient uptake. Inoculation with (V)AM fungi appears to became essential for the survival and growth of micropropagated oil palms.

The results of this study indicate that phosphate is probably the most limiting growth factor especially during the early post vitro stage of the oil palm clones and illustrates the mycorrhizal dependency of oil palm plantlets for taking up P. Addition of fertilizers does not greatly improve the nutrient status of propagated plants in their early growing stage because of their relatively small root systems and consequently inability to take up nutrients efficiently. The improvement of plant nutrition, especially with phosphate, is a physiological indicator that can be used to evaluate the functioning of the endomycorrhizal symbiosis.

Regarding future application of $(\mathrm{V}) \mathrm{AMF}$ inoculation in the micropropagation process of oil palms, an important criterion of this study was the inclusion of practical conditions, where plants grow in native soil. The performance of 'normal' nursery plants (non-inoculated, grown in unsterile soil), which are likely to develop some mycorrhizal infection naturally, was compared with (V)AMF inoculated plants. The results of this study show that the inoculation of micropropagated oil palms grown in 'normal', non-sterilized nursery soil with effective (V)AMF can be advantageous to plant survival and development, resulting in reduction of plant losses which occur during the acclimatization and hardening stage at IOPRI.

It can be concluded from this study that in soils containing infective but inefficient endomycorrhizal fungal populations, growth of micropropagated oil palms can be considerably improved by inoculation with effective (V)AM isolates. Weak mycorrhizal formation in the non-inoculated control plants, which occurred in all experiments after twelve weeks of post vitro growth, were due to indigenous fungi which were present in the native, non-sterilized soil. This colonization indicate the natural low levels of infection, which occur in plant roots under 'normal' nursery conditions. The low effectiveness of these fungi on plant survival and development was evident in this study. The introduced (V)AMF isolates were able to compete with the native fungi and infected the roots earlier and to a higher extent than the indigenous fungi, showing that they were more effective in the development of a well functioning symbiosis.

The benefits of inoculation are likely to extend beyond the nursery, as young oil palms which are sturdier survive and grow better after outplanting. Further studies are necessary to ensure that these beneficial mycorrhizal effects are maintained, and that root colonization by the introduced fungi persists after transferring to the nursery or outplanting into field conditions. 
Such investigations are presently hampered by the difficulty in being able to distinguish between different (V)AM fungi within the roots, and they emphasize the need to develop suitable immunological or nucleic acid probes to monitor control-inoculated efficient fungi after outplanting to non-sterilized soils.

Particularly for oil palm clones, the proposed methodology appears transferable, easy to handle with simple inputs and feasible for the ecophysiological conditions in the tropical areas where the oil palm is a key crop. The implementation of the method adapted for developing mycorrhizal association between roots of micropropagated oil palm plantlets and (V)AMF isolates during the present investigation is simple and most convenient to use. Laying crude inoculum immediately below/around the roots of the tissue-culture-raised plantlets at the time of transferring to ex vitro conditions is sufficient to establish a beneficial symbiotic association. This methodology is a direct single step process, being easy and suitable for commercial applications.

Commercially available inocula or company-produced inoculum can be considered as an inoculum source for implementation in the micropropagation process of oil palms. The latter can be produced in the company's own propagation culture. Both must be tested for effectiveness and could be used as single strain or mixed inoculum.

Pathogenic fungi are considered to be a main cause of the high mortality which is observed after oil palm plantlets were transferred to soil (Ginting, personal communication). In this study a direct connection between plant mortality and pathogenic fungi was not observed. The plant mortality was significantly reduced by the introduction of efficient (V)AM fungi, which resulted in an improved nutritional status of the oil palm plantlets. Plantlets which are mycorrhizal showed a higher vitality to resist pathogenes.

The presence of mycorrhizal fungi in the roots seems to induces some kind of resistance mechanism. The processes involved in this increased resistance are not clear, but one possibility is a permanent activation of plant defences by the mycorrhizal fungus.

In other studies, the effectiveness of mycorrhizal fungi was dependent on the plant cultivar or clone, a typical feature in using mycorrhizal fungi for micropropagated plants. Widiastuti and Tahardi (1993) reported differences in plant survival between oil palm clones during an experimental period of seven months, with no interaction between the oil palm genotype and the tested (V)AMF isolates. The lack of interaction is not unusual as it might be due to the relatively low host specificity of the (V)AMF species (Smith et al., 1992). Differences between the used clones were not detected in this study, may be due to the higher number of clones used and the low number of replicates within each clone, or the shorter period of this 
experiment. The relatively high number of clones used in the experiments could not be avoided due to the low number of available plantlets in total. As a consequence, the obtained clones were equally distributed over the treatments. For future research the number of clones with higher replicates must be taken into consideration.

In the recent years the interest on mycorrhiza has increased, partly due to economic benefits because most of the economically important plants in agriculture, horticulture and forestry have been found to be mycorrhizal. The savings of energy and chemical inputs due to significantly shorter production cycles in micropropagation and the increases in survival and uniformity of produced plants as a result of inoculation are a major incentive to introduce (V)AMF in such techniques. Considering this benefits in the future the biotechnology of (V)AMF inoculation will be an integral measure of most micropropagated systems. A carefully selected and produced (V)AMF inoculum based on relevant research is urgent needed.

In the short term, it is necessary to develop management practices taking into account the establishment, functioning and benefits of the mycorrhizas. Parameters such as substrate composition, forms and rates of fertilizers or other chemical products, as well as schedules for weaning and outplanting, may be optimized by the combination with these biotechnologies.

A perspective for the future should be the development of integral biotechnologies in which not only mycorrhizal fungi, but also other organisms capable of promoting plant growth or protection, such as symbiontic or associative bacteria, plant-growth promoting rhizo-bacteria (PGPR), pathogen antagonists, or hypovirulent strains of pathogens, should be incorporated into the substrates for micropropagated oil palms.

\section{Summary}

This study was implemented within the framework of the main project "Biotechnology Indonesia-Germany" (BTIG), which started in 1988. Among several other sub-projects, BTIG also included one project on the improvement of the oil palm (Elaeis guineensis Jacq.), which is an agronomically important crop species in Indonesia. The main aim was the application of modern techniques for improving conventional oil palm cultivation systems in Indonesia.

The 'Indonesian Oil Palm Research Institute' (IOPRI) is the largest oil palm seed producer in Indonesia. IOPRI started research activities in oil palm tissue culture in 1986. During 1992 and 1993 IOPRI produced 56.401 and 76.612 plantlets, only $63 \%$ and $58 \%$ of these plantlets were sold, respectively. This phenomenon was due to the high percentage of mortality (37- 
42\%) during the acclimatization process and after transferring the plantlets to the pre-nursery. The low percentage of plantlet survival still is a problem for expanding the commercial planting of clonal oil palms.

The technology used for micropropagated plants does not take into consideration the existence of a mutualistic symbiosis of mycorrhizae and other related plant growth promoting microorganisms like rhizobacteria. Their omission during micropropagation frequently results in poor development of plants so that their re-introduction during plant production is important. Most natural field soils and non-sterile nursery soils contain indigenous mycorrhizal fungi. Under natural conditions, the roots of oil palm are colonized by (vesicular) arbuscular mycorrhizal fungi (Nadarajah 1993; Blal and Gianinazzi-Pearson 1989). A decision to introduce mycorrhizal fungi under such conditions depends on the effectiveness of these indigenous fungi, i.e. on their ability to support plant growth in comparison with introduced fungi.

The objective of this thesis was to combine the use of (vesicular-) arbuscular mycorrhizal fungi ((V)AMF) with the production of micropropagated oil palms with a view to future practical applications. From 1996-1998, several experiments were carried out to determine whether introduced (V)AMF could enhance transplanting success and plantlet acclimatization as indicated by plant survival, plant growth and nutrient uptake.

The research for this study was carried out in collaboration with the Indonesian "Biotechnology Research Unit for Estate Crops" in Bogor and the "Indonesian Oil Palm Research Institute" in Medan, and with the "Institute of Plant Breeding" and the "Institute of Plant Production in the Tropics" of the University of Göttingen in Germany.

All experiments were conducted in the greenhouse of the biotechnological research unit of IOPRI, located in Marihat, North Sumatra. Micropropagated oil palm plantlets (E. guineensis Jacq.) of different origins were obtained from IOPRI. Cloning of oil palm was performed by somatic embryogenesis on calli of leaf origin according to the method of CIRAD-CP in France developed by Pennetier et al. (1981).

Micropropagated oil palm plantlets were transplanted into polybags containing a soil-sand mixture. The experimental soil originated from the oil palm plantation and was not sterilized in Experiments 1 and 2. Experiment 3 included treatments with sterilized and non-sterilized soil $\left(95^{\circ} \mathrm{C}\right)$, to kill native endophytes. The $\mathrm{pH}(\mathrm{KCl})$ of the soil was $4.3 ; \mathrm{P}_{2} \mathrm{O}_{5}$ (total) was 2.62 $\mathrm{mg} / 100 \mathrm{~g}$, and Bray-II P was $23.6 \mathrm{ppm}$.

Mycorrhizal inoculation was done at the time of transplanting. Plantlets were not inoculated (control plants), or inoculated with $10 \mathrm{~g}$ of soil inoculum below the plant roots. The inoculum 
consisted of rhizospheric soil from pot cultures containing heavily clonized root fragments with many internal spores. The used mycorrhizal fungal species were obtained from the (V)AMF culture collection of the "Institute of Plant Production in the Tropics", University of Göttingen, Germany. All mycorrhizal fungi originated from various tropical locations, were isolated and characterized, and propagated under greenhouse conditions in pure pot cultures of different host plants.

All polybags were arranged randomly on greenhouse benches and maintained under natural conditions with a temperature of max. $34^{\circ} \mathrm{C}$ during the day and $\min .21^{\circ} \mathrm{C}$ during the night. The greenhouse was covered by glass and the side walls were made of wire. These conditions created an almost natural environment where plants were sheltered from direct sunlight and rainfall. Humidity varied between 40 and $70 \%$ during the experimental period. The oil palm plantlets were watered as required, no fertilization was applied, except in Experiment 2.

Each experimental period lasted 3 months. During this period, survival of plants was controlled each day. If plants died, the date of mortality was recorded. Plant growth was determined every second week by measuring the shoot length and number of leaves. After harvesting, the plant roots were stained and examined for (V)AMF infection. Shoots were dried and analysed for biomass accumulation and nutrient uptake.

The first experiment of this study was conducted as an initial screening. Twelve different mycorrhizal isolates, representing a broad range of endomycorrhizal fungi, were tested for their effectiveness in improving the survival and development of micropropagated oil palms during twelve weeks of post vitro growth. From twelve mycorrhizal isolates which were introduced, eleven fungi were able to improve the survival rate significantly to $83-100 \%$, helping the plantlets to resist the environmental stress induced at transplanting from axenic conditions to normal cultivation in open pots. In contrast, only 55\% of the non-inoculated control plants survived during the three-month experimental period. The used isolates were also highly effective in promoting plant growth. The shoot dry weights of plantlets which were inoculated with these fungal isolates significantly increased compared to the noninoculated plants. Furthermore, inoculated plants showed a significantly increased P uptake.

All mycorrhizal fungi tested in the initial screening had been shown to form mycorrhizas with the oil palm plantlets. Levels of infection observed after trypan blue staining were relatively low and differed between isolates and ranged in most cases between 17-27\%. Despite the low percentage of root infection by the tested (V)AM fungi the effectiveness on plant survival and on growth improvement was significant in this study. 
Four or three out of the twelve tested (V)AMF isolates were selected for their effectiveness in improving plant survival and development and were investigated further in the second and third experiment, respectively.

At the end of Experiment 1, the remaining plants were visually classified as of 'good quality', which is an important factor for successful marketing of oil palm plantlets. The young plants were classified according to a scheme which is generally used at the 'Indonesian Oil Palm Research Institute' (IOPRI) when plantlets reach this growth stage and are to be sold to the planters or transferred to the nursery for further cultivation. Plantlets of Class $\mathrm{C}$, which were discarded, and the plantlets which died during the experimental period were summarized as total losses. Without inoculation, $45 \%$ of the non-inoculated control plants died during the experimental period and $7.5 \%$ of the remaining control plants were assessed for Class $\mathrm{C}$, which resulted in $52.5 \%$ total losses. This confirms further the low effectiveness of the soilindigenous mycorrhizal fungi which colonized the roots of the control plants.

Experiment 2 was conducted to compare the application of traditional plant nutrition, which is practiced at IOPRI, with the beneficial effect of mycorrhizal inoculation during the sensitive post vitro stage of clonal oil palms. Due to weakly developed roots of the oil palm plantlets "BAYFOLAN", a commercially available liquid, complete-foliar fertilizer was applied. As an alternative to "BAYFOLAN", hydroxy-apatite, a slow P-release fertilizer, was added to the soil and the influence of these two methods of fertilization was compared with non-fertilized control plants. The question here was whether the (V)AMF effect could be achieved in plantlets that were able to obtain adequate plant nutrients through fertilization.

The lowest percentage of plant survival (45\%) was observed in the non-inoculated control plants which were either non-fertilized or soil fertilized with hydroxy-apatite. These low survival rates were significantly improved by (V)AMF inoculation to $75-95 \%$ in the nonfertilized, and to $85-100 \%$ in the hydroxy-apatite fertilized plants, respectively. Control plants which received foliar fertilization with "BAYFOLAN" showed a plant survival rate of $80 \%$, which increased to $85-100 \%$ when plants were inoculated.

Without inoculation or fertilization plants grew very poorly. The application of both, the mycorrhizal inoculation and the fertilization, ensured maximum growth of the oil palms. The highest shoot dry weight was found in the inoculated plantlets which were fertilized either with hydroxy-apatite or "BAYFOLAN". The effect of soil fertilization with slowly soluble hydroxy-apatite on plant growth in this experiment was low, unless accompanied by mycorrhizal inoculation. 
Plantlets were grown in a growth substrate with a low $\mathrm{pH}$, which is frequent in tropical soils. Under such conditions, inoculation with the tested (V)AMF isolates was an important factor in facilitating plant recovery of $\mathrm{P}$ from these fertilizers. The improvement of fertilizer efficiency was not observed in the non-inoculated plants which were infected by indigenous mycorrhizal fungi of the native, non-sterilized soil.

The increase in oil palm growth obtained in this experiment by the combination of mycorrhizal inoculation and fertilization compared to the non-inoculated plants reflects the low P uptake capacity of the oil palm roots and the high mycorrhiza dependency of the oil palm plantlets in the initial growth phase. Inoculated plants which were fertilized with hydroxy-apatite showed the highest $\mathrm{P}$ uptake. The effect of BAYFOLAN fertilization on $\mathrm{P}$ uptake was low, unless plantlets were inoculated. However, the P uptake of these plants was lower compared to the inoculated plants of the hydroxy-apatite treatment.

The plantlets of Experiment 2 were harvested at two different growth stages, 6 and 12 weeks after transplanting, to investigate the effect of mycorrhizal inoculation during the early stages of post vitro plant development. The results show that during this period (V)AMF infection was initiated and that the introduced fungi colonized the host. The percentage of (V)AMF infection (9-23\%) was relatively low and varied between fungal isolates. At this early growth stage, the P uptake of mycorrhizal plants was 2 times higher compared to the non-inoculated control plants. Significantly increased nutrient uptake was only found for phosphate, but not for potassium or nitrogen. These results indicate that phosphate is probably the most limiting growth factor during the early post vitro stage of the oil palm clones. Addition of fertilizers does not markedly improved the nutrient status of the micropropagated oil palms in their early growing stage because of their relatively small root systems and inability to take up nutrients efficiently.

It was observed in this study that the first six weeks after transplanting were the most critical for survival of the sensitive oil palm plantlets. Most of the plants died during this period. The results of this study suggest that the reduced mortality in (V)AMF inoculated plants was probably due to the early mycorrhizal colonization of the plants, as a consequence of a better nutritional status, in particular $\mathrm{P}$.

Experiment 3 was conducted to examine the effects of mycorrhizal inoculation, protection measures and soil sterilization on the post vitro development of clonal oil palms. The plantlets were inoculated with three (V)A mycorrhizal fungi (M1-M3), which were selected for their effectiveness on survival and plant development based on the results of the screening in Experiment 1. Plantlets were transferred either to sterilized or non-sterilized soil and were 
cultivated under 'normal' pre-nursery conditions or with protection against pathogens by a plastic screen open at the top or covered by special plastic bags ('sunbag').

Plant survival and development was mainly influenced by soil sterilization and (V)AMF inoculation. The lowest survival rate $(40 \%)$ was detected in the non-inoculated plants which grew either in sterilized or non-sterilized soil. These results show that soil sterilization does not affect plant survival, suggesting a lack of soil-borne pathogens. (V)AMF inoculation highly increased plant survival in both soils, and the efficiency of the fungal isolates was enhanced by soil sterilization. If the inoculated plants were grown in non-sterilized soil, the survival was improved to $60-83 \%$, which increased to $97-100 \%$ when the soil was sterilized.

The improved effectiveness of the (V)AMF isolates due to soil sterilization also resulted in increased growth of the plantlets. The highest shoot dry weights were obtained when plantlets were inoculated and cultivated in sterilized soil. The growth improvement was associated with a greater $\mathrm{P}$ uptake of these plants, suggesting that soil sterilization leads to a combined effect of mineralization and mobilization of nutrients and a reduced competition between native and indigenous mycorrhizal fungi.

The assessment of root colonization at this plant stage showed that the soil sterilization influenced the degree to which the fungi colonized the root. In the sterilized soil, the rate of root infection was $27-42 \%$, while in the non-sterilized soil the infection rate was only 17 $23 \%$.

The use of protection measures in Experiment 3, such as covering plantlets with a plastic screen open at the top to prevent contamination by pathogens, was not effective in improving post vitro development of the oil palms. The plant growth promoting effect through cultivation in 'sunbags' was probably due to the development of a special micro-climate in this semi-closed system. These conditions were more similar to in vitro conditions and more favorable to plant development than 'normal' pre-nursery conditions. However, it is doubtful if this protection makes sense, because the main aim of the post vitro growth period in the greenhouse is the hardening of the sensitive micropropagated plantlets.

Weak mycorrhizal formation in the non-inoculated control plants, which occurred in all experiments after twelve weeks of post vitro growth, were due to indigenous fungi which were present in the native, non-sterilized soil. These colonisations indicated the natural levels of infection, which occurs in plant roots under 'normal' nursery conditions. The low effectiveness of these fungi on plant survival and development was evident in this study. The (V)AMF isolates were able to compete with the native fungi and infected the roots earlier and 
to a higher extent than the indigenous fungi, showing that they were more effective in the development of a well functioning symbiosis.

To summarize, the results of this study confirm that the biotechnology of using selected (V)AMF isolates to improve the survival and post vitro development of oil palm plantlets appears to be a promising way to optimize the production of micropropagated oil palms.

\section{Zusammenfassung}

Die vorliegende Arbeit wurde im Rahmen des Projektes "Biotechnology IndonesienDeutschland" (BTIG) durchgeführt. Durch Anwendung moderner Biotechnologie im Bereich der Zell- und Gewebekultur sollte versucht werden, Lösungen für akute Probleme des Ölpalmenanbaus in Indonesien zu finden. Die Ölpalme (Elaeis guineensis Jacq.) zählt in Indonesien zu den wichtigsten landwirtschaftlich genutzten Kulturpflanzen.

Das "Indonesian Oil Palm Research Institute" (IOPRI) ist einer der größten Ölpalm-Saatgut Erzeuger Indonesiens. 1986 begann IOPRI mit der Vermehrung der Ölpalme durch Gewebekultur. Von 1992-1993 produzierte IOPRI 56.401 bzw. 76.612 Ölpalmklone, wovon jedoch nur $63 \%$ bzw. 58\% marktfähig waren und verkauft werden konnten. Der Grund dafür lag in der hohen Sterblichkeitsrate der empfindlichen Jungpflanzen, die ein großes Problem für die Kommerzialisierung von Ölpalmklonen darstellt.

In vitro vermehrte Pflanzen werden unter sterilen, künstlichen Bedingungen vermehrt. Bevor die empfindlichen Jungpflanzen weiterkultiviert werden können, müssen sie in einem Akklimatisierungsprozess, den natürlichen Umweltbedingungen schrittweise angepasst werden.

Durch die sterilen Anzuchtbedingungen während der in vitro Vermehrung werden Symbiotische Mikroorganismen, wie Mikorrhizapilze und Rhizobien, die unter natürlichen Bedingungen im Boden vorkommen, ausgeschlossen. Die meisten natürliche Böden, sowie nicht sterilisierte Anzuchtböden, enthalten natürliche Mykorrhizapilzpopulationen. Aus vorangegangenen Untersuchungen ist bekannt, daß die Ölpalmen unter natürlichen Bedingungen von Endomykorrhizapilzen besiedelt werden (Nadarajah, 1993; Blal und Gianinazzi-Pearson, 1989). Ihre Induzierung unter diesen Umständen hängt von der Effektivität der Mykorrhizapilze, d.h. von ihrer Fähigkeit die Entwicklung der Pflanzen zu verbessern, ab. 
Die vorliegende Arbeit untersuchte, ob eine Einführung (vesikulär-) arbuskulärer MykorrhizaPilz-Isolate in den Akklimatisierungsprozeß der Ölpalmen zu einer Verbesserung der Überlebensraten und Entwicklung der empfindlichen Jungpflanzen führen kann. Im Hinblick auf eine spätere Einbindung dieses Verfahrens in die Akklimatisierungsphase wurden praxisrelevante Bedingungen bei der Planung und Durchführung der Versuche berücksichtigt.

Die Untersuchungen wurden in Zusammenarbeit mit der "Biotechnology Research Unit for Estate Crops" in Bogor und dem "Indonesian Oil Palm Research Institute" in Medan, sowie dem "Institut für Pflanzenzüchtung" und dem "Institut für Pflanzenproduktion in den Tropen und Subtropen", an der Universität Göttingen, geplant. Alle Versuche wurden von 1996-1998 im Gewächshaus der Biotechnologischen Forschungsabteilung von IOPRI in Marihat, Nordsumatra, durchgeführt.

Als Versuchspflanzen wurden in Gewebekultur vermehrte Ölpalmenklone, verschiedener Herkünfte verwendet, die von IOPRI zur Verfügung gestellt worden waren. Zum Zeitpunkt des Umpflanzens wurden die Ölpalmen in eine Boden-Sand Mischung gepflanzt, die üblicherweise am IOPRI verwendet wird. Der ursprünglich aus Ölpalmenplantagen stammende Versuchsboden wurde in Versuch 1 und 2 nicht sterilisiert. In Versuch 3 wurde neben der oben genannten Bodenmischung sterilisierter Boden verwendet. Der Boden wurde für 4 Tage auf $95^{\circ}$ erhitzt, um natürlich vorkommende Endomykorrhizapilze abzutöten. Der pH-Wert $(\mathrm{KCl})$ des Bodens betrug 4.3; $\mathrm{P}_{2} \mathrm{O}_{5}$ (Gesamt) 2.62/mg/100g und Bray-II P betrug $23.6 \mathrm{ppm}$.

Die Pflanzen wurden zum Zeitpunkt des Umpflanzens mit den verwendeten (V)AM-Isolaten inokuliert. Dazu wurde 10g des Inokulums direkt unter die Wurzeln abgelegt. Das Inokulum bestand aus Wurzel und Bodenmaterial von Topfkulturen. Die verwendeten Mykorrhizapilze stammten aus der Vermehrungskultur des Institutes für Pflanzenbau in den Tropen und Subtropen der Universität Göttingen. Alle Mykorrhizapilze stammten ursprünglich aus den Tropen und wurden in Reinkultur unter Gewächshausbedingungen vermehrt.

Die inokulierten Ölpalmen wurden während eines Versuchszeitraumes von drei Monaten im Gewächshaus weiterkultiviert. Das Gewächshaus war mit Glas abgedeckt um die Pflanzen vor Regen und direkter Sonneneinstahlung zu schützen. Die Seitenwände bestanden aus Draht, wodurch nahezu natürliche Wachstumsbedingungen herrschten. Die Temperatur betrug maximal $34^{\circ} \mathrm{C}$ während des Tages, und minimal $21^{\circ} \mathrm{C}$ während der Nacht. Die relative Luftfeuchtigkeit schwankte zwischen 40 und 70\%. Die Pflanzen wurden nach Bedarf gegossen und, ausser in Versuch 2, nicht gedüngt. 
Die Versuchsdauer betrug jeweils 12 Wochen. Während dieser Zeit wurde das Überleben der Pflanzen täglich kontrolliert. Das Datum abgestorbener Pflanzen wurde festgehalten. Das Wachstum der Pflanzen wurde in zweiwöchigen Abständen durch die Sproßlänge und die Anzahl der Blätter ermittelt. Am Ende der Versuchsperiode wurden die Pflanzen geerntet. Die Wurzeln wurden angefärbt, um die Infektionsraten der Mykorrhizapilze zu ermitteln. Die Sprosse wurden getrocknet, gewogen und anschließend wurde ihr Nährstoffgehalt bestimmt.

Im ersten Versuch der vorliegenden Arbeit wurde ein breites Spektrum von Endomykorrhizapilz Isolaten in einem sogenannten "Screening" auf ihre Wirksamkeit und Anwendbarkeit untersucht. Von den zwölf untersuchten (V)AM-Isolaten führte die Inokulation mit elf Isolaten zu einer Steigerung der Überlebensrate auf 83-100\%. Im Gegensatz dazu überlebten nur 55\% der nicht inokulierten Ölpalmen den dreimonatigen Versuchszeitraum. Die verwendeten Isolate wirkten sich ebenfalls sehr positiv auf die Entwicklung der Jungpflanzen aus. Die Sproßtrockengewichte der inokulierten Pflanzen wurden gegenüber den Kontrollpflanzen signifikant erhöht. Darüber hinaus wurde eine signifikant erhöhte Phosphat-Aufnahme festgestellt.

Alle untersuchten Mykorrhizapilze infizierten die Wurzeln der Ölpalmen. Die Infektionsraten waren relativ gering und variierten je nach Pilzart zwischen 17-22\%. Trotz der geringen Infektionsraten zeigten die untersuchten (V)AM-Pilze eine hohe Effizienz in der Verbesserung der Überlebensrate und der Pflanzenentwicklung. Vier, beziehungsweise drei, der effizientesten (V)AM-Isolate wurden ausgewählt und in den folgenden Versuchen weiter untersucht.

Am Ende der Untersuchungsperiode wurden die überlebenden Pflanzen in Versuch 1 visuell nach Qualitätsmerkmalen klassifiziert, einem wichtigen Faktor für die erfolgreiche Vermarktung der jungen Ölpalmen. Die Pflanzen wurden nach einem Schema bewertet, das normalerweise von IOPRI zu diesem Zeitpunkt verwendet wird, da die Pflanzen in diesem Entwicklungsstadium entweder an Pflanzer verkauft, oder in der Baumschule weiterkultiviert werden. Pflanzen der Klasse $\mathrm{C}$, die nach Abschluß dieser dreimonatigen Phase nicht ausreichend entwickelt sind, werden ausgesondert. Diese Pflanzen, sowie die während des Untersuchungszeitraumes abgestorbenen Pflanzen, wurden zusammen als Totalverluste bezeichnet. Ohne Inokulation starben während dieser Zeit $45 \%$ der Kontrollpflanzen ab, und 7,5\% der überlebenden Pflanzen wurden mit Klasse $\mathrm{C}$ bewertet, woraus sich 52,5\% Totalverluste ergaben.

Versuch 2 verglich traditionell am IOPRI durchgeführte Düngungsmethoden mit dem Effekt einer Mykorrhizapilz-Inokulation. "BAYFOLAN", ein handelsüblicher Blattdünger, wird 
wegen des schlecht entwickelten Wurzelsystems der Ölpalmklone verwendet. Als Altenative zu "BAYFOLAN" wurde Hydroxylapatit, ein schwerlöslicher Phosphatdünger verwendet. Diese beiden Düngungsmethoden wurden mit nicht gedüngten Pflanzen verglichen.

Diese Untersuchung wurden durchgeführt, um festzustellen, ob die positive Wirkung der (V)AM-Inokulation erreicht werden konnte, wenn Pflanzen gedüngt worden waren.

Die geringste Überlebensrate (45\%) wurde in den nicht inokulierten, ungedüngten oder mit Hydroxylapatit gedüngten Pflanzen festgestellt. Durch Inokulation wurden diese geringen Überlebensraten auf $75-95 \%$ in den ungedüngten, und auf $85-100 \%$ in den Hydroxylapatit gedüngten Pflanzen gesteigert. Nicht inokulierte Kontrollpflanzen, die mit "BAYFOLAN" gedüngt wurden zeigten eine Überlebensrate von $80 \%$, die auf $85-100 \%$ anstieg, wenn die Pflanzen inokuliert waren.

Ohne Inokulation und ohne Düngung wuchsen die Pflanzen nur schwach. Die Kombination von (V)AM-Inokulation und Düngung, entweder mit Hydroxylapatit oder "BAYFOLAN", führte zu den besten Wachstumsraten.

Der Effekt einer Hydroxylapatit Düngung war gering, wenn die Pflanzen nicht inokuliert waren. Der verwendete Versuchsboden hatte einen geringen $\mathrm{pH}-\mathrm{Wert}$, was in tropischen Böden häufig vorkommt. Unter diesen Bedingungen war die Anwendung effizienter (V)AMPilze ein wichtiger Faktor für die Nährstoffversorgung der Pflanzen.

Die Verbesserung des Pflanzenwachstums bei der Anwendung von Inokulation und Düngung spiegelte die geringe P-Aufnahme-Kapazität der Ölpalmwurzeln in dieser frühen Wachstumsphase wieder. Ohne Inokulation war der Effect der "BAYFOLAN"-Düngung auf die P-Aufnahme der Pflanzen gering.

Die Pflanzen in Versuch 2 wurden an zwei Terminen geerntet, sechs bzw. zwölf Wochen nach dem Umpflanzen, um die Wirkung einer Mykorrhiza-Beimpfung auf die frühe post vitro Entwicklung der Pflanzen zu untersuchen. Die Ergebnisse zeigten, dass die Pflanzen bereits $\mathrm{zu}$ diesem Zeitpunkt durch die (V)AM-Isolate infiziert waren. Die Infektionsraten waren verhältnismäßig gering und schwankten je nach Pilzart zwischen $9 \%$ und 23\%. Die PAufnahme der inokulierten Pflanzen war in diesem Wachstumsstadium zweimal höher als die der Kontrollpflanzen. Eine signifikant erhöhte Nährstoffaufnahme wurde nur bei Phosphat gefunden, nicht jedoch für Kalium oder Stickstoff. Diese Ergebnisse deuten darauf hin, daß P wahrscheinlich der am meisten begrenzende Wachstumsfaktor in diesem frühen post vitro Stadium der Pflanzen war. Die Nährstoffversorgung der Pflanzen wurde, bedingt durch ein schwach ausgebildetes Wurzelsystem, durch Düngung nicht verbessert. 
Die meisten Pflanzen starben in den ersten sechs Wochen nach dem Umpflanzen. Dieser Zeitraum stellt die kritischste Phase für das Überleben der empfindlichen Pflanzen dar. Die Ergebnisse der vorliegenden Arbeit deuten darauf hin, daß die reduzierte Sterblichkeit der (V)AM inokulierten Pflanzen auf einer frühen Besiedlung und einem verbesserten P-Status der Pflanzen beruhte.

Versuch 3 untersuchte die Wirkung der (V)AM-Inokulation auf den Einfluß pathogener Schaderreger, die bei der Sterblichkeit der Pflanzen eine große Rolle spielen. Die Pflanzen wurden mit drei selektierten Mykorrhizapilzen beimpft und in sterilisierten oder nicht sterilisierten Boden gepflanzt. Die Pflanzen wurden unter 'normalen' Gewächshausbedingungen kultiviert, oder waren durch eine nach oben hin offenen Plastikfolie vor Kontamination durch Spritzwasser geschützt. Ein Teil der Pflanzen wuchs in speziellen Tüten, sogenannten 'sunbag's, die einen Gasaustausch erlauben, aber die Pflanzen nach außen hin nahezu isolierten.

Der Effekt der Bodensterilisation wirkte sich nicht positiv auf das Überleben der Pflanzen aus. 40\% der nicht inokulierten Pflanzen starben, unabhangig von der Sterilisation des Bodens. Die Inokulation der Pflanzen erhöhte die Überlebensraten der Pflanzen in beiden Böden. Die Effizienz der Mykorrhizapilze wurde durch die Sterilisation des Bodens stark beeinflußt. In nicht sterilisiertem Boden zeigten die inokulierten Pflanzen eine Überlebensrate von 60-83\%, die in sterilisiertem Boden auf 97-100\% anstieg. Die gesteigerte Effiziens der (V)AM-Pilze führte auch zu einem verbesserten Wachstum der Pflanzen. Die höchsten Sproßtrockengewichte wurden erreicht, wenn die inokulierten Pflanzen in sterilisiertem Boden kultiviert wurden. Die Wachstumsverbesserung korrelierte mit einer verbesserten PAufnahme der Pflanzen. Dieser Effekt läßt vermuten, daß die Sterilisation des Bodens zu einer Mobilisierung von Nährstoffen führte, sowie zu einer Reduzierung der Konkurrenz zwischen natürlichen und induzierten Mykorrhiza-Pilzen.

Die Wurzeluntersuchungen zeigten, das die Bodensterilisation auch die Infektionsrate der (V)AM beeinflußte. In sterilisiertem Boden war die Infektionsrate höher (27-42\%), als in nicht sterilisiertem Boden (17-23\%).

Die Anwendung von speziellen Schutzmaßnahmen in Versuch 3, die zur Abschirmung der Pflanzen dienen sollte, wirkte sich nicht auf die Entwicklung der Pflanzen aus. Die Förderung des Pflanzenwachstum, die bei der Kultivierung in 'sunbags' festgestellt wurde, resultierte wahrscheinlich aus dem speziellen Mikroklima in diesem fast geschlossenen System. Diese Bedingungen waren vergleichbar mit in vitro Bedingungen und waren günstiger für die Entwicklung der Pflanzen. Es ist jedoch fraglich, ob diese Art der Kultivierung sinnvoll ist, da 
das Hauptziel der untersuchten post vitro Periode in der Abhärtung der Pflanzen an natürliche Bedingungen liegt.

Die schwache Mykorrhiza Entwicklung, die zum Ende der jeweiligen Versuchsperiode in den nicht inokulierten Kontrollpflanzen auftrat, war eine Folge der Infektion durch die natürlichen Mykorrhizapilzpopulation, die in dem nicht sterilisierten Versuchsboden vorkamen. Diese Infektion ähnelte der, die unter natürlichen Bedingungen im Gewächshaus vorkommen kann. Die geringe Wirkung dieser Pilze auf das Überleben und die Entwicklung der Ölpalmen wurde in dieser Untersuchung sehr deutlich. Die Inokulation der Pflanzen mit den verwendeten (V)AM-Isolaten führte zu einer früheren and stärkeren Infektion der Wurzeln und war effizienter in der Entwicklung einer gut fuktionierenden Symbiose.

Zusammenfassend bestätigen die Ergebnisse der vorliegenden Untersuchungen, daß die biotechnologische Anwendung selektierter (V)AM-Isolate eine vielversprechende Perspektive für eine verbesserte Produktion der in Gewebekultur vermehrten Ölpalmen darstellt. 


\section{References}

Abbott, L.K. and Robson, A.D. (1978)."Growth of subterranean clover in relation to the formation of endomycorrhizas by introduced and indigenous fungi in a field soil." New Phytologist 81: 575-587.

Abbott, L.K. and Robson, A.D. (1981). "Infectivity and effectiveness of five endomycorrhizal fungi: competition with indigenous fungi in field soils." Australian Journal of Agricultural Research 32: 621-630.

Abbott, L.K. and Robson, A.D. (1981). "Infectivity and effectiveness of vesicular arbuscular mycorrhizal fungi: effect of inoculum type." Australian Journal of Agricultural Research 32: 631-639.

Abbott, L.K. and Robson, A.D. (1982). "Infectivity of vesicular-arbuscular mycorrhizal fungi in agricultural soils." Australian Journal of Agricultural Research 33: 1049.

Abbott, L.K. and Robson, A.D. (1984). "The Effect of Mycorrhizae on Plant Growth," in VA mycorrhiza, edited by C. Ll. Powell and D. J. Bagyaraj (Boca Raton, Florida: CRC Press, Inc., 113-30.

Abbott, L.K. and Robson, A.D. (1992). "Factors influencing the occurrence of vesiculararbuscular mycorrhizas." Agriculture, Ecosystems and Environment 35: 121-150.

Ahuja, M.R. (Ed.) (1993). Micropropagation of woody plants. Kluwer Academic Publishers, Dordrecht, The Netherlands.

Allen, E.B. and Allen, M.F. (1980). "Natural re-establishment of vesicular-arbuscular mycorrhizae following stripmine reclamation in Wyoming." Journal of Applied Ecology 17. 137-148.

Allen, M.F., Sexton, J.C., Moore, T.S., and Christensen, M. (1981). "Influence of phosphate source on vesicular-arbuscular mycorrhizae of Bouteloua gracilis." New Phytologist 87: 687694.

Allen, E.B., Allen M.F., Helm D.J., Trappe J.M. Molina R., Rincon E. (1995). Patterns and regulation of mycorrhizal plant and fungal biodiversity. Plant and Soil 170, 47-62.

Allen, M.F. (1996). The ecology of arbuscular mycorrhizas: a look back into the $20^{\text {th }}$ century and a peek into the 21th . Mycological Research 100 (7), 769-782.

Arifin, S. and Susila, R. (1999). Development and prospect of palm oil industry in Indpnesia. IRD Journal Vol. 20, No. 2:25-32.

Azcón-Aguilar, C., Barcelo, A., Vidal, M.T., and Delavina, G. (1992). "Further Studies on the influence of Mycorrhizae on Growth and Development of Micropropagated Avocado Plants." Agronomie 12: 837-840.

Azcón-Aguilar, C. und Barea J.M. (1997). Applying mycorrhiza biotechnology to horticulture: significance and potentials. Scientia Horticulturae 68, 1-24. 
Azcón-Aguilar, C., Padilla, I.G., Encina, C.L., Azcon, R., and Barea, J.M. (1997). "Arbuscular mycorrhizal inoculation enhances plant growth and changes root system morphology in micropropagated Annona cherimola mill." Agronomie 16, no. 10: 647-652.

Azcón-Aguilar, C., Cantos, M., Troncoso, A., and Barea, J.M. (1997). "Beneficial effect of arbuscular mycorrhizas on acclimatization of micropropagated cassava plantlets." Scientia Horticulturae 72, no. 1: 63-71.

Azcón-Aguilar, C. and Barea, J.M. (1997). "Arbuscular mycorrhizas and biological control of soil-borne plant pathogens -An overview of the mechanisms involved." Mycorrhiza 6, no. 6: 457-464.

Azcón-Aguilar, C., Cantos, M., Troncoso, A., and Barea, J.M. (1997). "Beneficial effect of arbuscular mycorrhizas on acclimatization of micropropagated cassava plantlets." Scientia Horticulturae 72, no. 1: 63-71.

Azcón-Aguilar, C., Barea, J.M. (1997). Arbuscular mycorrhizas and biological control of soilborne plant pathogenes. An overview of the mechanisms involved. Mycorrhiza, 6, 457-464.

Barea J.M., Calvet C., Estaún, V., und Camprubi, A. (1996). Biological control as a key component in sustainable agriculture. Plant and Soil 185, 171-172.

Barea, J.M., Azcón-Aguilar, C., and Azcon, R. (1997). "Interactions between mycorrhizal fungi and rhizosphere microorganisms within the context of sustainable soil-plant systems," in Multitrophic Interactions in Terrestrial Systems, 65-77.

Barea, J.M., Andrade, G., Bianciotto, V., Dowling, D., Lohrke, S., Bonfante, P., O'Gara, F., and Azcón-Aguilar, C. (1998). Impact on arbuscular mycorrhiza formation of Pseudomonas strains used as inoculants for biocontrol of soil-borne fungal plant pathogens." Applied and Environmental Microbiology 64, no. 6: 2304-2307.

Basiron Y., Thiagajaran T., (1998). Asean: Oils and fats center of the world. AOCS Symposium on "Trends Global Oilseed Utilization and Processing", Chicago, Illinois, 1998.

Bécard, G. and Fortin, J.A. (1988). "Early events of vesicular-arbuscular mycorrhiza formation on Ri T-DNA transformed roots." New Phytologist 108: 211-218.

Bécard G., Piche Y., (1989). New aspects in the acquisition of biotrophic status by a vesicular-arbuscular mycorrhizal fungus Gigaspora margarita. New Phytologist 112: 77-83.

Beirnaert, A. \& Vanderweyen, R. (1941). Contribution a l'étude génétique et biométriques des variétés d' Elaeis guineensis Jacqin. Publ. Inst. Nat. Etude agron. Congo Belge, Sér. Sci., 27:101.

Berta, G., Fusconi, A., Trotta, A., and Scannerini, S. (1990). "Morphogeneic modifications induced by the mycorrhizal fungus Glomus strain E3 in the root system of Allium porrum L." New Phytologist 114: 207-215.

Berta, G., Trotta, A., Fusconi, A. Hooker, J.E., Munro, M., Atkinson, D., Giovanetti, M., Morini, S., Fortuna, P., Tisserant, B., Gianinazzi-Pearson, V., Gianinazzi, S. (1995). 
Arbuscular mycorrhizal induced changes to plant growth and root system morphology in Prunus cerasifera. Tree Physiology, 15, 281-293.

Bianciotto, V., Barbiero, G., and Bonfante, P. (1995). "Analysis of the cell cycle in an arbuscular mycorrhizal fungus by flow cytometry and bromodeoxyuridine labelling." Protoplasma 188, no. 3-4: 161-169.

Blal, B., Gianinazzi-Pearson, V. (1989). Interest of mycorrhiza for the production of micropropagated oil palm clones. Agricultural Ecosystems Environment 29: 39-43.

Blal, B., Morel, C., Gianinazzi-Pearson, V., Fardeau, J.C., and Gianinazzi, S. (1990). "Influence of vesicular-arbuscular mycorrhizae on phosphate fertilizer efficiency in two tropical acid soils planted with micropropagated oil palm (Elaeis guineensis Jacq.)." Biology and Fertility of Soils 9: 43-48.

Bolan, N.S. (1991). A critical review on the role of mycorrhizal fungi in the uptake of phosphorus by plants. Plant and Soil 134, 189-207.

Bonfante, P. (1995). "Arbuscular mycorrhizae: Biotechnological applications: An environmental sustainable biological agent - Foreword." Critical Reviews in Biotechnology 15, no. 3-4: U2-U3.

Bowen, G.D. (1987). "The biology and physiology of infection and its development," in Ecophysiology of VA Mycorrhizal Plants, edited by G. Safir (Boca Raton, Florida: CRC Press, Inc., 27-57.

Brainerd, K. E. nad Fuchigami, L.H. (1981). Acclimazization of aseptically cultured apple plants to low relative humidity. J Amer Soc Hort Sci 106:515-518.

Brundrett, M.C. (1991). "Mycorrhizas in natural ecosystems," in Advances in Ecological Research vol. 21, edited by M. Begon, A. H. Fitter, and A. MacFadyen (New York: Academic Press, 171-213.

Budi, S.W., Cordier, C., Trouvelot, A., Gianinazzi-Pearson, V., Gianinazzi, S., Blal, B., and Lemoine, M.C. (1998). "Arbuscular mycorrhiza as a way of promoting sustainable growth of micropropagated plants." Symposium On Plant Biotechnology As A Tool For The Exploitation Of Mountain Lands, no. 457: 71-77.

Casson, A. (1999). The Hesitant Boom: Indonesia's Oil Palm Subsector in an Era of Economic Crisis and Political Change. Program on the underlying causes of deforestation. Bogor, Indonesia: Center for International Forestry Research (CIFOR).

Charest, C., Dalpé, Y., and Brown, A. (1993). "The Effect of Vesicular-Arbuscular Mycorrhizae and Chilling on 2 Hybrids of Zea mays L." Mycorrhiza 4: 89-92.

Chavez, M.G. and Ferrera-Cerrato, R. (1990). "Effect of vesicular-arbuscular mycorrhizae on tissue culture- derived plantlets of strawberry." Horticultural Science 25: 903-905.

CIFOR: Center for International Forestry Research, Bogor, Indonesia. Online, CIFOR Homepage, http://www.cgiar.org/cifor. 
Conner, A.J, and Thomas, M.B. (1982). Re-establishing plants from tissue culture-a review. Proc Inter Pplant Prop Coc 31: 342-357.

Cooper, K.M. (1984). "Physiology of VA Mycorrhizal Associations," In: VA Mycorrhiza, edited by C. Ll. Powell and D. J. Bagyaraj (Boca Raton, Florida: CRC Press, Inc., 155-86.

Cordier, C. S., Gianinazzi, and Gianinazzi-Pearson, V. (1996). Colonisation patterns of root tissues by Phytophthora nicotianae var parasitica related to reduced disease in mycorrhizal tomato. Plant and Soil 185, 223-232.

Cordier, C., Trouvelot, A., Gianinazzi, S., and Gianinazzi-Pearson, V. (1997). "Arbuscular mycorrhiza technology applied to micropropagated Prunus avium and to protection against Phytophthora cinnamomi." Agronomie 16, no. 10: 679-688.

Corley, R.H.V. (1976). Oil Palm Research. Developments in Crop Science. Elsevier Scientific Publishing Company.

Corley, R.H.V., Barret, J.N., and Jones, L.H. (1977). Vegetative propagation of oil palm via tissue culture. Oil Palm News 22: 2-7.

Corley, R.H.V., Wooi, K.C., and Wong, C.Y. (1979). Progress with vegetative propagation of oil palm. Planter 55: 377-380.

Corley, R.H.V. (1982). Clonal planting material for the oil palm industry. Planter 55: 515528.

Corley, R.H.V. (1991). Fifteen years experience with oil palm clones - a review of progres. PORIM International Palm Oil Conference, 1991, Kuala Lumpur.

Daniels, B.A. and Skipper, H.D. (1982). "Methods for the recovery and quantitative estimation of propagules from soil," In: Methods and principles of mycorrhizal research, edited by N. C. Schenck St. Paul: The American Phytopathological Society, 29-35.

Davis, E.A. and Young, J.L. (1985). "Endomycorrhizal colonization of glasshouse-grown wheat as influenced by fertilizer salts when banded or soil-mixed." Canadian Journal of Botany 63: 1196-1203.

Deberg, P.C. and Zimmermann, R.H. (ed) (1991). Micropropagation Technology and Application. Kluwer Academic Publishers, Dordrecht, Boston, London.

Deberg, P. (1988). Improving mass propagation of in vitro plantlets. In: Horticulture in High Technology Era. Symp. Tokyo, Japan. May 10-11, 47-57.

Declerck, S., Plenchette, C., and Strullu, D.G. (1995). "Mycorrhizal dependency of banana (Musa acuminata, AAA group) cultivar." Plant and Soil 176, no. 1: 183-187.

Declerck, S., Strullu, D.G., and Plenchette, C. (1996). "In vitro mass-production of the arbuscular mycorrhizal fungus, Glomus versiforme, associated with Ri T-DNA transformed carrot roots." Mycological Research 100, no. Part 10: 1237-1242. 
Dehne, H.W. (1982). Interaction between vesicular-arbuscular mycorrhizal fungi and plant pathogenes. Phytopathology 72: 1115-1119.

Desjardins, Y. (1995). Factors affecting $\mathrm{CO}_{2}$ fixation in striving to optimize photoautotrophy in micropropagated plants. Plant Tiss Cult and Biotechnol, 1:13-25.

Desjardins, Y., Laforge, F., Lussier, C., Gosselin, A. (1988). Effect of CO2 enrichement and high photosynthetic photon flux on the development of autotrophy and growth of tissue cultured strawberry, raspberry, and asparagus plants. Acta Hort, 230:45-53.

Dhawan, V. and Bhojwani, S.S. (1987). Hardening in vitro and morpho-physiological changes in the leaves during acclimatization of micropropagated plants of Leucaena leucophalia L. De Wit. Plant Sci 53:65-72.

Diop, T.A., Bécard, G., and Piche, Y. (1992) "Long-Term In Vitro Culture of an Endomycorrhizal Fungus, Gigaspora margarita, on Ri T-DNA Transformed Roots of Carrot." Symbiosis 12: 249-259.

Dodd, J.C. and Jeffries, P. (1986). "Early development of vesicular-arbuscular mycorrhizas in autumn-sown cereals." Soil Biology and Biochemistry 18: 149-154.

Dodd, J.C., Gianinazzi-Pearson, V., Rosendahl, S., and Walker, C. (1994). "European Bank of Glomales - An essential tool for efficient international and interdisciplinary collaboration," in Impact of Arbuscular Mycorrhizas on Sustainable Agriculture and Natural Ecosystems, edited by J. C. Dodd et al. (Basel, Switzerland: Birkhauser Press, 41-46.

Douds D.D., Chaney W.R., (1986). The effect of high nutrition addition upon seasonal patterns of mycorrhizal development, host growth, root phosphorus and carbohydrate content in Fraxinus pennsylvanica March. New Phytol. 103: 91-106.

Douds, D.D., Galvez, L., Bécard, G., and Kapulnik, Y. (1998). "Regulation of arbuscular mycorrhizal development by plant host and fungus species in alfalfa." New Phytologist 138, no. 1: 27-35.

Douds, D.D. and Millner, P. (1999). "Biodiversity of arbuscular mycorrhizal fungi in agroecosystems." Agriculture, Ecosystems and Environment 74, no. 1-3: 77-93.

Donelly, D.J. and Vidaver, W.E. (1984). Leaf anatomy of red raspberry transferred from culture to soil. J Amer Soc Hort Sci 109: 172-176.

Donelly, D.J., Vidaver, W.E. and Lee, K.Y. (1985). The anatomy of tissue cultured raspberry prior to and after transfer to soil. Plant Cell Tissue Organ Culture 4: 43-50.

Durand Gasselin, T.. Le Guen, Konan, K, Duval, Y. (1989). Oil palm (Elaeis guineensi Jacq.) plantations in Cote d'Ivoire, obtained through in vitro culture, first results. In: NIFOR (Ed.) PROC INTER CONF on Palms and Palm Products, Benin.

Durand Gasselin, T.. Le Guen, Konan, K, Duval, Y. (1990). Oil palm productions in Ivory Coast obtained through in vitro culture. Oleagineux 43: 323-328. 
Duval, Y., Durand Gasselin, T., Konan, K. and Pannetier, C. (1988). Multiplication vegetative di palmier a huile (Elaeis guineensi Jacq.) par culture in vitro. Strategie et resultats (1) Oleagineux 43: 39-49.

Duval, Y. Aberlenc, F. and Touchet, B. (1995). ISOPB International Symposium on Recent Development in Oil Palm Tissue Culture and Biotechnology, 1993, Kuala Lumpur, Malaysia, pp 38-47.

Duval, Y. Amblard, P. Rival A., Konan E., Gogor, S., and Durand-Gasselin, T. (1997). Progress in oil palm tissue culture and clonal performance in Indonesia and Cote d'Ivoire. Planters.

Elmeskaoui, A., Damont, J.P., Poulin, M.J., Piche, Y., and Desjardins, Y. (1995). "A tripartite culture system for endomycorrhizal inoculation of micropropagated strawberry plantlets in vitro." Mycorrhiza 5, no. 5: 313-319.

Estaún, V., Calvet, C., Camprubi, A., and Pinochet, J. (1999). "Long-term effects of nursery starter substrate and AM inoculation of micropropagated peach $\mathrm{x}$ almond hybrid rootstock GF677." Agronomie 19, no. 6: 483-489.

Estrada-Luna, A.A., Davies, F.T., and Egilla, J.N. (2000). "Mycorrhizal fungi enhancement of growth and gas exchange of micropropagated guava plantlets (Psidium guajava L.) during ex vitro acclimatization and plant establishment." Mycorrhiza 10, no. 1: 1-8.

Fabbri, A, Sutter, E., and Dunston, S.K. (1986). Anatomical changes in persistent leaves of tissue cultured strawberry plants after removal from culture. Scientia Hort 28:331-337.

FAO: (Food and Agriculture Organization of the United Nations). Online, FAO Homepage: http://www.fao.org; FAOSTAT, statistical database.

Fitter, A.H. (1991). "Costs and benefits of mycorrhizas implications for functioning under natural conditions." Experinetia 47: 350-355.

Fitter, A.H. (1988). "Water relations of red clover Trifolium pratense L. as affected by VA mycorrhizal infection and phosphorus supply before and during drought." Journal of Experimental Botany 39: 595-603.

Fortuna, P., Citernesi, S., Morini, S., Giovannetti, M., and Loreti, F. (1992). "Infectivity and Effectiveness of Different Species of Arbuscular Mycorrhizal Fungi in Micropropagated Plants of Mr S 2/5 Plum Rootstock." Agronomie 12: 825-829.

Fortuna, P., Citernesi, A.S., Morini, S., Vitagliano, C., and Giovannetti, M. (1996). "Influence of arbuscular mycorrhizae and phosphate fertilization on shoot apical growth of micropropagated apple and plum rootstocks." Tree Physiology 16, no. 9: 757-763.

Fortuna, P., Morini, S., and Giovannetti, M. (1998). "Effects of arbuscular mycorrhizal fungi on in vivo root initiation and development of micropropagated plum shoots." J Hortic Sci Biotechnol 73, no. 1: 19-28. 
Frank, A. B. (1885). Über die Wurzelsymbiose beruhende Ernährung gewisser Bäume durch unterirdische Pilze. (On the nutrition of certain trees based on root symbiosis of underground fungi). Ber. Deutsche Botanische Gesellschaft. 3: 128-145.

Fuchigami, L.H., Cheng, T.Y. and Soeldner, A. (1981). Abaxial transpiration and water loss in aseptically cultured plum. J Amer Soc Hort Sci 106; 519-522.

Gaur, A. and Adholeya, A. (1999). "Mycorrhizal effects on the acclimatization, survival, growth and chlorophyll of micropropagated Syngonium and Draceana inoculated at weaning and hardening stages." Mycorrhiza 9, no. 4: 215-219.

Gerdemann and Nicolson, T.H. (1963 ). "Spores of mycorrhizal endogone extracted from soil by wet-sieving and decanting." Trans. Br. Mycol. Soc. 46: 235-244

Ginaninazzi, S.; Ginaninazzi -Pearson, V.; Trouvelot, A. (1990a): "Potentialities and procedures for the use of endomycorrhizas with emphasis on high value crops." In: WHIPS, J.M. und LUMSDEN, B. (Hrsg.): Biotechnology of fungi for improving plant growth. Cambridge University Press, Cambridge , 41-54.

Ginaninazzi, S.; Ginaninazzi-Pearson, V.; Trouvelot, A. (1990b): "Role and use of mycorrhizas in horticultural crop production. 23rd I.H.C. Plenary Lectures." Intern. Soc. for Hort. Sci., 25-30.

Ginaninazzi, S.; Schüepp, H. ; Masson, J.P. (1995 ): Arbuscular mycorrhizas in sustainable soil-plant systems. EC, Brüssel.

Gianinazzi-Pearson, V. (1981). "Ultrastructure and ultracytochemical features of Glomus tenuis mycorrhiza." New Phytologist 88: 633-639.

Ginaninazzi-Pearson, V.; and Ginaninazzi, S. (1986 ): "Mycorrhizae - a potential for better use of phosphate fertilizer." Fert. Agric. 92 , 1-10.

Gianinazzi-Pearson, V. and Gianinazzi, S. (1989). "Phosphorus metabolism in mycorrhizas," in Nitrogen, phosphorus and sulfur utilization by fungi, 1 ed., edited by L. Boddy, R. Marchant, and D. J. Read (New York: Cambridge University Press), 227-41.

Ginting, G., Lubis, A.U., Subronto, Fatmawati (1993). Management of oil palm tissue culture production for semi-commercial scale. In: Current status of Agricultural Biotechnology in Indonesia.

Giovannetti, M. and Mosse, B. (1980). "An evaluation of techniques for measuring vesicular arbuscular mycorrhizal infection in roots." New Phytologist 84: 489-500.

Glenn, M.G., Chew, F.S., and Williams, P.H. (1988). "Influence of glucosinolate content of Brassica (Cruciferae) roots on growth of vesicular-arbuscular mycorrhizal fungi." New Phytologist 110: 217-225.

Green, N.E., Graham, S.O., and Schenck, N.C. (1976). "The influence of $\mathrm{pH}$ on the germination of vesicular-arbuscular mycorrhizal spores." Mycologia 68: 929-934. 
Grout, B.W.W. (1975). Wax development on leaf surfaces of Brassica oleraceae var. Currawong regenerated from meristem culture. Plant Sci Lett 5: 401-405.

Grout, B.W.W.and Ashton, M.J. (1977). Transplanting of cauliflower plants regenerated from meristem culture. I. Water loss and water transfer related to changes in leaf wax and xylem regeneration. Hort Res 17:1-7.

Grout, B.W.W.and Millam, S. (1985). Photosynthetic development of micropropagated strawberry plantlets following transplanting. Ann Bot 55: 129-131.

Guillemin, J.P., Gianinazzi, S., Trouvelot, A. (1992). Screening of arbuscular-mycorrhizal fungi for establishment of micropropagated pineapple plants. Agronomie 12: 831-836.

Guillemin, J.P., Gianinazzi, S., Gianinazzi-Pearson, V., and Marchal, J. (1994). "Contribution of arbuscular mycorrhizas to biological protection of micropropagated pineapple (Ananas comosus (L.) Merr) against Phytophthora cinnamomi Rands." Agricultural Science in Finland 3: 241-251.

Hardon, J.J. (1984). The oil palm: Progress through plant breeding in Malaysia. Span 27: 5961.

Hardon, J.J., Corley, R.H.V., and Lee, C.H. (1987). Breeding and selecting the oil palm. In: Abbott, A.J. and Atkin, R.K. (Eds.) Improving vegetatively propagated crops. Pp. 63-81. Academic Press, London.

Hamilton, R. J. (1995). Development in oils and fats. Chapman\&Hall, 1995.

Harley, J.L. (1971). Mycorrhiza. Oxford, UK.

Harley, J.L., Smith, S.E. (1983). Mycorrhizal Symbiosis. Academic Press Inc, London.

Harley, J.L., Harley, E.L. (1987) A check list of mycorrhiza in the British Flora. Supplement to: The New Phytologist 105 (2), Academic Press London.

Hartley, C.W.S. (1988). The Oil Palm. Tropical Agriculture Series. Longman.

Hayman, D.D. and Mosse, B. (1972). "Plant growth responses to vesicular-arbuscular mycorrhiza.III. Increased uptake of labile P from soil." New Phytologist 71: 41-47.

Hooker, J.E., Gianinazzi, S., Vestberg, M., Barea, J.M., and Atkinson, D. (1994). "The application of arbuscular mycorrhizal fungi to micropropagation systems: an opportunity to reduce chemical inputs." Agricultural Science in Finland 3: 227-232.

Ibrahim A. (1999). The international trade in palm oil: Prospects and challenges. PORIM, International Palm Oil Congress, 1999.

Ikram, A., Mahmud, A.M., Ghani, M.N., Ibrahim, M.T., und Zainal, A.B. (1992). Field nursery inoculation of Hevea brasiliensis Muell. Arg. Seedling rootstock with vesiculararbuscular mycorrhizal (VAM) fungi. Plant and Soil 145: 231-236. 
Jalani, B.S., Chea, S.C., Rajanaidu, N. and Darus, A. (1997). Improvement of Palm Oil through Breeding and Biotechnology. JAOCS, Vol.74, no. 11:1451-1455.

Jakarta Post (English language Indonesian daily newspaper). 12/6/1998.

Jaquemard, J.C. (1998). Oil Palm. Macmillan Education LTD, London.

Jaizme-Vega M.C., und Azcón, R. (1995). Response of some tropical and subtropical cultures to endomycorrhizal fungi. Mycorrhiza 5: 213-217.

Jaizme-Vega, M.C., Tenoury, P., Pinochet, J., and Jaumot, M. (1997). "Interactions between the root-knot nematode Meloidogyne incognita and Glomus mosseae in banana." Plant and Soil 196, no. 1: 27-35.

Jeffries, P. and Dodd, J.C. (1991). "The use of mycorrhizal inoculants in forestry and agriculture," in Handbook of applied mycology. Vol I: Soil and Plants, edited by D. K. Arora et al. (New York: Marcel Dekker, Inc.), 155-85.

Jones, L.H. (1974). Propagation of clonal oil palms by tissue culture. Oil Palm News 17: 1-8. Planter 50: 374-381.

Jones, L.H. anf Hughes, W.H. (1989). Oil palm (Elaeis guineensis Jacq.) In: Bajaj YPS (Ed.) Biotechnology in Agriculture and Forestry. 5, Tree II Springer-Verlag, Berlin, Heidelberg, New York. Pp. 176-202.

Kahiluoto, H. and Vestberg, M. (1998). "The effect of arbuscular mycorrhiza on biomass production and phosphorus uptake from sparingly soluble sources by leek (Allium porrum L.) in Finnish field soils." Biological Agriculture \& Horticulture 16, no. 1: 65-85.

Koch, K.E. and Johnson, C.R. (1984). "Photosynthate partitioning in split-root citrus seedlings with mycorrhizal and nonmycorrhizal root systems." Plant Physiology 75: 26-30.

Koide, R.T. und Schneider, R.P. (1992.). Regulation of the vesicular-arbuscular mycorrhizal symbiosis. Annual Review of Plant Physiology and Plant Molecular Biology 43: 557-581.

Koomen, I., Grace, C., and Hayman, D.S. (1988). "Effectiveness of single and multiple mycorrhizal inocula on growth of clover and strawberry plants at two soil pHs." Soil Biology and Biochemistry 19: 539-544.

Kozai, T. (1988). High technology in protected cultivation - from environment control enginneering point of view. In: Horticulture in High Technology Era. Special Lecture. Tokyo. pp. 1-43.

Kozai, T. (1991). Autotrophic micropropagation, pp 313-343. In: Bajaj, Y.P.S (Ed.) Biotechnology in Agriculture and Forestry, Vol. 17. Springer Verlag Berlin, Heidelberg, New York, pp.528.

Lange-Ness, R.L. and Vlek, P.L.G. (2000). Mechanism of Calcium and Phosphate Release from Hxdroxy-Apatite by Mycorrhizal Hyphae. Soil Sci. Soc. Am. J. 64:949-955. 
Larson, D.F. (1996). Indonesian's oil palm subsector. Policy Research Working Paper No. 1654; International Economics Department, Commodity Policy and Analysis Unit, Word Bank, Washington, DC:

Lee, N., Wetzstein H.Y. and Sommer H-E. (1988). Quantum flux density effects on the anatomy and surface morphology of in vitro and in vivo developed sweetgum leaves. Amer Soc Hort Sci 113: 167-171.

Li, X.-L., George, E., Marschner, H., and Zhang, J.L. (1997). "Phosphorus acquisition from compacted soil by hyphae of a mycorrhizal fungus associated with red clover (Trifolium pratense)." Canadian Journal of Botany 75, no. 5: 723-729.

Lindermann, L.C. (1994). Role of VAM fungi in biocontrol. In Mycorrhizae and Plant Health. The American Phytopathological Society Press, St Paul, MN, USA; 1-27

Lovato, P., Guillemin, J.P., and Gianinazzi, S. (1992). "Application of commerical arbuscular endomycorrhizal fungal inoculants to the establishment of micropropagated grapevine rootstock and pineapple plants." Agronomie 12: 873-880.

Lovato, P.E., Hammat, N.H., Gianinazzi-Pearson, V., Gianinazzi, S. (1994). Mycorrhization of micropropagated mature wild cherry (Prunus avium L.) and common ash (Fraxinus excelsior L.). Agriculture Science in Finland 3: 297-303.

Lovato, P. E., Hammatt, N., Gianinazzi-Pearson, V., and Gianinazzi, S. (1994). "Mycorrhization of micropropagated mature wild cherry (Prunus avium L.) and common ash (Fraxinus excelsior L.)." Agricultural Science in Finland 3: 297-302.

Lovato, P.E., Gianinazzi-Pearson, V., Trouvelot A., Gianinazzi, S. (1996). The state of art of mycorrhizas and micropropagation. Advanced Horticulture Science 10: 46-52.

Lubis, A. U., Ginting, G. Fatmawati (1993). Yield and vegetative characteristics of oil palm clone planting material. Reprint A9; 1993 PIPOC PORIM Int. Palm Oil Congress 'update and vision', 20-25 September 1993; Kuala Lumpur.

Lubis, A. U., Ginting, G. Subronto and Fatmawati (1993). Early performance of oil palm clones produced by IOPRI. In: Current Status of Agricultural Biotechnology in Indonesia. IOPRI.

Lubis, A. U. and Daswir (1996). Progress in oil palm industry in the last ten years in Indonesia. Proceedings of the 1996 PORIM International Oil Palm Congress, Kuala Lumpur, Malaysia. Palm Oil Research Institute of Malaysia, Kuala Lumpur, pp. 1-16.

Lupien, J.R. and Menza, V. (1999). Assessing prospects for improving food security and nutrition. UNDP, 1999; World Bank, 1997.

Marin, J.A. and Gella, R. (1987). Acclimatization of micropropagated cherry rootstock 'Masto de Montana' (Prunus cerasus L.). Acta Hort 212: 603-609.

Marschner, H. und Dell, B. (1994 ). Nutrient uptake in mycorrhizal symbiosis. Plant Soil 159: 89-102. 
Marschner, H. (1995 ). Mineral nutrition of higher plants. Academic Press, Harcourt Brace \& Co, London.

Martins, A., Casimiro, A., and Pais, M.S. (1997). "Influence of mycorrhization on physiological parameters of micropropagated Castanea sativa Mill. plants." Mycorrhiza 7, no. 3: 161-165.

Matsubara, Y., Karikomi, T., Ikuta, M., Hori, H., Ishikawa, S., Harada, T. (1996). Effect of vesicular-arbuscular mycorrhizal fungi inoculation on growth of apple (Malus ssp.) seedlings. J. Japanese Soc. Hort. Sci. 65, 297-302.

Matos, B. and Da Silva, R. (1996). Effect of inoculation by arbuscular mycorrhizal fungi on the growth of micropropagated pineapple plants. Fruits, Vol. 51:155-119.

McBeth, J. (1997). El Nino gets blamed. Far Eastern Economic Review, October 9, 1997, 8091.

Menge, J.A. (1983). Utilisation of vesicular-arbuscular mycorrhizal fungi in agriculture. Can. J. Botany 61: 1015-1024.

Menge, J.A. (1984). "Inoculum production," in VA Mycorrhiza, edited by C. Ll. Powell and D. J. Bagyaraj (Boca Raton, Florida: CRC Press, Inc.), 187-203.

Mengel, K. und Krikby, E.A. (1987). Principles in Plant Nutrition. International Potash Institute, Worblaufen-Bern, Switzerland.

Mielke, S. (1991). Economic prospects for oilseeds, oils and fats towards the 21st century. In: Basiron, Y, and Ibrahim, A. (Ed.) The proceedings of the 1991 PORIM International Palm Oil Conference. Module iv: Promotion and Marketing. September 9-14, 1991, Kuala Lumpur. Palm Oil Research Institute of Malaysia, Kuala Lumpur, pp. 1-16.

Morandi, D., Branzanti, B., and Gianinazzi-Pearson, V. (1992). "Effect of some plant flavonoids on in vitro behaviour of an arbuscular mycorrhizal fungus." Agronomie 12: 811816.

Morton, J.B. (1993). Problems and solutions for integration of glomalean taxonomy, systematic biology and the study of endomycorrhizal phenomena. Mycorrhiza 2: 97-109.

Morton, J.B. (1995). "Taxonomic and phylogenetic divergence among five Scutellospora species based on comparativedevelopmental sequences." Mycologia 87, no. 1: 127-137.

Mosse, B., Hayman, D.S., and Arnold, D.J. (1973). "Plant growth responses to vesiculararbuscular mycorrhiza. V. Phosphate uptake by three plant species from P deficient soils labelled with 32P." New Phytologist 72: 809-815.

Mosse, B. (1975). Specificity in VA mycorrhizas. In: Sanders, F.E., Mosse, B. und P.B. Tinker (hrdg.): Endomycorrhizas, 469-484, Academic Press, London.

Mosse, B. and Hepper, C.M. (1975). "Vesicular-arbuscular mycorrhizal infections in root organ cultures." Physiological Plant Pathology 5: 215-223. 
Mosse, B. (1988). "Mycorrhiza in a sustainable agriculture," In: The role of microorganisms in a sustainable agriculture, edited by J. M. Lopez-Real and R. D. Hodges (Great Britian: A.B. Academic Publishers, 1986), 105-23.

Mosse, B. and Hayman, D.S. (1989). "Mycorrhizae in agricultural plants,".

Möllers, C., und Schultz, C. (1997). Biotechnological applications for oil palm improvement. In: Proceedings of the BTIG workshop on Oil Palm Improvement through Biotechnology. Bogor, Indonesien.

Munro, R.C., Wilson, J., Jefwa, J. and Mbuthia, K.W. (1999). A low-cost method of mycorrhizal inoculation improves growth of Acacia tortilis seedlings in the nursery. Forest Ecol and Management 113:51-56.

Murashige, T. and Skoog, F. (1962). A revised medium for rapid growth and bioassays with tobacco tissue cultures. Physiol Plant 15: 473-497.

Nadarajah, P. and Nawawi, A. (1993). Mycorrhizal status of epiphytes in malaysian oil palm plantations. Mycorrhiza 4: 21-25.

Nampoothiri, K.U.K. (1998). Oil palm breeding. Journal of plantation crops 26: 1-12.

Naqvi, N.S. and Mukerji, K.G. (1998). "Mycorrhization of micropropagated Leucaena leucocephala (Lam.) de Wit."Symbiosis 24, no. 1: 103-113.

Naqvi, N.S. and Mukerji, K.G. (2000). "Mycorrhizal technology in plant micropropagation system," ;217-33.

Nelson, C.E., und G.R. Safir (1982). Increased drought tolerance of mycorrhizal onion plants caused by improved phosphorus nutrition. Planta 154: 407-413.

Noiret, J.M. (1981). Application of in vitro culture to improvement and production of clonal material of the oil palm. Oleagineux 36:123-126.

Noiret, J.M., Gascon, J.P. and Pannetier, C. (1985). La production de palmier a huiele par culture In vitro. Oleagineux 543: 365-372.

Nowak, J. (1998). "Benefits of in vitro "biotization" of plant tissue cultures with microbial inoculants." In Vitro Cellular \& Developmental Biology-Plant 34, no. 2: 122-130.

Oil World (1999). Oil World 2020: Supply, Demand and Prices from 176 through 2020. Ista Mielke GmbH Hamburg, Germany

Paradis, R., Dalpé, Y., and Charest, C. (1995). "The combined effect of arbuscular mycorrhizas and short- term cold exposure on wheat." New Phytologist 129, no. 4: 637-642.

Pearson, J.N. and Jakobsen, I. (1993). "Symbiotic exchange of carbon and phosphorus between cucumber and three arbuscular mycorrhizal fungi." New Phytologist 124: 481-488. 
Pearson, J.N. and Jakobsen, I. (1993). "The relative contribution of hyphae and roots to phosphorus uptake by arbuscular mycorrhizal plants, measured by dual labelling with $32 \mathrm{P}$ and 33P." New Phytologist 124: 489-494.

Pennetier, C., Arhuis, P. and Lievoux, D. (1981). Neoformation of young Elaeis guineensis plantlets from primary callus obtained from leaf fragments cultured in vitro. Oleagineux 36 : 119-122.

Phillips, J.M. and Hayman, D.S. (1970). "Improved procedures for clearing roots and staining parasitic and vesicular-arbuscular mycorrhizal fungi for rapid assessment of infection." Transactions of the British Mycological Society 55: 158-161.

Pinochet, J., Calvet, C., Camprubí und Fernández, C. (1996). Interactions between migratory endoparasitic nematodes and arbuscular mycorrhizal fungi in perennial crops: A review. Plant and Soil 185, 183-190.

Pinochet, J., Fernandez, C., Jaizme, M.D., and Tenoury, P. (1997). "Micropropagated banana infected with Meloidogyne javanica responds to Glomus intraradices and phosphorus." Hortscience 32, no. 1: 101-103.

Ponders, F. Jr. (1984). Growth of mycorrhizal development of potted white ash and black walnut fertilized by two methods. Can J Botany 62, 509-512.

Pons, F., Gianinazzi-Pearson, V., Gianinazzi, S., and Navatel, J.C. (1983). "Studies of VA mycorrhizae in vitro: Mycorrhizal synthesis of axenically propogated wild cherry (Prunus avium L.) plants." Plant and Soil 71: 217-221.

Ponton, F., Piche, Y., Parent, S., and Caron, M. (1990). "Use of vesicular-arbuscular mycorrhizae in Boston fern production: II. Evaluation of four inocula." Horticultural Science 25: 416-419.

Powell, C.Ll. and Bagyaraj, D.J. (1984). VA mycorrhiza. (Boca Raton, FL: CRC Press, Inc., 1984).

Preece, J.E. and Sutter, E.G. (1991). Acclimatization of micropropagated plants to the greenhouse and field. In: Debergh, P.C. and Zimmermann, R.H. (ed.), Micropropagation, pp. 71-93. Kluwer Academic Publishers (1991).

Puthur, J.T., Prasad, K.V.S.K., Sharmila, P. und Saradhi, P.P. (1998). Vesicular-arbuscular mycorrhizal fungi improves establishment of micropropagated Leuceana leucocephala plantlets. Plant Cell Tissue Organ Culture 53 (1), 41-47.

Rabéchauld, H. and and Martin , J.P. (1976). Multiplication vegetative du palmier a huile (Elaeis guineensis Jacq.) a l'aide de cultures da tussue foliar. CR Acad Sci Paris Ser 283: 1733-1737.

Rapparini, F., Baraldi, R., Bertazza, G., Branzanti, B., and Predieri, S. (1994). "Vesiculararbuscular mycorrhizal inoculation of micropropagated fruit trees." Journal of Horticultural.Science 69, no. 6: 1101-1109. 
Ravolanirina, F., Gianinazzi, S., Trouvelot, A., and Carre, M. (1990). "Production of endomycorrhizal explants of microprogated grapevine rootstocks." Agriculture, Ecosystems and Environment 29: 323-327.

Read, D., Lewis, D., Fitter, A., und Alexander, I. (eds.) (1992). Mycorrhizas in Ecosystems. CAB International, Wallingford, UK.

Rehm, S. and Espig, G. (1993). Oil plants. In: The cultivated plants of the tropics and subtropics. Weikersheim: Margraf, 1991. pp 77-125.

Rival, A. Berlenc, A. Morcillo, F. Tregear, J. Verdeil, J.L. and Duval, Y. (1997). Scaling-up in vitro clonal propagation through somatic embryogenesis: the case of oil palm (Elaeis guineensis Jacq.). In: Plant Tissue Culture and Biotechnology, Vol.3 No.2: pp 74-83.

Salamanca, C.P., Herrera, M.A., and Barea, J.M. (1992). "Mycorrhizal Inoculation of Micropropagated Woody Legumes Used in Revegetation Programmes for Desertified Mediterranean Ecosystems." Agronomie 12: 869-872.

Sbrana, C., Giovannetti, M., and Vitagliano, C. (1994). "The effect of mycorrhizal infection on survival and growth renewal of micropropagated fruit rootstocks." Mycorrhiza 5, no. 2: 153-156.

Schellenbaum, L., Müller, J., Boller, T., Wiemken, A., and Schuepp, H. (1998). "Effects of drought on non-mycorrhizal and mycorrhizal maize: changes in the pools of non-structural carbohydrates, in the activities of invertase and trehalase, and in the pools of amino acids and imino acids." New Phytologist 138, no. 1: 59-66.

Schenck, N.C. (1991). Methods and Principles of Mycorrhizal Research. ASP Press, The American Phytopathological Society, St. Paul.

Schenck, N.C. und Perez, Y. (1987). Manual for the identification of VA-mycorrhizal fungi. INVAM, Univ. of Florida.

Schubert, A. and Martinelli, A. (1983). "Effect of vesicular-arbuscular mycorrhizae on growth of in vitro propagated Pistacia integerrima." Acta Horticulturae 227: 441-443.

Schubert, A., Bodrino, C., and Gribaudo, I. (1992). "Vesicular-Arbuscular Mycorrhizal Inoculation of Kiwifruit (Actinidia deliciosa) Micropropagated Plants." Agronomie 12: 847850.

Schubert, A. and Lubraco, G. (2000). "Mycorrhizal inoculation enhances growth and nutrient uptake of micropropagated apple rootstocks during weaning in commercial substrates of high nutrient availability." Applied Soil Ecology 15, no. 2: 113-118.

Schultz, C., Ginting, G., Moawad, A., Möllers, C., Pamin, K., Subronto, Tahardi, J.S., Vlek, P.L.G. (1997). The role of (vesicular-) arbuscular mycorrhiza in the weaning stage of micropropagated oil palms. In: Proceedings of the BTIG workshop on Oil Palm Improvement through Biotechnology. Bogor, Indonesien. 
Schultz, C., Ginting, G., Moawad, A.M., und Vlek, P.L.G. (1999). Verbesserung der Überlebensrate in vitro vermehrter Ölpalmen in der Akklimatisierungsphase durch (V)AMykorrhizapilze. In: Backhaus, G.F., und Feldmann, F. (1999). Arbuskuläre Mykorrhiza in der Pflanzenproduktion: Praxisbeispiele und Perspektiven. Mitteilungen aus der Biologischen Bundesanstalt für Land- und Forstwirtschaft, Berlin-Dahlem.

Sharmila, P., Puthur, J.T., and Saradhi, P.P. (2000). "Vesicular arbuscular mycorrhizal fungi improves establishment of micropropagated plants", 235-50.

Shetty, K.G., Hetrick, B.A.D., and Schwab, A.P. (1995). "Effects of mycorrhizae and fertilizer amendments on zinc toleranceof plants." Environmental Pollution 88, no. 3: 307314.

Short, K.C., Warburton, J. and Roberts, A.V. (1987). In vitro hardening of cultured cauliflower and chrysanthenum plantlets to humidity. Acta Hort 212: 329-334.

Sieverding, E. (1991). Vesicular-Arbuscular Managemant in Tropical Agrosystems. Deutsche Gesellschaft für Technische Zusammenarbeit (GTZ): Eschborn, Germany.

Simon, L., Bousquet, J., Levesque, R.C., und Lalonde, M. (1993). Origin and diversification of endomycorrhizal fungi and coincidence with vascular land plants. Nature 363, 67-69.

Smith, S.E. and Gianinazzi-Pearson, V. (1990). "Phosphate uptake and arbuscular activity in mycorrhizal Allium cepa L.: effects of photon irradiance and phosphate nutrition." Aust.J.Plant Physiol. 17: 177-188.

Smith, S.E. and Smith, F.A. (1991). "Structure and function of the interfaces in biotrophic symbioses as they relate to nutrient transport." New Phytologist 114: 1-38.

Smith, S.E., und Read, D.J. (1997). Mycorrhizal Symbiosis. $2^{\text {nd }}$ ed. Academic Press, London.

Srivastava, D., Kapoor, R., Srivastava, S.K. and Mkerji, K.G. (1996). Vesicular-arbuscular mycorrhiza - an overview. In: Concepts of mycorrhizal research, K.G. Mukerji, ed., Kluwer Academic Publishers, Dordrecht, Netherlands, pp.1-39.

St-Arnaud, M., Hamel, C., Vimard, B., Caron, M., and Fortin, J.A. (1995). "Altered growth of Fusarium oxysporum f.sp.chrysanthemi in an in vitro dual culture system with the vesicular arbuscular mycorrhizal fungus Glomus intraradices growing on Daucus carota transformed roots." Mycorrhiza 5, no. 6: 431-438.

St.John, T.V. and Hunt, H.W. (1983). "Statistical treatment of vesicular-arbuscular mycorrhizal infection data." Plant and Soil 73: 307-313.

Subhan, S., Sharmila, P., Pardha Saradhi, P. (1998). Glomus fasciculatum alleviates transplantation shock of micropropagated Sesbania sesban. Plant Cell Reports 17, 268-272.

Subramanian, K.S., Charest, C., Dwyer, L.M., Hamilton, R.I. (1995). Arbuscular mycorrhizas and water relation in maize under drought stress. Mycorrhiza in crop plants. Canadian journal of Botany 51, 2487-2493. 
Sunderlein, W. D. and Ida Aju Pradnja Resosudarno (1996). Rates and causes of deforestation in Indonesia: towards the resolution of an ambiguitie. Occasional Papare No. 9, Center for International Forestry Research (CIFOR), Bogor, Indonesia.

Sutter, E. (1984). Chemical compositions of epicuticular wax of cabbage plants grown in vitro. Can J Bot 62: 74-77.

Sutter, E.G. (1985). Morphological, physical and chemical characteristics of epicuticular wax on ornamental plants regenerated in vitro. Ann Bot 55: 321-329.

Srivastava, D. and Mukerji, K.G. (1995). "Field response of mycorrhizal and nonmycorrhizal Medicago sativa var local in the F1 generation." Mycorrhiza 5, no. 3: 219-221.

Sunderlin, W.D. (1999). The effects of economic crisis and political change on Indonesia's forest sector, 1997-99. CIFOR, Bogor, Indonesia.

Sylvia, D.M. and Williams, S.E. (1992). "Vesicular-arbuscular mycorrhizae and environmental stress," in Mycorrhizae in Sustainable Agriculture, edited by R. G. Linderman and G. J. Bethlenfalvay (Madison, WI: ASA Special Publication no 54: 101-24).

Tarafdar, J.C. and Marschner, H. (1994). "Efficiency of VAM hyphae in utilisation of organic phosphorus by wheat plants." Soil Science and Plant Nutrition 40, no. 4: 593-600.

Tarafdar, J.C. and Marschner, H. (1994). "Phosphatase activity in the rhizosphere and hyphosphere of VA mycorrhizal wheat supplied with inorganic and organic phosphorus." Soil Biology and Biochemistry 26: 387-395.

Tarafdar, J.C. and Marschner, H. (1995). "Dual inoculation with Aspergillus fumigatus and Glomus mosseae enhances biomass production and nutrient uptake in wheat (Triticum aestivum L) supplied with organic phosphorus as Na-phytate." Plant and Soil 173: no. 1: 97102.

Trotta, A., Varese, G.C., Gnavi, E., Fusconi,A., Sampo, S., and Berta, B. (1996). Interactions between the soilborne root pathogen Phytophtora nicotianae var parasitica and the arbuscular mycorrhizal fungus Glomus mosseae in tomato plants. Plant and Soil 185: 199-209.

Uosukainen, M. and Vestberg, M. (1994). "Effect of inoculation with arbuscular mycorrhizas on rooting, weaning and subsequent growth of micropropagated Malus (L.) Moench." Agricultural Science in Finland 3: 269-280.

Vaast, P., und Zasoski, R.J., (1992). Effects of VA-mycorrhiza and nutrient sources on rhozisphere soil characteristics, growth amd nutrient acquisition of coffee seedlings (Coffea arabica L.). Plant and Soil 147, 31-39.

Vaast, P., Zasoski, R.J., and Bledsoe, C.S. (1997). "Effects of vesicular-arbuscular mycorrhizal inoculation at different soil $\mathrm{P}$ availabilities on growth and nutrient uptake of in vitro propagated coffee (Coffea arabica 1) plants." Mycorrhiza 6, no. 6: 493-497.

Van Huylenbroeck, J.M., Debergh, P.C. (1996). Physiological aspects of micropropagated plantlets. Plant Tiss. Cult. And Biotechnol., 23:136-141. 
Varma, A. and Schüepp, H. (1994). "Infectivity and Effectiveness of Glomus intraradices on Micropropagated Plants."Mycorrhiza 5, no. 1: 29-37.

Varma, A. and Schüepp, H. (1994). "Positive influence of arbuscular mycorrhizal fungus on in vitro raised hortensia plantlets." Angewandte Botanik 68, no. 3-4: 108-115.

Varma, A. and Schuepp, H. (1995). "Mycorrhization of the commercially important micropropagated plants." Critical Reviews in Biotechnology 15, no. 3-4: 313-328.

Vestberg, M. (1992). "Arbuscular Mycorrhizal Inoculation of Micropropagated Strawberry and Field Observations in Finland." Agronomie 12: 865-867.

Vidal, M.T., Azcon-G.de Aguilar, C., Barea, J.M., and Pliegoalfaro, F. (1992). "Mycorrhizal Inoculation Enhances Growth and Development of Micropropagated Plants of Avocado." Hortscience 27: 785-787.

Vosátka, M. and Gryndler, M. (2000). "Response of micropropagated potatoes transplanted to peat media to post-vitro inoculation with arbuscular mycorrhizal fungi and soil bacteria." Applied Soil Ecology 15, no. 2: 145-152.

Wang, H., Parent, S., Gosselin, A., and Desjardins, Y. (1993). "Vesicular-Arbuscular Mycorrhizal Peat-Based Substrates Enhance Symbiosis Establishment and Growth of Three Micropropagated Species." Journal of the American Society of Horiticultural Science: 896901.

Walker, C. (1992). Sytematics and taxonomy of the arbuscular mycorrhizal fungi (Glomales)a possible way forward. Agronomy 12, 443-897.

Wardle, K., Dobbs, E.B. and Short, K.C. (1983). In vitro acclimatization of aseptically cultured plantlets to humidity. J Amer Soc Hort Sci 108: 386-389.

Weissenhorn, I., Glashoff, A., Leyval, C., and Berthelin, J. (1994). "Differential tolerance to $\mathrm{Cd}$ and $\mathrm{Zn}$ of arbuscular mycorrhizal (AM) fungal spores isolated from heavy metal- polluted and unpolluted soils." Plant and Soil 167, no. 2: 189-196.

Widiastuti, H., und Tahardi, J.S. (1993). Effect of vesicular-arbuscular mycorrhizal inoculation on the growth and nutrient uptake of micropropagated oil palm. Menara Perkebunan 61, (3), 56-60.

Williams, S.C.K., Vestberg, M., Uosukainen, M., Dodd, J.C., and Jeffries, P. (1992). "Effects of fertilizers and arbuscular mycorrhizal fungi on the post vitro growth of micropropagated strawberry." Agronomie 12: 851-857.

Wooi, K.C. (1990). Oil palm (E. guineensis Jacq.): Tissue culture and micropropagation. In: Biotechnology in Agriculture and Forestry10: Legumes and Oilseed Crops I Vol.I; Bajaj, Y.P.S. (Ed.), Springer-Verlag Berlin, Heidelberg, New York, 1990: 570-591.

Wong, G. Tan, C.C., Soh, A.C. (1997). Large scale propagation of oil palm clonesexpiriences todate. Hort. Biotech. In Vitro Cult. and Breeding. (Eds. A. Altma, M. Ziv), Acta Hort 444: 649-658. 
World Bank (1998). Commodity markets and the developing countries: A World Bank quaterly; Washington DC; 1998; 6: 1-17.

Wood T. (1992 ): "VA Mycorrhizal fungi: Challenges for commercialisation." Handb. Appl. Mycol. 4 , 823-847

Wood, B.J. and Corley, R.H.V. (1991). The energy bylance of oil palm cultivation. In: Basiron, Y, Sukaimi, J., Chang, K.C., Cheah, S.C., Henson, I.E., Kamaruddin, N., Paranjothy, K., Rajanaidu, n., Dolmat, T.H.T. and Araffin, D. (Ed.) The proceedings of the 1991 PORIM International Palm Oil Conference. Kuala Lumpur. Palm Oil Research Institute of Malaysia, Kuala Lumpur, pp. 130-143..

Wood, T., und Cummings, B. (1992). Biotechnology and the future of VAM commercialisation. In: M. J. Allen (ed): Mycorrhizal Functioning. Chapman \& Hall, New York, 468487.

Yano-Melo, A.M., Saggin, O.J., Lima, J.M., Melo, N.F., and Maia, L.C. (1999). "Effect of arbuscular mycorrhizal fungi on the acclimatization of micropropagated banana plantlets." Mycorrhiza 9, no. 2: 119-123.

Zakaria, Z.Z., (1996). VA mycorrhiza and its potential on oil palm. ISOPA Newsletter: 4, 5-6.

Ziv, M., Schwartz, A. and Fleminger, D. (1987). Malfunctioning stomata in vitreous leaves of carnation (Dianthus caryophyllus) plants propagated in vitro, implications of hardening. Plant Sci 52: 127-134.

Ziv, M. (1991). Vitrification: morphological and physical disorders of in vitro plants. In: Deberg, P.C. and Zimmermann, R.H. (ed) (1991). Micropropagation Technology and Application. Kluwer Academic Publishers, Dordrecht, Boston 


\section{Annex}

Table A1: ANOVA of main factors and their interaction on the shoot length increase $(\mathrm{cm})$ of micropropagated oil palms measured in two-weeks intervals and calculated for the three-months period of post vitro growth.

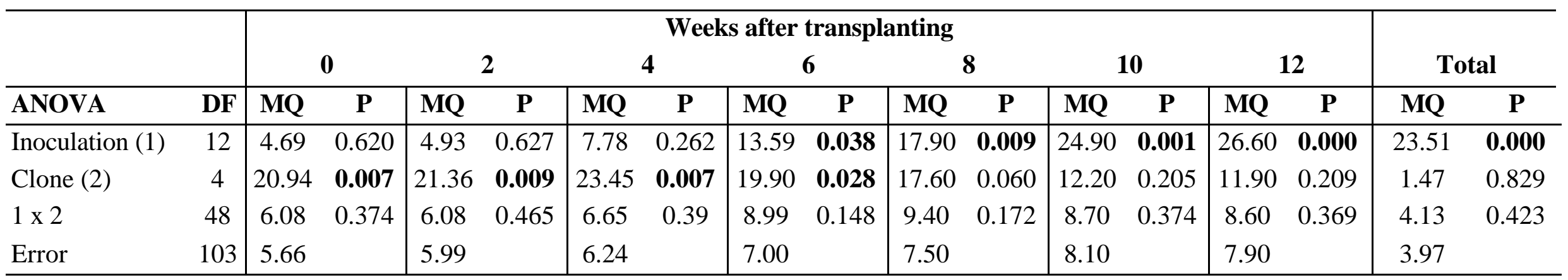

Table A2: ANOVA of main factors and their interaction on the relative growth rate (RGR) of micropropagated oil palms measured in two-weeks intervals and calculated for the three-months period of post vitro growth.

\begin{tabular}{|c|c|c|c|c|c|c|c|c|c|c|c|c|c|c|c|}
\hline \multirow[b]{3}{*}{ ANOVA } & \multirow[b]{3}{*}{ DF } & \multicolumn{12}{|c|}{ Weeks after transplanting } & \multirow{2}{*}{\multicolumn{2}{|c|}{ Average }} \\
\hline & & \multicolumn{2}{|c|}{2} & \multicolumn{2}{|c|}{4} & \multicolumn{2}{|c|}{6} & \multicolumn{2}{|c|}{8} & \multicolumn{2}{|c|}{10} & \multicolumn{2}{|c|}{12} & & \\
\hline & & MQ & $\mathbf{P}$ & MQ & $\mathbf{P}$ & MQ & $\mathbf{P}$ & MQ & $\mathbf{P}$ & MQ & $\mathbf{P}$ & MQ & $\mathbf{P}$ & MQ & $\mathbf{P}$ \\
\hline Inoculation (1) & 12 & 0.000 & 0.263 & 0.000 & 0.197 & 0.000 & 0.931 & 0.000 & 0.035 & 0.000 & $\mathbf{0 . 0 3 3}$ & 0.000 & 0.000 & 0.000 & 0.004 \\
\hline Clone (2) & 4 & 0.000 & 0.004 & 0.000 & 0.653 & 0.000 & 0.512 & 0.000 & 0.922 & 0.000 & 0.586 & 0.000 & 0.179 & 0.000 & 0.087 \\
\hline $1 \times 2$ & 48 & 0.000 & 0.409 & 0.000 & 0.073 & 0.000 & 0.098 & 0.000 & 0.368 & 0.000 & 0.759 & 0.000 & 0.365 & 0.000 & 0.558 \\
\hline Error & 103 & 0.000 & & 0.000 & & 0.000 & & 0.000 & & 0.000 & & 0.000 & & 0.000 & \\
\hline
\end{tabular}


Table A3: ANOVA of main factors and their interaction on the number of leaves of micropropagated oil palms measured in two-weeks intervals and calculated for the three-months period of post vitro growth.

\begin{tabular}{|c|c|c|c|c|c|c|c|c|c|c|c|c|c|c|c|c|c|}
\hline \multirow[b]{3}{*}{$\overline{\text { ANOVA }}$} & \multirow[b]{3}{*}{ DF } & \multicolumn{14}{|c|}{ Weeks after transplanting } & & \\
\hline & & \multicolumn{2}{|c|}{$\mathbf{0}$} & \multicolumn{2}{|c|}{2} & \multicolumn{2}{|c|}{4} & \multicolumn{2}{|c|}{6} & \multicolumn{2}{|c|}{8} & \multicolumn{2}{|c|}{10} & \multicolumn{2}{|c|}{12} & \multicolumn{2}{|c|}{ Total } \\
\hline & & MQ & $\mathbf{P}$ & MQ & $\mathbf{P}$ & MQ & $\mathbf{P}$ & MQ & $\mathbf{P}$ & MQ & $\mathbf{P}$ & MQ & $\mathbf{P}$ & MQ & $\mathbf{P}$ & MQ & $\overline{\mathbf{P}}$ \\
\hline Clone (2) & 4 & 0.82 & 0.017 & 1.12 & 0.004 & 2.08 & 0.002 & 2.36 & 0.008 & 2.75 & 0.005 & 4.02 & 0.002 & 5.67 & 0.001 & 2.33 & 0.013 \\
\hline $1 \times 2$ & 48 & 0.29 & 0.305 & 0.36 & 0.133 & 0.543 & 0.243 & 0.84 & 0.130 & 0.79 & 0.273 & 1.04 & 0.309 & 1.04 & 0.541 & 0.65 & 0.602 \\
\hline Error & 103 & 0.26 & & 0.27 & & 0.46 & & 0.65 & & 0.69 & & 0.93 & & 1.08 & & 0.70 & \\
\hline
\end{tabular}


Table A4: ANOVA of main effects and their interactions on the shoot length increase $(\mathrm{cm})$ of micropropagated oil palms in between two-weeks intervals and calculated for the three-months period of post vitro growth.

\begin{tabular}{|c|c|c|c|c|c|c|c|c|c|c|c|c|c|c|c|c|c|}
\hline \multirow[b]{3}{*}{ ANOVA } & \multirow[b]{3}{*}{$\mathbf{D F}$} & \multicolumn{14}{|c|}{ Weeks after transplanting } & \multirow{2}{*}{\multicolumn{2}{|c|}{ Total }} \\
\hline & & \multicolumn{2}{|c|}{$\mathbf{0}$} & \multicolumn{2}{|c|}{2} & \multicolumn{2}{|r|}{4} & \multicolumn{2}{|c|}{6} & \multicolumn{2}{|c|}{8} & \multicolumn{2}{|c|}{10} & \multicolumn{2}{|c|}{12} & & \\
\hline & & MQ & $\mathbf{P}$ & MQ & $\mathbf{P}$ & MQ & $\mathbf{P}$ & MQ & $\mathbf{P}$ & MQ & $\mathbf{P}$ & MQ & $\mathbf{P}$ & MQ & $\mathbf{P}$ & MQ & $\mathbf{P}$ \\
\hline Inoculation (1) & 4 & 6.01 & 0.739 & 10.16 & 0.585 & 14.88 & 0.377 & 30.32 & 0.063 & 43.3 & 0.008 & 64.6 & 0.000 & 104.5 & 0.000 & 82.04 & 0.000 \\
\hline Fertilization (2) & 2 & 1.65 & 0.884 & 2.44 & 0.843 & 6.32 & 0.636 & 10.78 & 0.440 & 32.5 & 0.066 & 59.6 & 0.005 & 111.4 & 0.000 & 96.34 & 0.000 \\
\hline Clone (3) & 4 & 20.06 & 0.209 & 24.54 & 0.154 & 22.51 & 0.178 & 15.30 & 0.327 & 10.4 & 0.467 & 8.4 & 0.528 & 4.4 & 0.761 & 10.19 & 0.052 \\
\hline $1 \times 3$ & 16 & 9.22 & 0.793 & 10.83 & 0.723 & 9.45 & 0.805 & 9.18 & 0.777 & 8.4 & 0.757 & 6.8 & 0.830 & 6.9 & 0.755 & 3.9 & 0.489 \\
\hline $2 \times 3$ & 8 & 11.07 & 0.578 & 12.16 & 0.558 & 12.02 & 0.550 & 13.51 & 0.413 & 15.2 & 0.246 & 12.3 & 0.327 & 12.4 & 0.253 & 5.0 & 0.287 \\
\hline $1 \times 2 \times 3$ & 32 & 6.06 & 0.992 & 8.59 & 0.943 & 9.08 & 0.909 & 8.50 & 0.908 & 6.3 & 0.969 & 5.6 & 0.975 & 5.1 & 0.975 & 3.4 & 0.689 \\
\hline Error & 75 & 13.32 & & 14.24 & & 13.91 & & 12.97 & & 11.5 & & 10.5 & & 9.5 & & 4.0 & \\
\hline
\end{tabular}


Table A5: ANOVA of main effects and their interactions on the number of leaves of micropropagated oil palms in between two-weeks intervals and calculated for the three-months period of post vitro growth.

\begin{tabular}{|c|c|c|c|c|c|c|c|c|c|c|c|c|c|c|c|c|c|}
\hline \multirow[b]{3}{*}{ ANOVA } & \multirow[b]{3}{*}{ DF } & \multicolumn{14}{|c|}{ Weeks after transplanting } & \multirow{2}{*}{\multicolumn{2}{|c|}{ Total }} \\
\hline & & \multicolumn{2}{|c|}{$\mathbf{0}$} & \multicolumn{2}{|c|}{2} & \multicolumn{2}{|c|}{4} & \multicolumn{2}{|c|}{6} & \multicolumn{2}{|c|}{8} & \multicolumn{2}{|c|}{10} & \multicolumn{2}{|c|}{12} & & \\
\hline & & MQ & $\mathbf{P}$ & MQ & $\mathbf{P}$ & MQ & $\mathbf{P}$ & MQ & $\mathbf{P}$ & MQ & $\mathbf{P}$ & MQ & $\mathbf{P}$ & MQ & $\mathbf{P}$ & MQ & $\mathbf{P}$ \\
\hline Inoculation (1) & 4 & 0.19 & 0.385 & 0.28 & 0.152 & 0.71 & 0.056 & 1.02 & $\mathbf{0 . 0 2 8}$ & 1.51 & 0.005 & 1.54 & 0.007 & 9.54 & 0.000 & 8.79 & 0.000 \\
\hline Fertilization (2) & 2 & 0.14 & 0.463 & 0.07 & 0.959 & 1.14 & 0.025 & 4.09 & 0.000 & 4.58 & 0.000 & 2.41 & 0.004 & 0.83 & 0.121 & 0.61 & 0.226 \\
\hline Clone (3) & 4 & 0.17 & 0.433 & 0.21 & 0.273 & 0.36 & 0.307 & 0.56 & 0.190 & 0.66 & 0.140 & 0.38 & 0.453 & 0.75 & 0.107 & 0.36 & 0.473 \\
\hline $1 \times 2$ & 8 & 0.24 & 0.240 & 0.18 & 0.350 & 0.59 & 0.056 & 0.70 & 0.059 & 0.67 & 0.084 & 0.85 & 0.048 & 1.01 & 0.013 & 0.99 & 0.019 \\
\hline $1 \times 3$ & 16 & 0.28 & 0.100 & 0.23 & 0.146 & 0.29 & 0.466 & 0.35 & 0.481 & 0.32 & 0.616 & 0.18 & 0.964 & 0.24 & 0.845 & 0.27 & 0.801 \\
\hline $2 \times 3$ & 8 & 0.32 & 0.091 & 0.34 & 0.054 & 0.27 & 0.518 & 0.19 & 0.832 & 0.29 & 0.597 & 0.38 & 0.490 & 0.14 & 0.940 & 0.26 & 0.740 \\
\hline $1 \times 2 \times 3$ & 32 & 0.19 & 0.384 & 0.19 & 0.256 & 0.33 & 0.333 & 0.24 & 0.885 & 0.21 & 0.958 & 0.29 & 0.850 & 0.28 & 0.84 & 0.44 & 0.354 \\
\hline
\end{tabular}


Table A6: Leaf development of oil palm clones during 12 weeks of post vitro growth. The total number of leaves developed during the experimental period was calculated and tested for significant difference. Values with different letters are significantly different at $P=0.05$ as indicated by LSD-test.

\begin{tabular}{c|ccccccc|c}
\hline \hline & \multicolumn{7}{|c|}{ Weeks after transplanting } & \\
Clone & $\mathbf{0}$ & $\mathbf{2}$ & $\mathbf{4}$ & $\mathbf{6}$ & $\mathbf{8}$ & $\mathbf{1 0}$ & $\mathbf{1 2}$ & Total \\
\hline & & & & & & & & \\
$\mathbf{1}$ & $3.6 \mathrm{a}$ & $3.7 \mathrm{a}$ & $4.6 \mathrm{a}$ & $5.0 \mathrm{a}$ & $5.3 \mathrm{a}$ & $5.9 \mathrm{a}$ & $6.7 \mathrm{a}$ & $\mathbf{3 . 1} \mathbf{~ a}$ \\
$\mathbf{2}$ & $3.2 \mathrm{~b}$ & $3.3 \mathrm{~b}$ & $4.1 \mathrm{bc}$ & $4.7 \mathrm{ab}$ & $4.9 \mathrm{~b}$ & $5.3 \mathrm{bc}$ & $5.9 \mathrm{~b}$ & $\mathbf{2 . 7} \mathbf{b}$ \\
$\mathbf{3}$ & $3.2 \mathrm{~b}$ & $3.2 \mathrm{~b}$ & $4.1 \mathrm{bc}$ & $4.4 \mathrm{~b}$ & $4.7 \mathrm{~b}$ & $5.3 \mathrm{bc}$ & $5.7 \mathrm{~b}$ & $\mathbf{2 . 5} \mathbf{b}$ \\
$\mathbf{4}$ & $3.3 \mathrm{~b}$ & $3.3 \mathrm{~b}$ & $3.9 \mathrm{c}$ & $4.3 \mathrm{~b}$ & $4.5 \mathrm{~b}$ & $5.0 \mathrm{c}$ & $5.6 \mathrm{~b}$ & $\mathbf{2 . 3} \mathbf{b}$ \\
$\mathbf{5}$ & $3.4 \mathrm{ab}$ & $3.5 \mathrm{ab}$ & $4.3 \mathrm{ab}$ & $4.6 \mathrm{ab}$ & $4.9 \mathrm{~b}$ & $5.7 \mathrm{ab}$ & $6.2 \mathrm{ab}$ & $\mathbf{2 . 8} \mathbf{~ a b}$ \\
\hline \hline
\end{tabular}

Table A7: ANOVA of main effects and their interaction on the shoot and root fresh weights $(\mathrm{g})$ and the root:shoot ratios of micropropagated oil palms after 6 weeks of post vitro growth.

\begin{tabular}{l|c|cc|cc|cc}
\hline \hline & & \multicolumn{2}{|c|}{ Shoot fresh weight $(\mathbf{g})$} & \multicolumn{2}{|c|}{ Root fresh weight (g) } & \multicolumn{2}{c}{ Root:shoot ratio } \\
ANOVA & DF & MQ & $\mathbf{P}$ & MQ & P & MQ & P \\
\hline Inoculation (1) & 4 & 0.343 & $\mathbf{0 . 0 0 2}$ & 0.061 & 0.126 & 0.015 & 0.551 \\
Fertilization (2) & 2 & 0.031 & 0.658 & 0.008 & 0.796 & 0.001 & 0.958 \\
1 x 2 & 8 & 0.043 & 0.788 & 0.010 & 0.967 & 0.008 & 0.904 \\
Clone & 1 & 0.020 & 0.604 & 0.258 & 0.005 & 0.270 & 0.000 \\
Error & 95 & 0.074 & & 0.003 & & 0.020 & \\
\hline \hline
\end{tabular}

Table A8: ANOVA of main effects and their interactions on the shoot and root fresh weight (g) and the root:shoot ratio of micropropagated oil palms after 12 weeks of post vitro growth.

\begin{tabular}{|c|c|c|c|c|c|c|c|}
\hline \multirow[b]{2}{*}{ ANOVA } & \multirow[b]{2}{*}{ DF } & \multicolumn{2}{|c|}{ Shoot fresh weight (g) } & \multicolumn{2}{|c|}{ Root fresh weight (g) } & \multicolumn{2}{|c|}{ Root:shoot ratio } \\
\hline & & MQ & $\mathbf{P}$ & MQ & $\mathbf{P}$ & MQ & $\mathbf{P}$ \\
\hline Inoculation (1) & 4 & 5.89 & 0.000 & 0.058 & 0.518 & 0.063 & 0.000 \\
\hline Fertilization (2) & 2 & 0.05 & 0.623 & 0.003 & 0.964 & 0.001 & 0.851 \\
\hline Clone (3) & 4 & 0.04 & 0.834 & 0.039 & 0.700 & 0.008 & 0.433 \\
\hline $1 \times 2$ & 8 & 0.154 & 0.142 & 0.103 & 0.191 & 0.009 & 0.391 \\
\hline $1 \times 3$ & 16 & 0.05 & 0.954 & 0.067 & 0.526 & 0.009 & 0.415 \\
\hline $2 \times 3$ & 8 & 0.09 & 0.501 & 0.089 & 0.278 & 0.011 & 0.278 \\
\hline $1 \times 2 \times 3$ & 32 & 0.12 & 0.218 & 0.096 & 0.144 & 0.011 & 0.236 \\
\hline Error & 66 & & & 0.071 & & 0.009 & \\
\hline
\end{tabular}


Table A 9: ANOVA of main effects and their interactions on the shoot dry weight $(\mathrm{g})$ of micropropagated oil palms after 6 weeks of post vitro growth.

\begin{tabular}{l|c|c|c}
\hline \hline ANOVA & DF & MQ & P \\
\hline Inoculation (1) & 4 & 0.013 & $\mathbf{0 . 0 0 1}$ \\
Fertilization (2) & 2 & 0.005 & 0.161 \\
$1 \times 2$ & 8 & 0.001 & 0.788 \\
Clone & 1 & 0.000 & 0.706 \\
Error & 74 & 0.003 & \\
\hline
\end{tabular}

Table A 10: ANOVA of main effects and their interaction regarding the $\mathrm{P}$ concentration (mg/g plant) and P uptake (mg/plant) in shoot tissue of micropropagated oil palms after 6 weeks of post vitro growth.

\begin{tabular}{|c|c|c|c|c|c|}
\hline \multirow[b]{2}{*}{ ANOVA } & \multirow[b]{2}{*}{ DF } & \multicolumn{2}{|c|}{$\begin{array}{c}\text { P concentration } \\
\text { ( } \mathrm{mg} / \mathrm{g} \text { plant })\end{array}$} & \multicolumn{2}{|c|}{$\begin{array}{l}\text { P uptake } \\
\text { (mg/plant) }\end{array}$} \\
\hline & & MQ & $\mathbf{P}$ & MQ & $\mathbf{P}$ \\
\hline Inoculation (1) & 4 & 1.647 & 0.000 & 0.140 & 0.000 \\
\hline Fertilization (2) & 2 & 0.262 & 0.284 & 0.013 & 0.398 \\
\hline $1 \times 2$ & 8 & 0.178 & 0.547 & 0.004 & 0.966 \\
\hline Clone & 1 & 0.164 & 0.373 & 0.001 & 0.837 \\
\hline Error & 74 & 0.204 & & 0.012 & \\
\hline
\end{tabular}

Table A 11: ANOVA of main effects and their interaction regarding the K concentration (mg/g plant) and K uptake (mg/plant) in shoots of micropropagated oil palms after 6 weeks of post vitro growth.

\begin{tabular}{|c|c|c|c|c|c|}
\hline \multirow[b]{2}{*}{ ANOVA } & \multirow[b]{2}{*}{ DF } & \multicolumn{2}{|c|}{$\begin{array}{c}\text { K concentration } \\
(\mathrm{mg} / \mathrm{g} \text { plant })\end{array}$} & \multicolumn{2}{|c|}{$\begin{array}{c}\text { K uptake } \\
\text { (mg/plant) }\end{array}$} \\
\hline & & MQ & $\mathbf{P}$ & MQ & $\mathbf{P}$ \\
\hline Inoculation (1) & 4 & 33.85 & 0.128 & 10.14 & 0.001 \\
\hline Fertilization (2) & 2 & 5.93 & 0.722 & 1.31 & 0.499 \\
\hline $1 \times 2$ & 8 & 17.82 & 0.456 & 1.08 & 0.794 \\
\hline Clone & 1 & 0.00 & 0.995 & 0.53 & 0.595 \\
\hline Error & 74 & 18.12 & & 1.86 & \\
\hline
\end{tabular}


Table A12: ANOVA of main effects and their interaction regarding the $\mathrm{N}$ concentration (mg/g plant) and $\mathrm{N}$ uptake (mg/plant) in shoot tissue of micropropagated oil palms after 6 weeks of post vitro growth.

\begin{tabular}{l|c|cc|cc}
\hline \hline & & \multicolumn{2}{|c|}{$\begin{array}{c}\text { N concentration } \\
\text { (mg/g plant) }\end{array}$} & \multicolumn{2}{c}{$\begin{array}{c}\text { N uptake } \\
\text { (mg/plant) }\end{array}$} \\
\hline ANOVA & DF & MQ & P & MQ & P \\
\hline & & & & & \\
Inoculation (1) & 4 & 22.96 & 0.359 & 2.95 & 0.115 \\
Fertilization (2) & 2 & 0.86 & 0.959 & 2.31 & 0.227 \\
1 x 2 & 8 & 9.32 & 0.885 & 0.61 & 0.917 \\
Clone & 1 & 78.23 & 0.066 & 1.37 & 0.348 \\
& & & & & 1.52 \\
Error & 63 & 20.66 & &
\end{tabular}

Table A13: ANOVA of main effects and interaction on the $\mathrm{N}$ concentration $(\mathrm{mg} / \mathrm{g})$ and $\mathrm{N}$ uptake (mg/plant) of micropropagated oil palms after 12 weeks of post vitro growth.

\begin{tabular}{|c|c|c|c|c|c|}
\hline \multirow[b]{2}{*}{$\overline{\text { ANOVA }}$} & \multirow[b]{2}{*}{ DF } & \multicolumn{2}{|c|}{$\begin{array}{c}\mathbf{N} \text { concentration } \\
(\mathrm{mg} / \mathrm{g} \text { plant })\end{array}$} & \multicolumn{2}{|c|}{$\begin{array}{l}\mathrm{N} \text { uptake } \\
\text { (mg/plant) }\end{array}$} \\
\hline & & MQ & $\mathbf{P}$ & MQ & $\mathbf{P}$ \\
\hline Inoculation (1) & 4 & 104.07 & 0.001 & 213.81 & 0.000 \\
\hline Fertilization (2) & 2 & 41.35 & 0.122 & 101.79 & 0.000 \\
\hline Clone (3) & 4 & 7.53 & 0.813 & 6.90 & 0.395 \\
\hline $1 \times 2$ & 8 & 23.19 & 0.304 & 9.31 & 0.213 \\
\hline $1 \times 3$ & 16 & 17.74 & 0.543 & 6.48 & 0.496 \\
\hline $2 \times 3$ & 8 & 15.59 & 0.592 & 4.40 & 0.725 \\
\hline $1 \times 2 \times 3$ & 32 & 13.23 & 0.876 & 3.52 & 0.977 \\
\hline Error & 74 & 19.14 & & 6.67 & \\
\hline
\end{tabular}

Table A14: ANOVA of main effects and their interaction on the (V)AMF infection rate (\%) in roots of micropropagated oil palms after 6 weeks of post vitro growth.

\begin{tabular}{l|c|c|c}
\hline \hline ANOVA & DF & MQ & P \\
\hline & & 1291.71 & $\mathbf{0 . 0 0 0}$ \\
Inoculation (1) & 4 & 28.43 & 0.862 \\
Fertilization (2) & 2 & 32.42 & 0.994 \\
$1 \times 2$ & 8 & 50.11 & 0.610 \\
Clone & 1 & 190.59 & \\
& & & \\
Error & 74 & & \\
\hline \hline
\end{tabular}


Table. A15: ANOVA of main effects and their interactions on the shoot length increase $(\mathrm{cm})$ of micropropagated oil palms in between twoweeks intervals and calculated for the three-months period of post vitro growth.

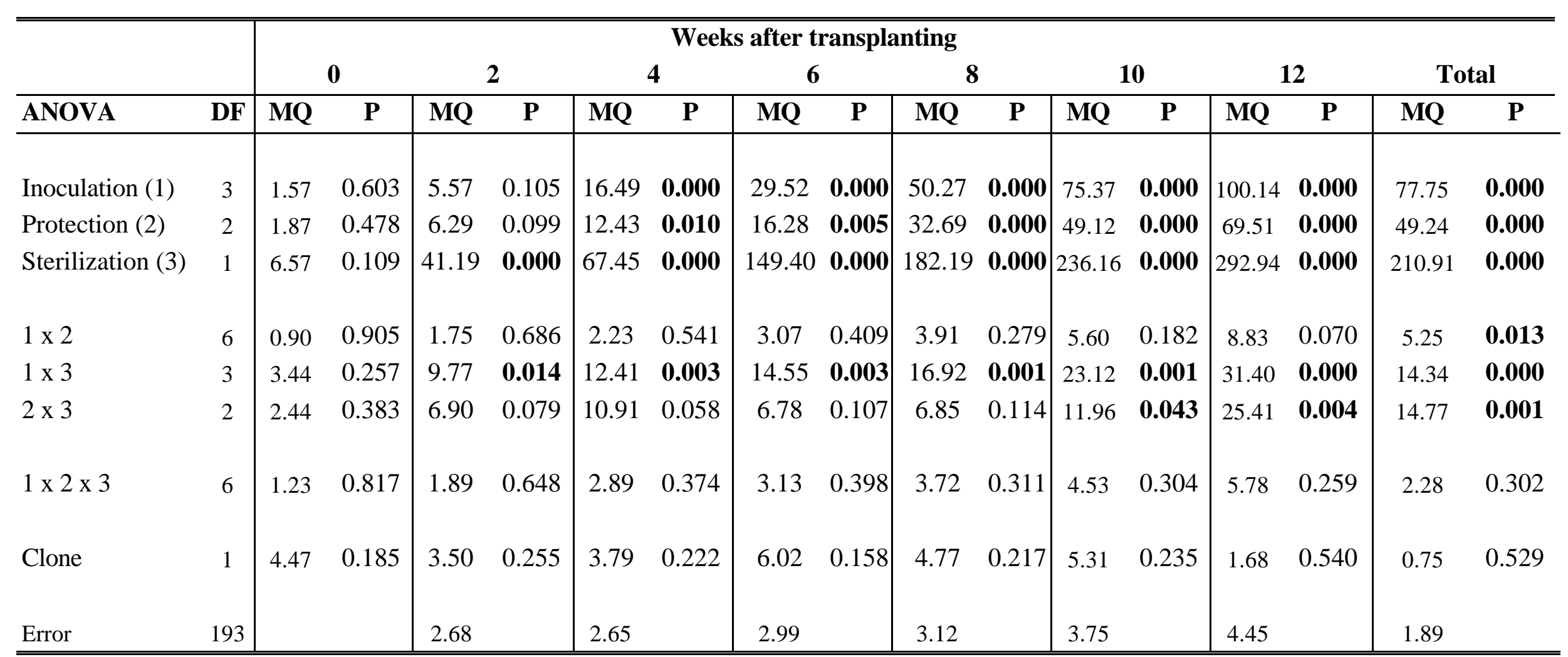


Table A16: ANOVA of main effects and their interactions on the number of leaves of micropropagated oil palms in between two-weeks intervals and calculated for the three-months period of post vitro growth.

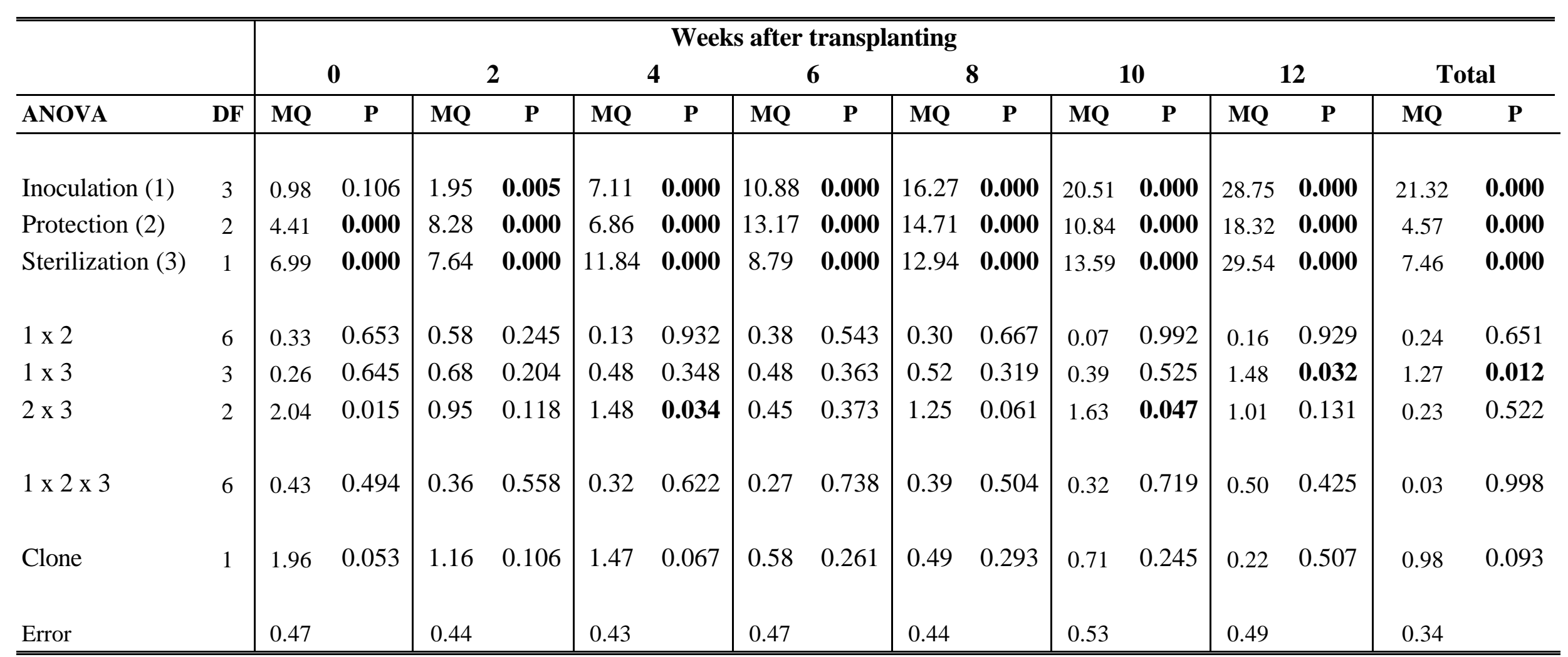




\section{Acknowledgments}

My sincere thanks go to Prof. Dr. P.L.G. Vlek for the initiation of this study, stimulating and valuable criticism and support.

I also like to thank Prof. H. Becker from the Institute of Agronomy and Plant Breeding, University of Göttingen, for taking over the co-referee.

I would like to express my thanks to Dr. A.M. Moawad for his helpful and constructive suggestions, critical comments and assistance during this study.

I would like to thank Dr. Ronald Kühne, without his statistical advises, good ideas and critical comments the data analysis would not be accomplished that fast.

I thank all my colleagues and staff at the Institute of Agronomy in the Tropics, Göttingen for supporting me and sharing my good and bad tempers.

I would like to thank Dr. C. Moellers for the valuable comments and support with necessary information during the initial period of this study.

I would like to express my sincere thanks to Dr. J. Tahardi, Subronto and Gale Ginting for good discussions, helpful suggestions and supporting me during my experimental work in Indonesia.

I would like to express my sincere thanks to IOPRI for providing technical assistance and research infrastructure.

Special thanks to my family, particularly my grandma for her patience and supporting me in all the time.

I also like to thank my friends for the constant presence and moral support.

Finally I thank the BMFT for partially financing this study within the frame of the project 'Biotechnology Indonesia Germany' (BTIG). The financial support of my study by the Institute of Agronomy in the Tropics, University of Göttingen and the Center for Development Research (ZEF), University of Bonn, are gratefully acknowledged. 


\section{Curriculum vitae}

\section{Personal data}

Name:

Date of Birth:

Place of Birth:

\section{Professional Experiences}

since 1993

March 1996-November 1998

April 1994-December 1995

June-December 1995
Claudia Schultz

April 10, 1964

Kassel, Germany

Research Associate at the Institute of Agronomy in the Tropics, Georg-August University, Göttingen, Germany Head: Prof. Dr. P.L.G. Vlek until March 1998

Doctoral student at the Institute of Plant Breeding,

Georg-August University, Göttingen, Germany

Head: Prof. H. Becker

October 1996-February 1998: on-station experiments at the 'International Oil Palm Research Institute', Medan, Indonesia

Post-graduate Program of Studies in Agricultural Science in the Tropics and Subtropics, Faculty of Agriculture, University of Göttingen, Germany;

including 6 month experimental work at ICRISAT, India

Grant DAAD for the research project: "Influence of drought stress on pearl millet (Pennisetum glaucum L.) genotypes in India"

M.Sc. Agricultural Sciences (Dipl.-Ing. Agrar)

University of Göttingen; Studies of Agricultural Sciences One-year practice period at an agricultural research station 